\title{
Performance of Heavy Timber Connections in Fire
}

\author{
A thesis submitted to \\ the Faculty of Graduate Studies and Research \\ in partial fulfilment of the requirements for the degree of \\ Doctor of Philosophy \\ by \\ Lei Peng
}

Ottawa-Carleton Institute of

Civil and Environmental Engineering

Department of Civil and Environmental Engineering

Carleton University

Ottawa, Ontario, Canada

May 2010

C Copyright 2010, Lei Peng 


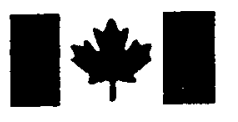

\author{
Library and Archives \\ Canada \\ Published Heritage \\ Branch \\ 395 Wellington Street \\ Ottawa ON K1A ON4 \\ Canada
}

Bibliotheqque et

Archives Canada

Direction du

Patrimoine de l'édition

395 , rue Wellington

Ottawa ON K1A ON4

Canada
Your file Votre référence
ISBN: $978-0-494-70566-7$
Our file Notre référence
ISBN: $978-0-494-70566-7$
NOTICE:

The author has granted a nonexclusive license allowing Library and Archives Canada to reproduce, publish, archive, preserve, conserve, communicate to the public by telecommunication or on the Internet, loan, distribute and sell theses worldwide, for commercial or noncommercial purposes, in microform, paper, electronic and/or any other formats.

The author retains copyright ownership and moral rights in this thesis. Neither the thesis nor substantial extracts from it may be printed or otherwise reproduced without the author's permission.
AVIS:

L'auteur a accordé une licence non exclusive permettant à la Bibliothèque et Archives Canada de reproduire, publier, archiver, sauvegarder, conserver, transmettre au public par télécommunication ou par l'Internet, prêter, distribuer et vendre des thèses partout dans le monde, à des fins commerciales ou autres, sur support microforme, papier, électronique et/ou autres formats.

L'auteur conserve la propriété du droit d'auteur et des droits moraux qui protège cette thèse. Ni la thèse ni des extraits substantiels de celle-ci ne doivent être imprimés ou autrement reproduits sans son autorisation.
In compliance with the Canadian Privacy Act some supporting forms may have been removed from this thesis.

While these forms may be included in the document page count, their removal does not represent any loss of content from the thesis.
Conformément à la loi canadienne sur la protection de la vie privée, quelques formulaires secondaires ont été enlevés de cette thèse.

Bien que ces formulaires aient inclus dans la pagination, il n'y aura aucun contenu manquant.

\section{Canadä}




\section{Abstract}

In heavy timber construction, connections using bolts, dowels and steel plates are widely used to assemble wood components and transfer loads. From the fire safety point of view, understanding the fire performance of heavy timber connections is particularly important because they are recognized as the weakest link in heavy timber buildings under fire attack. Due to the variety of connection types, geometries and fastener arrangements, and the significant variabilities in the properties of wood and steel at elevated temperatures, the analysis of the fire performance of timber connections is complex.

The experimental part of this research consisted of a series of fire-resistance tests conducted in compliance with CAN/ULC-S101 for wood-steel-wood (WSW) and steelwood-steel (SWS) bolted timber connections loaded in tension. The effects of wood side member thickness, fastener diameter, number of fasteners, edge distance, load level and type of protection were studied. Results showed that the fire resistances of all tested WSW bolted connections with no protection were less than 45 minutes and the fire resistances of all tested SWS bolted connections with no protection were less than 25 minutes. Specimens with thicker wood side members were found to exhibit better fire resistances. Decreasing the load ratio increased the fire resistance. The results of tests on protected specimens showed that the protection provided by a single-layer of $15.9 \mathrm{~mm}$ type $\mathrm{X}$ gypsum board increased the fire resistance by more than 30 minutes, whereas a double-layer of $12.7 \mathrm{~mm}$ Douglas fir plywood increased the fire resistance by 15 minutes. 
The modelling part of this research included a three-dimensional finite-element heat transfer model and an analytical structural model for the fire resistance of timber connections. Comparison with test data generated in the experimental program indicated that both thermal and structural models show reasonable agreement with the measured specimen temperatures and fire resistances of the timber connections.

Furthermore, the third part of this research is devoted to developing simplified calculation methods for wood-wood-wood and wood-steel-wood connections using bolts or dowels, and bolted steel-wood-steel connections. Test data found in the literature and the test results generated in this research were used to develop the simplified calculation methods. Comparison between the predictions using the simplified calculation methods and the measured results in fire-resistance tests or modelled results using the heat transfer model and the analytical structural model, shows that the predictions for wood-wood-wood and wood-steel-wood connections are almost always within a $\pm 15 \%$ envelope, and the predictions for steel-wood-steel connections are almost always within a $\pm 10 \%$ envelope. 


\section{Acknowledgements}

I would like to express my appreciation to my supervisor, Professor George Hadjisophocleous for his enthusiastic support and patient guidance during this research. Special thanks go to Dr. Jim Mehaffey, Dr. Mohammad Mohammad and Dr. Noureddine Benichou for providing generous information and advice throughout the research. Thanks also go to Dr. Steven Craft and Dr. Ehab Zalok for their interest in this work and sharing their knowledge.

I would like to thank Mr. Ba Lam-Thien for his laboratory support that allowed the experimental tests to be completed. I also thank Mr. Bruce Taber, Mr. George Crampton, Mr. Michael Ryan, Mr. Michael Wright, Mr. Eric Gibbs, Mr. Sasa Muradori, and Mr. Joseph Cingel at the National Research Council U-96 facilities, Almonte, for their kind help during the experimental tests. I also like to thank Ms. Ling Lu, Mr. Osama Salem and Ms. Yoon Ko, as working together and discussing with them helped me through my study and research at Carleton University.

感谢我的父母和家人，谢谢他们多年来的教诲、理解和支持。 


\section{Table of Contents}

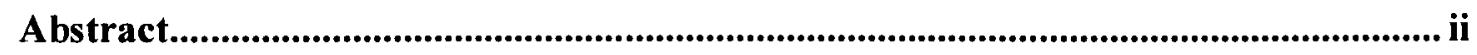

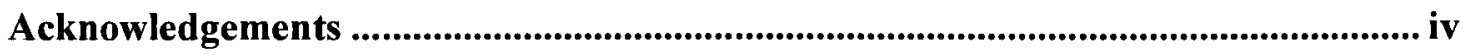

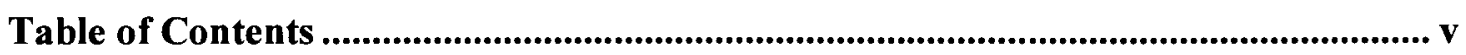

List of Tables

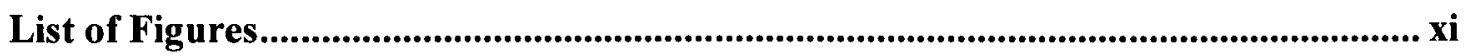

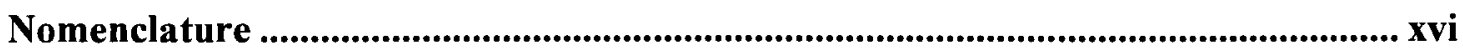

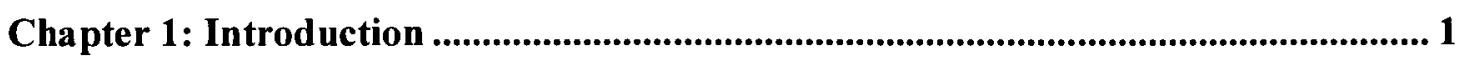

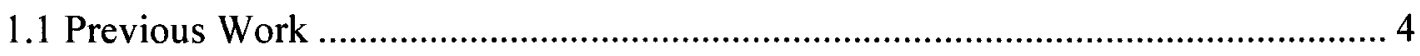

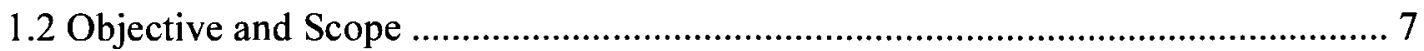

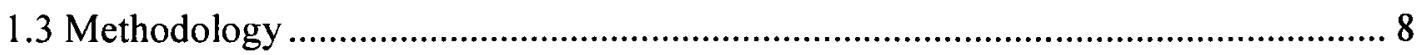

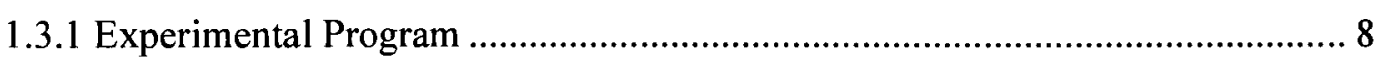

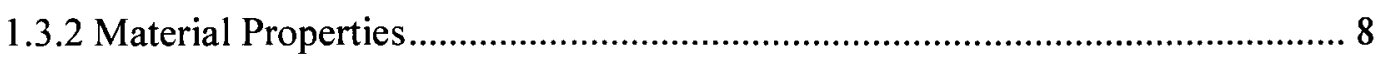

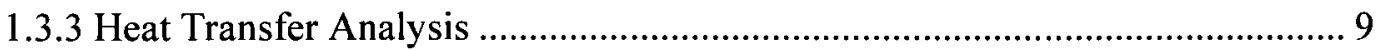

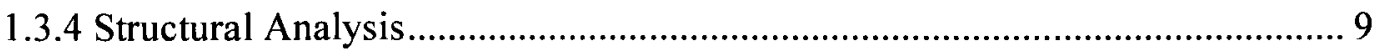

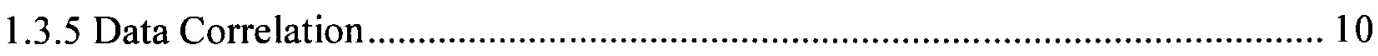

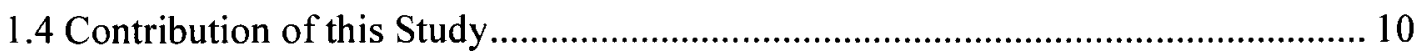

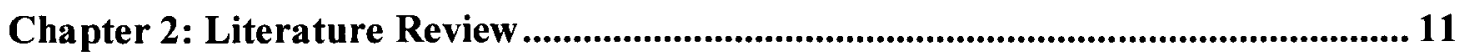

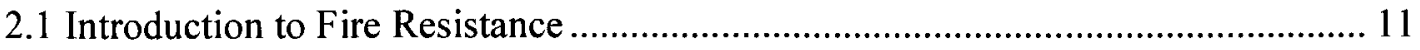

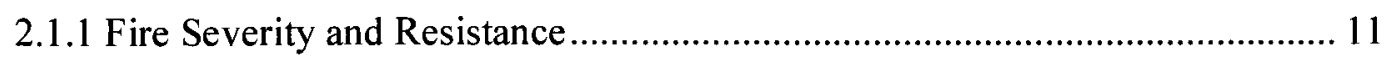

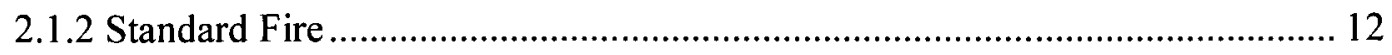

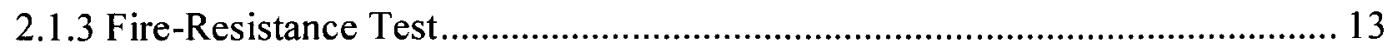

2.1.4 Fire-Resistance Rating .................................................................... 14

2.1.5 Fire-Resistance Rating by Calculation................................................. 14 


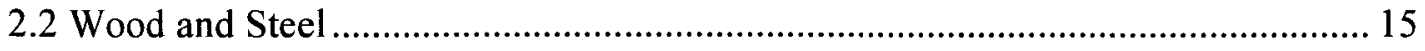

2.2.1 Wood at Ambient Temperature ................................................................. 15

2.2.2 Steel at Ambient Temperature ………………............................................. 17

2.2.3 Wood at Elevated Temperatures.................................................................... 17

2.2.3.1 Charring Rate of Wood ......................................................................... 19

2.2.3.2 Thermal Properties of Wood.................................................................... 21

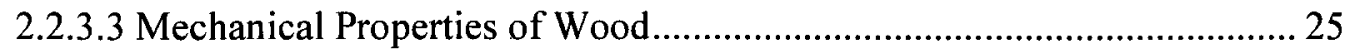

2.2.4 Steel at Elevated Temperatures........................................................................ 30

2.2.4.1 Thermal Properties of Steel .............................................................. 30

2.2.4.2 Mechanical Properties of Steel ........................................................... 32

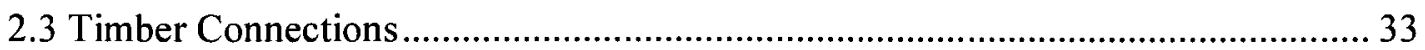

2.3.1 Timber Connections at Normal Temperature ................................................ 33

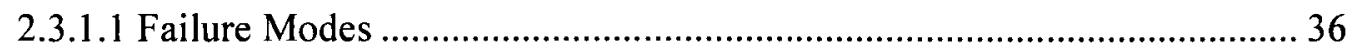

2.3.1.2 Load-Carrying Capacity............................................................................. 39

2.3.1.3 Ultimate Load Capacity .......................................................................... 40

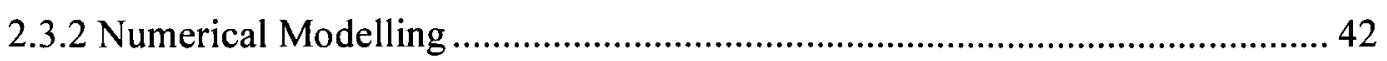

2.3.3 Timber Connections at Elevated Temperatures .............................................. 45

2.3.3.1 Previous Experimental Tests.................................................................... 45

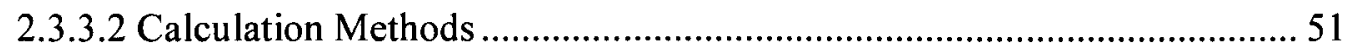

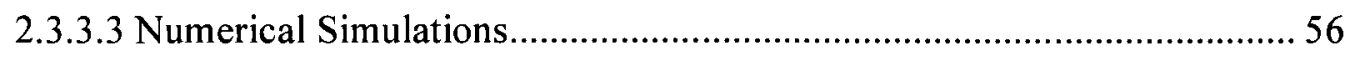

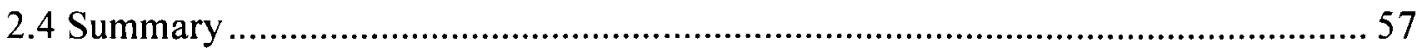

Chapter 3: Experimental Research ....................................................................................... 59

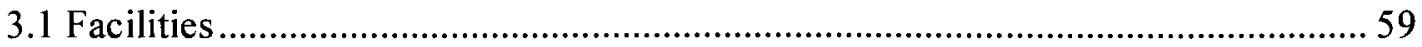

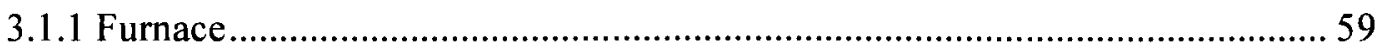

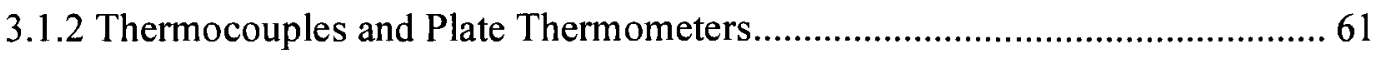

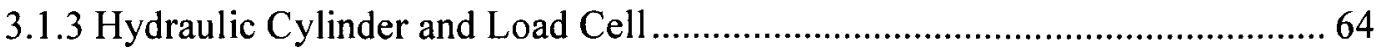

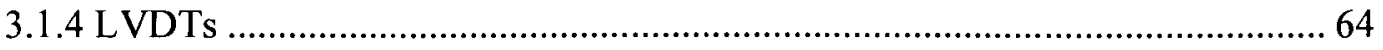

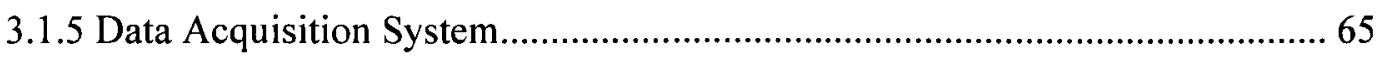

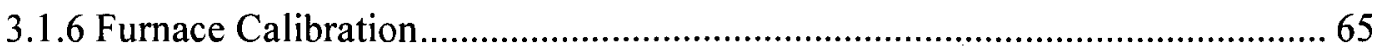




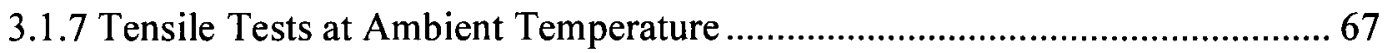

3.2 Fire-Resistance Tests of Bolted WSW Connections .................................................68

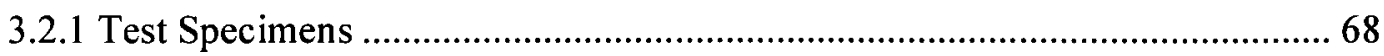

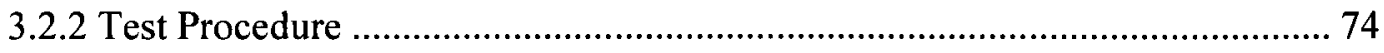

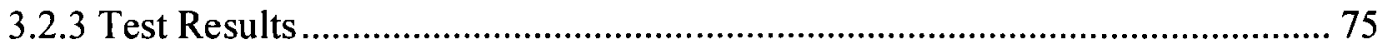

3.2.3.1 Furnace Temperature ………………………….................................... 77

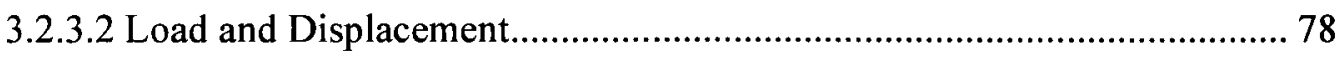

3.2.3.3 Specimen Temperature ….................................................................... 79

3.2.3.4 Failure Time and Failure Mode ............................................................. 86

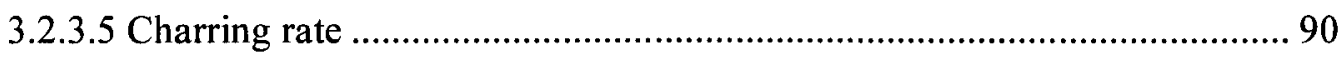

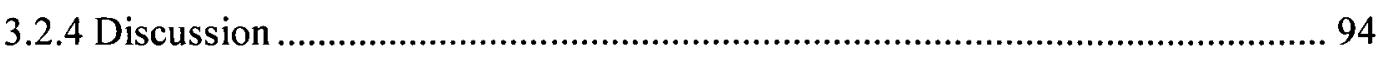

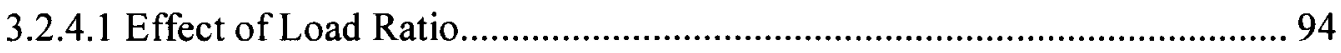

3.2.4.2 Effect of Wood Side Member Thickness.................................................. 95

3.2.4.3 Effect of Bolt Diameter....................................................................... 95

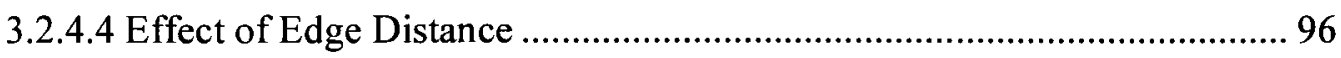

3.2.4.5 Effect of Protection ............................................................................ 96

3.3 Fire-Resistance Tests of SWS Connections......................................................... 99

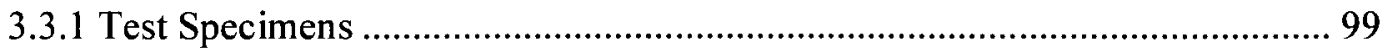

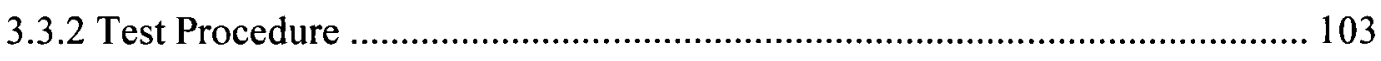

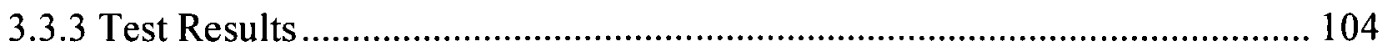

3.3.3.1 Furnace Temperature ............................................................................ 106

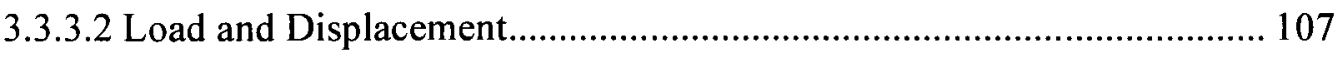

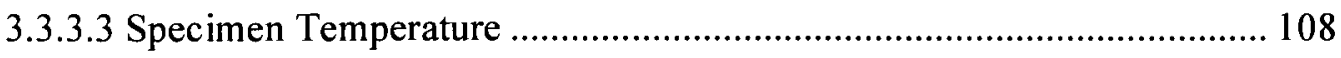

3.3.3.4 Failure Time and Failure Mode ...................................................... 114

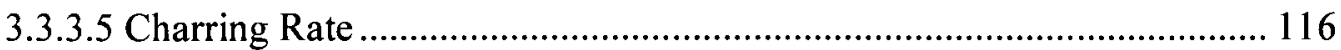

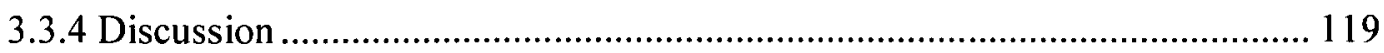

3.3.4.1 Effect of Load Ratio and Wood Thickness............................................ 119

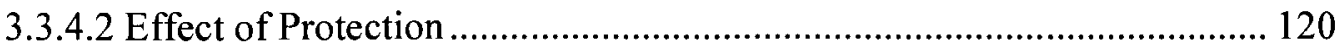

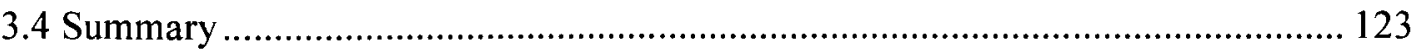

vii 
Chapter 4: Heat Transfer Analysis ................................................................................ 125

4.1 Heat Transfer Model ..................................................................................... 125

4.1.1 Boundary Conditions ............................................................................. 125

4.1.2 Heat Conduction within Specimen ......................................................... 128

4.1.3 Heat Transfer between Members ............................................................ 128

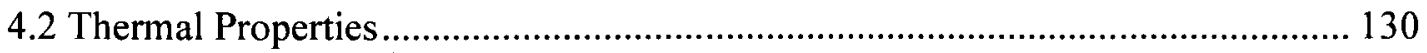

4.2.1 Thermal Properties of Wood....................................................................... 130

4.2.2 Thermal Properties of Steel ........................................................................ 131

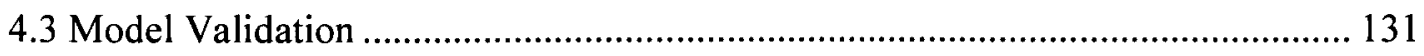

4.3.1 Validation of Wood Thermal Properties.......................................................... 131

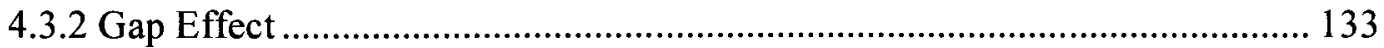

4.3.3 Validation against Experimental Data ............................................................. 137

4.3.3.1 WSW Connection ........................................................................... 137

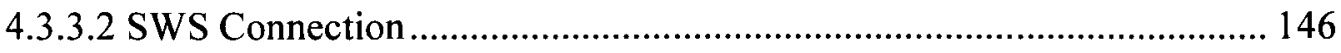

4.4 Sensitivity Analysis ........................................................................................ 153

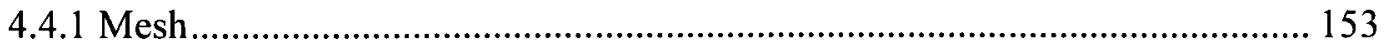

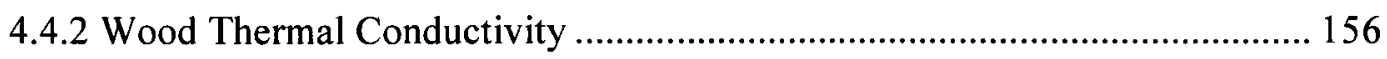

4.4.3 Wood Specific Heat ................................................................................. 157

4.4.4 Wood Density …………………………………....................................... 159

4.4.5 Furnace Temperature ……………………………................................... 160

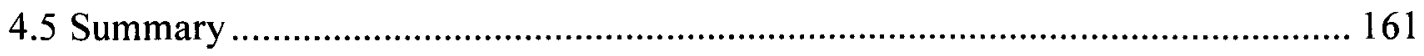

Chapter 5: Structural Analysis............................................................................................... 163

5.1 Structural Analysis for WSW Connections ........................................................ 163

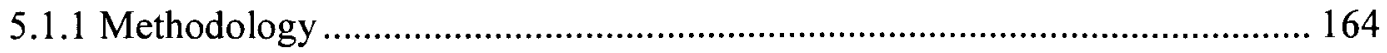

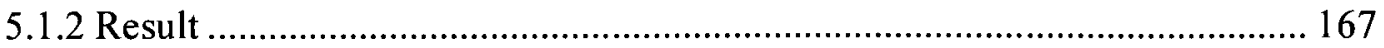

5.2 Structural Model for SWS Connections ……………....................................... 170

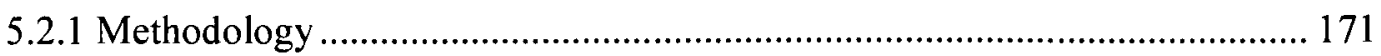

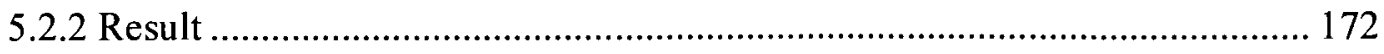




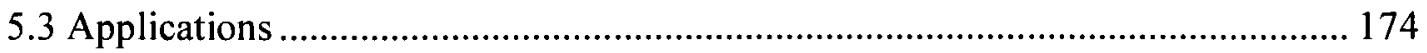

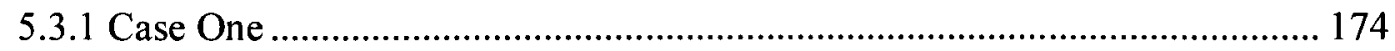

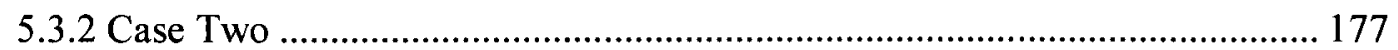

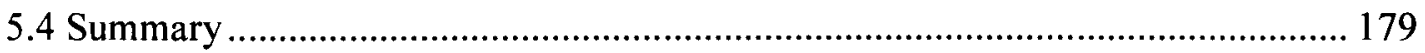

Chapter 6: Calculation Method ............................................................................................ 180

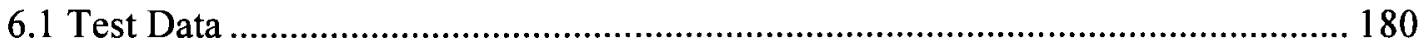

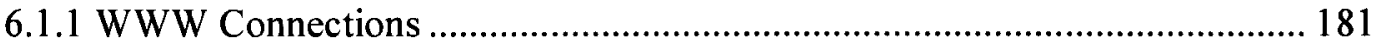

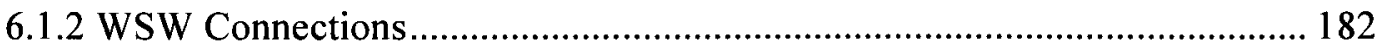

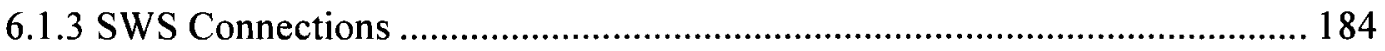

6.2 Correlations for WSW and WWW Connections ……………………………..... 185

6.3 Correlation for SWS Connections .................................................................... 192

6.4 Protected Timber Connections.......................................................................... 195

6.4.1 Contribution of Protective Membrane ……................................................ 195

6.4.2 Concealed Fasteners.................................................................................... 198

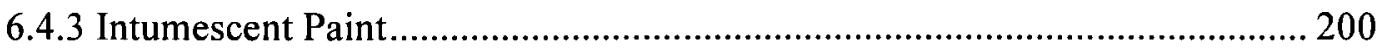

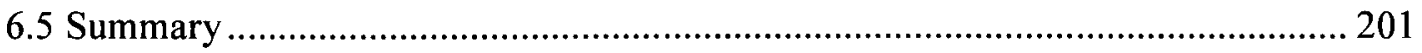

Chapter 7: Summary and Conclusions .....................................................................203

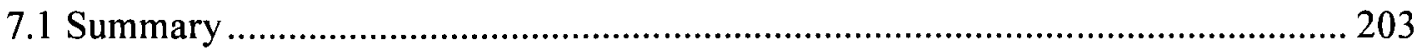

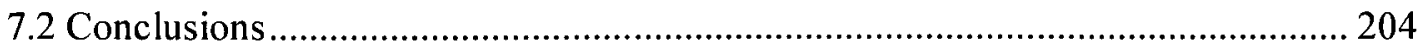

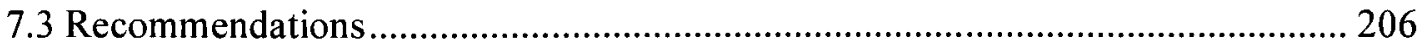

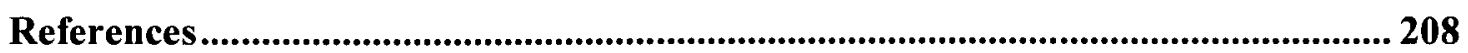

Appendix A: Calculation of Load Capacity of Timber Connections at Ambient

Temperature .............................................................................................................................. 218

Appendix B: Code Capacity vs. Ultimate Capacity ......................................................... 224

Appendix C: Tensile Tests of Timber Connections at Ambient ................................. 227

Appendix D: Thermocouple Locations in Fire-Resistance Tests ............................... 229 


\section{List of Tables}

Table 1.1 Minimum Heavy Timber Dimensions, from NBCC (2005) ............................. 4

Table 2.1 Fire resistance of unprotected connections with wood side members, from

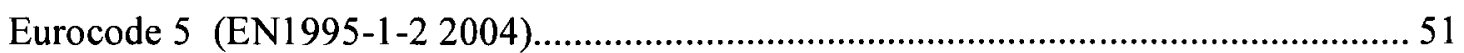

Table 2.2 Connection Parameter $k$ from Eurocode 5 (EN1995-1-2 2004) ....................... 53

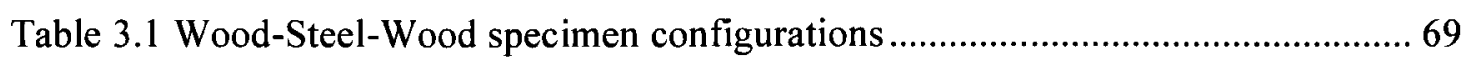

Table 3.2 Load ratios in fire-resistance tests .................................................................. 70

Table 3.3 Test results: failure time and failure modes................................................... 88

Table 3.4 Charring rates in fire tests........................................................................... 93

Table 3.5 Steel-wood-steel specimen configurations .................................................. 100

Table 3.6 Test results: failure time and failure modes of SWS connections .................. 114

Table 3.7 Charring rates in SWS fire tests............................................................... 118

Table 5.1 Fire resistances for Case One................................................................. 176

Table 5.2 Fire resistances for Case Two …………………..................................... 178

Table 6.1 Fire-resistance results of bolted WWW connections...................................... 181

Table 6.2 Fire-resistance results of doweled WWW connections ................................... 182

Table 6.3 Fire-resistance results of bolted WSW connections ....................................... 183

Table 6.4 Fire-resistance results of doweled WSW connections.................................... 184

Table 6.5 Fire-resistance results of bolted SWS connections ........................................ 184

Table 6.6 Correlation results.................................................................................. 190

Table 6.7 Connection factors for timber connections ................................................... 190

Table 6.8 Time assigned to protective membranes (White 2008) …………………...... 196 


\section{List of Figures}

Figure 1.1 Single-shear timber connections: (a) wood-wood connection; (b) wood-steel connection

Figure 1.2 Double-shear timber connections: (a) wood-wood-wood connection; (b) woodsteel-wood connection; (c) steel-wood-steel connection .............................................. 2

Figure 2.1 Standard time-temperature curves for CAN/ULC-S101 and ISO 834 ......... 12

Figure 2.2 Three principle axes in wood, (Wood Handbook 1999) ............................... 15

Figure 2.3 Stress-strain relationship for wood .......................................................... 16

Figure 2.4 Layers in a wood section exposed to fire, SFPE (White 2008)..................... 18

Figure 2.5 Charring depth as a function of fire exposure time, Konig (1999) ............... 19

Figure 2.6 Thermal conductivity of wood at elevated temperatures .............................. 22

Figure 2.7 Specific heat of wood at elevated temperatures ......................................... 23

Figure 2.8 Density of wood at elevated temperatures............................................... 24

Figure 2.9 Elastic modulus of wood at elevated temperatures ..................................... 26

Figure 2.10 Elastic modulus of wood at elevated temperatures .................................... 26

Figure 2.11 Tensile strength of wood at elevated temperatures ................................... 28

Figure 2.12 Compressive strength of wood at elevated temperatures ........................... 28

Figure 2.13 Shear strength of wood at elevated temperatures ....................................... 29

Figure 2.14 Thermal properties of steel at elevated temperatures ................................. 31

Figure 2.15 Mechanical properties of steel at elevated temperatures ........................... 33

Figure 2.16 Interaction between a bolt and wood loaded in the grain direction............... 34

Figure 2.17 Typical failure modes in wood connections ........................................... 37

Figure 2.18 Ductile failure modes of double-shear connections, reproduced from.......... 38

Figure 2.19 Wood embedding strength at elevated temperatures.................................. 55

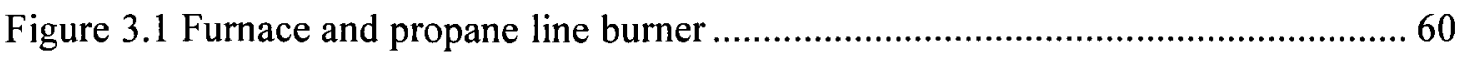

Figure 3.2 Front and top view of the furnace with a specimen mounted........................ 61 
Figure 3.3 Schematic of shielded thermocouple ............................................................ 62

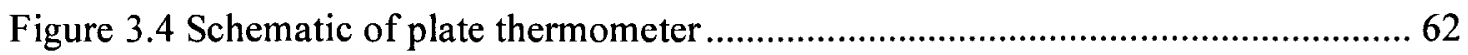

Figure 3.5 Shielded thermocouples and plate thermometers in the furnace...................... 63

Figure 3.6 Locations of TCs and PTs in the furnace ......................................................63

Figure 3.7 Measured time-temperature curves and CAN/ULC-S101 standard curve ...... 66

Figure 3.8 Bolted WSW connection ..................................................................................6

Figure 3.9 Schematic of test specimen \#5.2 ........................................................... 71

Figure 3.10 Schematic of WSW connection with protective membranes: \#4.3 ………... 73

Figure 3.11 Schematic of WSW connection with protective membranes: \#5.4 ............... 73

Figure 3.12 A typical specimen before and after the fire test, Test $\# 4.2 \ldots \ldots \ldots \ldots \ldots \ldots \ldots \ldots \ldots . . . .75$

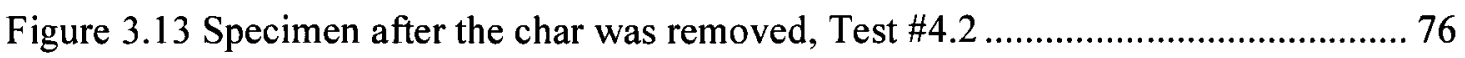

Figure 3.14 A typical plot of furnace temperature curves, Test \#5.1 …………………. 77

Figure 3.15 A typical plot of applied load and specimen displacement, Test \#5.1 ......... 78

Figure 3.16 Thermocouple locations for Group \#4 ...................................................... 79

Figure 3.17 Bolt temperature histories for Test \#4.1 .................................................. 81

Figure 3.18 Wood temperature histories for Test $\# 4.1$.................................................. 81

Figure 3.19 Bolt temperature histories for Test \#4.3 ...................................................... 83

Figure 3.20 Wood and cavity temperature histories for Test \#4.3 .................................. 83

Figure 3.21 Bolt temperature histories for Test \#5.4 .................................................... 85

Figure 3.22 Wood and cavity temperature histories for Test \#5.4 ................................... 85

Figure 3.23 Typical failures of WSW connections........................................................ 89

Figure 3.24 A typical specimen after the char was removed............................................. 90

Figure 3.25 Charring at both cross-section A-A and B-B ............................................... 91

Figure 3.26 Test results of WSW Group \#1-5 .............................................................. 94

Figure 3.27 Bolted steel-wood-steel connection............................................................... 99

Figure 3.28 Schematic of SWS connection with protective membranes: \#1.3 ............... 102

Figure 3.29 Schematic of SWS connection with intumescent paint: \#2.3 ..................... 102

Figure 3.30 A typical specimen before and after the fire test, Test $\# 2.2 \ldots \ldots \ldots \ldots \ldots \ldots . . . . . . . . .104$

Figure 3.31 Specimen after the char was removed, Test \#2.2 ....................................... 105 
Figure 3.32 A typical plot of furnace temperature, Test \#2.1 ……………………….... 106

Figure 3.33 A typical plot of applied load and specimen displacement, Test \#2.2 ....... 107

Figure 3.34 Thermocouple locations for Group \#1 ................................................. 108

Figure 3.35 Bolt temperature histories for Test \#1.1 ................................................ 110

Figure 3.36 Wood temperature histories for Test \#1.1 .............................................. 110

Figure 3.37 Bolt temperature histories for Test \#1.3 ..................................................... 112

Figure 3.38 Wood and cavity temperature histories for Test \#1.3................................. 112

Figure 3.39 Bolt temperature histories for Test \#2.3 ………………………….......... 113

Figure 3.40 Wood temperature histories for Test \#2.3 ……......................................... 113

Figure 3.41 Typical failures of SWS connections ..................................................... 115

Figure $3.42 \mathrm{~A}$ typical SWS specimen after the char was removed................................. 116

Figure 3.43 Charring at both cross-section A-A and B-B ............................................ 117

Figure 3.44 Test results of SWS Group \#1 and \#2 ……......................................... 119

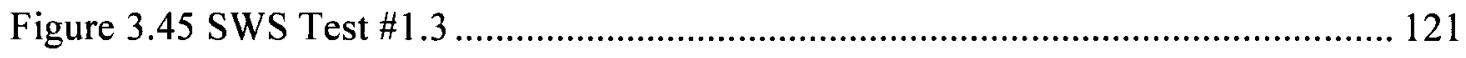

Figure 3.46 Intumescent paint for SWS Test \#2.3 …………..................................... 122

Figure 4.1 Plate thermometer and thermocouple measurements, Test \#4.1 ................... 126

Figure 4.2 Thermocouple locations in Konig's tests .................................................... 132

Figure 4.3 Temperature histories in one dimensional heat transfer of wood.................. 133

Figure 4.4 A simple bolt-wood assembly .................................................................... 134

Figure 4.5 Temperature histories for bolt-wood assembly .......................................... 135

Figure 4.6 Mesh generated in ABAQUS/Standard for WSW-Test\#2, thermocouple locations, and configuration factors......................................................................... 138

Figure 4.7 Bolt temperatures for WSW specimen \#2.1: model vs. test.......................... 140

Figure 4.8 Wood temperatures for WSW specimen \#2.1: model vs. test....................... 140

Figure 4.9 Temperature contour at cross-section $y_{s}-y_{s}$ for WSW \#2.1 at $28 \mathrm{~min}$........... 143

Figure 4.10 Temperature contour at cross-section $y_{w}-y_{w}$ for WSW \#2.1 at $28 \mathrm{~min} . . . . . . .143$

Figure 4.11 Residual cross-section view at $y_{s}-y_{s}$, from ABAQUS/Standard and test..... 144

Figure 4.12 Residual cross-section view at $y_{w}-y_{w}$, from ABAQUS/Standard and test ... 145 
Figure 4.13 Mesh generated in ABAQUS/Standard for SWS-Group\#2 and thermocouple locations

Figure 4.14 Bolt Temperatures for SWS specimen \#2.1: model vs. test ...................... 148

Figure 4.15 Wood Temperatures for SWS specimen \#2.1: model vs. test .................... 148

Figure 4.16 Temperature contour at cross-section $y_{s}-y_{s}$ for SWS \#2.1 at $23.5 \mathrm{~min} . . . \ldots . .150$

Figure 4.17 Temperature contour at cross-section $y_{w}-y_{w}$ for SWS \#2.1 at $23.5 \mathrm{~min} . . . .150$

Figure 4.18 Residual cross-section view at $y_{s}-y_{s}$, from ABAQUS/Standard and test..... 151

Figure 4.19 Residual cross-section view at $y_{w}-y_{w}$, from ABAQUS/Standard and test ... 152

Figure 4.20 Mesh $\mathrm{A}$ and temperature locations ........................................................ 154

Figure 4.21 Mesh B and Mesh C for mesh study ………....................................... 154

Figure 4.22 Temperature histories for mesh study ................................................... 155

Figure 4.23 Thermal conductivity of wood at elevated temperatures ........................... 156

Figure 4.24 Temperature histories for wood thermal conductivity sensitivity analysis. 157

Figure 4.25 Specific heat of wood at elevated temperatures ........................................ 157

Figure 4.26 Temperature histories for wood specific heat sensitivity analysis .............. 158

Figure 4.27 Temperature histories for density sensitivity analysis............................... 159

Figure 4.28 Furnace temperature vs. time ........................................................... 160

Figure 4.29 Temperature histories for furnace temperature sensitivity analysis ............ 161

Figure 5.1 Failure mode 1 of a WSW connection ..................................................... 165

Figure 5.2 Reduction of wood embedding strength at elevated temperatures ................ 166

Figure 5.3 Elements used to determine the embedding strength for both Moss's and

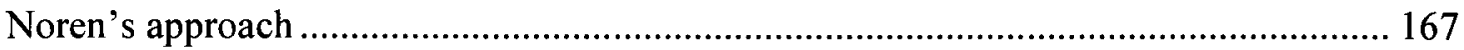

Figure 5.4 Calculated results compared with test results for WSW Group \#1 ............... 168

Figure 5.5 Calculated results compared with test results for WSW Group \#2 ………... 168

Figure 5.6 Calculated results compared with test results for WSW Group \#3 and \#4 ... 169

Figure 5.7 Calculated results compared with test results for WSW Group \#5 …........... 169

Figure 5.8 Failure mode 1 of a SWS connection .......................................................... 171

Figure 5.9 Failure mode 4 of a SWS connection ........................................................ 172

Figure 5.10 Calculated results compared with test results for SWS Group \#1.............. 173 
Figure 5.11 Calculated results compared with test results for SWS Group \#2............. 173

Figure 6.1 Curve fitting analysis result for bolted WWW connections......................... 188

Figure 6.2 Curve fitting analysis result for bolted WSW connections .......................... 188

Figure 6.3 Curve fitting analysis result for doweled WWW connections ..................... 189

Figure 6.4 Curve fitting analysis result for doweled WSW connections....................... 189

Figure 6.5 Comparison between measured or modelled fire resistances and predicted fire resistances using Equation (6.5)

Figure 6.6 Failure time vs. load ratio for SWS connections ..................................... 193

Figure 6.7 Correlation result for SWS connections ................................................. 193

Figure 6.8 Comparison between measured or modelled fire resistances and predicted fire resistances using Equation (6.6)

Figure 6.9 Concealed fasteners in WSW connections 


\section{Nomenclature}

$c_{p} \quad$ - specific heat, $\mathrm{J} / \mathrm{kgK}$

d - fastener diameter, $\mathrm{mm}$

$d^{*} \quad$ - non-dimensional fastener diameter

$E_{T} \quad$ - steel modulus of elasticity, $\mathrm{MPa}$

$f_{p, T} \quad$ - steel proportional limit at temperature $T, \mathrm{MPa}$

$f_{y, T} \quad$ - steel yield strength at temperature $T, \mathrm{MPa}$

$f_{w} \quad$ - embedding strength, $\mathrm{MPa}$

$h$ - convection coefficient, $\mathrm{W} / \mathrm{m}^{2} \mathrm{~K}$

$k \quad$ - connection factor in Eurocode 5

$k_{f l u x} \quad$ - heat flux factor in Eurocode 5

$M, N$ - connection factors in the correlations

$\dot{Q} \quad$ - internal heat source, $\mathrm{W} / \mathrm{m}^{3}$

$\dot{q}^{\prime \prime} \quad$ - heat flux, W/m ${ }^{2}$

$\dot{q}_{G}^{\prime \prime} \quad$ - heat flux through the gap, $\mathrm{W} / \mathrm{m}^{2}$

$R_{0} \quad$ - ultimate load capacity, $\mathrm{kN}$

$R_{0}^{5 t h}-5^{\text {th }}$ percentile value of the ultimate load capacity, $\mathrm{kN}$ 
$R_{\text {code }} \quad$ - code allowed load capacity, $\mathrm{kN}$

$R_{f i} \quad$ - applied load in fire tests, $\mathrm{kN}$

$t \quad$ - time, $\mathrm{s}$

$t^{*} \quad$ - non-dimensional failure time

$t_{1} \quad$ - thickness of side members in timber connections, $\mathrm{mm}$

$t_{2} \quad$ - thickness of the central member in timber connections, $\mathrm{mm}$

$t_{a} \quad$ - additional fire resistance rating from protections, minute

$t_{f} \quad$ - fire resistance rating or failure time of timber connections, minute

$t_{f i, d} \quad$ - design fire resistance rating of timber connections, minute

$t_{\text {req }} \quad$ - required fire resistance rating of timber connections, minute

$t_{c h}$ - time when protected wood starts to char according to Eurocode 5, minute

$T \quad$ - temperature, ${ }^{\circ} \mathrm{C}$

$T_{0} \quad$ - initial temperature, ${ }^{\circ} \mathrm{C}$

$T_{\text {air }} \quad$ - air temperature, ${ }^{\circ} \mathrm{C}$

$T_{p} \quad$ - wood charring temperature, ${ }^{\circ} \mathrm{C}$

$T_{f} \quad$ - effective furnace temperature, ${ }^{\circ} \mathrm{C}$

$T_{s} \quad$ - surface temperature, ${ }^{\circ} \mathrm{C}$

$u \quad$ - moisture content 
$x \quad-$ dimension in the $x$-direction, $\mathrm{m}$

$y \quad$ - dimension in the $y$-direction, $\mathrm{m}$

$z \quad$ - dimension in the $z$-direction, $m$

\section{Greek Letters}

$\beta \quad$ - charring rate, $\mathrm{mm} / \mathrm{min}$

$\beta_{n} \quad$ - notional charring rate, $\mathrm{mm} / \mathrm{min}$

$\varepsilon_{T} \quad$ - strain at temperature $T$

$\varepsilon_{p, T} \quad$ - strain at the proportional limit of steel at temperature $T$

$\varepsilon_{t, T} \quad$ - limit strain for yield strength of steel at temperature $T$

$\varepsilon_{y, T} \quad$ - yield strain of steel at temperature $T$

$\varepsilon_{u, T} \quad$ - ultimate strain of steel at temperature $T$

$\varepsilon_{e f f} \quad$ - effective emissivity

$\varepsilon_{f} \quad$ - furnace emissivity

$\varepsilon_{s} \quad$ - surface emissivity

$\Phi \quad$ - configuration factor

$\eta \quad$ - load ratio

$\lambda \quad$ - thermal conductivity, $\mathrm{W} / \mathrm{mK}$

$\lambda_{\text {air }}$ - thermal conductivity of air, $\mathrm{W} / \mathrm{mK}$ 
$\lambda_{G} \quad$ - equivalent gap thermal conductivity, $\mathrm{W} / \mathrm{mK}$

$\rho \quad$ - density, $\mathrm{kg} / \mathrm{m}^{3}$

$\sigma_{T} \quad$ - stress at temperature $T, \mathrm{MPa}$

$\sigma \quad$ - Stefan-Boltzmann constant, $5.67 \times 10^{-8} \mathrm{~W} / \mathrm{m}^{2} \mathrm{~K}^{4}$ 


\section{Chapter 1: Introduction}

Timber structures tend to fall into two distinct categories: light framing timber constructions and heavy timber structures. Light framing constructions refer to structural systems assembled from small dimension lumber (e.g. nominal $2 \times 6$ or $2 \times 10$ ). They are widely used in residential buildings as wall-assemblies and floor-assemblies. Heavy timber structures are those which use large size sawn timber, glue-laminated timber or other wood composite products as principal structural elements such as beams, columns, decks or truss members. Heavy timber members are commonly used in non-residential structures.

In terms of fire performance of timber structures, light framing constructions can have excellent fire resistance, provided by the protection of lining materials, such as gypsum plaster boards. Gypsum plaster is a good construction material for fire-resisting protection because of the fact that there is approximately $21 \%$ by weight chemically bound water in gypsum crystals. A large amount of heat is absorbed by gypsum board during dehydration, which slows down the heat transfer from the fire to wood studs or joists.

Heavy timbers are recognized as having good fire resistance even if they are exposed to fire directly. During fire exposure, the charred layer on the exposed surface acts as a thermal barrier for the solid wood below preventing the attack of flame and blocking oxygen penetration. The charring rate (the rate of advance of char into the wood) can stay 
very low in fire. For example, the charring rate is about $0.6-0.7 \mathrm{~mm} / \mathrm{min}$ for heavy timber members in the standard fire exposure (White 2008).

In timber structural systems, connections are widely used to assemble components and transfer loads between members, but they are recognized as the weakest link in a timber construction. In most national building codes and standards around the world, i.e. EN1995-1-1 (2004), CAN/CSA-O86-01 (2005) and NDS (2005), design of timber connections is emphasized more than timber members such as beams and columns to ensure the stability of timber construction. In light framing constructions, nails, screws, or metal-plate connectors are commonly used. In heavy timber structures, bolts, dowels and steel plates are more popular connectors, since they are able to carry heavy loads. Figure 1.1 and Figure 1.2 show different types of heavy timber connections, including both single-shear and double-shear timber connections.
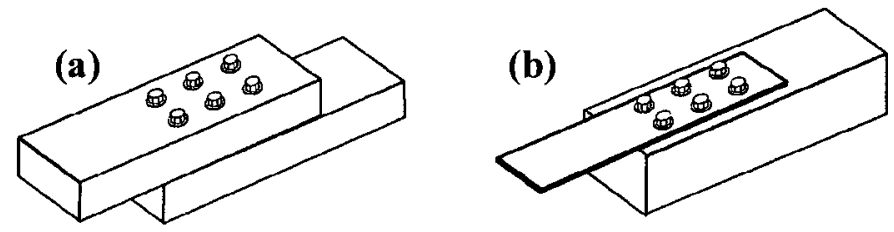

Figure 1.1 Single-shear timber connections: (a) wood-wood connection; (b) woodsteel connection

(a)

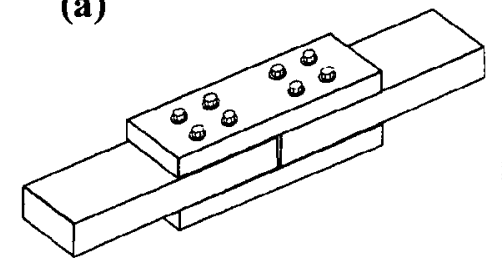

(b)

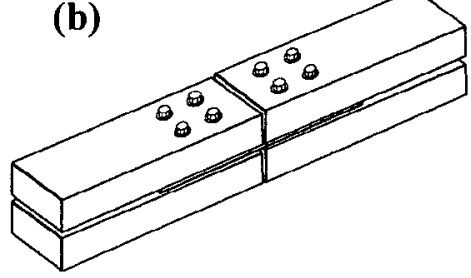

(c)

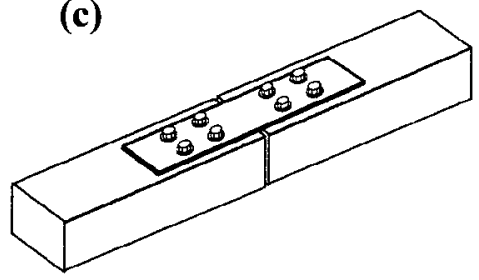

Figure 1.2 Double-shear timber connections: (a) wood-wood-wood connection; (b) wood-steel-wood connection; (c) steel-wood-steel connection 
Usually, timber connections are required to have the same fire resistance as main members such as timber beams and columns, if fire resistance is required. However, during a fire exposure, unprotected metal connectors heat up quickly and loose their stiffness and strength at high temperatures. They also transfer heat into wood members and cause wood to char faster because of the high conductivity of metal. Therefore, the capacity of timber connections can be reduced to a great extent with metal fasteners. The analysis of the fire performance of timber connections is very complicated because there are various connection types, different geometries and fastener arrangements, and also because of the great variability of the properties of wood and char at elevated temperatures.

In Canada, the fire performance of heavy timber connections is an area that has received little attention by researchers. According to the National Building Code of Canada (NBCC 2005), the structure of most buildings permitted to be of combustible construction must have either a 45-min or 1-hour fire-resistance rating. If the fire-resistance rating of a combustible construction is required to be $45-\mathrm{min}$ or more, heavy timber construction is permitted. For a 45-min requirement, the minimum permitted cross-sectional dimensions of wood elements in heavy timber construction are given and prescriptive guidance on design of connections is provided. Table 1.1 shows the minimum dimensions of wood elements in heavy timber construction given in the NBCC, which provides a level of fire safety equivalent to a $45-\mathrm{min}$ fire resistance rating. The $\mathrm{NBCC}$ also states that splice plates used at splices of roof trusses, roof beams and roof girders shall be not less than 64 mm thick. However, it has been observed from French experimental results (Dhima 1999) 
that splice plates of about $60 \mathrm{~mm}$ thick were far not able to resist 45 minutes standard fire exposure without protection. Moreover, neither the NBCC nor any other Canadian document provides detailed information on the estimation of the fire resistance for different connection types and geometries.

Table 1.1 Minimum Heavy Timber Dimensions, from NBCC (2005)

\begin{tabular}{|c|c|c|c|c|}
\hline $\begin{array}{l}\text { Supported } \\
\text { Assembly }\end{array}$ & Structural Element & $\begin{array}{c}\text { Solid Sawn } \\
\text { (width } \times \text { depth), } \\
\mathrm{mm} \times \mathrm{mm}\end{array}$ & $\begin{array}{c}\text { Glulam } \\
\text { (width } \times \text { depth), } \\
\mathrm{mm} \times \mathrm{mm}\end{array}$ & $\begin{array}{c}\text { Round } \\
\text { (diameter), } \\
\mathrm{mm} \times \mathrm{mm}\end{array}$ \\
\hline \multirow{4}{*}{ Roof only } & Columns & $140 \times 191$ & $130 \times 190$ & 180 \\
\hline & $\begin{array}{l}\text { Arches supported on the tops of } \\
\text { walls or abutments }\end{array}$ & $89 \times 140$ & $80 \times 152$ & - \\
\hline & Beams, girders and trusses & $89 \times 140$ & $80 \times 152$ & - \\
\hline & $\begin{array}{l}\text { Arches supported at or near the } \\
\text { floor line }\end{array}$ & & & - \\
\hline $\begin{array}{l}\text { Floor, } \\
\text { floors plus } \\
\text { roofs }\end{array}$ & $\begin{array}{l}\text { Columns } \\
\text { Beams, girders, trusses and } \\
\text { arches }\end{array}$ & $\begin{array}{c}191 \times 191 \\
140 \times 241 \text { or } 191 \\
\times 191\end{array}$ & $\begin{array}{c}175 \times 190 \\
130 \times 228 \text { or } 175 \\
\times 190\end{array}$ & 200 \\
\hline
\end{tabular}

For a 1-hour requirement, a simple method is given in the NBCC to calculate the minimum cross-sectional dimensions of glulam beams- in bending and-columns in -.. compression, but no guidance is provided on calculating the fire resistance of glulam members in tension. Again, neither the NBCC nor any other Canadian document provides guidance on the selection of timber connections to meet the required 1-hour fireresistance rating (Mehaffey 2003).

\subsection{Previous Work}

A brief review is undertaken in this section to summarize the relevant work that forms the background of the performance of timber connections at ambient temperature as well as under fire exposures. A comprehensive literature review is presented in Chapter 2. 
First of all, understanding the mechanical behaviour of timber connections in ambient conditions is basic and important in this research. In timber structure design, the behaviour of timber connections has been a subject of intensive research for decades. Most national codes (EN1995-1-1 2004; CAN/CSA-O86-01 2005; NDS 2005) provide detailed regulations and calculation equations on how to design timber connections. These methods are mostly based on Johansen's yield model (Johansen 1949) and connections are assumed to fail in ductile modes. On the other hand, connections that fail in brittle modes have caught researchers' eyes in order to improve the prediction in design codes, because brittle failures may govern the capacity of connections in some cases. As a result, new equations based on brittle failure modes have been proposed (Quenneville 2000; Mohammad 2001) and adopted in the new Canadian standard for wood engineering design (CAN/CSA-O86-09 2009).

In recent years, numerical modelling using the Finite Element method has also been conducted by some researchers to predict the slip-load behaviour of timber connections and capture the failure modes (Patton-Mallory 1996; Guan 2000; Moses 2000; Kharouf 2001; Hong 2007). However, it is very challenging to correctly model the exact failure and mechanical behaviour of timber connections due to the complexity of non-linear material properties and contacts, and the complexity of failure mechanisms of timber connections.

Second of all, our knowledge of the fire performance of wood and steel would contribute to the understanding of the fire behaviour of timber connections. For decades, a lot of effort has been made by researchers to study the fire performance of wood and steel 
structures. It is known that thermal and mechanical properties of wood and steel are significantly influenced by elevated temperatures. Wood is converted to char at about $300^{\circ} \mathrm{C}$. Understanding thermal and physical properties of wood and steel is crucial and fundamental in assessing the fire-resistance behaviour of timber connections. However, especially for wood, property values are not well defined and vary among researchers (Benichou and Sultan 2000; Buchanan 2001). For steel, the properties at elevated temperatures are well defined and can be found in Eurocode 3 (EN1993-1-2 2005).

In terms of the performance of timber connections exposed to fire, prior to the $1990 \mathrm{~s}$, our knowledge was very limited. Carling (1989) gave a comprehensive review of the fire performance of connections in timber structures. At that time, there was no method for assessing the fire resistance of wood joints exposed to fire, nor calculation of their load capacities in fire. In the last two decades, this area has received increasing attention and a number of research works have been carried out in order to improve design rules for timber connections in fire safety. So far, most of the experimental research has been conducted in Europe (Noren 1996; Dhima 1999; Kruppa 2000; Ayme 2003; Erchinger 2006a; Frangi 2009). In Eurocode 5 (EN1995-1-2 2004), simple methods based on research results by Noren (1996) and Dhima (1999) were adopted for structural fire design of timber connections. However, Konig (2001) summarized regulations and calculation methods for structural fire design of timber connections in Eurocode 5 and pointed out that a large number of tests are also required to study the influence of the various parameters governing the fire performance due to the complexity of connections. In New Zealand, researchers (Lau 2006; Chuo 2007; Austruy 2008; Moss 2008) conducted a series of timber connection tests and developed a calculation method 
combining the reduced embedment strength model (Noren 1996) and Johansen's yield model (Johansen 1949). Moreover, some numerical modelling has been carried out as well by Laplanche (2006) and Erchinger (2006b) based on available experimental results.

\subsection{Objective and Scope}

The objective of this study was to develop calculation methods that can be used to design suitable heavy timber connections to satisfy the fire-resistance ratings prescribed in building codes. The calculation methods were to be simple, yet accurate, taking into consideration different types of timber connections (i.e. wood-wood-wood, wood-steelwood and steel-wood-steel) and different types of fasteners (i.e. bolts and dowels). Other parameters including wood member thickness, fastener diameter, load level and protection, were also to be considered in the methods.

In this study, two types of bolted timber connections, steel-wood-steel (SWS) and woodsteel-wood (WSW) were investigated experimentally. They are commonly used in heavy timber constructions in North America. Although a small number of tests have been carried out for these two types of timber connections, comprehensive and parametric research was still necessary to generate knowledge and empirical data for numerical modelling and the development of the calculation methods. Wood-wood-wood (WWW) connections were not studied directly in this research project since a large number of experimental tests have already been carried out in Europe. The existing test results, however, were used in the development of the calculation methods in this research. 


\subsection{Methodology}

Both experimental tests and numerical analyses were carried out to investigate the fire performance of timber connections.

\subsubsection{Experimental Program}

Tensile tests at ambient temperature are necessary for a timber connection because they are used to determine the ultimate strength as the reference capacity of the connection (i.e. for benchmarking). In fire tests, loads were applied at selected ratios of the reference capacities at ambient temperature. In this study, the reference capacities of connections at ambient temperature were either obtained from the literature (Quenneville 2000; Mohammad 2001) or determined from tests conducted by the author. Testing procedures as outlined in ASTM D1761-88 (ASTM 2000) were followed.

Fire-resistance tests were conducted in a medium size furnace. Temperatures in the furnace were controlled by shielded thermocouples and fire exposure conditions were also measured by plate thermometers. The exposure conditions followed the (CAN/ULCS101 2007) standard. Tests specimens were loaded in tension parallel to grain, and loading level, displacement and temperatures within the specimens were measured during the tests.

\subsubsection{Material Properties}

In order to carry out thermal and structural simulations, thermal and mechanical properties of materials are required. Because of the complexity and high variability of material properties at elevated temperatures, no tests were carried out to determine them 
in this study. Input data were found from many different researchers, as summarized in the literature review.

\subsubsection{Heat Transfer Analysis}

A three dimensional heat transfer analysis was conducted to predict the temperature distribution of timber connections in the standard fire exposure using the finite element program ABAQUS/Standard (Hibbitt 2008). ABAQUS/Standard is able to simulate transient heat conduction in a solid body, and define boundary conditions and contact interactions for heat exchange between members.

The three dimensional heat transfer modelling was a challenge because of the nonhomogeneity of the connection, temperature-dependant properties, three different materials (char is regarded as a different material), and gaps between members. The model was validated by comparisons with the experimental results.

\subsubsection{Structural Analysis}

Based on the temperature profile calculated using the heat transfer model, the structural analysis was conducted by modifying analytical models at ambient temperature to calculate the strength of a connection at elevated temperatures. The calculation of the strength at elevated temperatures was based on different failure modes observed in the fire-resistance tests, and temperature-based mechanical properties of wood and steel. The fire-resistance rating was determined as the time when the strength of the connection at elevated temperatures dropped to the applied tensile load. 


\subsubsection{Data Correlation}

Finally, simplified empirical calculation methods were developed using data correlation. The data obtained from existing experimental tests and the results generated in this study were used to develop the correlations.

\subsection{Contribution of this Study}

As to the author's knowledge, this research was the first in North America, to extensively study the performance of bolted WSW and SWS connections under the ULC/CAN-S101 (or ASTM E119) fire exposure. The information generated throughout the experimental tests revealed the influence of different factors on the fire performance of bolted WSW and SWS connections, and enlarged the research background on the fire performance of timber connections.

The proposed 3-D heat transfer analysis method and the structural analysis method based on possible failure modes were proven to be able to model heat transfer and the strength of a timber connection at elevated temperatures. In future research, these methods can be applied to analyze the fire resistance of other types of timber connections (i.e. connections loaded in tension perpendicular to the gain).

Furthermore, the simple, yet accurate, empirical calculation methods developed in this research can be used to predict fire resistances of WSW, WWW and SWS timber connections, covering a commonly wide range of timber thicknesses and load ratios. Based on the proposed calculation methods, recommendations were made on how to design suitable timber connections to satisfy code requirements on fire safety. 


\section{Chapter 2: Literature Review}

In this chapter, reviewed literature includes an introduction to fire resistance, material properties of steel and wood at normal and elevated temperatures, the performance of timber connections at normal and elevated temperatures, and existing studies on timber connections in fire.

\subsection{Introduction to Fire Resistance}

This section gives a basic overview of methods for designing structural members for fire safety. It describes fire severity, fire resistance, standard fire, fire-resistance test and fireresistance rating.

\subsubsection{Fire Severity and Resistance}

Fire severity is a measure of the destructive impact of a fire. It can be defined in the time domain, the temperature domain, or the strength domain. Most often, it is quantified in terms of an equivalent period of exposure during a standard fire for comparison (Buchanan 2001).

Fire resistance characterizes the ability of a building element to resist a fire. The element might be a single element such as a column or a beam, or it might be a complex assembly such as a floor or wall frame system. Fire resistance can also be defined in the time domain, the temperature domain, or the strength domain. Most often, it is quantified as the time that the element can sustain a standard fire exposure. In fire safety design for structures, the following equation must be satisfied: 


\subsubsection{Standard Fire}

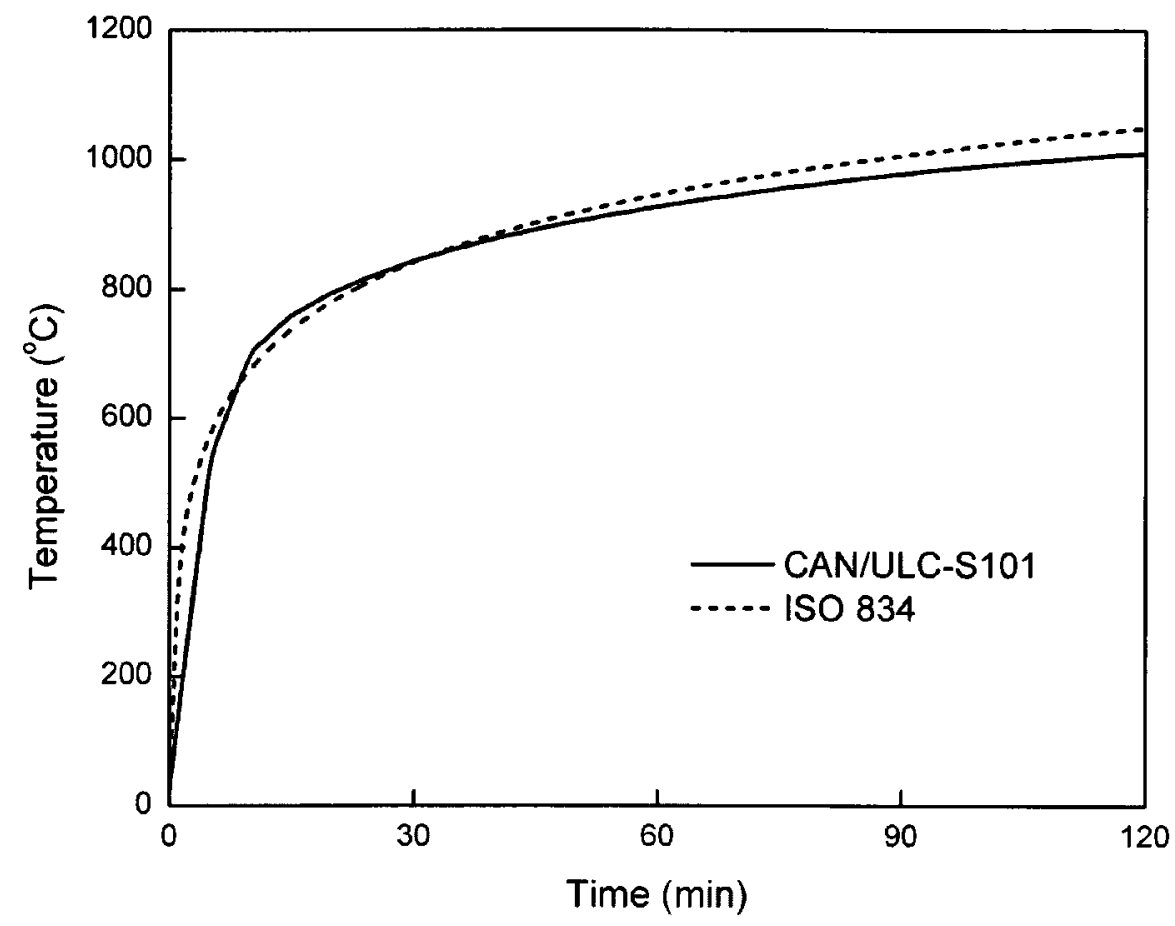

Figure 2.1 Standard time-temperature curves for CAN/ULC-S101 and ISO 834

Standard fires are time-temperature curves used in the fire-resistance test. Most national standards are based on either ASTM E119 (2007) or ISO 834 (1999). The Canadian Standard CAN/ULC-S101 (2007) curve follows ASTM E119. The time-temperature curves for the CAN/ULC-S101 and ISO 834 standards are reproduced in Figure 2.1.

It can be seen in Figure 2.1 that the two curves are very similar. However, the thermal exposure condition can be considerably different between CAN/ULC-S101 and ISO 834 tests, due to different temperature measuring methods. In a CAN/ULC-S101 test, thermocouples shielded by heavy steel pipes are used and this results in a more severe fire 
exposure than a standard test controlled by bare thermocouples, especially in the first 10 minutes (Sultan 2006). On the other hand, heat exposure in a fire test also depends on furnace parameters such as furnace wall material, furnace size and type of fuel. In this manner, to reduce the differences in severity of exposure between furnaces in different countries, some researchers suggested using plate thermometers to replace thermocouples for harmonization of fire-resistance test furnaces (Cooke 1994; Wickstrom 1994). The plate thermometer measures the exposure of the test specimen rather than the furnace temperature (Buchanan 2001).

\subsubsection{Fire-Resistance Test}

Fire-resistance test is a test method used to directly determine the fire-resistance performance of structural elements and assemblies. Most widely used standards for fireresistance testing are ASTM E119 (2007) and ISO 834 (1999). Standards in European countries are similar to ISO 834, and ASTM E119 is used in the United States and some other countries. The Canadian Standard CAN/ULC-S101 (2007) is based on ASTM E119. According to the standards, test furnaces, test methods and failure criteria are also described and defined.

There are three possible failure criteria for fire-resistance testing: stability, integrity and insulation. The stability failure refers to the structural failure of an element if it can no longer carry the applied load. The integrity failure refers to the development of any cracks or fissures on an assembly, which allow the passage of hot gases or flames hot enough to ignite a cotton waste. The insulation failure refers to the exceeded temperature 
increase on the unexposed surface of an assembly, i.e., an average temperature increase of $140^{\circ} \mathrm{C}$ or a temperature increase of $180^{\circ} \mathrm{C}$ at a single location.

If a construction element is fire-rated, it must satisfy one or more of the three failure criteria, based on the function of the element. For example, for wall and floor assemblies, all the three failure criteria must be met. However, for beams and columns, the stability criterion must be met.

\subsubsection{Fire-Resistance Rating}

Fire-resistance rating is the fire resistance assigned to a construction element or assembly based on a standard test or some other approved method. The most common method of determining the fire-resistance rating is to conduct a standard fire-resistance test. In addition, listings and calculation methods permitted by codes are also used to assess the fire-resistance rating.

Fire-resistance rating provides a measure of the time for evaluating the relative performance of different structural members exposed to a standard fire, but it does not mean that the structural member will last that time during a real fire.

\subsubsection{Fire-Resistance Rating by Calculation}

Although fire-resistance tests are the direct method used to assess fire-resistance ratings, they are expensive and time consuming. An economical alternative method is to carry out mathematical or numerical analyses to study the fire performance of structural members. Three essential components: a fire model, a heat transfer model and a structural model, 
are important in calculating the structural fire performance (Buchana 2001). Calculation models should be verified or validated against the full-scale fire-resistance test results.

\subsection{Wood and Steel}

This section summarizes the structural behaviour of wood and steel at normal temperature as well as at elevated temperatures.

\subsubsection{Wood at Ambient Temperature}

Wood is one of the most frequently used engineering materials. It is a cellular, anisotropic and heterogeneous natural material on the micro scale. However, in engineering, clear wood specimens are usually treated as a homogenous continuum if the specimen scale is much larger than the cell size.

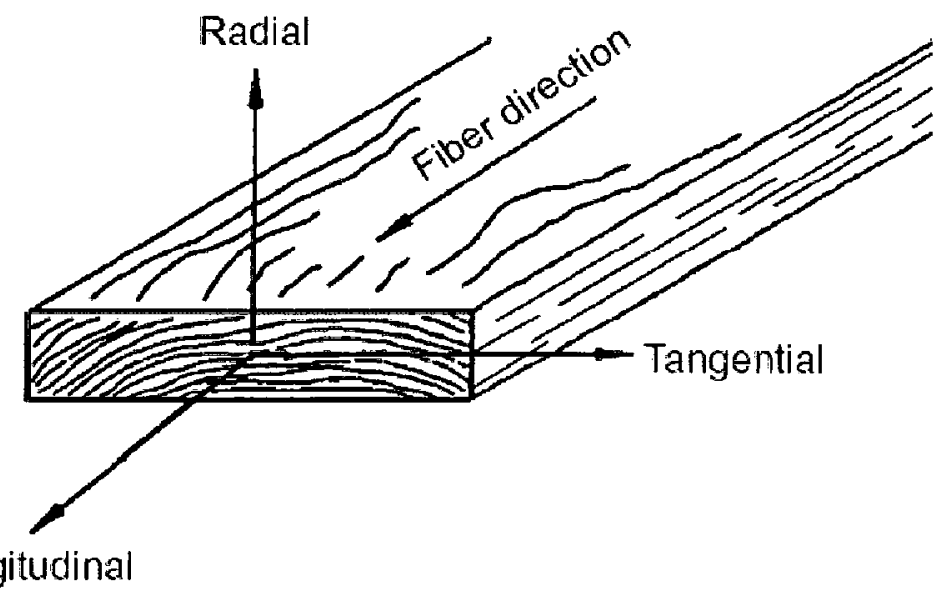

Figure 2.2 Three principle axes in wood, (Wood Handbook 1999)

Wood has three principle axes, as illustrated in Figure 2.2. The longitudinal direction (L) is parallel to the grain, the radial direction $(R)$ is normal to the growth rings and the tangential direction $(T)$ is tangential to the growth rings. Both the radial direction $(R)$ and 
tangential direction $(\mathrm{T})$ are in a plane perpendicular to the grain. In each direction, wood is observed to experience relatively unique and independent material properties. In this manner, wood is often considered as an orthotropic material. The strength in the longitudinal direction is the greatest, usually about 10 times the strength in the radial and tangential directions. The difference in strength between the radial and tangential directions is relatively small compared to the difference between either of these directions and the longitudinal direction. As a result, wood is sometimes idealized as a transversely isotropic material.

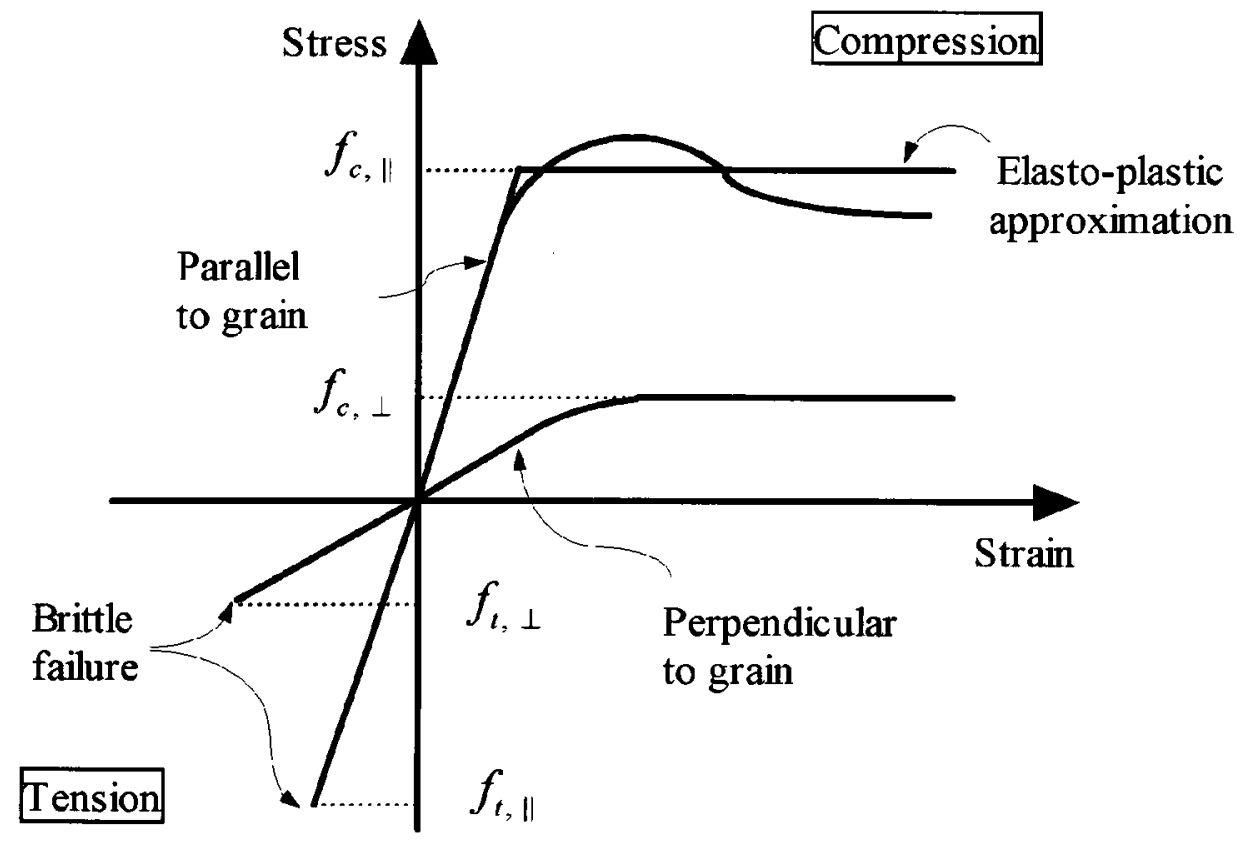

Figure 2.3 Stress-strain relationship for wood

A typical stress-strain relationship for clear wood is shown in Figure 2.3, reproduced from Buchanan (2001). When loaded parallel to the grain, wood shows a linear elastic behaviour in tension and brittle failure occurs at a specific tensile stress; whereas on the compression side, the line is linear in the elastic region and then curves due to yielding or 
crushing of wood. Approximately, a bilinear elasto-plastic behaviour can be assumed for wood in compression. Using this simplified relationship, the maximum value of the compressive strength is somewhat smaller than the exact value due to the decay of compression strength when the strain increases.

When wood is loaded perpendicular to the grain, the stress-strain relationship shows ductile behaviour in compression with strain increasing slowly as stress increases. In tension perpendicular to grain, brittle failure happens due to splitting of wood when the stress linearly reaches the tensile strength.

\subsubsection{Steel at Ambient Temperature}

Steel is an isotropic material. Hot-rolled low carbon or mild carbon steel is often used in timber connections as fasteners and connectors, such as steel bolts and steel plates. The stress-strain relationship of steel begins with a linear elastic curve followed by a plastic plateau after reaching the yield point. As the strain increases, steel exhibits work hardening and the stress increases as well. In wood connection tests, steel fasteners and plates do not experience deformations as severe as wood members, although yielding has been observed sometimes in steel members. Practically, it is acceptable to assume steel as an elasto-plastic material in timber connections.

\subsubsection{Wood at Elevated Temperatures}

When wood is heated by an external source, moisture evaporates between $100^{\circ} \mathrm{C}$ and $120^{\circ} \mathrm{C}$. When the temperature reaches above $200^{\circ} \mathrm{C}$, the wood undergoes a pryrolysis reaction and generates combustible products. After combustible gases have burned out, a charred layer is left on the surface, which protects the residual wood from the external 
heat exposure and oxidation penetration. Figure 2.4 illustrates the layers in a fire-exposed wood.

The temperature to determine the charring layer is commonly accepted as $300^{\circ} \mathrm{C}$ or $288^{\circ} \mathrm{C}$. Due to the steep temperature gradient through the wood and char, the difference made by $288^{\circ} \mathrm{C}$ or $300^{\circ} \mathrm{C}$ is insignificant (Buchanan 2001). The temperature profile in the wood beneath the charring layer can be expressed in a parabolic equation, from Eurocode 5 (EN1995-1-2 2004):

$$
\frac{T-T_{0}}{T_{p}-T_{0}}=\left(1-\frac{x}{a}\right)^{2}
$$

where $T_{0}$ is the initial temperature, $T_{p}$ is the charring temperature $\left(288^{\circ} \mathrm{C}\right.$ or $\left.300^{\circ} \mathrm{C}\right)$, $x(\mathrm{~mm})$ is the distance below the char layer and $a(\mathrm{~mm})$ is the thickness of the heated but not yet charred wood. Eurocode 5 (EN1995-1-2 2004) uses a as $40 \mathrm{~mm}$, while Janssens (1994b) proposed $a$ as $35 \mathrm{~mm}$.

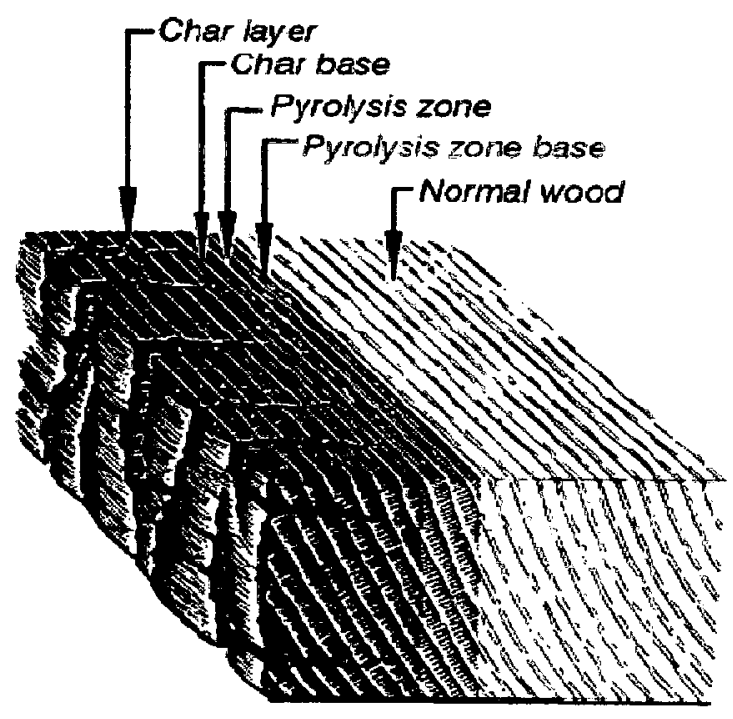

Figure 2.4 Layers in a wood section exposed to fire, SFPE (White 2008) 


\subsubsection{Charring Rate of Wood}

The charring rate of wood generally refers to the charred depth divided by the exposure time. The charred layer is recognized to have no strength and rigidity, so it carries no loads. It is the non-charred wood underneath the charred layer that carries the load, although it partially loses its strength and rigidity at elevated temperatures. In order to evaluate the capacity of a wood member under fire exposure, the determination of the wood charring rate is critical in structural design.

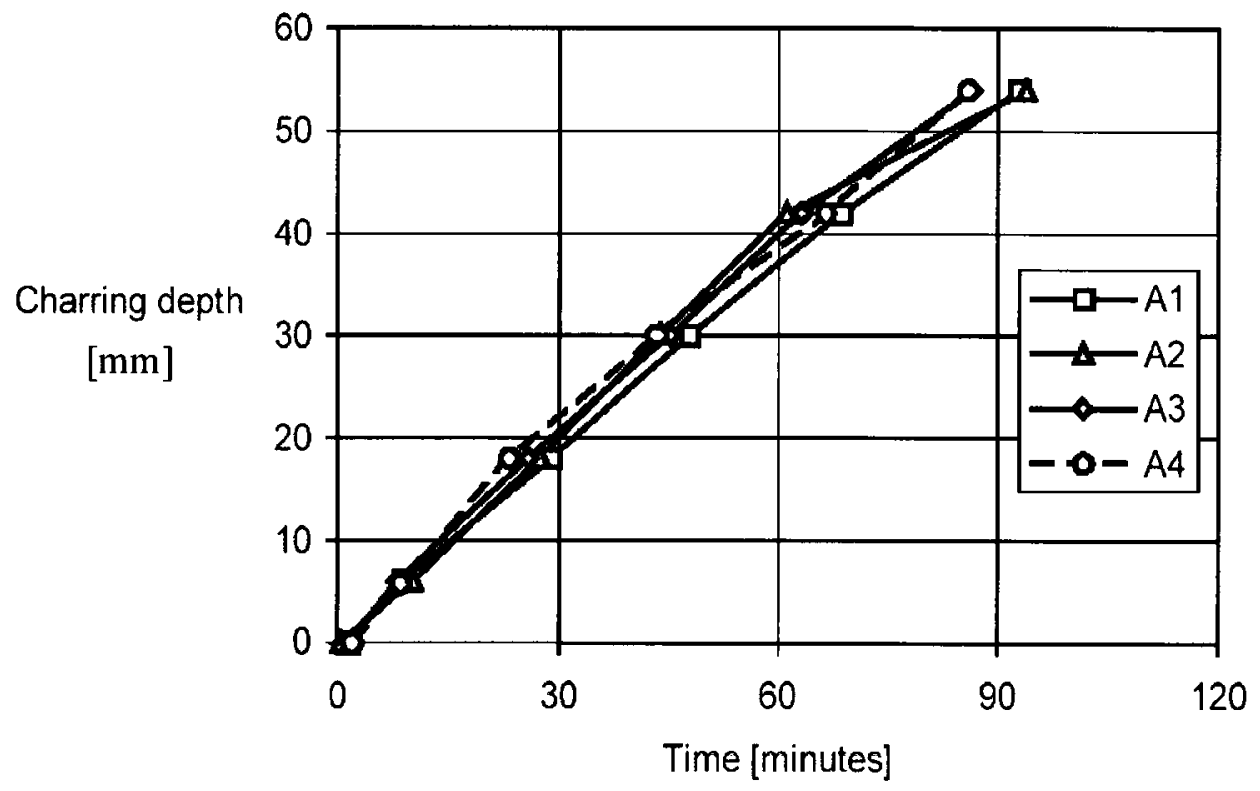

Figure 2.5 Charring depth as a function of fire exposure time, Konig (1999)

In standard fire tests, the rate of charring is predictable, depending on the density, moisture content and permeability of the wood. Figure 2.5 shows typical relationships between the charring depth and the ISO 834 fire exposure time from the literature (Konig 1999) for large dimension wood members. In the figure, A1 to A4 represent four identical tests, and the curves are found to be almost linear. 
Most national codes specify a constant charring rate during standard fire exposures. In North America, the generally accepted value is $0.635 \mathrm{~mm} / \mathrm{min}$ for solid wood and glulam timber (White 2000). Lie (1977) used a value of $0.60 \mathrm{~mm} / \mathrm{min}$ in developing the calculation methods for columns and beams in the NBCC (2005). Eurocode 5 (EN19951-2 2004) gives a charring rate of $0.65 \mathrm{~mm} / \mathrm{min}$ for softwoods and $0.5 \mathrm{~mm} / \mathrm{min}$ for hardwoods. A slightly larger value is used if the effect of corner rounding is included in Eurocode 5. In the New Zealand code (SNZ 1993), a rate of $0.65 \mathrm{~mm} / \mathrm{min}$ is adopted for softwoods. In Australia, the code (SAA 1990) gives the notional charring rate as:

$$
\beta=0.4+(280 / \rho)^{2}
$$

where $\rho\left(\mathrm{kg} / \mathrm{m}^{3}\right)$ is the wood density.

On the other hand, non-constant charring rate estimation methods are also used by researchers. A widely accepted empirical model was developed by White (1988) for the calculation of charring rate in the ASTM E1 19 fire tests:

$$
t=m x_{c}{ }^{1.23}
$$

where $t$ is the time of exposure $(\mathrm{min}), x_{c}$ is the char depth $(\mathrm{mm})$ and $m$ is called the reciprocal charring rate which is a function of the density, moisture content and char contraction factor (see detailed explanation in White 1998).

For structural composite lumber products, such as laminated veneer lumber (LVL), parallel strand lumber (PSL) and laminated strand lumber (LSL), fire-resistance tests have showed that their charring rates were comparable with that of solid wood (White 2000). 
The fire-resistance rating calculation methods for solid wood can be used to estimate the ratings of composite lumber products.

\subsubsection{Thermal Properties of Wood}

Thermal properties, including thermal conductivity, specific heat and density, are important in heat transfer models. Thermal properties of wood are highly affected by temperature, moisture content, grain orientation and wood species. Many researchers have reported their results based on either experimental tests or best fit with numerical simulations.

\section{Thermal Conductivity}

Since wood is orthotropic, it has different thermal conductivities in the radial, tangential and longitudinal directions. However, the difference between the radial and the tangential thermal conductivity is usually very small. According to the SFPE Handbook of Fire Protection Engineering (White 2008), the ratio of the tangential conductivity to the radial conductivity is 0.9 to 0.95 for hardwood and 0.97 for softwood containing relatively little latewood and 0.87 when there is much latewood. The longitudinal conductivity is considerably greater than the conductivity perpendicular to the grain. In the SFPE Handbook (White 2008), it is suggested that the longitudinal conductivity is about 1.5 to 2.8 times the transverse property.

Figure 2.6 shows the wood thermal conductivity values (perpendicular to the grain) at elevated temperatures, reported from different researchers: Knudson (1973), Fredlund (1993), Mehaffey (1994), Janssens (1994), and Konig (2000). 


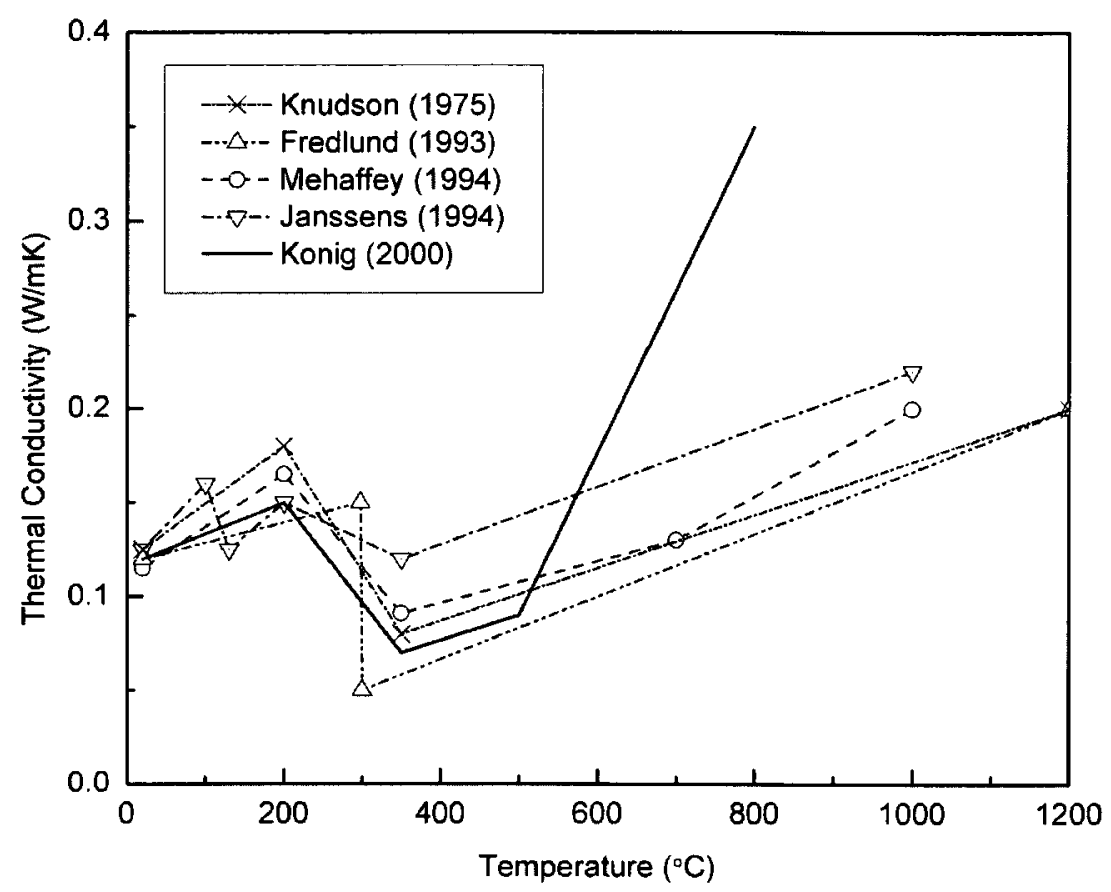

Figure 2.6 Thermal conductivity of wood at elevated temperatures

Knudson (1975) used a linear relationship for wood from $20^{\circ} \mathrm{C}$ up to $200^{\circ} \mathrm{C}$ and a linear relationship for char over $350^{\circ} \mathrm{C}$, and assumed a linear curve between $200^{\circ} \mathrm{C}$ and $350^{\circ} \mathrm{C}$ for the decomposition of wood. Fredlund (1993) used one curve for wood and another for char and assumed the transformation from wood to char occurred at $300^{\circ} \mathrm{C}$. Values used by Mehaffey (1994) were derived from the literature (Lie 1992). Janssens (1994) calculated the conductivity based on wood oven-dry density and moisture content. Konig (2000) claimed that the thermal conductivity values of the char layer should be increased at temperatures over $500^{\circ} \mathrm{C}$, in order to take into account the influence of cracks and shrinkage of the char layer.

In summary, most researchers agree that the thermal conductivity increases initially up to about $200^{\circ} \mathrm{C}$, then decreases linearly between $200^{\circ} \mathrm{C}$ and $350^{\circ} \mathrm{C}$, and increases after 
$350^{\circ} \mathrm{C}$. The scatter may come from different wood species, densities, moisture contents and methods used by researchers for determining the values.

\section{Specific Heat}

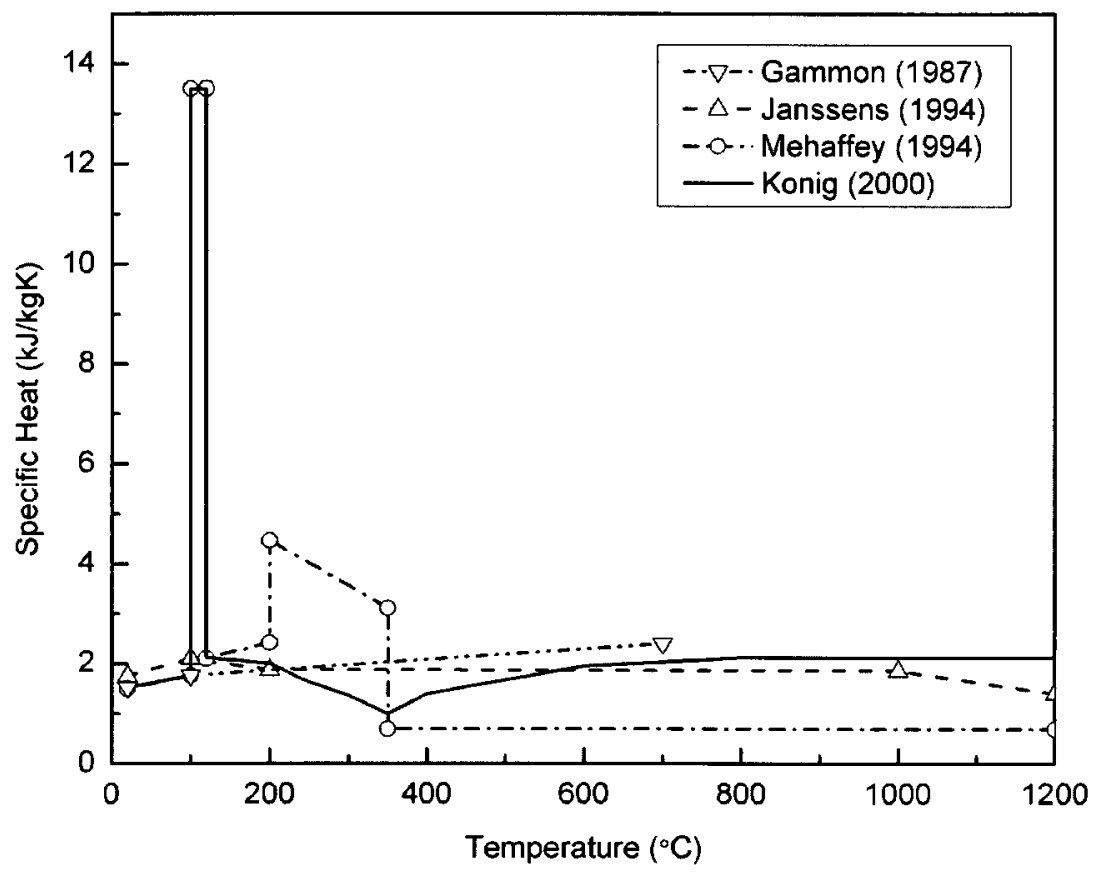

Figure 2.7 Specific heat of wood at elevated temperatures

Figure 2.7 shows the wood specific heat values at elevated temperatures from different researchers. The basic equation, used by Gammon (1987), Mehaffey (1994) and Janssens (1994) for determining the specific heat of wood, is:

$$
c_{p}=(a+b T+4.187 u) /(1+u)+\Delta c
$$

where $c_{p}(\mathrm{~kJ} / \mathrm{kgK})$ is specific heat, $T\left({ }^{\circ} \mathrm{C}\right)$ is temperature and $u(\mathrm{~kg} / \mathrm{kg})$ is moisture content. Different values have been used for coefficients $a$ and $b$ by researchers to 
determine the specific heat (Thomas 1997). $\Delta c$ is the moisture correction, used only by Janssens (1994) as:

$$
\Delta c=(23.55 T-1326 u+2417) u
$$

It has to be mentioned that Mehaffey (1994) and Konig (2000) used the extra energy required to evaporate moisture, resulting in a peak value between $100^{\circ} \mathrm{C}$ and $120{ }^{\circ} \mathrm{C}$ to the specific heat. Mehaffey (1994) also added the extra energy to the specific heat for the pyrolysis degradation, which was not reported by other researchers.

\section{Density}

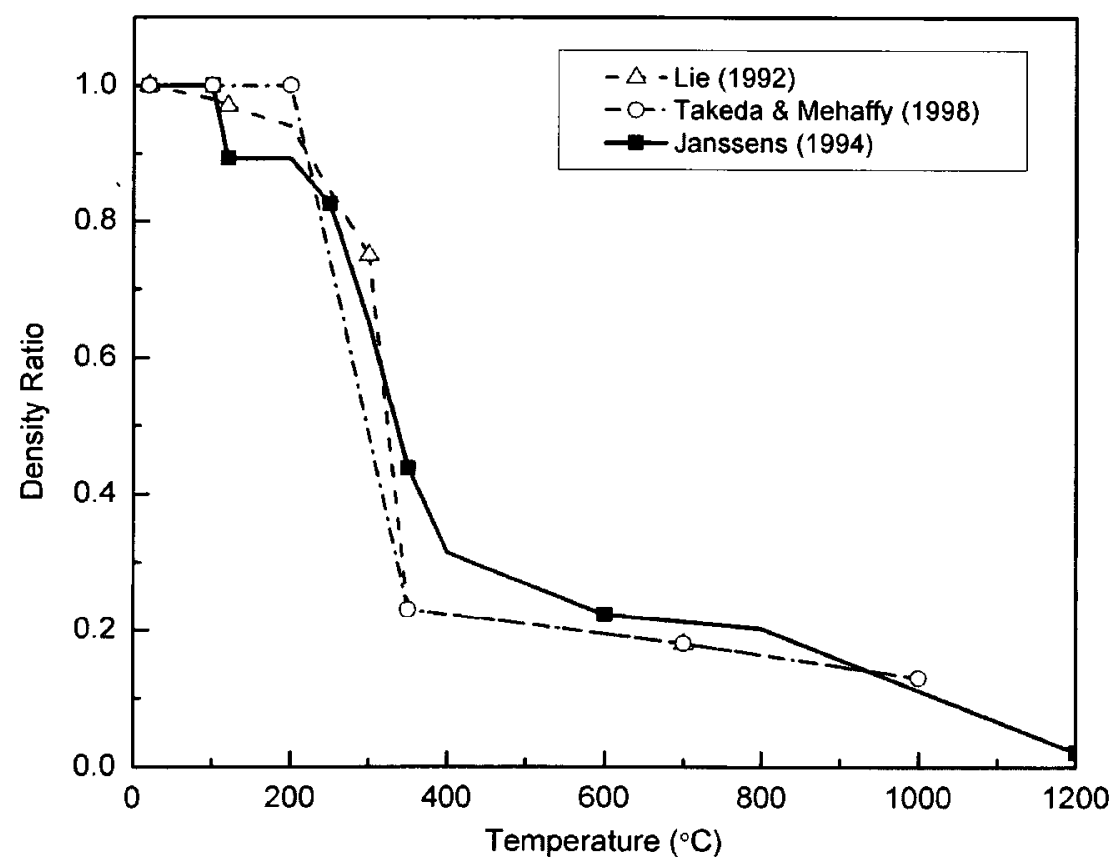

Figure 2.8 Density of wood at elevated temperatures

Wood changes density at elevated temperature because of moisture evaporation and thermal degradation of wood fibers. Figure 2.8 shows the density ratio as a function of 
temperature reported by researchers: Lie (1992), Takeda and Mehaffey (1998) and Janssens (1994). The ratio refers to the density at ambient temperature. It can be seen that the density ratio curves drop to a value between 0.9 and 0.95 at $200^{\circ} \mathrm{C}$ due to the evaporation of moisture, and then decrease significantly down to an approximate value of 0.2 or 0.3 at about $350^{\circ} \mathrm{C}$ due to thermal decomposition. After this point, the char density decreases very slowly.

\subsubsection{Mechanical Properties of Wood}

Wood's mechanical properties are highly affected by temperature as well as the thermal properties of wood.

\section{Modulus of Elasticity}

In terms of the modulus of elasticity parallel to the grain at elevated temperatures, some researchers (Preusser 1968; Schaffer 1970; Ostman 1985; Lie 1992; Janssens 1997) reported the same reduction factor for tension and compression, shown in Figure 2.9; but Thomas (1997) and Konig (2000) used different relationships for the stiffness in tension and compression, shown in Figure 2.10.

As seen in Figure 2.9, the modulus of elasticity was reported to drop slowly down to a temperature of about $200^{\circ} \mathrm{C}$. After $200^{\circ} \mathrm{C}$, the thermal decomposition in wood reduces the stiffness rapidly until wood becomes char at about $280^{\circ} \mathrm{C}$ to $300^{\circ} \mathrm{C}$. 


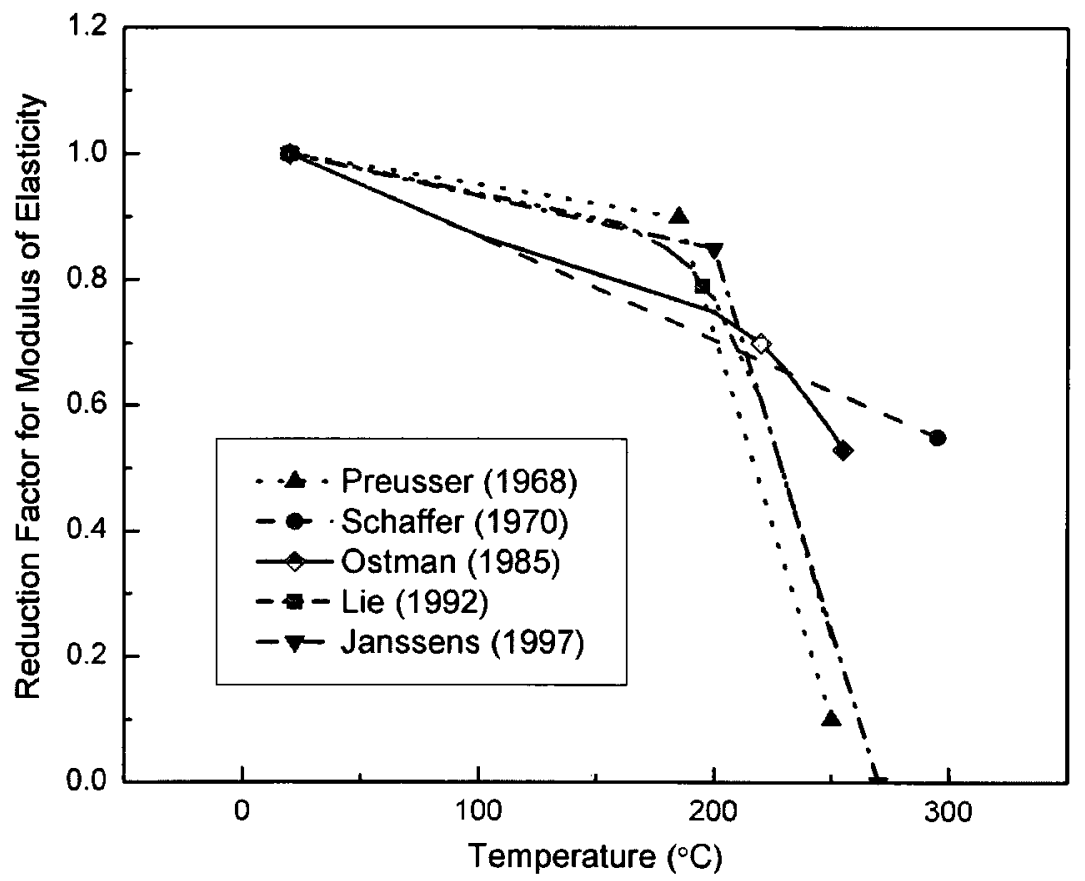

Figure 2.9 Elastic modulus of wood at elevated temperatures

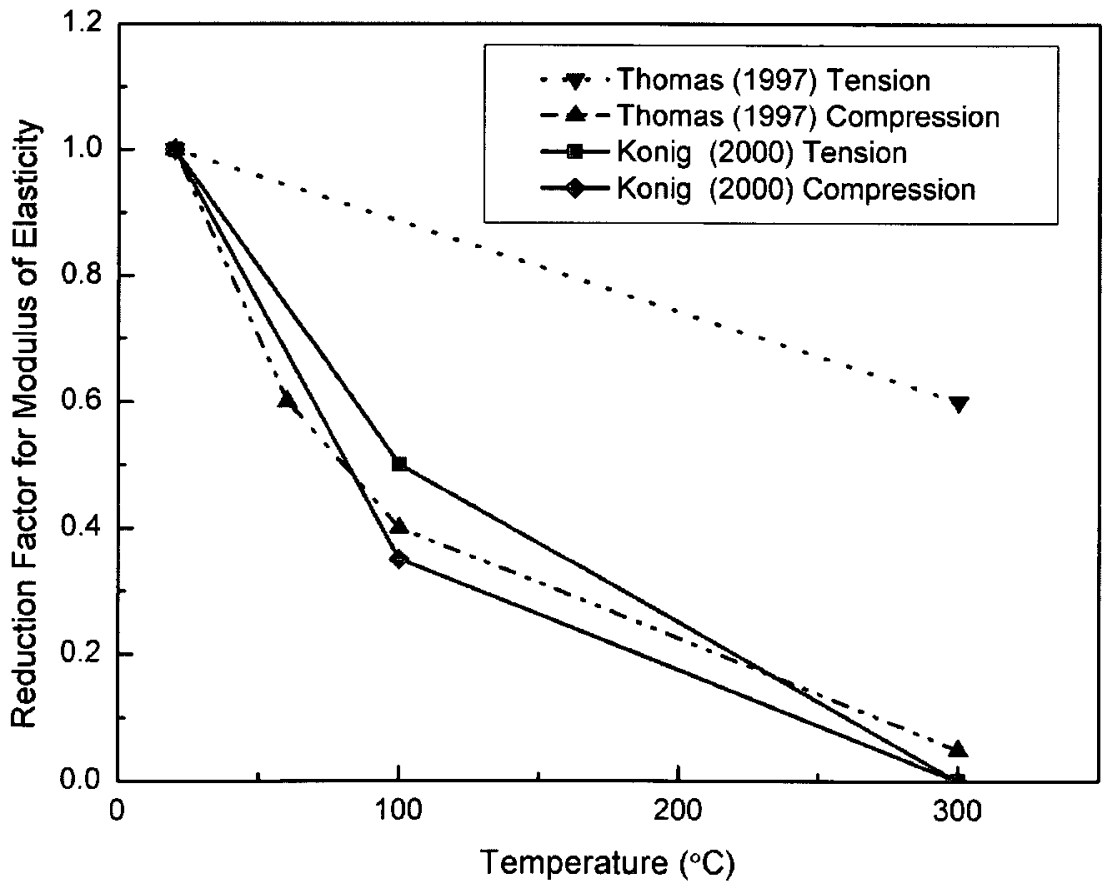

Figure 2.10 Elastic modulus of wood at elevated temperatures 
Thomas claimed that the stiffness in compression was the effective stiffness by including the loss of stiffness due to the presence of the steam in the compression zone for bending tests, as shown in Figure 2.10. Konig reported the effect of temperature on the stiffness in compression was of the same order of magnitude as in tension. However, Konig's values are somewhat lower than other researchers' results and he claimed that the effects of transient moisture and creep of timber were included.

\section{Tensile and Compressive Strength}

The tensile strength of wood as a function of temperature is shown in Figure 2.11. Knudson (1973) and Lie (1992) used a linear decreasing relationship from $20^{\circ} \mathrm{C}$ to about $300^{\circ} \mathrm{C}$. Schaffer $(1970)$ assumed a slow decrease until $200^{\circ} \mathrm{C}$, followed by a rapid decline after $200^{\circ} \mathrm{C}$. Thomas (1997) assumed that tensile strength drops linearly between $80^{\circ} \mathrm{C}$ and $295^{\circ} \mathrm{C}$ and wood loses its strength at $310^{\circ} \mathrm{C}$. A bilinear relationship was used by Konig (2000) with a breakpoint at $100^{\circ} \mathrm{C}$, but Konig's reduction factors of the tensile strength are smaller than those from other sources, as seen in Figure 2.11.

Some researchers (Schaffer 1970, Lie 1992) stated that the compressive strength behaves similarly to the tensile strength at elevated temperatures. The compressive strength of dry wood drops linearly from initial to about $300^{\circ} \mathrm{C}$, but more rapidly than the tensile strength, as shown in Figure 2.12. However, Konig (2000) and Thomas (1997) used bilinear curves for wood specimens with $12 \%$ moisture content with a breakpoint at $100^{\circ} \mathrm{C}$. 


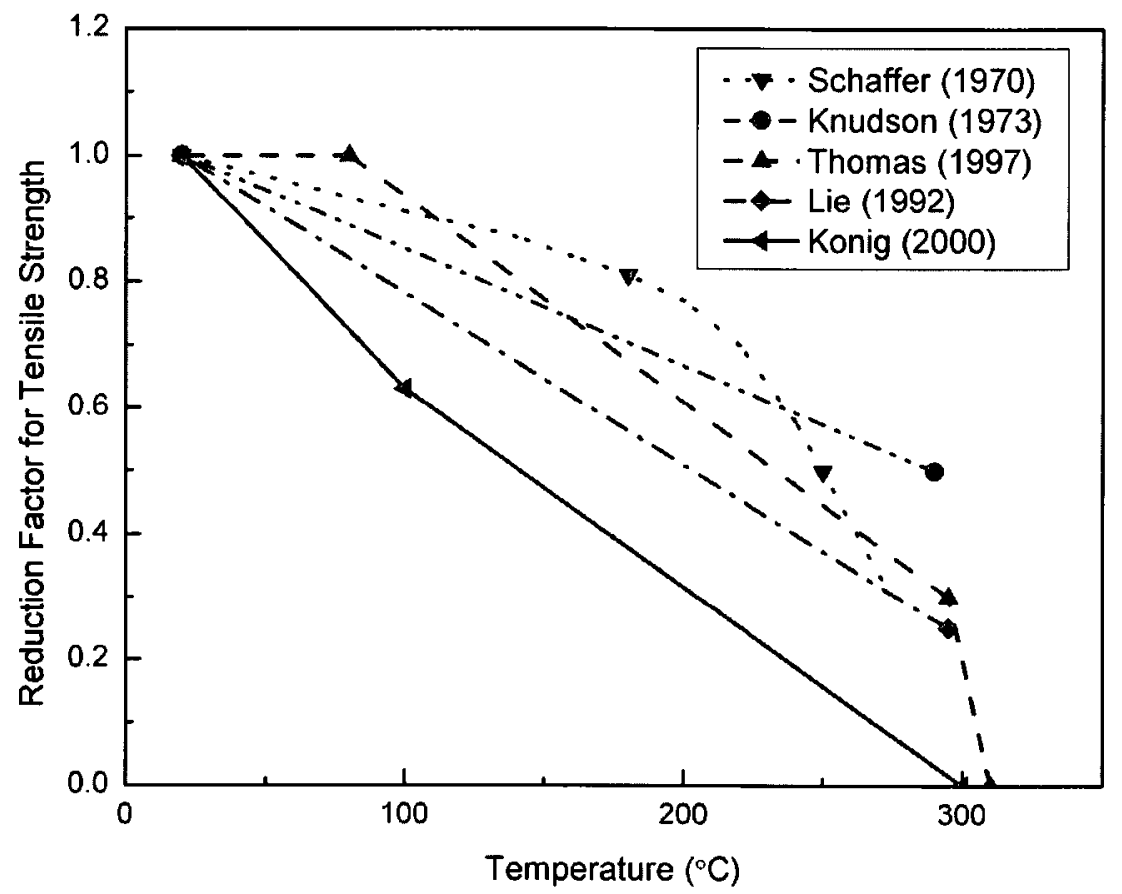

Figure 2.11 Tensile strength of wood at elevated temperatures

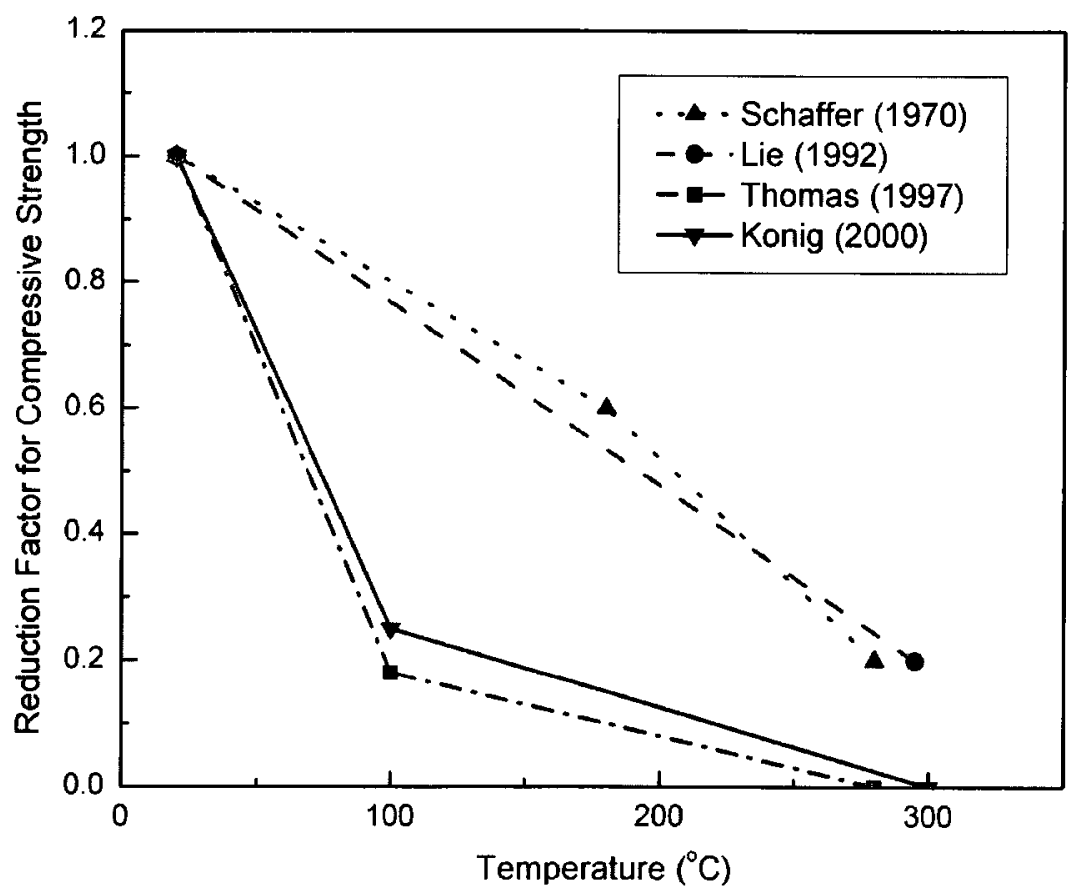

Figure 2.12 Compressive strength of wood at elevated temperatures 


\section{Shear Modulus and Strength}

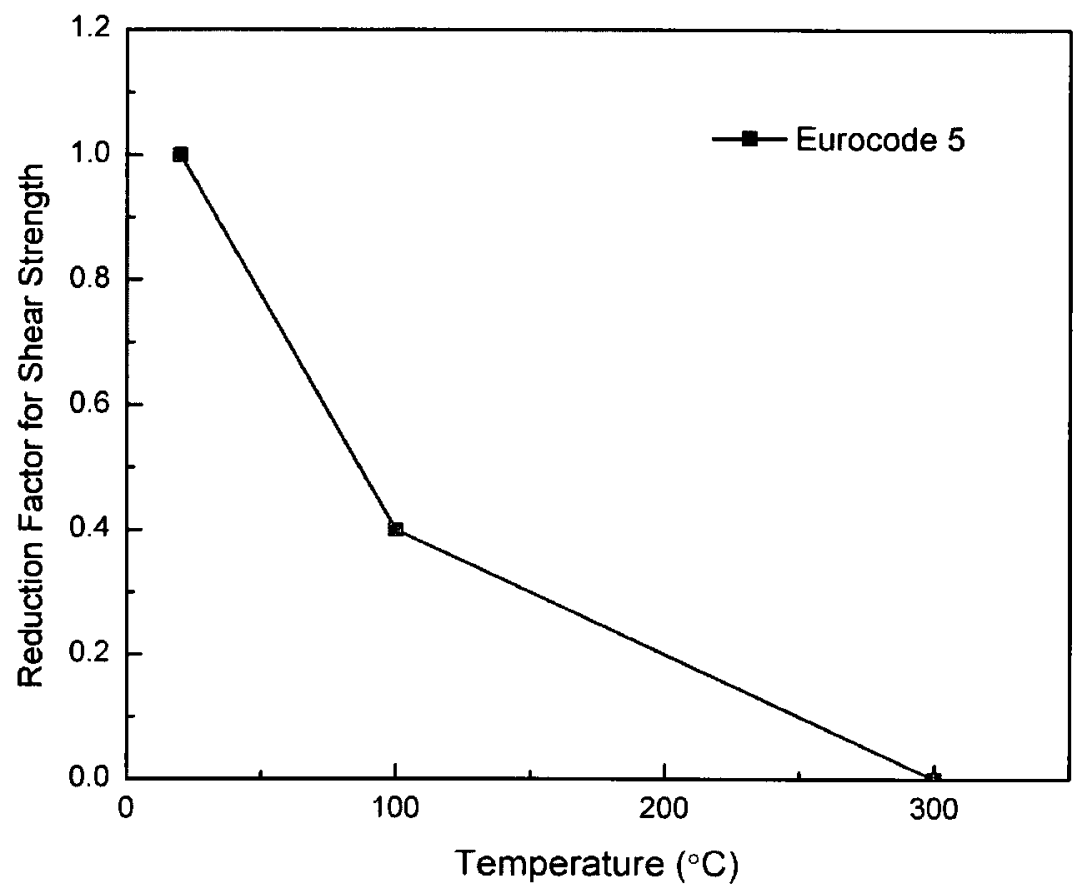

Figure 2.13 Shear strength of wood at elevated temperatures

Gerhards (1982) summarized the influence of temperature on shear modulus and strength from the literature and reported that the reduction factor of the shear modulus drops to $0.2-0.5$ at $80^{\circ} \mathrm{C}$ and the shear strength decreases rapidly to about $0.1-0.3$ at $150^{\circ} \mathrm{C}$. Figure 2.13 shows the reduction factor of as a function of temperature for shear strength parallel to grain, recommended in Eurocode 5 Annex B (EN 1995-1-2, 2004).

\section{Properties Perpendicular-to-the-grain}

For compression perpendicular to the grain, the same reduction of strength at elevated temperatures may be applied as for compression parallel to the grain, recommended by Eurocode 5 Annex B (EN 1995-1-2, 2004). The same reduction of elasticity was used for 
both parallel and perpendicular to the grain directions in modelling timber connections in fire by Laplanche (2006).

\subsubsection{Steel at Elevated Temperatures}

Under fire exposure, steel temperature increases rapidly due to the high thermal conductivity. Steel loses its strength and stiffness significantly at elevated temperatures. As a result, steel members can suffer possible deformation and failure.

Compared to the complexity of wood properties influenced by temperature, the properties of steel at elevated temperatures are less complicated and better documented. In this subsection, the influence of temperature on steel thermal properties and mechanical properties is discussed. The main source is Eurocode 3 (EN1993-1-2 2005).

\subsubsection{Thermal Properties of Steel}

The influences of temperature on the thermal properties of steel, i.e. specific heat and thermal conductivity, are discussed in this section. However, the density of steel is assumed to remain constant with temperature as $7850 \mathrm{~kg} / \mathrm{m}^{3}$. The volumetric change of steel at high temperatures is assumed to be small and is ignored.

\section{Specific Heat}

Figure 2.14 shows the specific heat versus temperature according to Eurocode 3 (EN1993-1-2 2005). The equations are given as: 


$$
\begin{aligned}
c_{p} & =425+0.773 T-1.69 \times 10^{-3} T^{2}+2.22 \times 10^{-6} T^{3} & & 20^{\circ} C \leq T<600^{\circ} C \\
& =666+13002 /(738-T) & & 600^{\circ} C \leq T<735^{\circ} C \\
& =545+17820 /(T-731) & & 735^{\circ} C \leq T<900^{\circ} C \\
& =650 & & 900^{\circ} C \leq T<1200^{\circ} C
\end{aligned}
$$

where $T$ is the steel temperature. The peak results from a metallurgical phase change (see Figure 2.14).

\section{Thermal Conductivity}

A bilinear relationship between thermal conductivity and temperature is recommended in the EuroCode 3 (EN1993-1-2 2005), shown in Figure 2.14. The equations are given as:

$$
\begin{array}{ll}
\lambda=54-0.0333 T & 20^{\circ} C \leq T<800^{\circ} C \\
\lambda=27.3 & 800^{\circ} C \leq T<1200^{\circ} C
\end{array}
$$

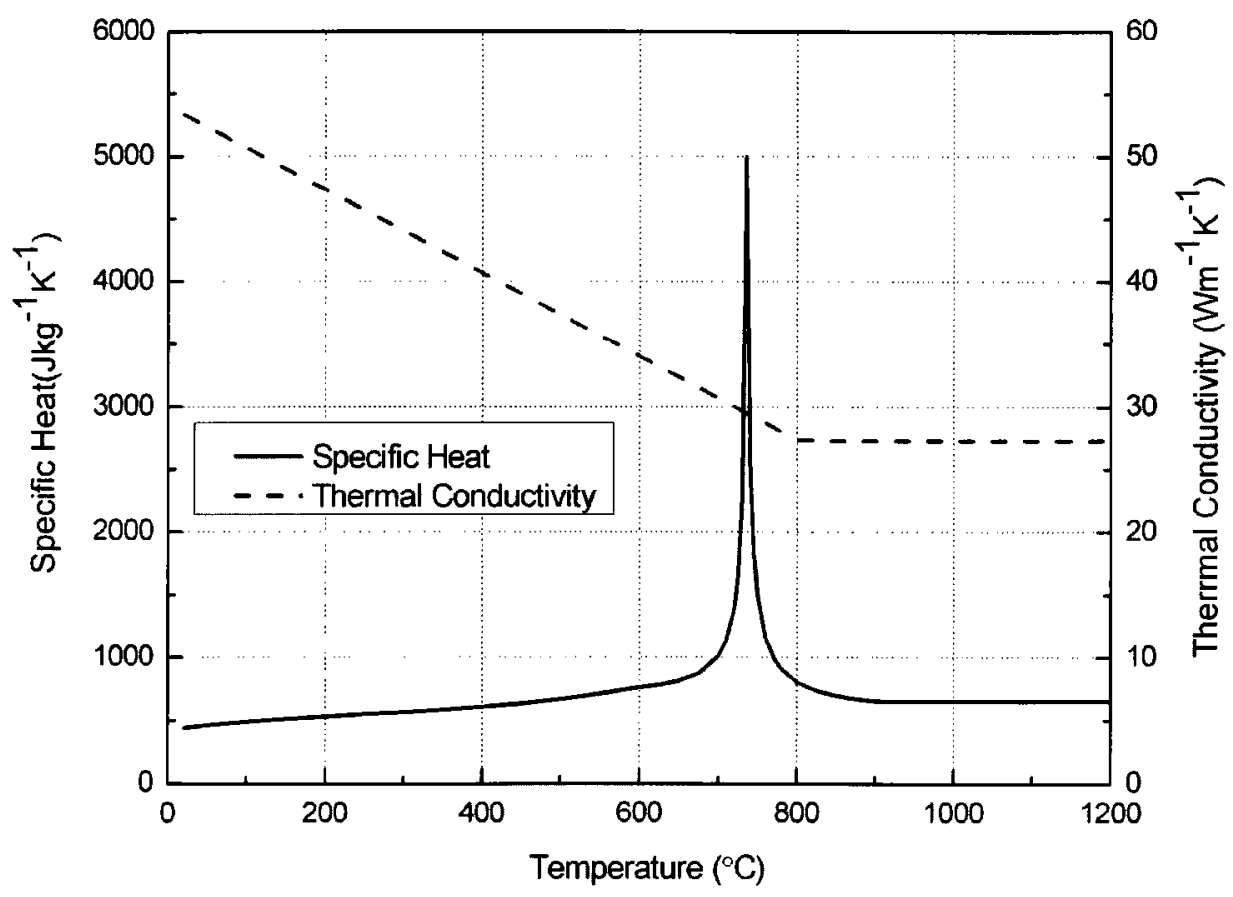

Figure 2.14 Thermal properties of steel at elevated temperatures 


\subsubsection{Mechanical Properties of Steel}

Eurocode 3 (EN1993-1-2 2005) gives a comprehensive material model for hot-rolled structural steels at high temperatures. Equation 2-17 shows the stress-strain relationship of steel at elevated temperatures:

$$
\begin{array}{rrr}
\sigma_{T}=\varepsilon_{T} E_{T} & \varepsilon_{T} \leq \varepsilon_{p, T} \\
=f_{p, T}-c+\left(\frac{b}{a}\right)\left[a^{2}-\left(\varepsilon_{y, T}-\varepsilon_{T}\right)^{2}\right]^{1 / 2} & \varepsilon_{p, T}<\varepsilon_{T} \leq \varepsilon_{y, T} \\
=f_{y, T} & \varepsilon_{y, T}<\varepsilon_{T} \leq \varepsilon_{t, T} \\
=f_{y, T} \frac{1-\left(\varepsilon_{T}-\varepsilon_{t, T}\right)}{\left(\varepsilon_{u, T}-\varepsilon_{t, T}\right)} & \varepsilon_{t, T}<\varepsilon_{T} \leq \varepsilon_{u, T} \\
=0 & \varepsilon_{T}>\varepsilon_{u, T}
\end{array}
$$

where $f_{y, T}$ is the effective yield strength, $f_{p, T}$ is the proportional limit, $E_{T}$ is the slope the linear elastic range, $\varepsilon_{p, T}$ is the strain at the proportional limit, $\varepsilon_{y, T}$ is the yield strain, $\varepsilon_{t, T}$ is the limit strain for yield strength and $\varepsilon_{u, T}$ is the ultimate strain, and the parameters are given as:

$$
\begin{aligned}
& \varepsilon_{p, T}=f_{p, T} / E_{T} \\
& \varepsilon_{y, T}=0.02 \\
& \varepsilon_{t, T}=0.15 \\
& \varepsilon_{u, T}=0.2 \\
& a^{2}=\left(\varepsilon_{y, T}-\varepsilon_{p, T}\right)\left(\varepsilon_{y, T}-\varepsilon_{p, T}+c / E_{T}\right) \\
& b^{2}=c\left(\varepsilon_{y, T}-\varepsilon_{p, T}\right) E_{T}+c^{2} \\
& c^{2}=\left(f_{y, T}-f_{p, T}\right)^{2} /\left[\left(\varepsilon_{y, T}-\varepsilon_{p, T}\right) E_{T}-2\left(f_{y, T}-f_{p, T}\right)\right]
\end{aligned}
$$

In terms of the reduction factors of steel at elevated temperatures, Buchanan (2001) stated that steel mechanical properties show considerable scatter at elevated temperatures after reviewing the literature. However, the design values proposed in many national codes are 
only slightly different. Figure 2.15 shows the relationships of elasticity modulus, proportional limit and yield strength, according to Eurocode 3.

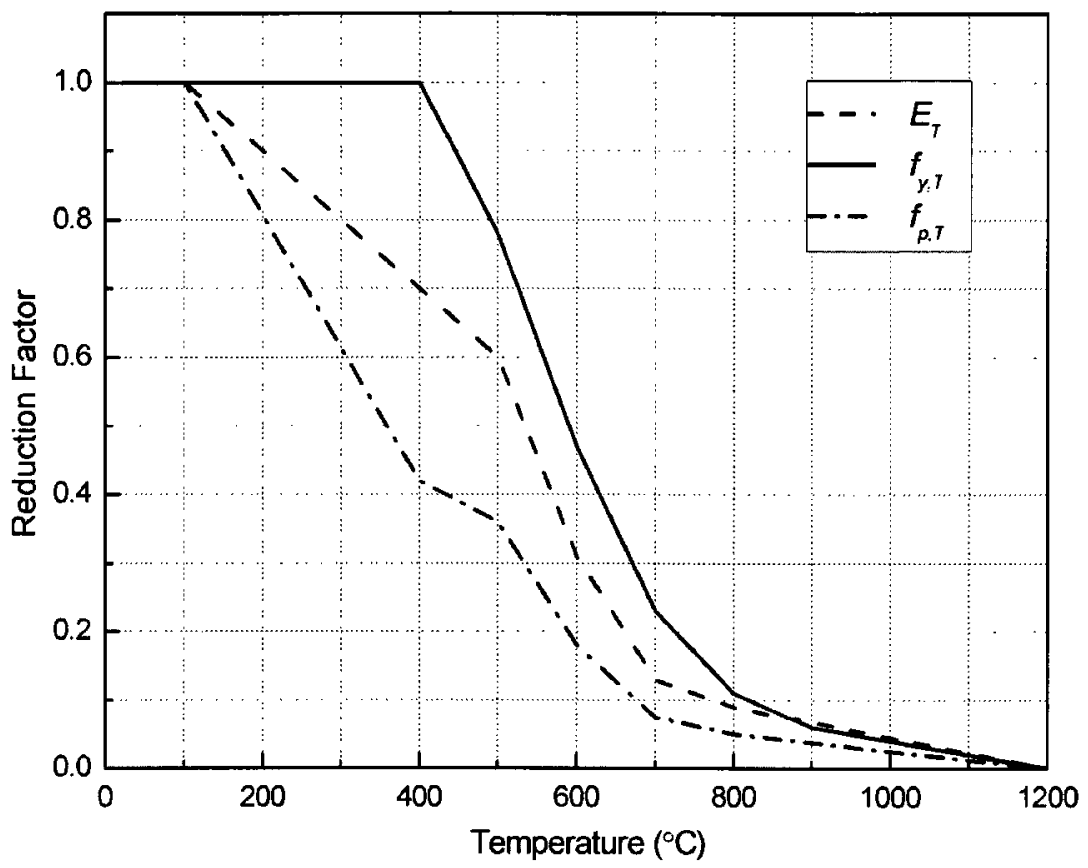

Figure 2.15 Mechanical properties of steel at elevated temperatures

\subsection{Timber Connections}

As discussed in Chapter 1, timber connections have attracted people's concern for decades in timber structure design, because connections have a great impact on the capacity of a timber structure even at ambient conditions. This section summarizes the timber connection behaviour at normal temperatures as well as at elevated temperatures.

\subsubsection{Timber Connections at Normal Temperature}

The load transmission mechanics between members of a timber connection are very complicated. Generally, for a bolted timber connection, the load is transferred into the bearing area where the bolt is in contact with the hole. The load causes bending and shear 
stresses in the bolt. On the other hand, the wood underneath the bolt is subjected to high concentrated compression and can fail in bearing or crushing, or in a brittle manner due to excessive shear stress or tension perpendicular to the grain stress.

Figure 2.16 shows a detailed interaction between a bolt and a hole, loaded in the grain direction. In the figure, $F_{t}$ is the applied force, $F_{r}$ is the reaction force in normal direction and $F_{\mu}$ is the friction. The column underneath the bolt is subject to high compressive stress and failure can occur due to crushing of the wood fiber. This compression column triggers a splitting force and may shear out wood underneath the bolt. Moreover, this compression column acts as a wedge and causes a tensile stress perpendicular to the grain at the end of the wood. This may initiate cracks and results in splitting in the wood.

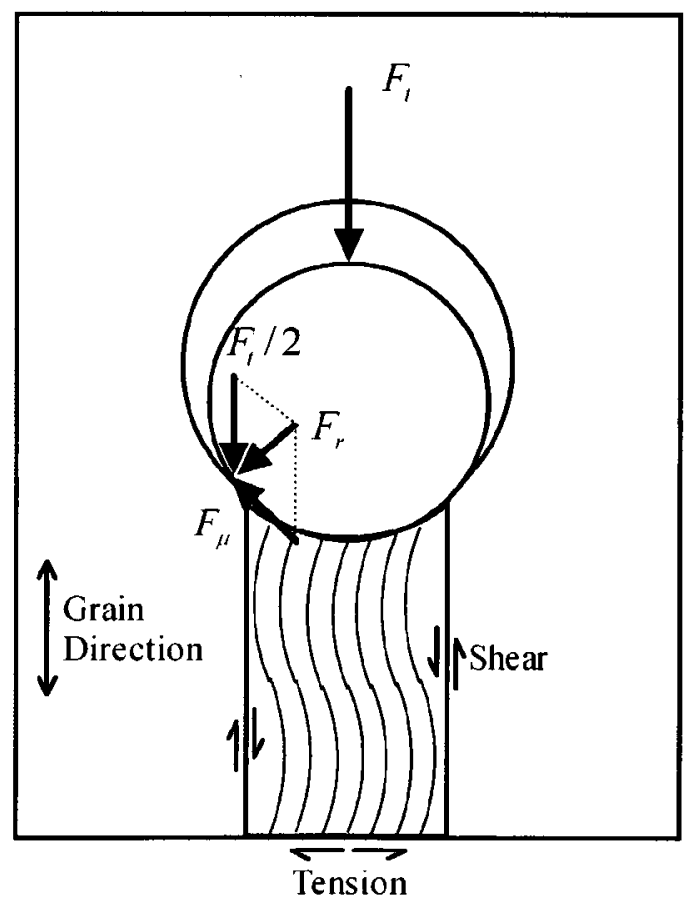

Figure 2.16 Interaction between a bolt and wood loaded in the grain direction 
The friction between the bolt and the hole was found to play an important role to the load transfer and failure modes. The higher the coefficient of friction, the wider the compression column is and two cracks are more likely to form. These two cracks are along the compression column boundary and caused by shear stresses along the boundary, as shown in Figure 2.16. The smaller the coefficient of friction, the closer the two cracks move together and one crack is likely to form (Rodd 1973; Jorissen 1998; Sjodin 2008).

Rodd (1973) conducted tests to determine the coefficient of friction between a dowel and timber. The coefficient of friction was found to be 0.339 for smooth dowels and 0.558 for rough dowels. Sjodin (2008) compared the numerical simulation with experimental results and declared that the coefficient of friction lies between 0 and 0.3 for a smooth dowel and it lies between 0.3 and 0.5 for a rough surface. Xu (2008) and Laplanche (2006) used 0.3 in modelling dowel-type timber connections. However, a high coefficient value was assumed as 0.75 by Guan (2000) and 0.7 by Khorouf (2001).

In practice, a fastener hole is drilled slightly larger than the fastener diameter for installation reasons. Generally, a 1/32" $(0.8 \mathrm{~mm})$ or $1 / 16^{\prime \prime}(1.6 \mathrm{~mm})$ oversized drill bit is used to make the fastener hole. The bolt/hole clearance ratio (bolt diameter/hole diameter) has a great effect on the contact area and the stress distribution in the contact area. In general, decreasing the bolt/hole clearance ratio results in a small contact area and higher radial stresses in the contact area (Patton-Mallory 1996). The load capacity also decreases with a larger hole clearance. In the Canadian wood design code (CAN/CSA-O86-09 2009), a clearance is required to be in the range of 1.0 to $2.0 \mathrm{~mm}$ for timber connections. 


\subsubsection{Failure Modes}

A wood connection can fail in a non-catastrophic mode (bearing mode) or a catastrophic mode (brittle mode), depending on the load transfer mechanism and the slenderness ratio of wood and bolt. The possible failure modes in a bolted timber connection subjected to a load parallel to the grain are summarized in Figure 2.17.

The bearing failure mode (Figure 2.17a) is due to excessive deformation of wood in the contact area, either alone or combined with steel yielding of the fastener in bending or shearing. As for double-shear connections loaded parallel to the grain, there are four possible yielding failure modes, seen in Figure 2.18. In structural design, the bearing failure mode is preferred over brittle modes because it allows a more ductile behaviour and improves load sharing among bolts in a multiple bolt connection. The bearing failure modes are critical for seismic design. 

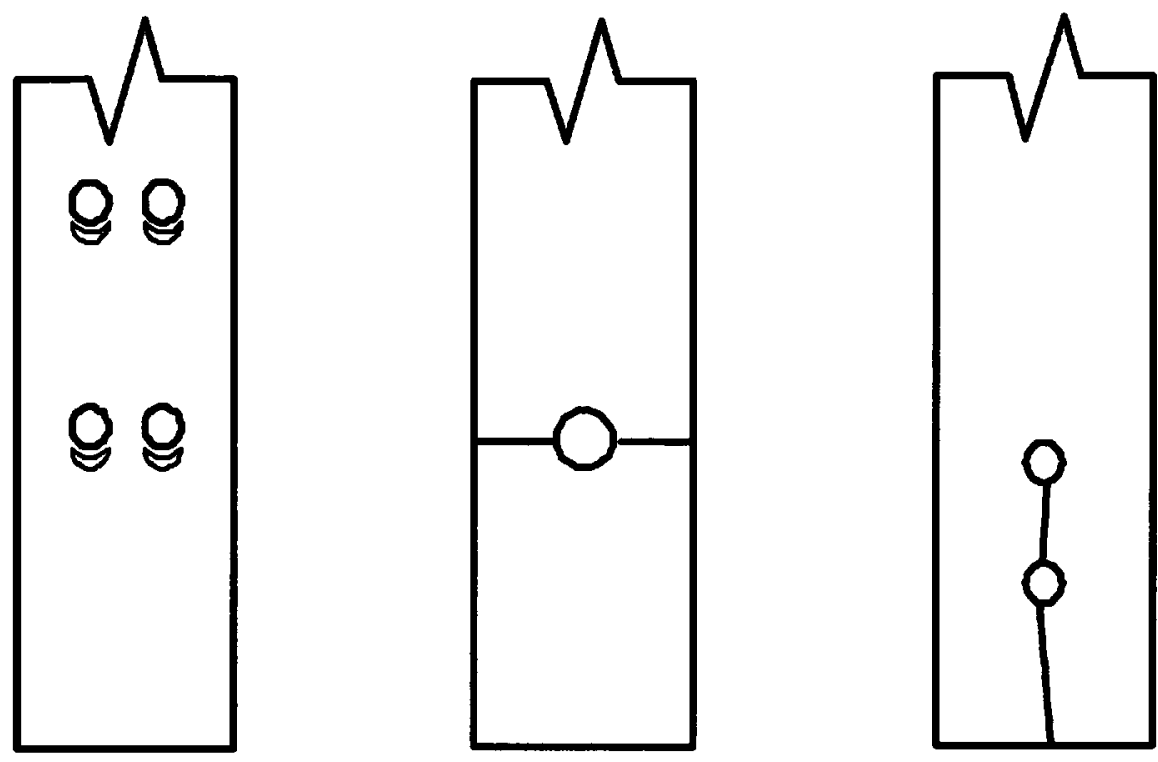

a) Bearing

b) Net Tension

c) Splitting
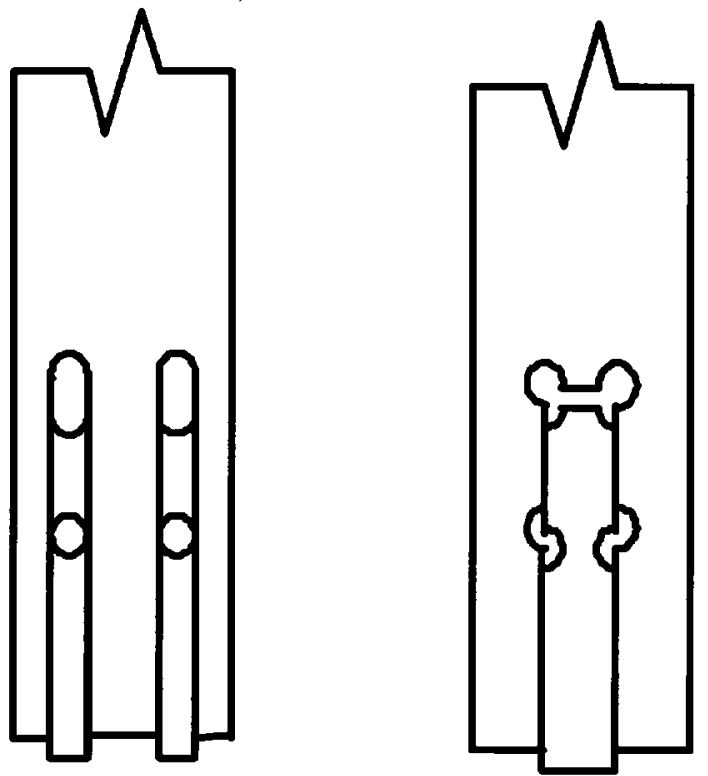
d) Shear-out
e) Group Shear-out

Figure 2.17 Typical failure modes in wood connections 


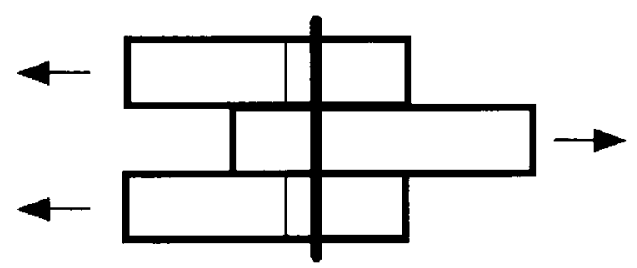

(1)

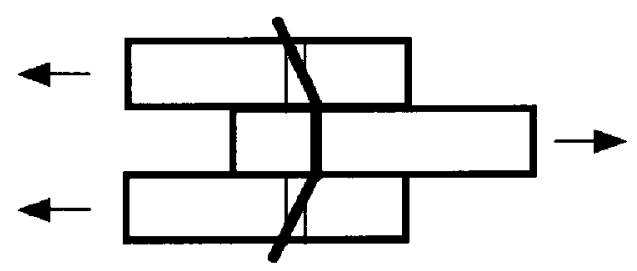

(3)

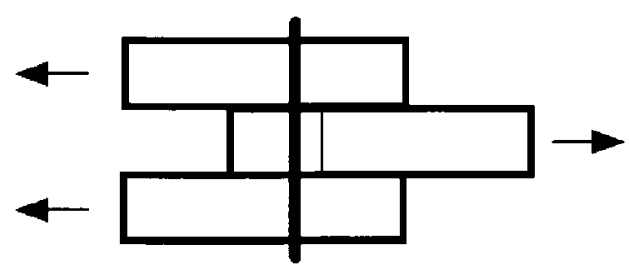

(2)

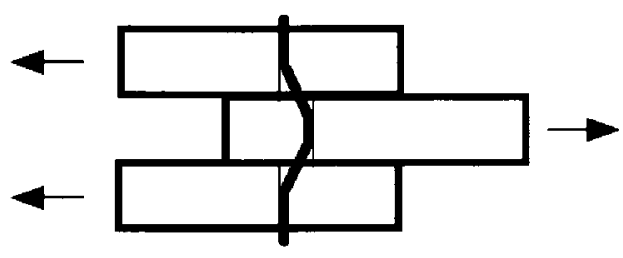

(4)

Figure 2.18 Ductile failure modes of double-shear connections, reproduced from CAN/CSA-O86-09 (2009)

Net tension failure mode (Figure $2.17 \mathrm{~b}$ ) is catastrophic due to the brittle behaviour in tension parallel to the grain. However, the tensile strength parallel to the grain is typically over 2 times the strength in compression, and this failure mode can be easily avoided by providing enough edge distance of 1.5 bolt diameter (Patton-Mallory 1996).

Tension perpendicular to the grain stresses in the end of the wood member is another reason that leads to catastrophic failure in wood connections (Figure 2.17c). The tensile strength perpendicular to the grain is relatively low compared to the strength properties in other directions. The wood in compression beneath the fastener acts like a wedge splitting the wood fiber matrix. Cracks that initiate at the end of the wood member may propagate through the member to a catastrophic failure. However, for wood connections with adequate end distance and member thickness, tension perpendicular to the grain may only 
initiate a few cracks, but such cracks will not propagate catastrophically throughout the member.

Wood connections can fail catastrophically due to shear fracture in the wood member underneath the bolt (typically called "Row Shear-out" failure mode, see Figure 2.17d). This failure mode often occurs in wood members with inadequate end distance and small thickness. In addition, multiple fastener wood connections may tend to fail due to a combination of row shear-out and net tension, frequently called "Group Tear-out" (Figure 2.17e).

\subsubsection{Load-Carrying Capacity}

Traditionally, load-carrying capacities of timber connections are predicted if the connections are assumed to fail in ductile failure modes only. The yield theory, which is well-known as the European Yield Model (EYM), was originally introduced by Johansen (1949) to calculate the lateral resistance of a dowel-type timber connection by assuming that the connection would fail in ductile modes as a result of the plasticity in the wood or in the fastener. The equations derived from Johansen's theory form the basis for design rules given in most national codes, i.e. EN1995-1-1 (1949), NDS (2004) and CAN/CSA086-09 (2009).

In European countries, fasteners with small diameters are more likely to be used by designers to obtain the ductile failure modes. However, designers in North America tend to use fewer large diameter fasteners to save on fabrication costs. As a result, the probability of brittle failure modes increases. Brittle failure modes have often been 
observed in tensile tests (Masse 1988; Quenneville 2000; Mohammad 2001). However, these failures can not be predicted by the EYM.

The Canadian timber design standard for bolted timber connections is based on the EYM which was modified by Larsen (1973). To overcome the drawbacks of the EYM not accounting for the brittle failure modes occurring in timber connections, modification factors were introduced in previous version of the Canadian design standard (CAN/CSAO86-01 2005). However, this effort resulted in a very conservative situation and the connection strengths were much underestimated (Quenneville 2000; Mohammad 2001). Therefore, new design equations were subsequently proposed by Quenneville (1998; 2000) to predict timber connection strengths based on row shear-out and group tear-out failure modes.

In the new version of Canadian design standard (CAN/CSA-O86-09 2009), the equations proposed for brittle failures are adopted and the equations based on the EYM are also valid for ductile failures. The load-carrying capacity of a connection is the smallest resistance value calculated based on all potential failure modes as discussed in the standard. For all possible failure modes, the calculation equations, given in CAN/CSAO86-09 (2009), are summarized in Appendix A.

\subsubsection{Ultimate Load Capacity}

The ultimate load-carrying capacity $\left(R_{0}\right)$ is the tensile strength of a connection at ambient temperature as determined by testing. Specimens are subjected to a displacement-control tensile force at a rate of $0.9 \mathrm{~mm} / \mathrm{min}$ in accordance with ASTM Standard D1761-88 
(ASTM 2000). The maximum load recorded before failure is defined as the ultimate loadcarrying capacity.

In the limit states design (LSD) format, the $5^{\text {th }}$ percentile value is calculated using a twoparameter Weibull distribution with $75 \%$ confidence and a factor of $80 \%$ is applied for the normal-duration application. The load-carrying capacity $\left(R_{\text {code }}\right)$, calculated according to the standard, is supposed to be comparable to $80 \%$ of the $5^{\text {th }}$ percentile value of the ultimate capacity $\left(0.8 R_{0}^{\text {sth }}\right)$.

Generally, an adjustment factor can be used to convert a mean ultimate value to a code allowable design value by multiplying the mean ultimate value with a factor. The adjustment factor is reported to be about $0.35(1 / 2.85)$ in TR 10 (AWC 2003) for bending and tensile wood members. In Lie's models, this adjustment factor was assumed to be 0.33 for large timber beams and columns (Lie 1992).

In terms of timber connections, Mohammad (2001) and Quenneville (2000) reported a large number of tensile tests on WSW connections and SWS connections. If one compares the code allowable design capacity based on CAN/CSA-O86-09 and the mean ultimate capacity from their experimental results, it would be found that the ratio between the Canadian code allowed capacity and the average ultimate capacity is about 0.32 for WSW connections, averaged from 22 groups, and about 0.31 for SWS connections averaged from 38 groups. The details relevant to the ratio between the code allowed capacity and ultimate capacity are in Appendix B. 


\subsubsection{Numerical Modelling}

As discussed before, the mechanical behaviour of wood connections is influenced by material properties, connection types and geometries, and loading parameters. Other parameters such as friction, diameter and clearance of bolts, bolt spacing and end distance also have an influence on the stress concentration in the area of contact where the failure is most likely to occur. Due to these complexities, it is very expensive and time consuming to experimentally investigate the influence of the various parameters on the behaviour of connections. By using appropriate material models and failure criteria, numerical modelling can be an efficient and non-expensive approach to analyze the behaviour of connections and predict their behaviour.

In recent years, the nonlinear finite element method (FEM) has been used to study the mechanical behaviour of wood joints affected by the various parameters (Patton-Mallory 1996; Guan 2000; Moses 2000; Kharouf 2001; Laplanche 2006; Hong 2007; Xu 2008). To develop a finite element model for timber connections, constitutive models of materials, a contact algorithm and failure criteria are required.

As discussed before, wood is usually assumed to be a homogenous and orthotropic continuum. In numerical analysis, most often this assumption is expanded to a transversely isotropic material which assumes identical properties in the tangential and radial directions. In order to model the non-linear compressive response of wood in joints, researchers attempted to model wood as an elasto-plastic material in compression. Rahman (1991) considered the nonlinearity of wood by assigning different tangent moduli at different stress-strain regions for the 2-D analysis of bolted joints. Bouchair 
(1995) used a plastic flow rule according to the Tsai criterion in a 2-D FEM for bolted timber joints. Kharof (2001) modelled wood as an elasto-plastic orthotropic material in bi-axial compression according to the Hill yield criterion in a 2-D FEM (Hill 1950).

Patton-Mallory (1996) developed a 3-D model for the study of bolted joints. A trilinear stress-strain was used to model the nonlinearity of wood in compression and shear. Guan (2000) introduced a 3-D FEM for a hollow doweled timber connection using orthotropic elasticity for wood and elasto-plastic for hollow steel dowels. The reason for using elasticity for wood was that the connections with hollow dowels were designed to fail in ductile modes due to the plasticity of hollow dowels in almost all cases. Laplanche (2006) and $\mathrm{Xu}$ (2008) conducted 3-D FEM for multiple-doweled timber connections by assuming orthotropic plasticity compression behaviour of the timber according to the Hill yield criterion.

In addition to the plasticity of wood in compression zone, the wood fiber experiences other different failure modes in the parallel and perpendicular directions. Generally, the failure criteria fall into two categories: limit criteria and interactive criteria. For limit criteria, failure depends on individual stress or strain; for interactive criteria, failure depends on more than one component of stress or strain.

The maximum stress or strain criteria are the most simple but frequently used criteria, although they do not account for the combination effects of stresses or strains. Tsai and $\mathrm{Wu}$ (1971) developed a tensor polynomial strength criterion for anisotropic materials. It is an interactive failure criterion and the polynomial describes the failure surface in stress 
space. Patton-Mallory (1996) used the maximum stress criterion and the Tsai-Wu criterion as failure criteria in modelling the 3-D single bolt connections.

Hoffman's criterion is essentially a modification of the Hill criterion to account for the different strength properties in tension and compression. It contains linear and quadratic stress terms (Hoffman 1967). In Xu's FE modelling for multiple-doweled timber connections, Hoffman's failure criterion was adopted in modelling the failure of timber in association with Hill's yield criterion for the timber elasto-plastic behaviour (Xu 2008).

The Tsai-Wu and Hoffman interactive failure criteria are able to predict the failure but can not predict the mode of failure. Hashin (1980) originally developed a set of interactive failure criteria for transversally isotropic unidirectional laminates. The criteria were able to evaluate different failure modes named as tensile fiber failure, compressive fiber failure, tensile matrix failure, compressive matrix failure, fiber-matrix shear-out and interlaminar failure. Hashin's criteria were used in non-wood composites in prediction of the different types of failure (Chang 1987; Jaunky 2001; Tserpes 2001; McCarthy 2003), and also used in LS-DYNA (2007) as the failure criteria for wood. In utilizing the Hashin criteria, tensile matrix failure and fiber matrix shear-out criteria can be adopted to account for the splitting failure by tension perpendicular to the grain and the shear-out failure by shear force in timber connections. 


\subsubsection{Timber Connections at Elevated Temperatures}

This subsection summarizes research that has been done on the behaviour of timber connections exposed to fire.

\subsubsection{Previous Experimental Tests}

\section{Noren}

In Sweden, Noren (1996) performed fire-resistance tests on nailed wood-wood-wood joints exposed to the ISO 834 standard fires and constant tensile loads. The central members were $45 \times 120 \mathrm{~mm}$ for all specimens. Four groups were tested by varying the thickness of lateral members: $20,28,40$ and $45 \mathrm{~mm}$ and nail diameters: 2.8 and $4.0 \mathrm{~mm}$. The geometry and arrangement of nails were chosen to satisfy the requirements of the Swedish Code (NBHP 1988). The wood members were spruce with oven-dry density in the range of $381-422 \mathrm{~kg} / \mathrm{m}^{3}$ that contained about $14 \%$ moisture content prior to the tests. Specimens were exposed to the ISO 834 fire curve at different loads ranging between $10 \%$ and $60 \%$ of the ultimate load capacity of the joints at normal temperature.

Noren's test results showed that the side member thickness and the load ratio had significant influences on the performance of wood joints in fire. If thicker side members were nailed to the center wood, a better fire performance could be achieved for the joints. At the same load level, when the side member thickness was increased from $28 \mathrm{~mm}$ to 40 $\mathrm{mm}$ and $45 \mathrm{~mm}$, the improvement in fire resistance was about $13.4 \mathrm{~min}$ and $14.8 \mathrm{~min}$ respectively. On the other hand, the test results showed that the effect of the diameter of nails on the fire performance of nailed joints was not important. 
Noren's tests showed that there were two major failure modes for nailed timber connections exposed to fire: failure mode (1) and failure mode (3), shown in Figure 2.18. The failure mode tended to change from failure mode (1) to failure mode (3) near the load ratio of about 0.35 .

Noren proposed an exponential equation to describe the relationship between load ratio and time to failure for nailed timber joints:

$$
R_{f i} / R_{0}=e^{-k t_{f}}
$$

where $R_{f i}$ is the applied load during fire exposure, $R_{0}$ is the ultimate load at normal temperature, $t_{f}$ is the failure time and $k$ is the coefficient for nailed timber joints.

Noren also proposed a reduced embedding strength model to calculate the load capacity of nailed joints exposed to fire. The K.W. Johansen's yield model (Johansen 1949) was modified by replacing the constant embedding strength at normal temperature with reduced values at high temperatures. The temperature profiles within joints were determined based on experimental measurements.

\section{Dhima and Kruppa}

Dhima (1999) and Kruppa (2000) reported a series of fire tests on timber connections carried out in France. Five types of connections were tested: bolted wood-wood-wood connections, doweled wood-wood-wood connections, bolted wood-steel-wood connections, nailed wood-wood-wood connections, and tooth plate connectors. Specimens were exposed to the ISO 834 fire during the fire tests. 
The diameters of bolts and dowels were $12 \mathrm{~mm}$ and $20 \mathrm{~mm}$ in all connections. The number of fasteners varied from 8 to 16 in wood-wood-wood connections and varied from 4 to 16 in wood-steel-wood connections. The side wood member thicknesses were either $50 \mathrm{~mm}$ or $60 \mathrm{~mm}$. Applied loads were at about load ratios of $30 \%$ and $60 \%$ respectively. The ultimate load capacities of connections at normal temperature were determined either according to Eurocode 5 (EN1995-1-1 2004) methods using measured mechanical properties of timber and fasteners in small-scale tests, or from direct tensile tests at normal temperature.

The results showed that the load ratio played an important role in the fire resistance for both wood to wood and wood to steel connections. The fastener type (bolt or dowel) also had an important effect. However, the effects of fastener diameter and fastener number were very small in fire tests. The effect of wood side member thickness was not studied because the side wood member thicknesses were only $50 \mathrm{~mm}$ or $60 \mathrm{~mm}$.

One of the major observed failure modes was wood crushing underneath fasteners and elongation of fastener holes in the tensile load direction for WWW and WSW connections with bolts and dowels. For specimens loaded at large load levels, slight or even severe deformations of fasteners were observed. These two failure modes were similar to nailed connections in Noren's tests. In addition, splitting of side wood members was also observed in some fire tests. No charring was found around fasteners for connections in shorter fire exposures but slight charring was found around fasteners in longer exposures. 


\section{Ayme}

As an extension of Dhima and Kruppa's work, Ayme (2003) reported a series of fireresistance tests of timber connections. This parametric study focused on the doweled WSW connections by varying the timber thickness, fastener diameter and load ratio. Dowels were $12 \mathrm{~mm}, 16 \mathrm{~mm}$ and $20 \mathrm{~mm}$ in diameter and wood side members were 75 $\mathrm{mm}$ and $100 \mathrm{~mm}$ thick. The fire exposure conditions followed the ISO 834 curve. The applied loads varied from $10 \%$ to $30 \%$ of the ultimate load capacities at cold temperatures.

This study expanded the experimental research of WSW connections from the specimens with $50 \mathrm{~mm}$ and $60 \mathrm{~mm}$ thick wood side members to the specimens with $75 \mathrm{~mm}$ and 100 mm thick wood side members. The results showed that the specimens with thicker wood side members had much better fire resistance.

\section{Laplanche}

As another extension of Dhima and Kruppa's work, Laplanche reported a series of fireresistance tests of doweled WWW connections (Laplanche 2006). This study focused on the effects of timber thickness and load ratio. Specimens with $64 \mathrm{~mm}$ and $84 \mathrm{~mm}$ thick wood side members were studied and the diameter of dowels was $16 \mathrm{~mm}$. The applied loads varied from $10 \%$ to $30 \%$ of the ultimate load capacities at cold temperatures.

This study expanded the experimental research of doweled WWW connections. It was found that the effects of timber thickness and load ratio are also important for this type of connections. 


\section{Erchinger}

Erchinger (2006a, 2006b) conducted a series of experimental studies on multiple shear steel-to-timber connections with dowels as fasteners at the Swiss Federal Institute of Technology in Zurich (ETH). The timber members were $200 \mathrm{~mm} \times 200 \mathrm{~mm}$ wood in cross-section, Grade GL24h, with two or three slotted-in steel plates of $5 \mathrm{~mm}$ in thickness and dowels of either $6.3 \mathrm{~mm}$ or $12 \mathrm{~mm}$ in diameter. The applied constant loads in fire tests were $7.5 \%, 15 \%$ or $30 \%$ of the measured load capacity at normal temperature. To study the effect of increased timber size, specimens with $280 \mathrm{~mm} \times 280 \mathrm{~mm}$ wood were also studied. In addition, some connections covered with timber boards or gypsum boards were also tested to study the effect of protection.

The results showed that the unprotected multiple shear steel-to-timber connections using dowels reached a fire resistance of about $30 \mathrm{~min}$. It was found that the load ratio did not play an important role but increasing the timber size leads to a significant increase in the fire resistance. The observed failure modes were hole elongation of wood members and fastener yielding, as shown in in Figure 2.18 as failure mode (1) and failure mode (3).

The failure mode (4) was reported to happen at ambient temperature but not during fire tests.

The protective boards attached on the connections were found to increase the performance of multiple shear connections in fire significantly. The connections with 27 $\mathrm{mm}$ timber boards and 15 or $18 \mathrm{~mm}$ fire-rated gypsum board resulted in an increase in fire resistance by about $25 \mathrm{~min}$ and $27 \mathrm{~min}$, respectively. 


\section{Lau and Chuo}

Lau (2006) and Chuo (2007), in New Zealand, conducted a series of bolted timber connection tests in different conditions including constant elevated temperatures and fire exposures, using a small furnace and loading frame. The heating system was an electrical coil that provided either a constant temperature or fire conditions. Tested connections were bolted WWW, WSW, and SWS. The size of the joined timber members were $65 \times 150 \mathrm{~mm}$ Laminated Veneer Lumber (LVL). Side wood members were $45 \times 150 \mathrm{~mm}$ for WWW joints. Steel plates were $6 \mathrm{~mm}$ thick for both side and central members in SWS and WSW joints. The bolts were $12 \mathrm{~mm}$ in diameter. The applied loads in fire were $33 \%$ of the designed load at cold conditions.

Specimens were first tested at different constant temperatures, in order to determine the embedment strength for LVL at elevated temperatures. Their efforts were used to develop a simple calculation model to predict the failure strength in fire conditions. The developed model was similar to Noren's model and it takes into account the reduced embedment strength at elevated temperatures in Johansen's yield model (Noren 1996). In addition, fire tests were also performed in the furnace to investigate the performance of connections during fire exposure and were used to validate the model.

In terms of failure modes, test results showed that LVL connections were likely to fail in ductile modes at the applied load ratio in fire tests. Chuo summarized that the most probable failure mode for WSW and WWW connections was the hole elongation of wood side members, and for SWS connections, it was the hole elongation of the central wood members. 


\subsubsection{Calculation Methods}

\section{Eurocode 5 Rules}

In Eurocode 5 - Part 2 (EN1995-1-2 2004), simplified rules were adopted for unprotected connections. The code states that connections satisfying Eurocode 5 - Part 1(EN1995-1-1 2004) for normal temperature will have a fire resistance of either $15 \mathrm{~min}$ or $20 \mathrm{~min}$, as shown in Table 2.1.

Table 2.1 Fire resistance of unprotected connections with wood side members, from Eurocode 5 (EN1995-1-2 2004)

\begin{tabular}{|l|c|l|}
\hline & $\begin{array}{c}\text { Time of fire } \\
\text { resistance } \\
\boldsymbol{t}_{\mathrm{f}, \mathrm{d}} \\
\text { min }\end{array}$ & Provisions $^{\mathrm{a}}$ \\
\hline Smooth nails & 15 & $d \geq 2,8 \mathrm{~mm}$ \\
\hline Screws & 15 & $d \geq 3,5 \mathrm{~mm}$ \\
\hline Bolts & 15 & $t_{1} \geq 45 \mathrm{~mm}$ \\
\hline Dowels & 20 & $t_{1} \geq 45 \mathrm{~mm}$ \\
\hline $\begin{array}{l}\text { Connectors according } \\
\text { to EN 912 }\end{array}$ & 15 & $t_{1} \geq 45 \mathrm{~mm}$ \\
\hline${ }^{\mathrm{a}} \boldsymbol{t}_{1}$ is the thickness of the side member \\
\hline
\end{tabular}

If the required fire resistance $t_{f, d}$ is greater than those given in Table 2.1 , the side member thickness, end and edge distance should be increased by an additional thickness $a_{f i}$ :

$$
a_{f i}=k_{f l u x} \beta_{n}\left(t_{r e q}-t_{f i, d}\right)
$$

where $t_{\text {req }}(\min )$ is the required fire resistance time, $t_{f i, d}(\min )$ is the designed time according to Table $2.1, \beta_{n}(\mathrm{~mm} / \mathrm{min})$ is the notional charring rate and $k_{f u x}$ is a factor 
taken as 1.5 . However, Equation (2.12) is only valid for fire resistance times not more than 30 minutes and $k_{f l u x}$ has only been verified for nails and non-projected head fasteners.

If the connection is protected by wood, wood-based panels or gypsum boards, the fire resistance can be calculated by:

$$
t_{r e q}=t_{c h}+0.5 t_{f i, d}
$$

where $t_{c h}(\mathrm{~min})$ is the time when protected connection starts to char, $t_{r e q}(\mathrm{~min})$ is the required fire resistance time, $t_{f i, d}(\mathrm{~min})$ is the designed time according to Table 2.1. However, the 0.5 factor in Equation (2.13) might lead to conservative results, in comparison with the Component Additive Method (CAM). The Component Additive Method will be discussed in the following chapters.

Alternatively, a calculation model called the reduced load method is adopted in Eurocode 5. This simplified exponential equation was based on Noren's and Dhima's results and given as:

$$
R_{f i}=R_{0} \cdot e^{-k k_{f, d}}
$$

where $R_{f i}$ is the load capacity of connections in a standard fire, $R_{0}$ is the load capacity of connections at normal temperature, $t_{f, d}$ is the design fire resistance rating of the unprotected connection in minutes, and $\mathrm{k}$ is the connection parameter which is given in Table 2.2. 
Konig (2001) summarized the rules presented in Eurocode 5 and pointed out that the simplified exponential model would be correct for some cases but very conservative when thick side members of timber are used. So far, the experimental background was insufficient. Another drawback in Eurocode 5 is that the period of validity for the $k$ factor is limited to 20 minutes for nailed connections, 40 minutes for wood-to-wood connections and 25 minutes for other connections. Of course, a large amount of experiments are also required to determine the $k$ factor for various connections and for longer fire-resistance ratings.

Table 2.2 Connection Parameter $k$ from Eurocode 5 (EN1995-1-2 2004)

\begin{tabular}{|l|c|c|}
\hline \multicolumn{1}{|c|}{ Connection with } & $k$ & $\begin{array}{c}\text { Maximum time of } \\
\text { validity for } \\
\text { unprotected } \\
\text { connection } \\
\text { min }\end{array}$ \\
\hline Smooth nails & 0,08 & 20 \\
\hline Bolts wood-to-wood with $d \geq 12 \mathrm{~mm}$ & 0,065 & 25 \\
\hline Bolts steel-to-wood with $d \geq 12 \mathrm{~mm}$ & 0,085 & 25 \\
\hline Dowels wood-to-wood ${ }^{2}$ with $d \geq 12 \mathrm{~mm}$ & 0,04 & 40 \\
\hline Dowels steel-to-wood ${ }^{a}$ with $d \geq 12 \mathrm{~mm}$ & 0,085 & 25 \\
\hline Connectors & 0,065 & 25 \\
\hline $\begin{array}{l}\text { a The values for dowels are for connections with up to } 20 \% \text { bolts to avoid } \\
\text { separation of side members }\end{array}$ \\
\hline
\end{tabular}

\section{TR 10 Requirements}

The American Wood Council publication Technical Report 10 (TR 10) is cited in the American building codes (NDS 2005) for assessing the fire resistance rating of large timber members. TR 10 (AWC 2003) states that where one-hour fire endurance is required, connectors and fasteners must be protected from fire exposure by wood $(38 \mathrm{~mm}$ thick), fire-rated gypsum board (5/8", or $19.1 \mathrm{~mm}$ thick), or any coating approved for the 
required endurance time. If appearance is a factor, fasteners or connectors should be concealed within wood members and wood plugs should be used to cover the fasteners.

However, the inherent fire resistance of the connection itself is not taken into account in TR 10. It assumes that the protection of wood panels, fire-rated gypsum boards or coatings can provide the entire 1-hour rating. Therefore, this assumption can result in over-estimation of the fire resistance for timber connections with small wood sizes, and the result can be under-estimated for timber connections with large wood sizes.

\section{Embedment Reduction Model}

The embedment reduction model was initially proposed by Noren (1996) to predict the fire resistance of nailed timber connections. The model was based on K.W. Johansen's yield model (Johansen 1949) by replacing the constant mechanical strengths at normal temperature with reduced values at high temperatures.

In Noren's study, the temperature profiles within joints were determined based on experimental measurements at several locations and interpolation between those locations (Noren 1996). The embedding strength of wood in fire exposure is a function of temperature. Noren proposed three relationships between embedding strength and temperature and substituted the reduced strength properties into Johansen's yield model based on the estimated temperature profile in the connection. One of the relationships was found to agree well with the results of the fire tests.

Similar to Noren's model, Moss modified the Johansen's model to calculate the fire resistance of timber connections (Moss 2008). In Moss's research, the connection 
strength obtained in heating tests at elevated temperatures was substituted back into Johansen's yield equations to determine the embedding strength as a function of temperature, and then this temperature-based embedding strength was used to calculate the strength of the connection in fire exposure. Moss's research was based on Chuo and Lau's experimental research work (Lau 2006; Chuo 2007).

Figure 2.19 shows the wood embedding strength reduction factor as a function of temperature. Moraes's relationship was determined directly from tests. It is necessary to mention that the data reported by Moraes (2005) and Moss (2008) were determined in pre-heated tests and the influence of moisture was not taken into account. However, the relationship proposed by Noren (1996) was claimed to have the effect of moisture and creep considered.

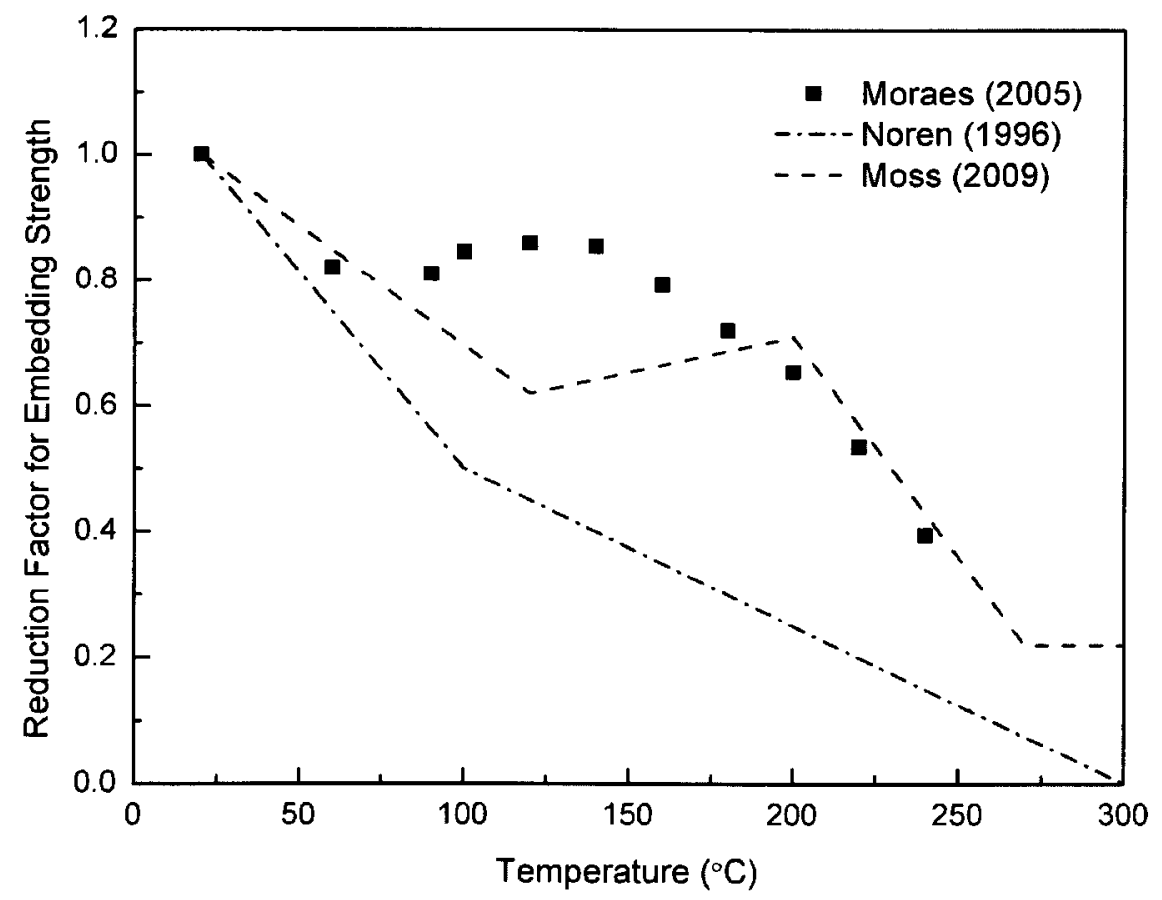

Figure 2.19 Wood embedding strength at elevated temperatures 


\section{Component Model}

A component model was developed by Cachim (2009) to estimate the fire resistance for doweled timber connections. The model treated a connection as an assembly of individual components: the timber component and the steel dowel component, with their own stiffnesses and strengths. The connection was modelled by discretizing the dowel as a series of beam elements, connected with springs representing the timber behaviour. The component model was firstly verified at room temperatures and then used for timber connections at elevated temperatures. The temperature profile within the connection was calculated by carrying out a numerical thermal analysis, using the finite element program SAFIR. The temperature-based properties were obtained from Eurocode 5 for timber and from Eurocode 3 for steel.

\subsubsection{Numerical Simulations}

Numerical simulation provides an economical and efficient approach to obtain large amount of results required to optimize the performance of connections in fire. Due to the large number of connection types, member geometries and fastener arrangements, experimental research, although necessary, is expensive and time consuming for investigating the effects of numbers of factors.

Erchinger (2006b) carried out thermal analysis using a finite element model to study heat transfer within connections with multiple slotted-in steel plates and dowels exposed to the ISO 834 fire. The specimens received convective and radiative heat flux from the flames. Laser scanning technology was used to analyze the residual cross-section and determine 
the charring rate. The comparison between the modelling and the laser-scanning results showed good agreement.

The finite element program, SAFIR, was also used by Cachim (2009) and Moss (2008) to generate temperature profiles for the analytic models. In Cachim's analysis, the heat transfer in a connection was simplified as the heat transfer for an isolated fastener and axial-symmetric assumption was assumed. Moss' heat transfer model simplified the fastener as a square rod but the temperature field within the connection was not predicted accurately.

The finite element approach was also used to conduct the thermo-mechanical analysis of timber connections by Laplanche (2006).

\subsection{Summary}

Generally, wood can be treated as a transversely isotropic material in structural design. Wood exhibits elasto-plastic behaviour in compression and elastic behaviour in tension until brittle failure. Wood connections can fail in either ductile or brittle modes based on material properties, connection types, geometries and load conditions.

The influence of temperature on the thermal and mechanical properties of wood and steel was summarized in this chapter and scatter was found among researchers. Appropriate input data should be adopted in order to successfully model thermal and structural behaviour for timber connections.

In terms of structural fire design of timber connections, our knowledge is still limited although some simplified rules are given in Eurocode 5 but they have some drawbacks 
because of insufficient research background. More experimental research is required in order to improve the fire resistance design of timber bolted connections.

Fire-resistance testing is the direct method to estimate the fire resistance of a connection and provides necessary data for validation of any proposed calculation model. Due to the complexity of connection types, geometries and load conditions, the numerical analysis provides an economical and efficient approach. Both methodologies are important in the investigation of the fire resistance of timber connections. 


\section{Chapter 3: Experimental Research}

The experimental program of this research falls into three phases. In the first phase, a new medium-size furnace was designed and constructed at the Full-scale Fire Research Facilities of Carleton University and instrumentation and data acquisition systems were set-up. Calibration tests were also carried out to ensure the furnace time-temperature curve followed the standard curve within the allowable tolerances. In the second phase, fire-resistance tests were carried out in the furnace for bolted WSW connections, loaded in tension to certain load levels. In the third phase, bolted SWS connections were tested in the furnace, similar to the WSW connections. This chapter describes the test facilities, test specimens and test procedures for both WSW and SWS connections, as well as provides a brief summary and discussion of the test results. The results are revisited in Chapter 4 and Chapter 5 .

\subsection{Facilities}

In this section, test facilities, including the furnace and measuring devices, are described.

\subsubsection{Furnace}

The furnace, located at the Full-scale Fire Research Facility of Carleton University in Almonte, Ontario, was initially designed for testing the fire performance of both timber connections and steel connections. Figure 3.1 (left) shows an exterior view of the furnace with the loading frame. The furnace was equipped with two propane line burners. One of the line burners is shown in Figure 3.1 (right). Two blowers were installed on the burner 
side walls, supplying fresh air for combustion. The furnace temperature can be controlled so that it can follow the standard fire curve or any other fire curve.
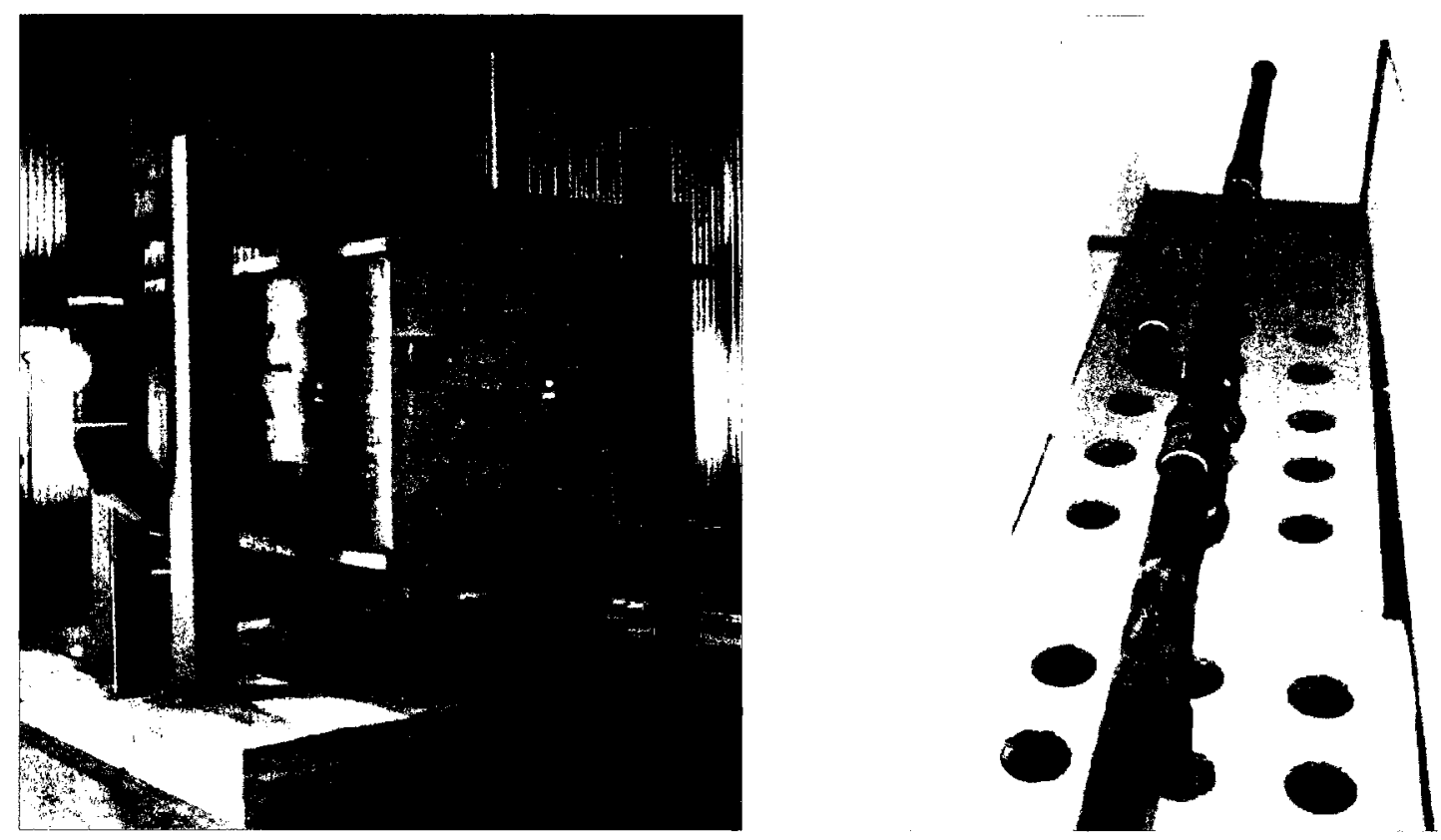

Figure 3.1 Furnace and propane line burner

Figure 3.2 shows a front cross-section and a top cross-section view of the furnace with a connection mounted on the frame. The interior dimensions of the furnace are $2.7 \mathrm{~m} \times 2.7$ $\mathrm{m} \times 2.2 \mathrm{~m}(\mathrm{~B} \times \mathrm{L} \times \mathrm{H})$. The interior ceiling and walls were insulated with a layer of mineral blanket $\left(l^{n}\right.$ or $25 \mathrm{~mm}$ thick) from Fibrefrax ${ }^{\circledR}$. LVDT stands for linear variable displacement transducer in the figure.

Although the medium-size furnace was initially designed for testing connections, it can be used in future research projects for other construction elements under necessary modification. The furnace provides an economical and effective solution of testing the fire performance of construction elements in either standard fires or arbitrary fires rather than using a full-scale furnace. 

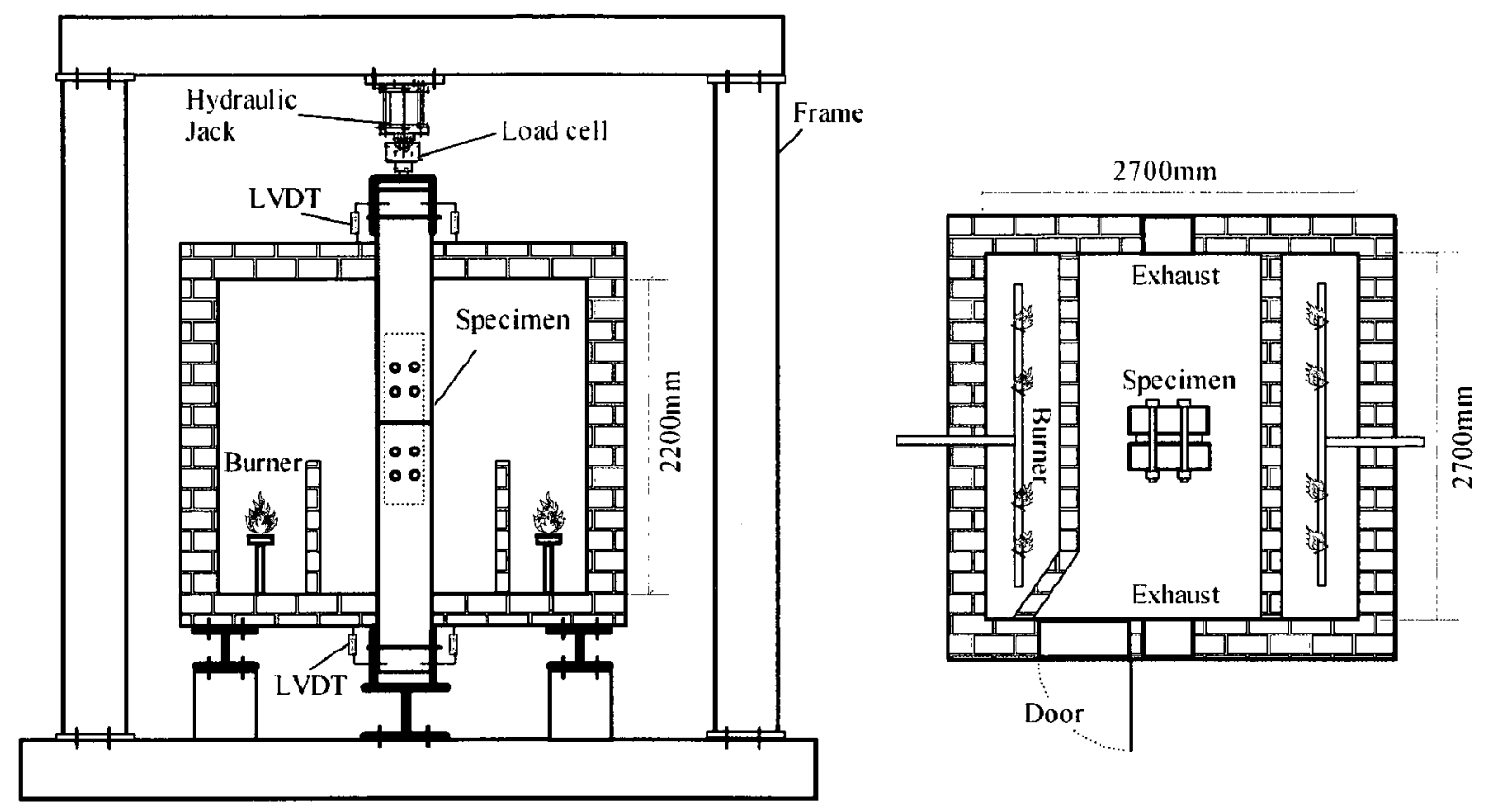

Figure 3.2 Front and top view of the furnace with a specimen mounted

\subsubsection{Thermocouples and Plate Thermometers}

Furnace temperatures were measured using shielded thermocouples and plate thermometers. Shielded thermocouples were used to control the time-temperature curve in the furnace, in accordance with the CAN/ULC-S101 standard (2007). A shielded thermocouple was fabricated using the No.18 gauge type $K$ thermocouple wire insulated within a porcelain tube. The thermocouple with the porcelain tube was inserted into a $21 \mathrm{~mm}$ outer diameter (O.D.) steel pipe with a sealed end. A schematic of the shielded thermocouple is shown in Figure 3.3, reproduced from Sultan (2006). 


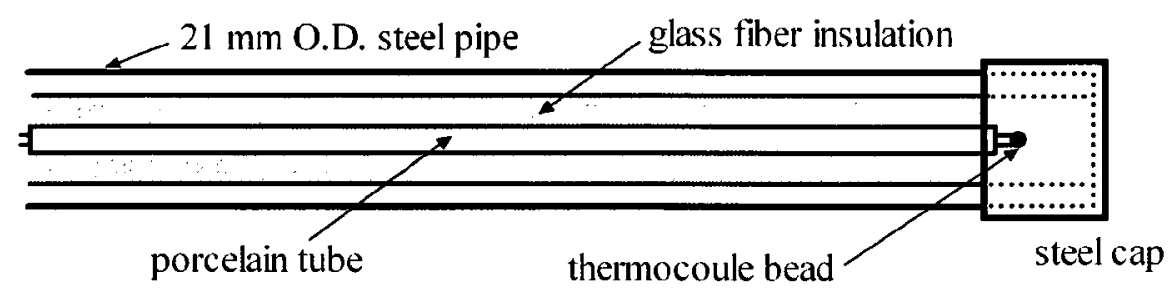

Figure 3.3 Schematic of shielded thermocouple

Plate thermometers act faster than shielded thermocouples and they are recognized as a direct measurement of the heat load as experienced by a typical specimen in the fire test (Wickstrom 1994; Buchanan 2001). Therefore, their measurements are often used as input boundary conditions in the numerical finite element modelling. A schematic drawing of the plate thermometer, Model PL1001 from Thermal-Elecra ${ }^{(}$, is shown in Figure 3.4 .
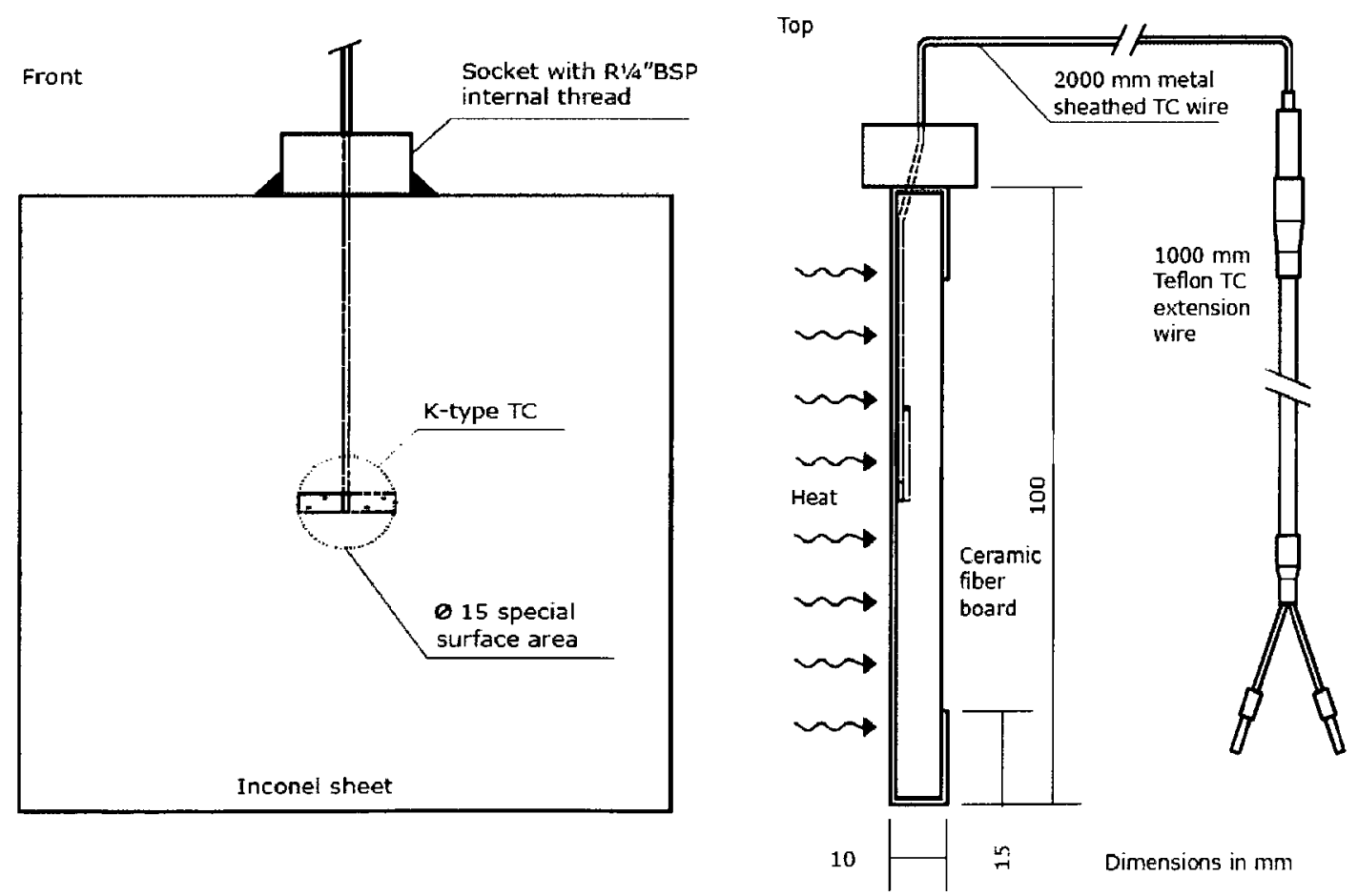

Figure 3.4 Schematic of plate thermometer 


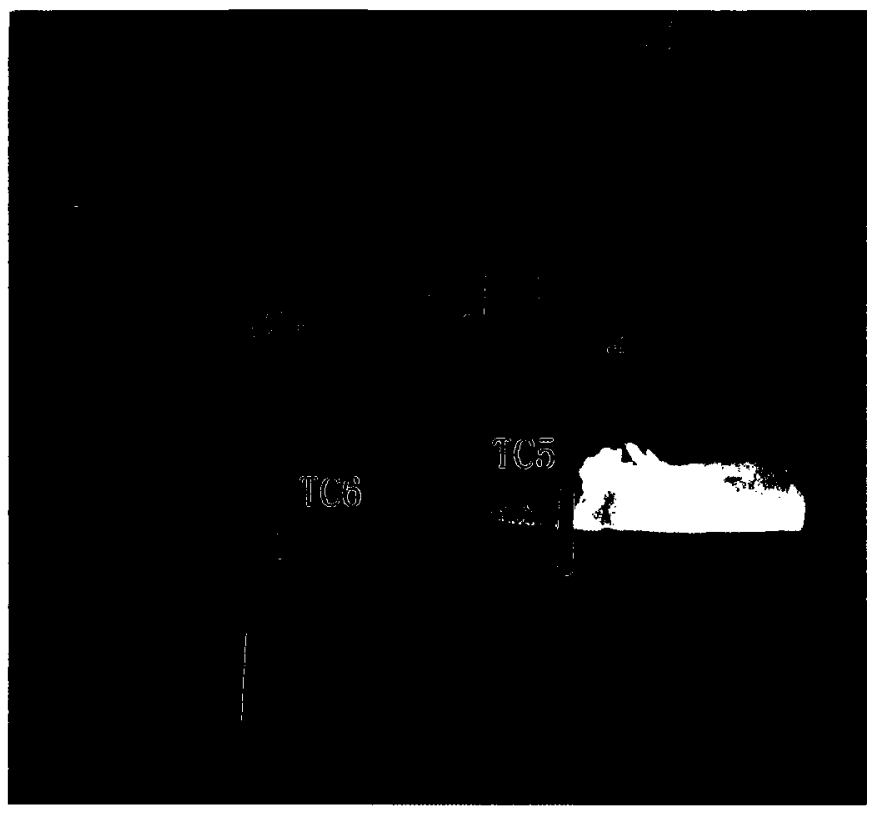

Figure 3.5 Shielded thermocouples and plate thermometers in the furnace

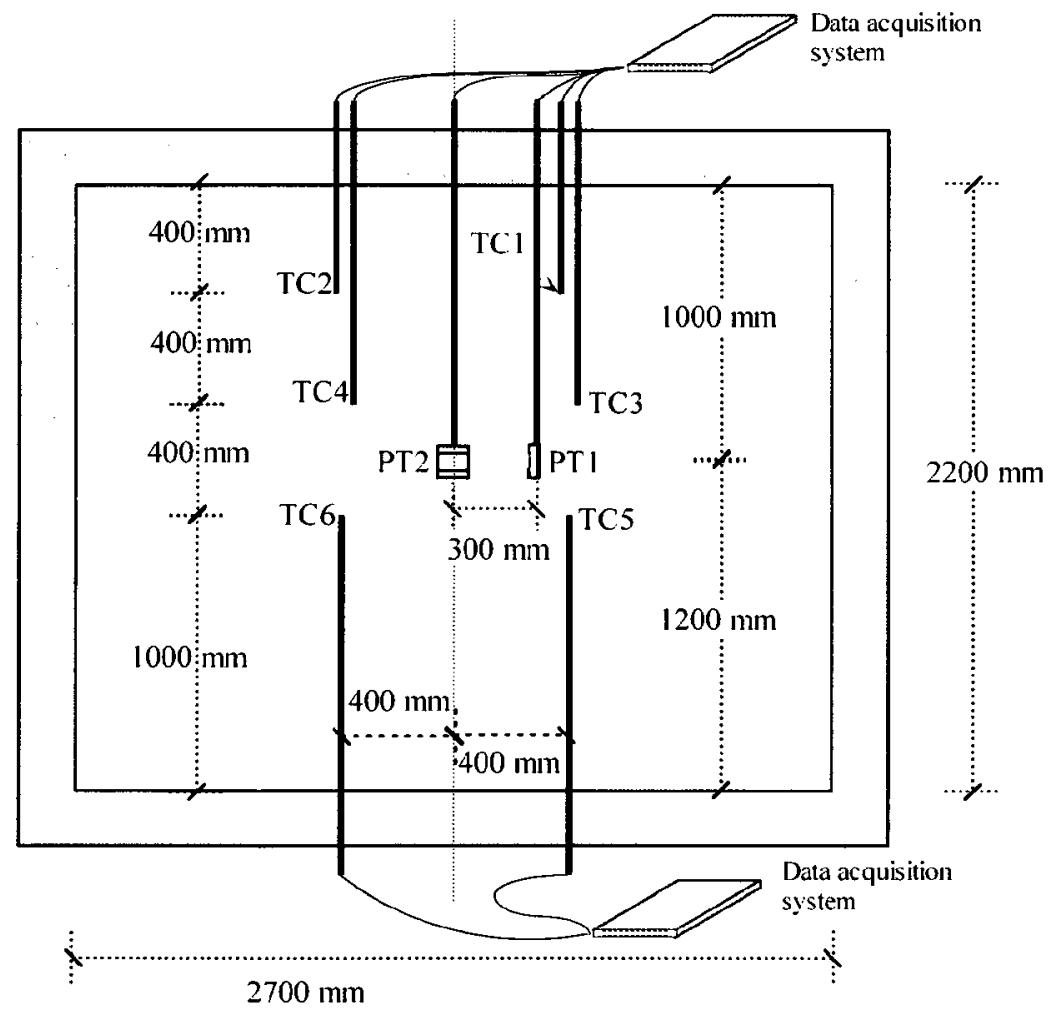

Figure 3.6 Locations of TCs and PTs in the furnace 
In the furnace, six shielded thermocouples and two plate thermometers were installed, as shown in Figure 3.5. The locations of the shielded thermocouples and plate thermometers in the furnace are illustrated in Figure 3.6. The shielded thermocouples were placed at three levels about $400 \mathrm{~mm}$ away from the center line of the furnace. Two plate thermometers were located about $300 \mathrm{~mm}$ away from the center line, with the front sides facing the walls and the back sides facing the center line.

In addition, metal-sheathed and mineral-insulated (MSMI) type $\mathrm{K}$ thermocouples (1.6 $\mathrm{mm}$ diameter) were used to measure temperatures in wood members by inserting them into pre-drilled pilot holes in wood. MSMI type $\mathrm{K}$ thermocouples $(0.8 \mathrm{~mm}$ diameter $)$ thermocouples were used to measure temperatures along bolt shanks. Thermocouple locations for each group are shown in Appendix D.

\subsubsection{Hydraulic Cylinder and Load Cell}

A hydraulic cylinder, Model RD1610 from Enerpac ${ }^{(}$, mounted on the top steel beam, was used to apply tensile loads and the loads were measured by a load cell (MTS ${ }^{\circledR} 661.22 \mathrm{D}$ 01 ) attached to the cylinder, as shown schematically in Figure 3.2. The load cell works in the range of -250 to $250 \mathrm{kN}$ and was calibrated before the tests.

\subsubsection{LVDTs}

Four linear variable displacement transducers (LVDTs) were used to record the displacement of the specimen during a test. As shown in Figure 3.2, two LVDTs are mounted at the top and two at the bottom. The overall displacement of a connection was calculated by subtracting the bottom displacement from the top displacement measured from the LVDTs. The LVDTs were also calibrated before the tests. 


\subsubsection{Data Acquisition System}

Two 5000-Series Ethernet IMP (from Solartron Mobrey Limited ${ }^{\mathbb{B}}$ ) were set up as the data acquisition system. Each Ethernet IMP has a capability of 20 analog channels. The IMP devices were connected to a PC via an Ethernet cable and data were recorded at every second.

\subsubsection{Furnace Calibration}

It was necessary to calibrate the furnace temperatures before fire-resistance tests to make sure that the time-temperature curve could follow the standard. As described in CAN/ULC-S101, the area under the time-temperature curve, obtained by averaging the results from the furnace thermocouple readings, shall be within $\pm 10 \%$ of the corresponding area under the standard time-temperature curve for fire tests of 1 hour or less duration, $\pm 7.5 \%$ for those over 1 hour but not more than 2 hours, and $\pm 5 \%$ for tests exceeding 2 hours in duration.

Calibration tests were carried out in the furnace without any specimen installed. Propane flow rates were monitored and controlled in order to generate temperature curves within the acceptable tolerance. Figure 3.7 shows the measured time-temperature curves of the 6 shielded thermocouples (TC1-6) and 2 plate thermometers (PT1 and PT2) from a typical calibration test. The curves from the shielded thermocouples were in good agreement with the standard in the calibration test. The plate thermometer temperatures were higher than the shielded thermocouple temperatures, especially in the first 5-7 $\mathrm{min}$, but the difference was very small after $10 \mathrm{~min}$. The $\pm 10 \%$ boundaries of the standard curve are also shown in the figure. It should be mentioned that the measured temperature curves 
could exceed the $\pm 10 \%$ boundaries, as long as the area under the measured curves is with in the $\pm 10 \%$ of the area under the standard time-temperature curve.

It should also be noted that in a fire-resistance test, the heat generated by a combustible specimen would contribute to the time-temperature curve. This extra heat is a factor which needs to be considered in order to follow the standard curve in a fire-resistance test rather than in a calibration test. Fortunately, the heat release rate generated from wood members of a connection can be calculated based on the charring rate, exposed wood area and combustion heat of wood. It was found that this value was much less than the heat release rate generated from the propane burners. Therefore, the heat contribution from the specimen to the temperature-time curve could be neglected.

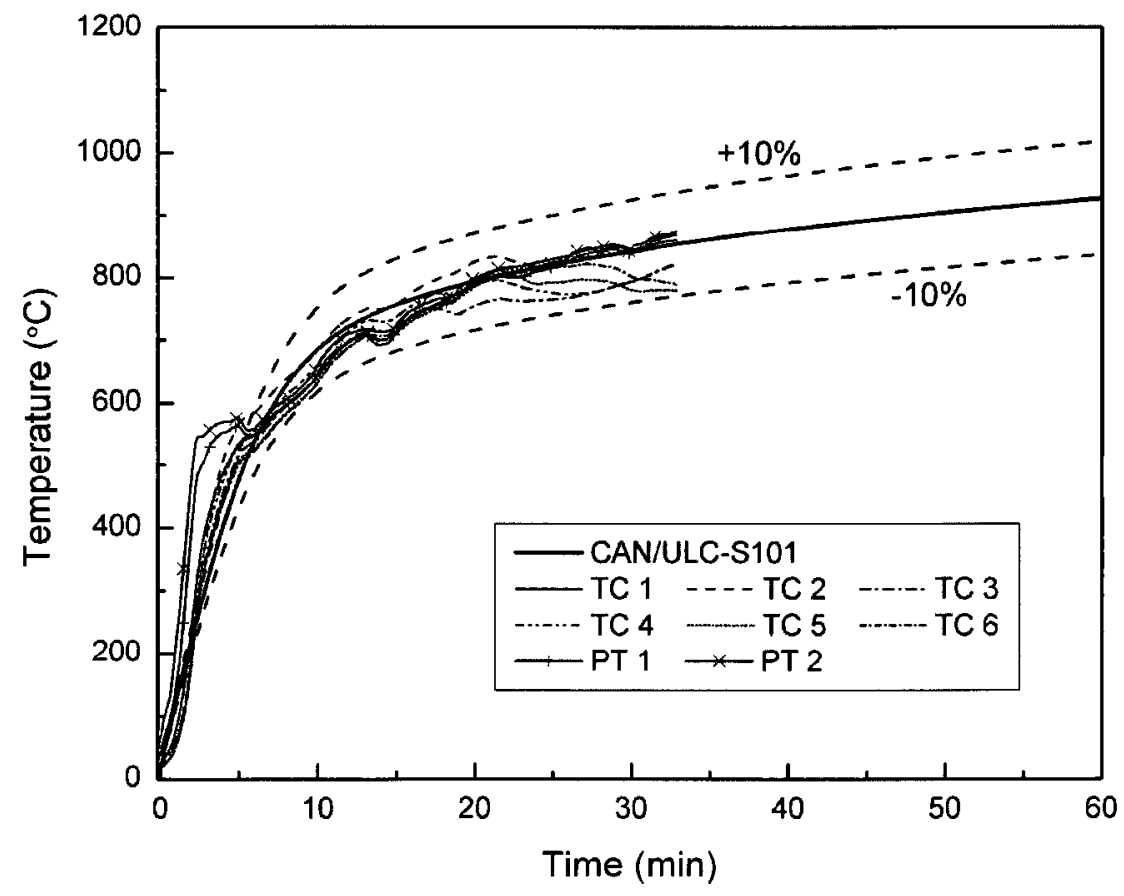

Figure 3.7 Measured time-temperature curves and CAN/ULC-S101 standard curve 


\subsubsection{Tensile Tests at Ambient Temperature}

Prior to the fire-resistance tests, the loading system was used to conduct a group of tensile tests at ambient temperature. The purpose of testing specimens at ambient temperature was to determine the ultimate capacity of this group, as well as to make sure the system work perfectly without a fire. Testing procedures as outlined in ASTM D1761-88 (2000) were followed.

The detailed description of the test process and results are not included here, but given in Appendix C. 


\subsection{Fire-Resistance Tests of Bolted WSW Connections}

This section describes specimens, test procedures and test results of bolted WSW connections.

\subsubsection{Test Specimens}

All WSW connections in this research satisfied the Canadian standard CAN/CSA-O86-09 (2009). Specimens were fabricated with either two wood members sandwiching a steel plate or one wood member with a concealed steel plate. A typical bolted WSW connection is shown in Figure 3.8.

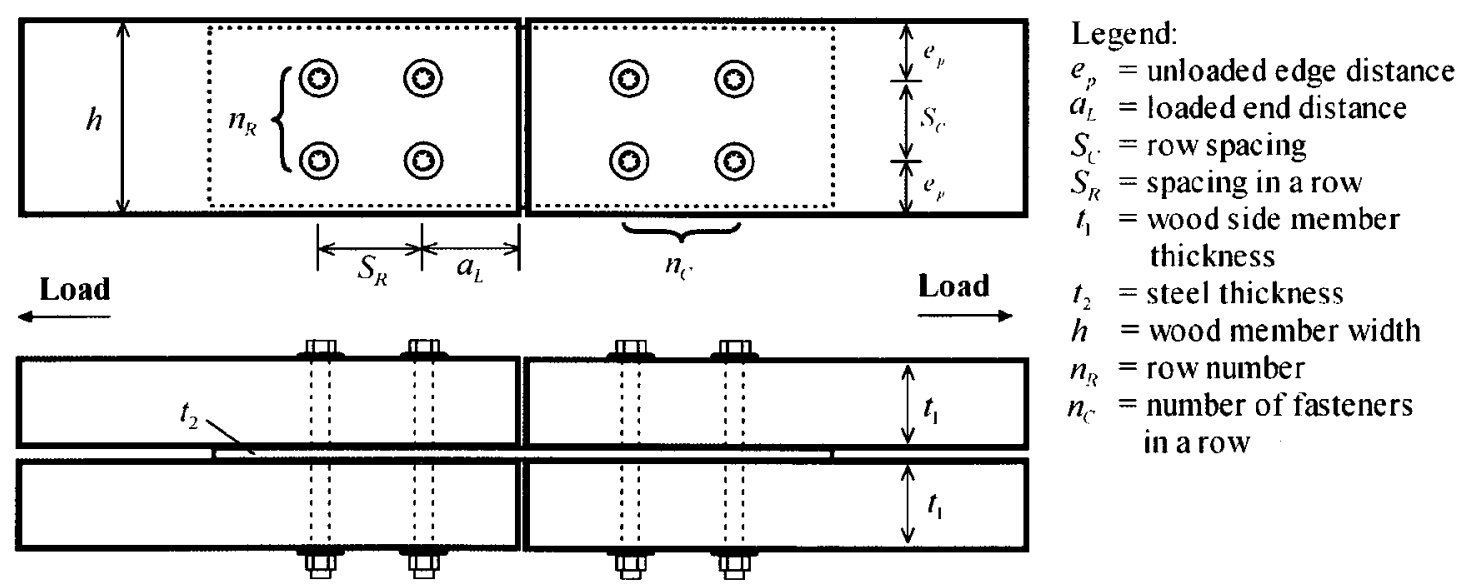

Figure 3.8 Bolted WSW connection

Wood members used in connections were either Canadian spruce-pine-fir (SPF) sawn lumber or spruce-pine (SP) grade $20 \mathrm{f}-\mathrm{EX}$ glulam with a side thickness of $38 \mathrm{~mm}, 60 \mathrm{~mm}$ or $80 \mathrm{~mm}$. All wood members had been conditioned at $20^{\circ} \mathrm{C}$ and $60 \%$ relative humidity (RH), and the moisture content and density were measured prior to the tests. The moisture content was found to be about $11 \%$ and the density varied between 416 and $503 \mathrm{~kg} / \mathrm{m}^{3}$, with a mean value of $455 \mathrm{~kg} / \mathrm{m}^{3}$. Steel plates (grade $300 \mathrm{~W}$ ) were $9.5 \mathrm{~mm}\left(3 / 8^{\prime \prime}\right)$ thick. 
ASTM A307 (equivalent to SAE grade 2) bolts had diameter of $12.7 \mathrm{~mm}(1 / 2$ ") or 19.1 $\mathrm{mm}\left(3 / 4^{\prime \prime}\right)$. Specimen configurations are summarized in Table 3.1 for all 5 groups. It is worth pointing out the tensile strength of a $130 \times 190 \mathrm{~mm}$ grade $20 \mathrm{f}-\mathrm{EX}$ SP glulam timber is $282 \mathrm{kN}$ calculated using CAN/CSA-O86-09 (2009); while the connection capacities calculated using CAN/CSA-O86-09 (i.e. $51 \mathrm{kN}$ for Group \#2 and $88 \mathrm{kN}$ for Group \#4) are much lower than the tensile strength of the solid timber. Therefore, the connection strength dominates the load capacity at ambient temperatures.

Table 3.1 Wood-Steel-Wood specimen configurations

\begin{tabular}{|c|c|c|c|c|c|c|c|c|c|c|c|c|}
\hline \multirow{2}{*}{ 官 } & \multirow{2}{*}{ 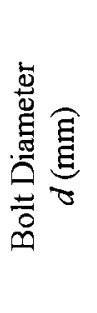 } & \multirow{2}{*}{ 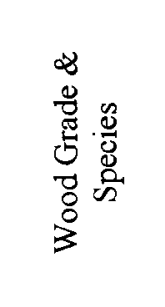 } & \multirow{2}{*}{ 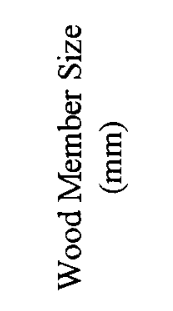 } & \multirow{2}{*}{ 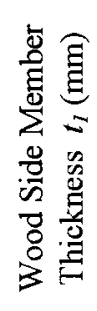 } & \multirow{2}{*}{ 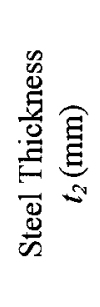 } & \multirow{2}{*}{ 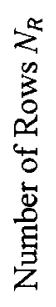 } & \multirow{2}{*}{ 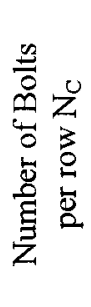 } & \multirow{2}{*}{ 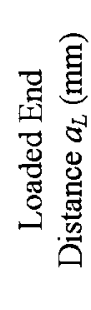 } & \multirow{2}{*}{ 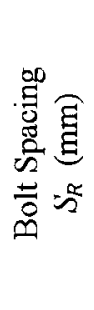 } & \multirow{2}{*}{ 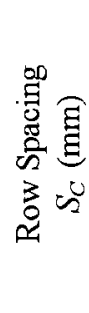 } & \multicolumn{2}{|c|}{$\begin{array}{c}\text { Load } \\
\text { Capacity } \\
(\mathrm{kN})\end{array}$} \\
\hline & & & & & & & & & & & $\begin{array}{l}\dot{\theta} \\
0\end{array}$ & $\stackrel{\stackrel{Ð}{\Xi}}{. \Xi}$ \\
\hline 1 & 12.7 & $\begin{array}{c}\text { No.2 SPF } \\
\text { Lumber }\end{array}$ & $2 @ 38 \times 140$ & 38 & 9.5 & 1 & 2 & $10 \mathrm{~d}$ & $10 \mathrm{~d}$ & $\mathrm{Na}$ & 16 & 58 \\
\hline 2 & 12.7 & $\begin{array}{c}\text { 20f-EX S- } \\
\text { P Glulam }\end{array}$ & $130 \times 190$ & 60 & 9.5 & 2 & 2 & $10 \mathrm{~d}$ & $10 \mathrm{~d}$ & $5 \mathrm{~d}$ & 51 & 115 \\
\hline 3 & 19.1 & $\begin{array}{l}\text { 20f-EX S- } \\
\text { P Glulam }\end{array}$ & $130 \times 190$ & 60 & 9.5 & 1 & 1 & $10 \mathrm{~d}$ & $\mathrm{Na}$ & $\mathrm{Na}$ & 22 & 65 \\
\hline 4 & 19.1 & $\begin{array}{l}\text { 20f-EX S- } \\
\text { P Glulam }\end{array}$ & $130 \times 190$ & 60 & 9.5 & 2 & 2 & $10 \mathrm{~d}$ & $10 \mathrm{~d}$ & $5 \mathrm{~d}$ & 88 & 227 \\
\hline 5 & 19.1 & $\begin{array}{l}\text { 20f-EX S- } \\
\text { P Glulam }\end{array}$ & $2 @ 80 \times 190$ & 80 & 9.5 & 2 & 2 & $10 \mathrm{~d}$ & $10 \mathrm{~d}$ & $5 \mathrm{~d}$ & 105 & 243 \\
\hline
\end{tabular}

\section{Load Ratio}

Load ratio is defined as the applied load in fire conditions divided by the ultimate loadcarrying capacity at ambient conditions. The load ratio applied on a structural member during a fire test can have a significant effect on its fire resistance performance. In CAN/ULC-S101 (2007), it is recommended that the specimen be subjected to a load that is as close to the factored resistance of the test specimen as possible in accordance with 
the design standard published by the Canadian Standards Association, i.e. CAN/CSAO86-09 (2009) for timber connections. However, the standard also allows lower loads to be used in fire-resistance tests but the load conditions should be identified and reported.

Table 3.2 Load ratios in fire-resistance tests

\begin{tabular}{|c|c|c|c|c|c|}
\hline $\begin{array}{c}\text { Test } \\
\#\end{array}$ & $\begin{array}{c}\text { Bolt } \\
\text { Diameter } \\
d(\mathrm{~mm}) \\
\end{array}$ & $\begin{array}{c}\text { Wood } \\
\text { Grade \& } \\
\text { Species }\end{array}$ & $\begin{array}{c}\text { Wood } \\
\text { Member } \\
\text { Size }(\mathrm{mm}) \\
\end{array}$ & $\begin{array}{c}\text { Ultimate } \\
\text { Load } \\
(\mathrm{kN})\end{array}$ & $\begin{array}{l}\text { Load } \\
\text { Ratio }\end{array}$ \\
\hline $\begin{array}{l}1.1 \\
1.2 \\
1.3 \\
1.4 \\
\end{array}$ & 12.7 & $\begin{array}{l}\text { No.2 SPF } \\
\text { Lumber }\end{array}$ & $2 @ 38 \times 140$ & 58 & $\begin{array}{l}10 \% \\
10 \% \\
30 \% \\
30 \% \\
\end{array}$ \\
\hline $\begin{array}{l}2.1 \\
2.2 \\
2.3 \\
\end{array}$ & 12.7 & $\begin{array}{l}\text { 20f-EX S-P } \\
\text { Glulam }\end{array}$ & $130 \times 190$ & 115 & $\begin{array}{l}10 \% \\
20 \% \\
30 \% \\
\end{array}$ \\
\hline $\begin{array}{l}3.1 \\
3.2 \\
\end{array}$ & 19.1 & $\begin{array}{c}\text { 20f-EX S-P } \\
\text { Glulam }\end{array}$ & $130 \times 190$ & 65 & $\begin{array}{l}10 \% \\
30 \% \\
\end{array}$ \\
\hline $\begin{array}{l}4.1 \\
4.2 \\
4.3^{\dagger} \\
\end{array}$ & 19.1 & $\begin{array}{l}\text { 20f-EX S-P } \\
\text { Glulam }\end{array}$ & $130 \times 190$ & 227 & $\begin{array}{l}10 \% \\
30 \% \\
30 \% \\
\end{array}$ \\
\hline $\begin{array}{c}5.1 \\
5.2^{*} \\
5.3 \\
5.4^{*}\end{array}$ & 19.1 & $\begin{array}{l}\text { 20f-EX S-P } \\
\text { Glulam }\end{array}$ & $2 @ 80 \times 190$ & 243 & $\begin{array}{l}10 \% \\
10 \% \\
30 \% \\
30 \% \\
\end{array}$ \\
\hline
\end{tabular}

$\dagger$ : This specimen was protected by a single-layer of $15.9 \mathrm{~mm}$ Type X gypsum board.

\$: This specimen was protected by a double-layer of $12.7 \mathrm{~mm}$ Douglas fir plywood.

: This specimen was designed to test the effect of edge distance. See the next page.

In the fire tests, specimens were subjected to constant tensile loads parallel to the grain. The planned load ratio for each test specimen is shown in Table 3.2. There are 16 tests in total, 14 unprotected and 2 protected specimens. A uniform $30 \%$ load ratio was planned for all groups because the ratio between the Canadian code design load and the ultimate load capacity is found to be about 0.3 (also seen in subsection 2.3.1.3). In addition, reduced load ratios, $10 \%$ and $20 \%$, were also chosen to investigate the effect of load ratio on the fire performance of WSW connections. In Group \#1, two identical tests were designed for both $10 \%$ and $30 \%$ load ratios, to examine the repeatability of the fire tests. 


\section{Test \#5.2}

Test \#5.2 was designed to test the effect of edge distance. As shown in Figure 3.9, one layer of $19.1 \mathrm{~mm}(3 / 4 ")$ plywood was installed on each lateral side of the specimen, using $57 \mathrm{~mm}(2-1 / 4 ")$ long types $\mathrm{S}$ screws. This modification increased the width of the specimen from $190 \mathrm{~mm}$ to $228 \mathrm{~mm}$. Accordingly, the edge distance increased from $47.5 \mathrm{~mm}(2.5 d)$ to $66.5 \mathrm{~mm}(3.5 d)$.

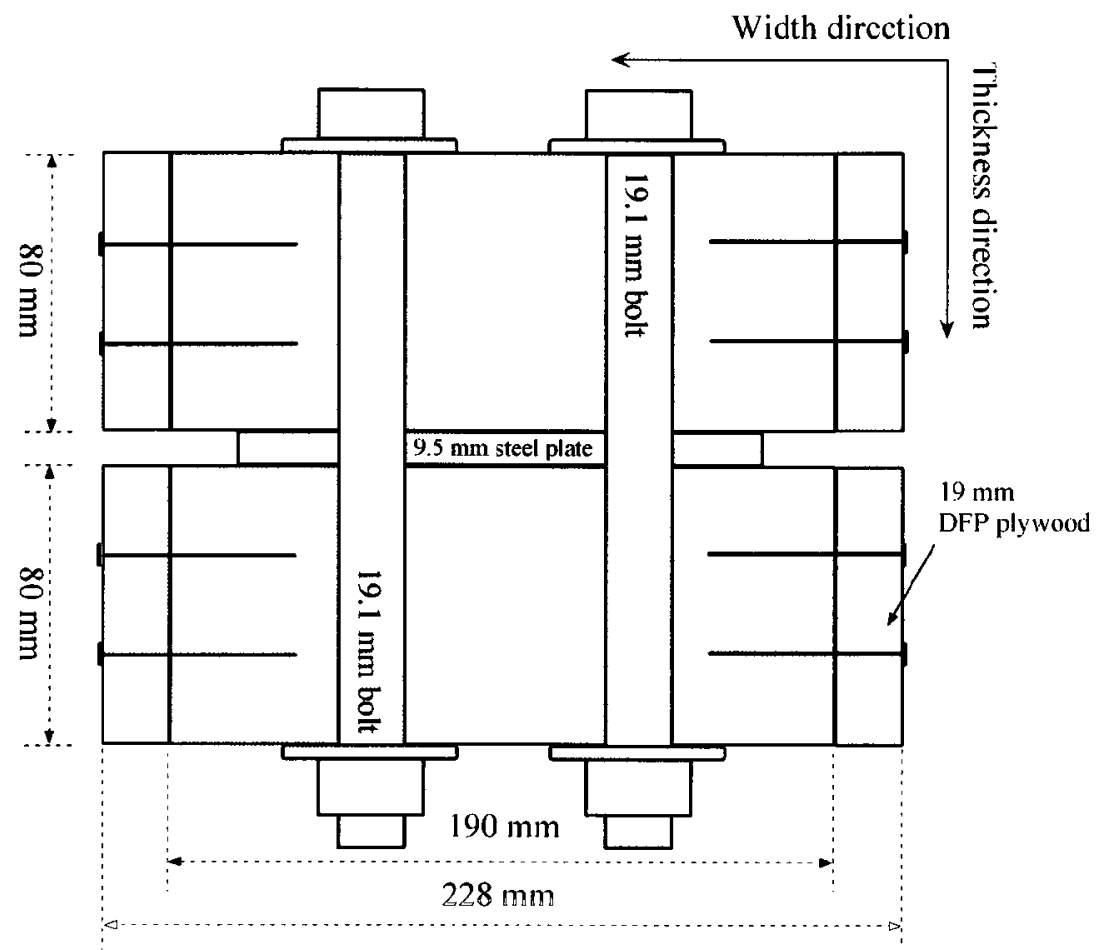

Figure 3.9 Schematic of test specimen \#5.2

It is necessary to point out that the specimen is not equivalent to a specimen using $80 \mathrm{~mm}$

$\times 228 \mathrm{~mm}$ solid wood members. However, since an edge distance over $2.5 d$ does not have much influence on the strength of timber connections, the protection of the additional plywood is assumed to be equivalent to the protection of extra solid wood in a fire exposure. 


\section{Protection}

As shown in Table 3.2, two specimens were protected. A single-layer of $15.9 \mathrm{~mm}\left(5 / 8^{\prime \prime}\right)$ Type X gypsum board and a double-layer of $12.7 \mathrm{~mm}(1 / 2 ")$ Douglas fir plywood were used as the protective membranes for Test \#4.3 and Test \#5.4, respectively.

As recommended in the TR 10 (AWC 2003), in order to meet the one-hour fire resistance, a timber connection should be covered in with either wood (38 $\mathrm{mm}$ thick) or $15.9 \mathrm{~mm}$ fire-rated gypsum board as protection, or bolt heads and nuts should be concealed in wood members and wood plugs should be used to cover the bolts. For the specimens in this study, if holes were drilled to conceal fasteners, a large amount of cross-section material would be removed. For this reason, connections were designed to be boxed, with wood strips installed around the connection as furring and protective membranes attached to the furring. It should be pointed out that only the connection zone was covered by protection membranes, not the entire specimen along the longitudinal direction.

Examples of installing protective membranes are shown in Figure 3.10 and Figure 3.11. The wood strips $(38 \times 30 \mathrm{~mm})$ were cut from $2 \times 3$ SPF $\# 2$ lumber. Type $S$ wall board screws, $57 \mathrm{~mm}$ long, were used to fasten furring strips and they were placed $20 \mathrm{~mm}$ away from wood edges. For specimen \#4.3, a gypsum board was installed to the strips in the width direction using $41 \mathrm{~mm}$ long type $\mathrm{S}$ wall board screws, as shown in Figure 3.10; while in the thickness direction, a gypsum board was installed directly to the specimen using $41 \mathrm{~mm}$ type $\mathrm{S}$ wall board screws, overlapping the gypsum boards in the width direction. For specimen \#5.4, a double-layer of $12.7 \mathrm{~mm}$ thick Douglas fir plywood was used as protective membranes, as shown in Figure 3.11. 


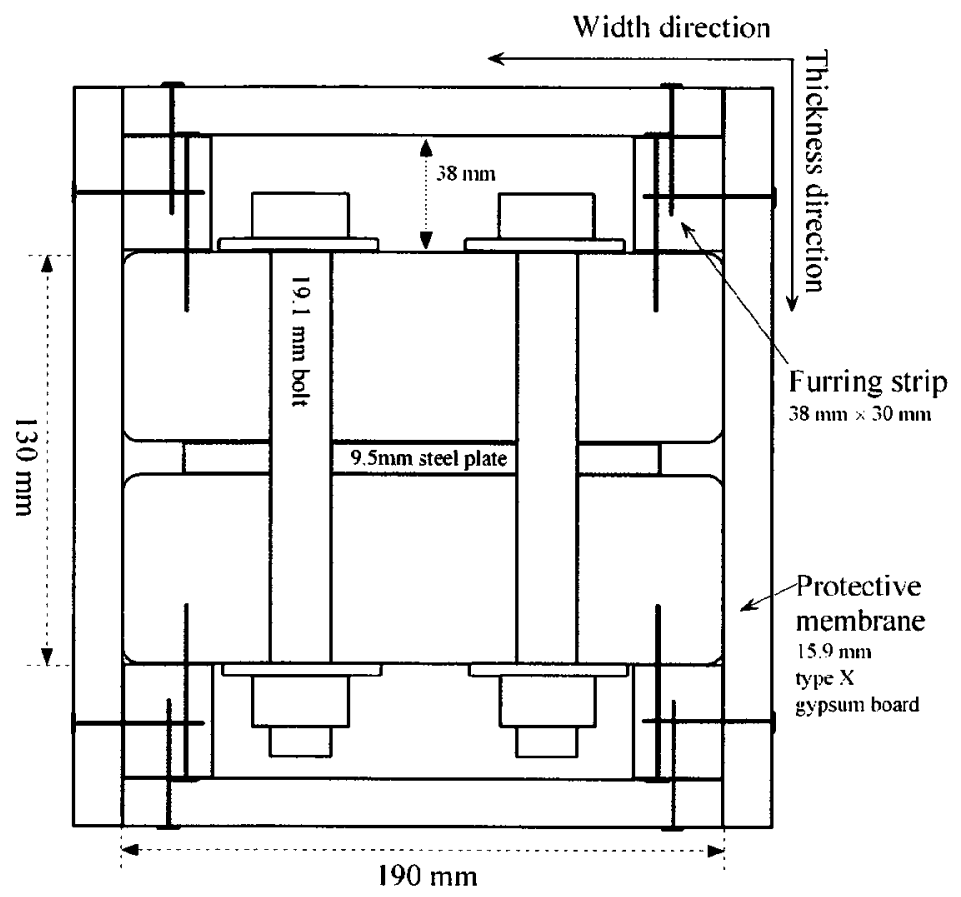

Figure 3.10 Schematic of WSW connection with protective membranes: \#4.3

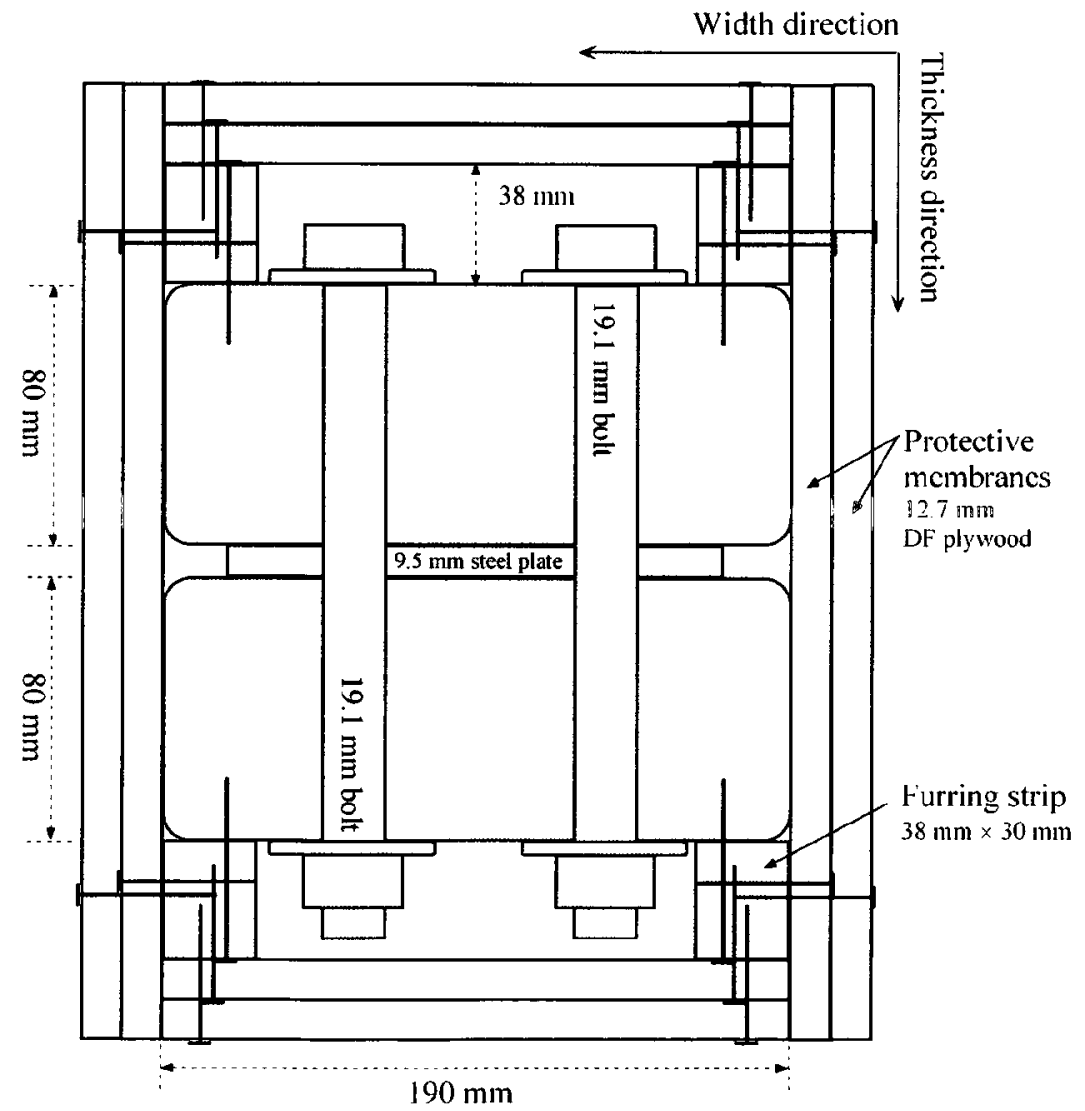

Figure 3.11 Schematic of WSW connection with protective membranes: \#5.4 


\subsubsection{Test Procedure}

The procedure to conduct a fire-resistance test for bolted WSW connections is given below:

1. Install the specimen in the furnace;

2. Connect the load system, thermocouples and LVDTs to the data acquisition system;

3. Apply the pre-tensile load at the designated load ratio for more than $20 \mathrm{~min}$;

4. Ignite the fire and sustain the load level until failure;

5. Shut down the propane burners immediately after the failure;

6. Stop charring in wood members by spraying water to the specimen.

Failure was assumed to occur when the specimen could not withstand the applied load, or the load dropped with no recovery in the specimen. After a fire test, the char was removed and the residual wood dimensions were recorded for calculating the charring rate.

It has to be pointed out that wood charring was stopped by spraying water to the specimen in the furnace normally 3-5 minutes after the burners were shut down, due to the difficulty of immediately removing the specimen from the furnace after failure. Therefore, a correction must be made when the charring rate was calculated. This will be discussed in subsection 3.3.3.5 


\subsubsection{Test Results}

In this subsection, the following test results are presented: furnace temperature, load, displacement, specimen temperature, failure time, failure mode, and charring rate.

Figure 3.12 shows a typical specimen in the furnace, before and after a test. For every specimen, the connection (both top and bottom section) was exposed to fire as well as an additional part of solid wood in each section. The length of the additional exposed part of solid wood was equal to the width of the specimen. The rest of the solid wood was insulated with mineral blankets, as seen in Figure 3.12 (left). Figure 3.13 shows a typical specimen after the char was removed. It can be seen that the failure was due to the wood members, while the steel plate and bolts show no considerable deformations.

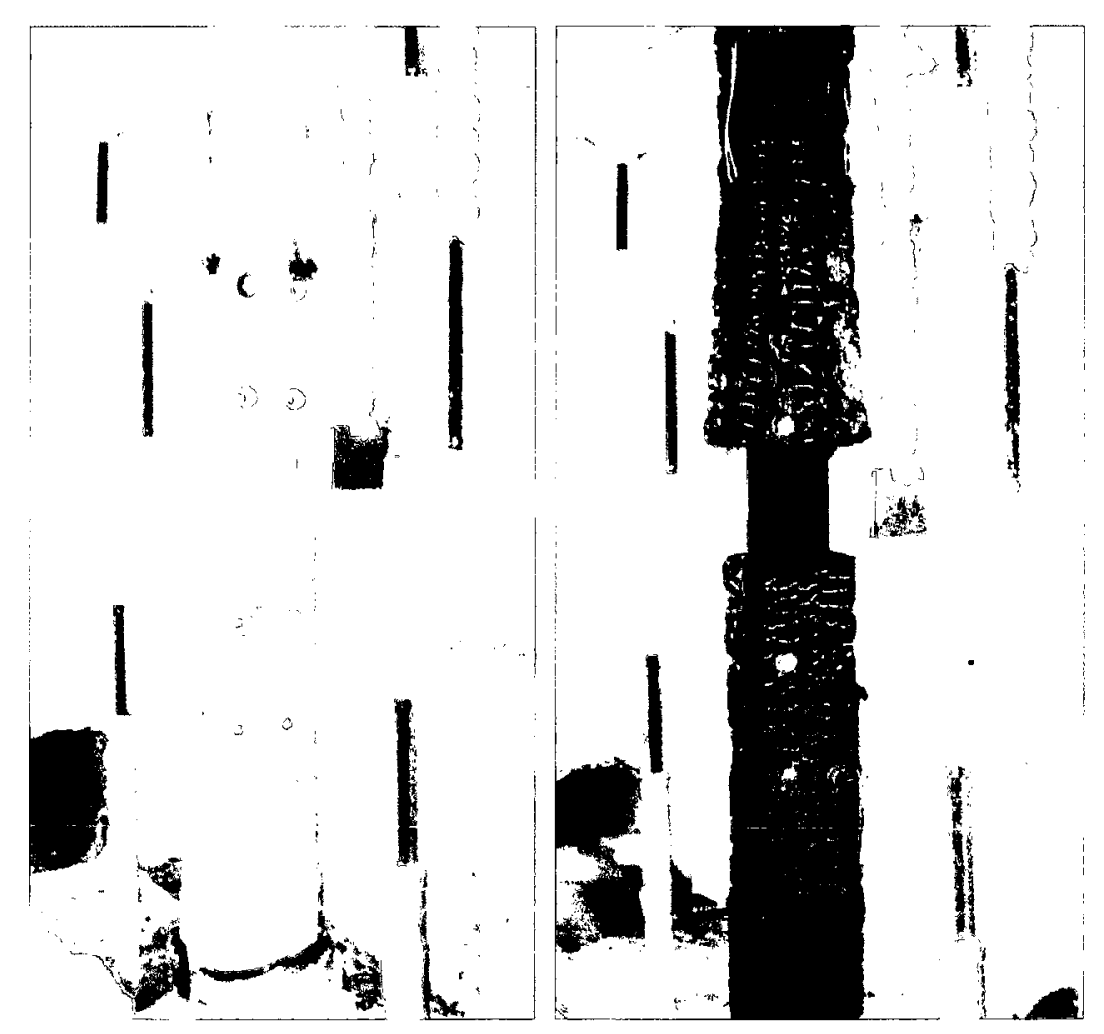

Figure 3.12 A typicai specimen before and after the fire test, Tesi $\$ 4.2$ 


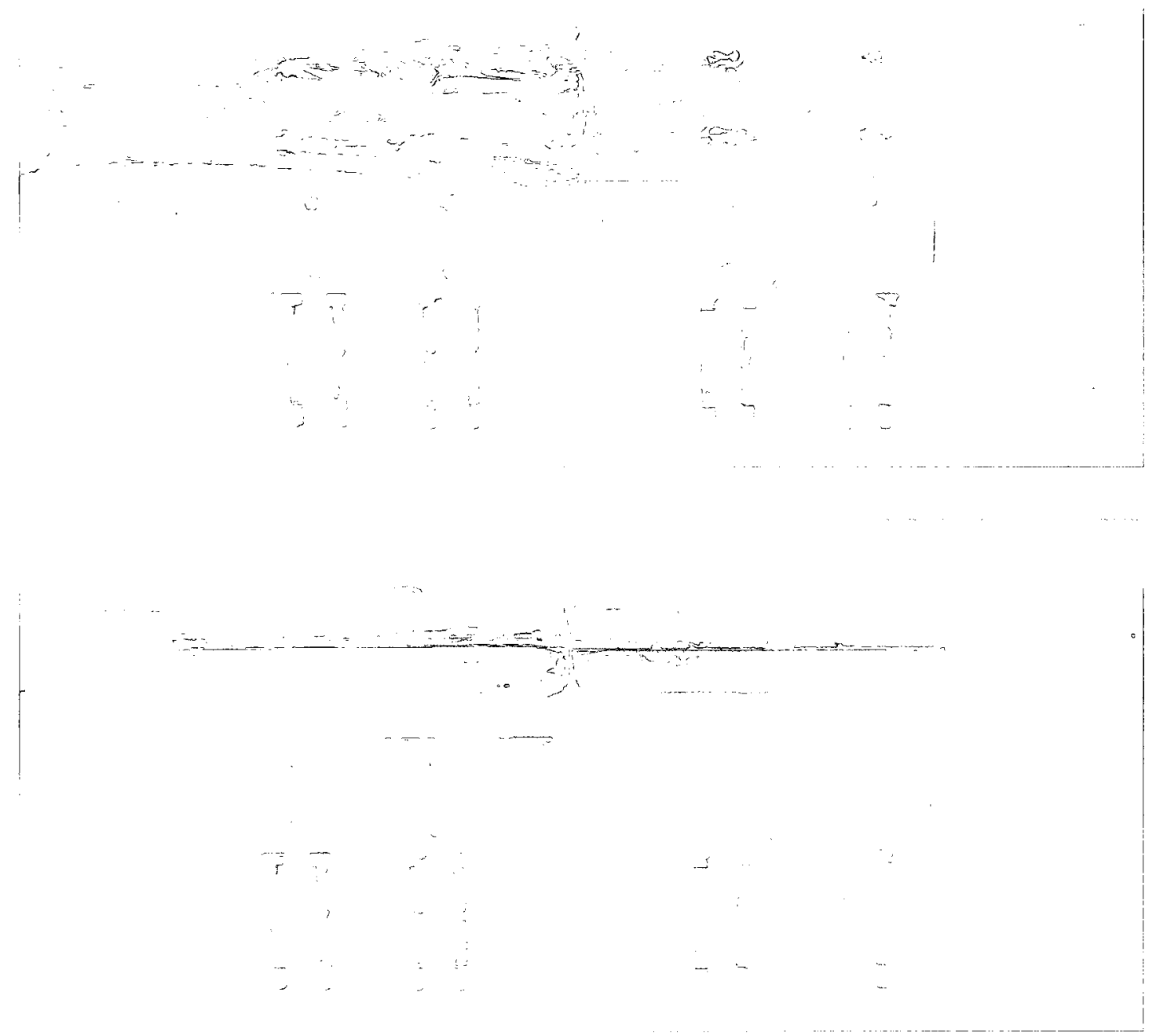

Figure 3.13 Specimem 2ifter the char was removed, Test $44_{2}$ 


\subsubsection{Furnace Temperature}

In Figure 3.14, typical furnace temperature curves averaged from 6 shielded thermocouples (TC) and 2 plate thermometers (PT) are plotted for Test \#5.1. The average TC temperature curve followed the standard curve quite well. The average PT curve showed slightly higher values than the TC curve throughout the test, due to the faster response of plate thermometers. Note that the curves decreased right after the failure at $36.5 \mathrm{~min}$ because the burners were turned off.

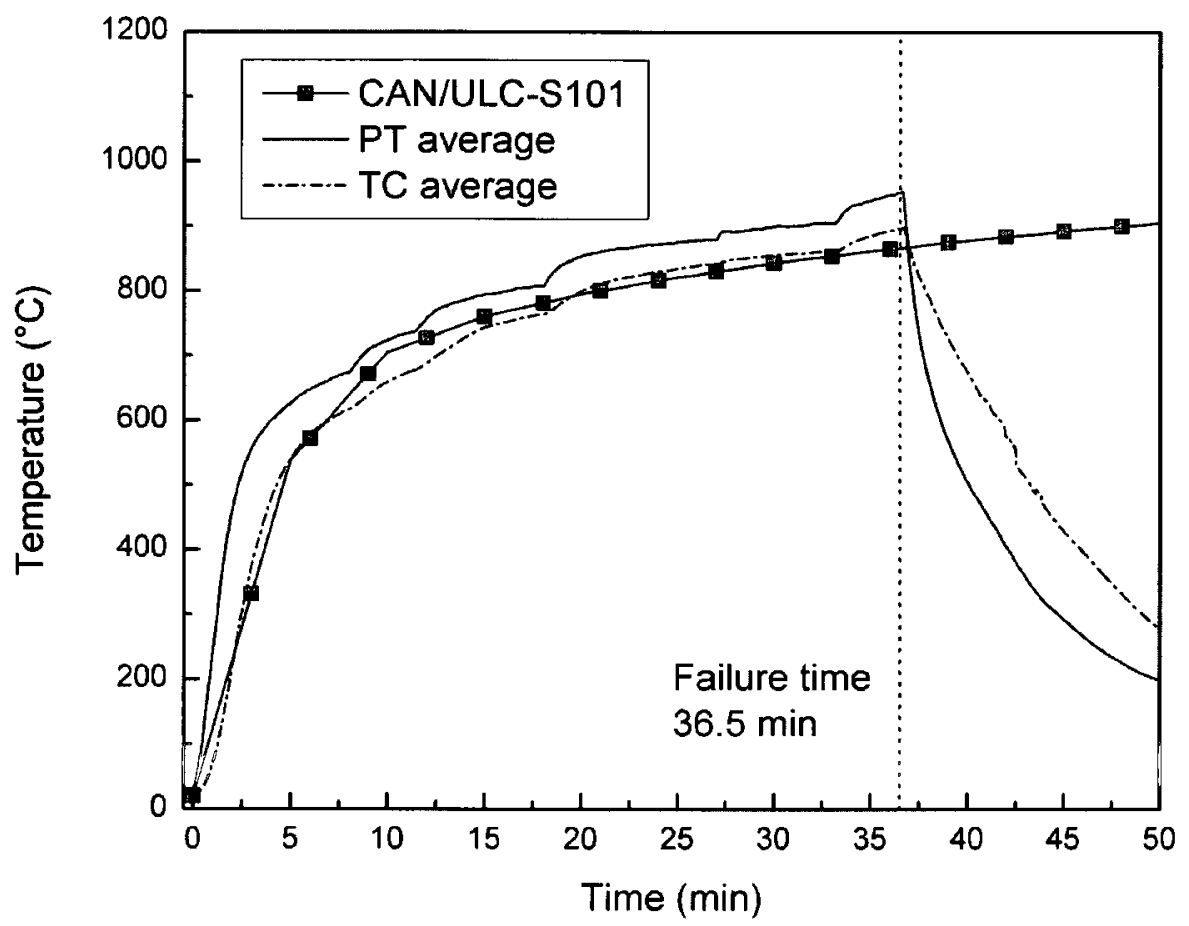

Figure 3.14 A typical plot of furnace temperature curves, Test \#5.1 


\subsubsection{Load and Displacement}

The load and displacement curves are plotted in Figure 3.15 for Test \#5.1 as an example. The average applied load during the test was $25.5 \mathrm{kN}$. At $36.5 \mathrm{~min}$ when the specimen failed, the load curve dropped rapidly without recovery while the displacement curve increases quickly. A plateau of the displacement curve after failure was observed because the hydraulic pump was stopped after the specimen failed.

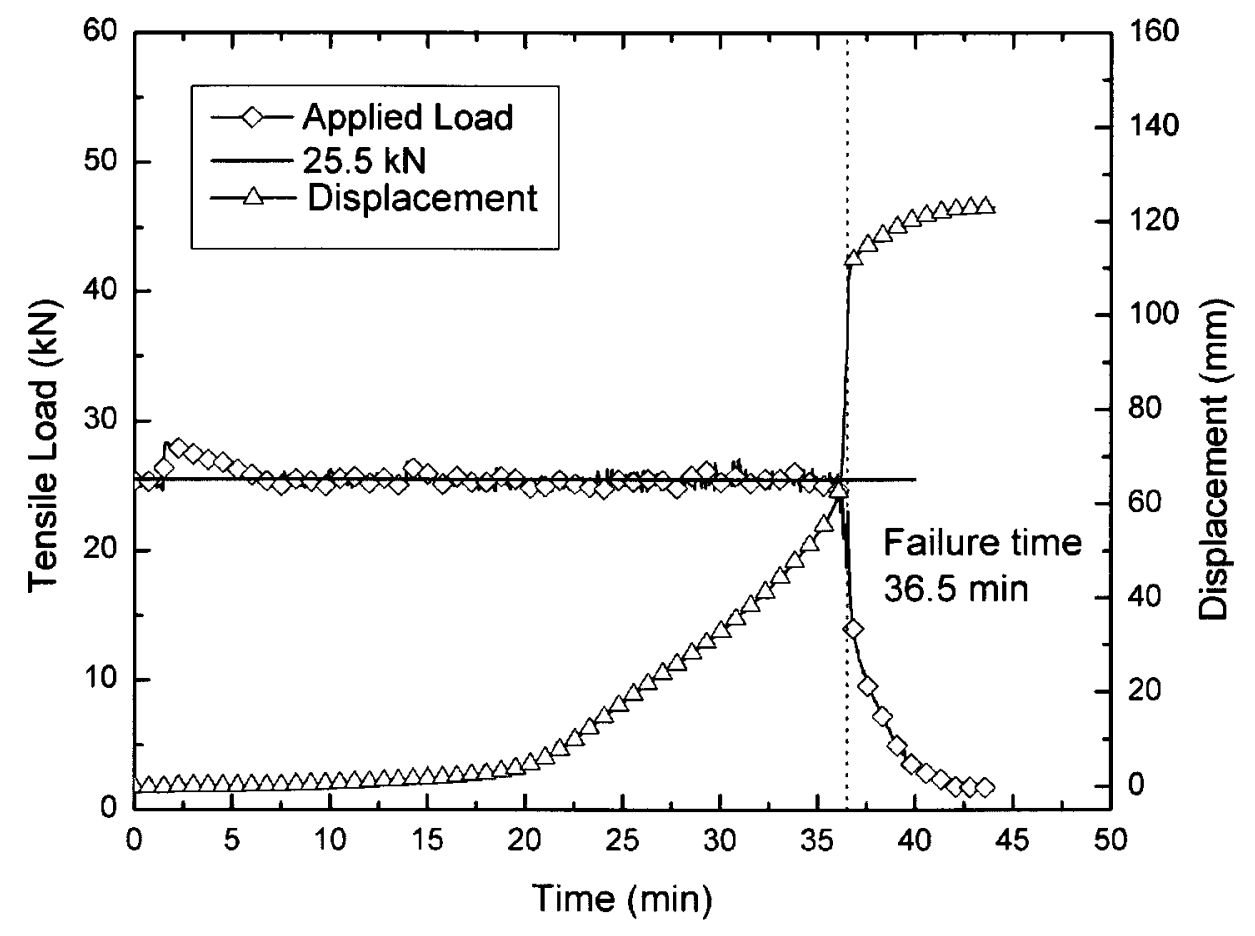

Figure 3.15 A typical plot of applied load and specimen displacement, Test \#5.1 


\subsubsection{Specimen Temperature}

In the fire tests, temperature histories in wood members and bolts were measured at different locations. Figure 3.16 shows the thermocouple locations of the specimens for Group \#4. Thermocouples T1-T7 were placed in the top part of the specimen and thermocouples B1-T7 were located in the bottom part, symmetrically. Thermocouples T1$\mathrm{T} 3$ and $\mathrm{B} 1-\mathrm{B} 3$ were placed on bolts, and T4-T7 and B4-B7 were placed in wood. The thermocouple locations for each group are given in Appendix D.

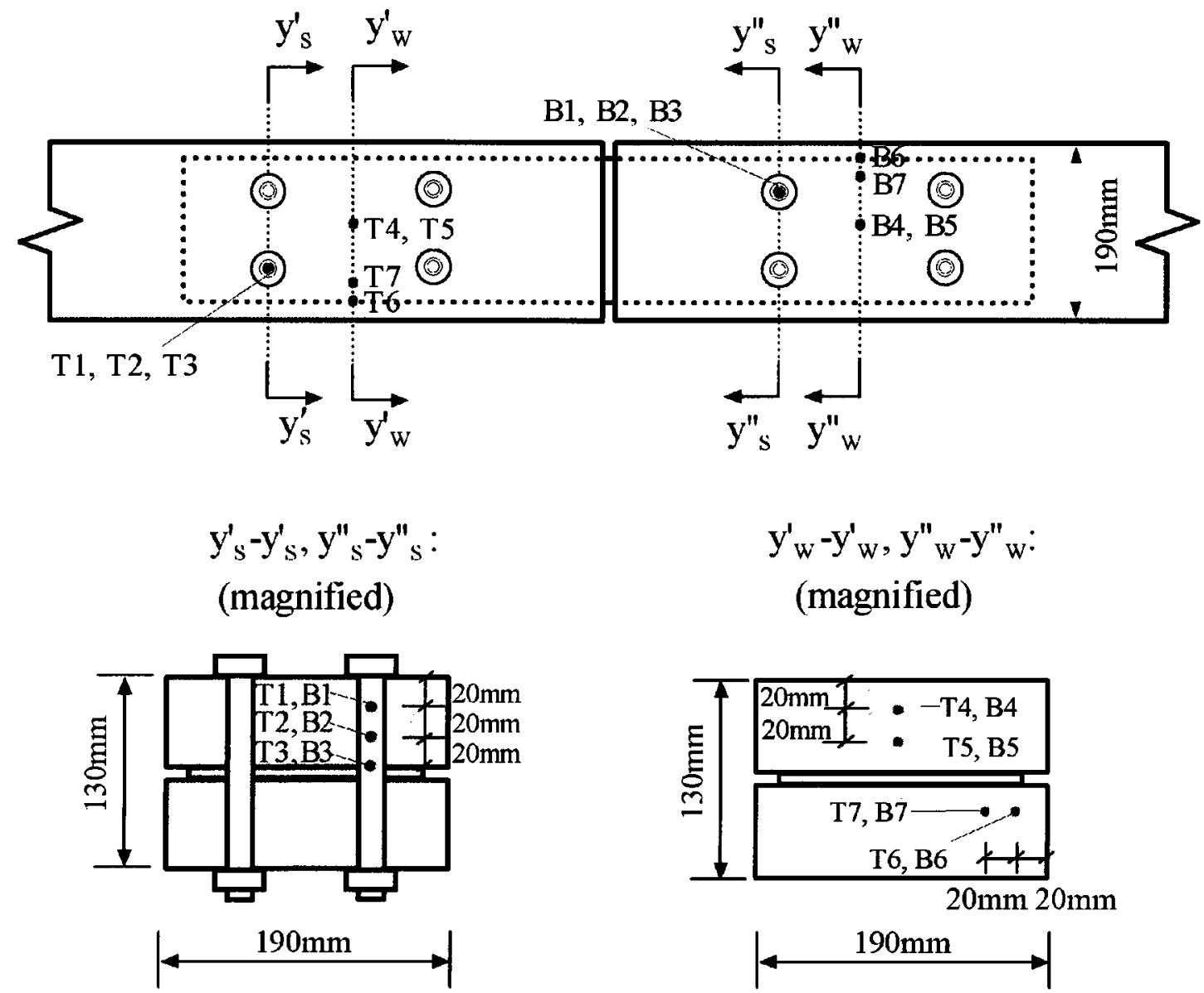

Figure 3.16 Thermocouple locations for Group \#4 
The measured temperature histories in the bolts are shown in Figure 3.17 for Test \#4.1. The temperature gradient along the bolt shank was measured for two bolts. The temperature measured in the top bolt was found to be slightly higher than the temperature measured in the bottom bolt at the same distance from the exposed surface. This is probably because the top section received more heat from the flames in the furnace. However, the difference, with a maximum about $20-30^{\circ} \mathrm{C}$, was not significant.

The measured temperature histories in the wood members are shown in Figure 3.18, for Test \#4.1. Thermocouples T6/B6 and T7/B7 measured higher temperatures than thermocouples T4/B4 and T5/B5. This is because T6/B6 and T7/B7 were more affected by the two-dimensional heat transfer due to the presence of the steel plate in the center and also because the thickness-wise surfaces $(130 \mathrm{~mm})$ were facing the burners. Again, the wood temperature measured in the top section was found to be slightly higher than the wood temperature measured in the bottom section, but the difference was not significant. 


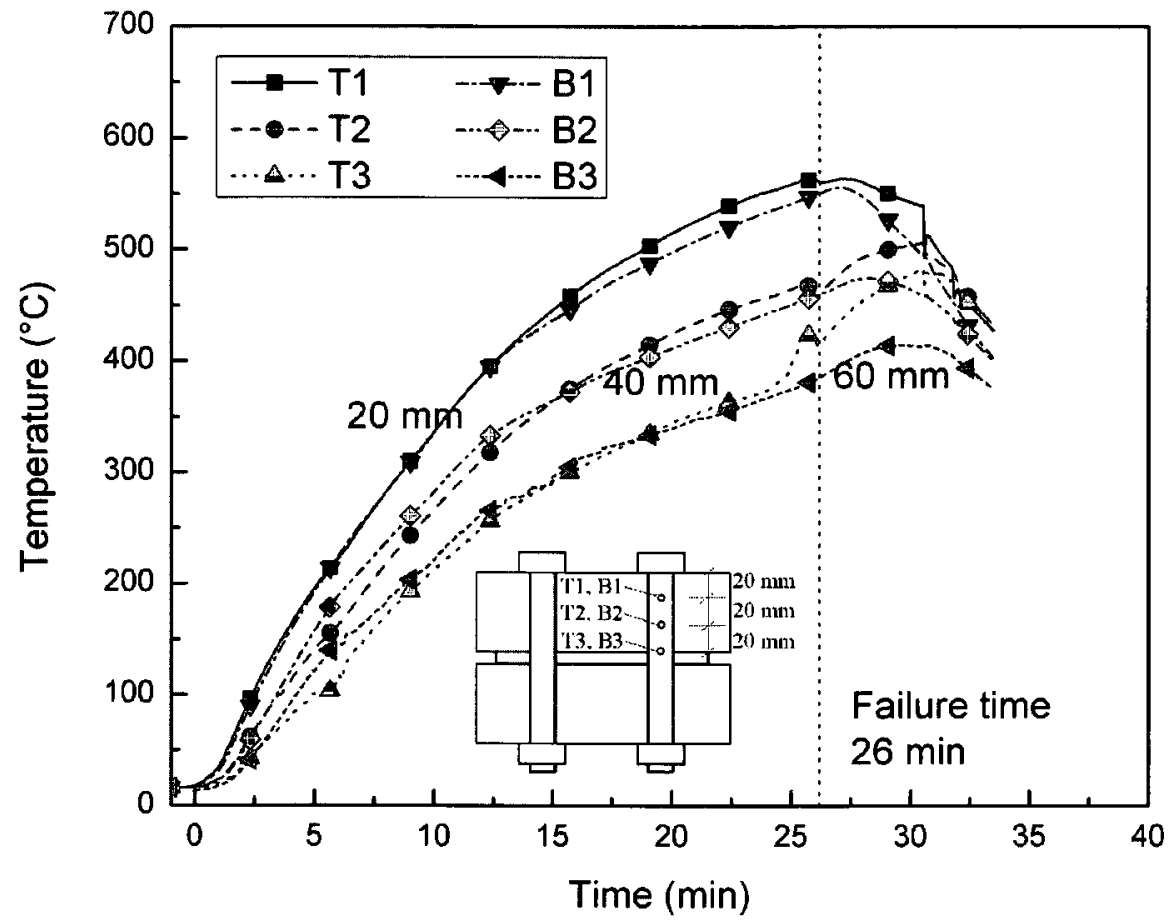

Figure 3.17 Bolt temperature histories for Test \#4.1

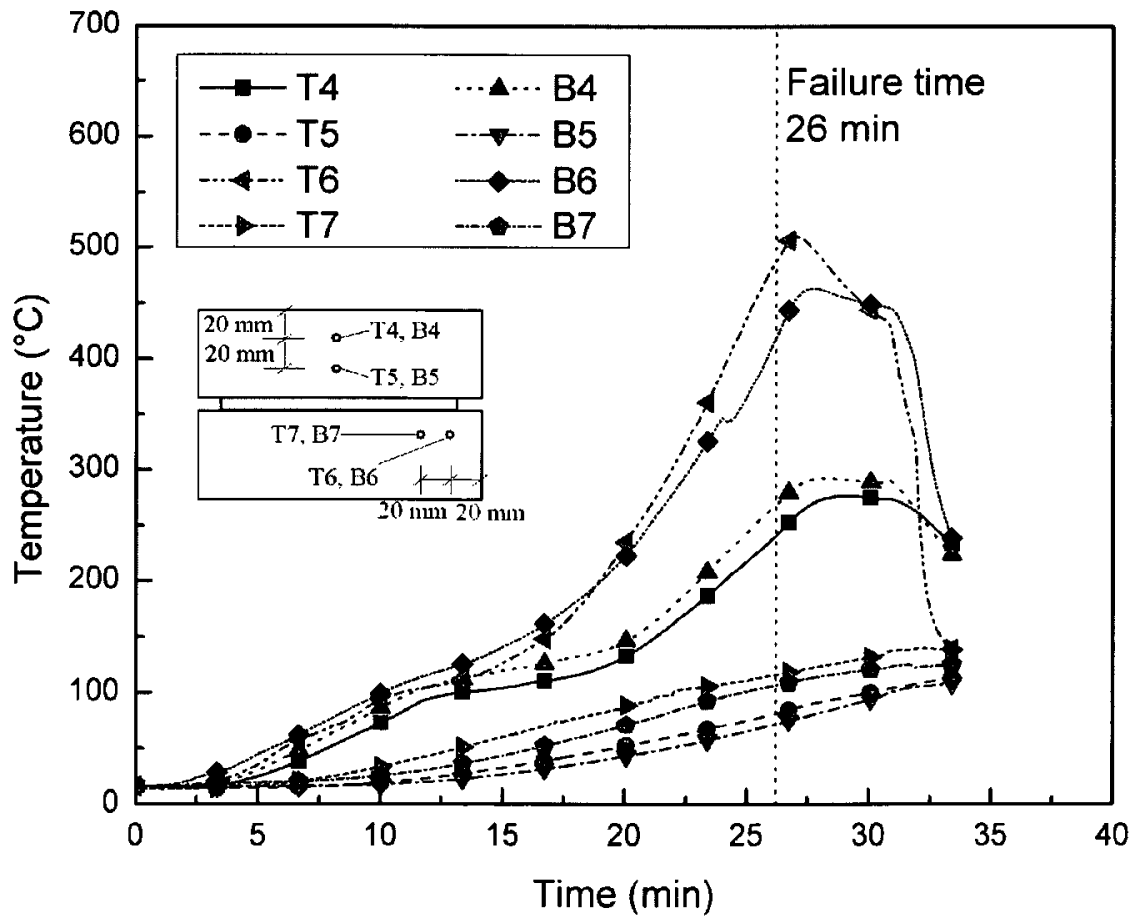

Figure 3.18 Wood temperature histories for Test \#4.1 
Figure 3.19 shows the measured temperature histories in bolts for Test \#4.3. The connection zone was boxed and protected by a single-layer of $15.9 \mathrm{~mm}$ Type X gypsum board. It can be seen that within the first $30 \mathrm{~min}$, the bolt temperatures increased very slowly and remained lower than about $120^{\circ} \mathrm{C}$ due to the protection of gypsum board. After about $35 \mathrm{~min}$, the temperature curves increased quite quickly until the specimen failed. Throughout the test, the temperatures in the top bolt were higher than the temperatures in the bottom bolt. This is probably because of the buoyancy effect in the cavity. The air temperature in the top part of the cavity was higher than that in the bottom part. Therefore, the top bolt received more heat flux from the air in the cavity.

Figure 3.20 shows the measured temperature histories in the wood members and cavity for Test \#4.3. Thermocouple C1 was located in the top part of the cavity and C2 was in the bottom part. Thermocouple $\mathrm{C} 1$ increased faster than $\mathrm{C} 2$. The temperatures in the cavity were also used to determine the $140 / 180^{\circ} \mathrm{C}$ finish rating and the time for a temperature of $300^{\circ} \mathrm{C}$ behind the protective membranes. The $140 / 180^{\circ} \mathrm{C}$ finish rating is defined as the time when thermocouples placed between the protective membrane and the protected specimen reach an average temperature rise of $140^{\circ} \mathrm{C}$ or an individual temperature of $180^{\circ} \mathrm{C}$ (UL 1993). It was found that the $140 / 180^{\circ} \mathrm{C}$ finish rating was about $23 \mathrm{~min}$ and the time for a temperature of $300^{\circ} \mathrm{C}$ behind the protective membranes was 30 min for the protection with $15.9 \mathrm{~mm}$ Type X gypsum board. 


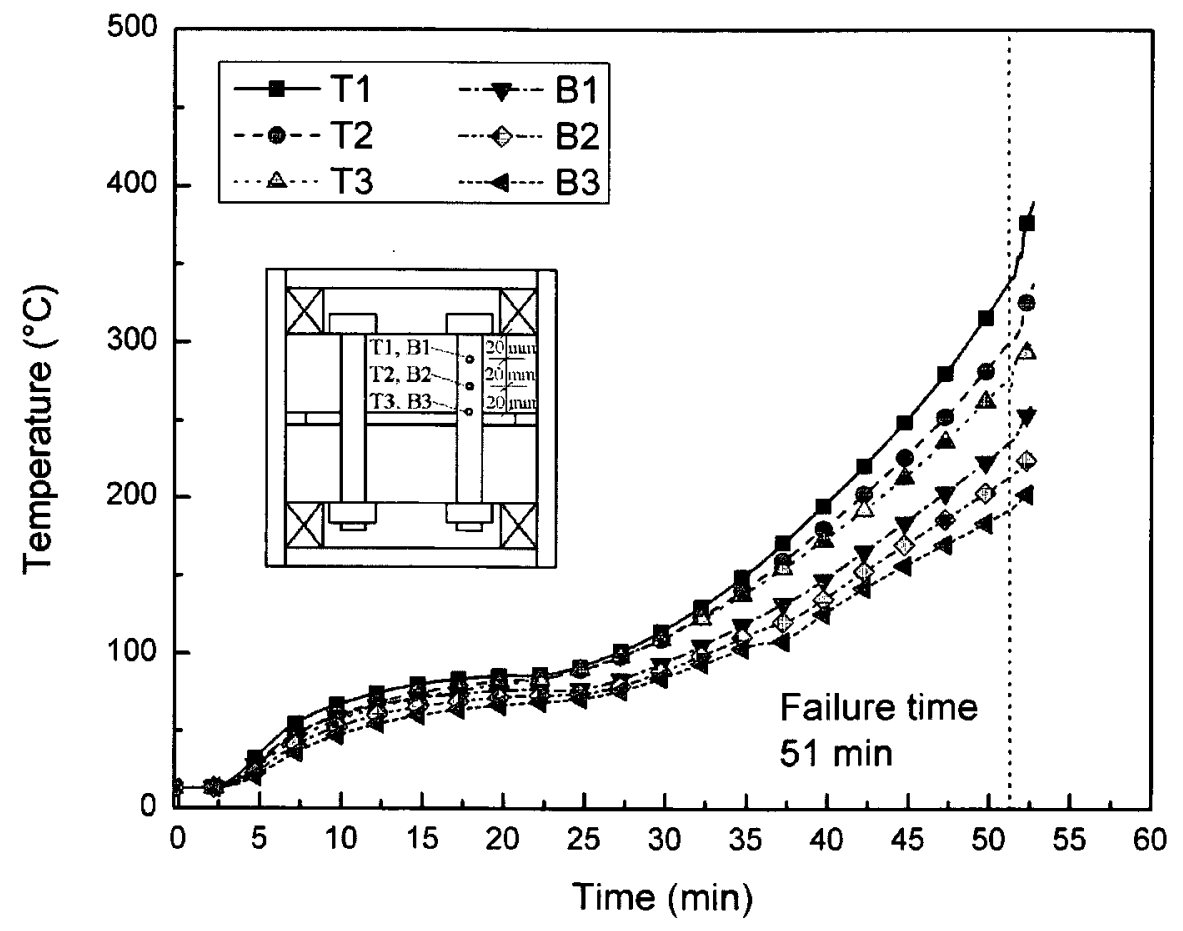

Figure 3.19 Bolt temperature histories for Test \#4.3

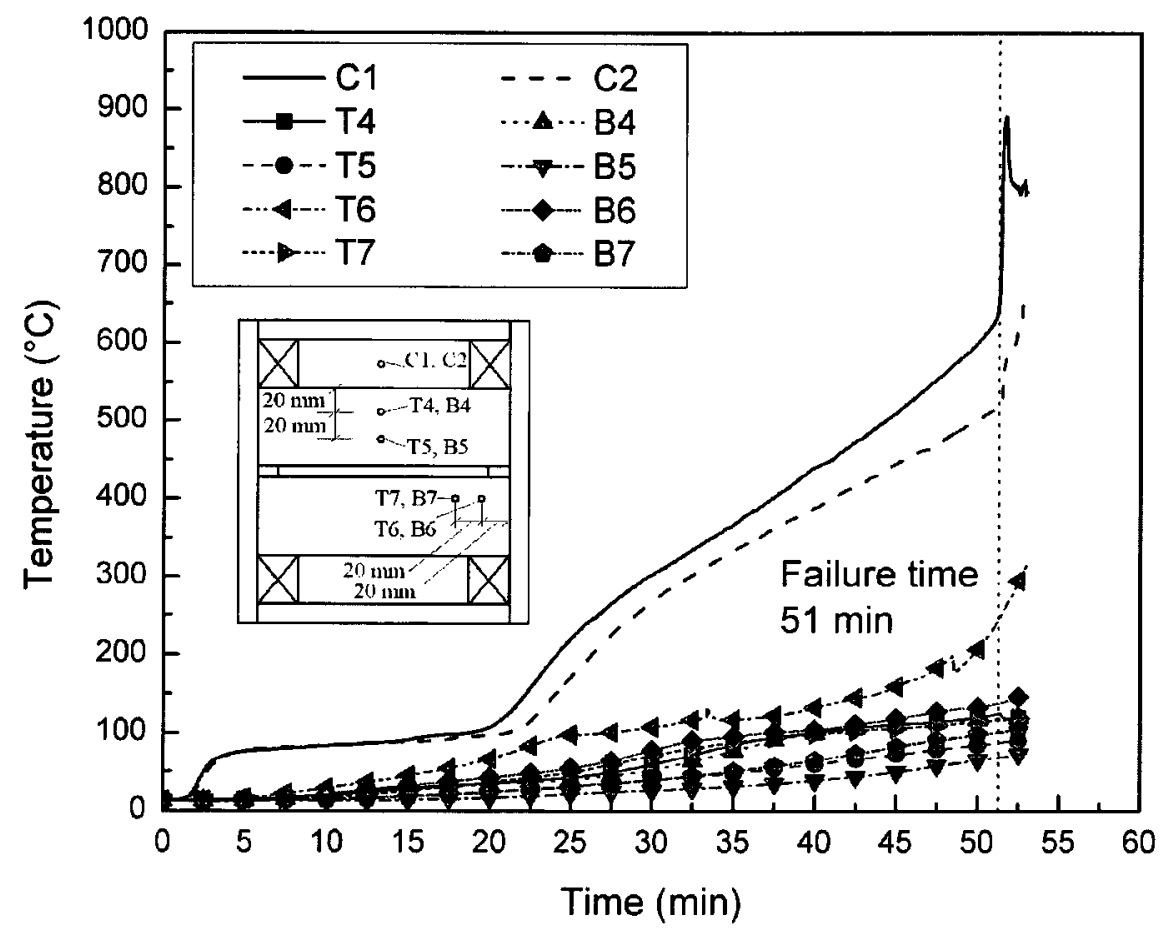

Figure 3.20 Wood and cavity temperature histories for Test \#4.3 
Figure 3.21 shows the measured temperature histories on the bolts for Test \#5.4, protected by a double-layer of $12.7 \mathrm{~mm}$ plywood. Within the first $20 \mathrm{~min}$, the bolt temperatures remained low and increased very slowly due to the protection of the plywood board. After about 20-25 $\mathrm{min}$, the temperature curves increased quickly until the specimen failed. Again, the temperature of the top bolt was higher than that of the bottom bolt.

Figure 3.22 shows the measured temperature histories in the wood members and cavity for Test \#5.4. Thermocouples $\mathrm{C} 1$ and $\mathrm{C} 2$ increased rapidly when the cavity temperature was higher than about $100^{\circ} \mathrm{C}$. At about $20-25 \mathrm{~min}$, the cavity temperatures were close to the furnace temperature because the plywood boards had burned off and the char layers had fallen. The $140 / 180^{\circ} \mathrm{C}$ finish rating and the time for a temperature of $300^{\circ} \mathrm{C}$ behind the protective membranes were determined to be about $23 \mathrm{~min}$ and $30 \mathrm{~min}$, respectively, for the protection of a double-layer of $12.7 \mathrm{~mm}$ plywood.

In general, the specimen temperatures that are shown in this subsection are representative among all the tests. Not all the 16 test temperatures are shown in this thesis, but they will be included in a complete research report. It should be noted that some temperatures were not measured properly for some specimens at the beginning of the test program. This is because the glass-fibre-insulated thermocouple wires were used at the beginning, and the insulation failed during the fire tests so that wrong temperatures were measured. Those incorrect temperatures were found to be close to the furnace temperatures and they could not represent the proper temperatures within the specimens. Later on, when MSMI thermocouples were adopted, the recorded temperatures seemed to be reasonable and to accurately represent the specimen temperatures. 


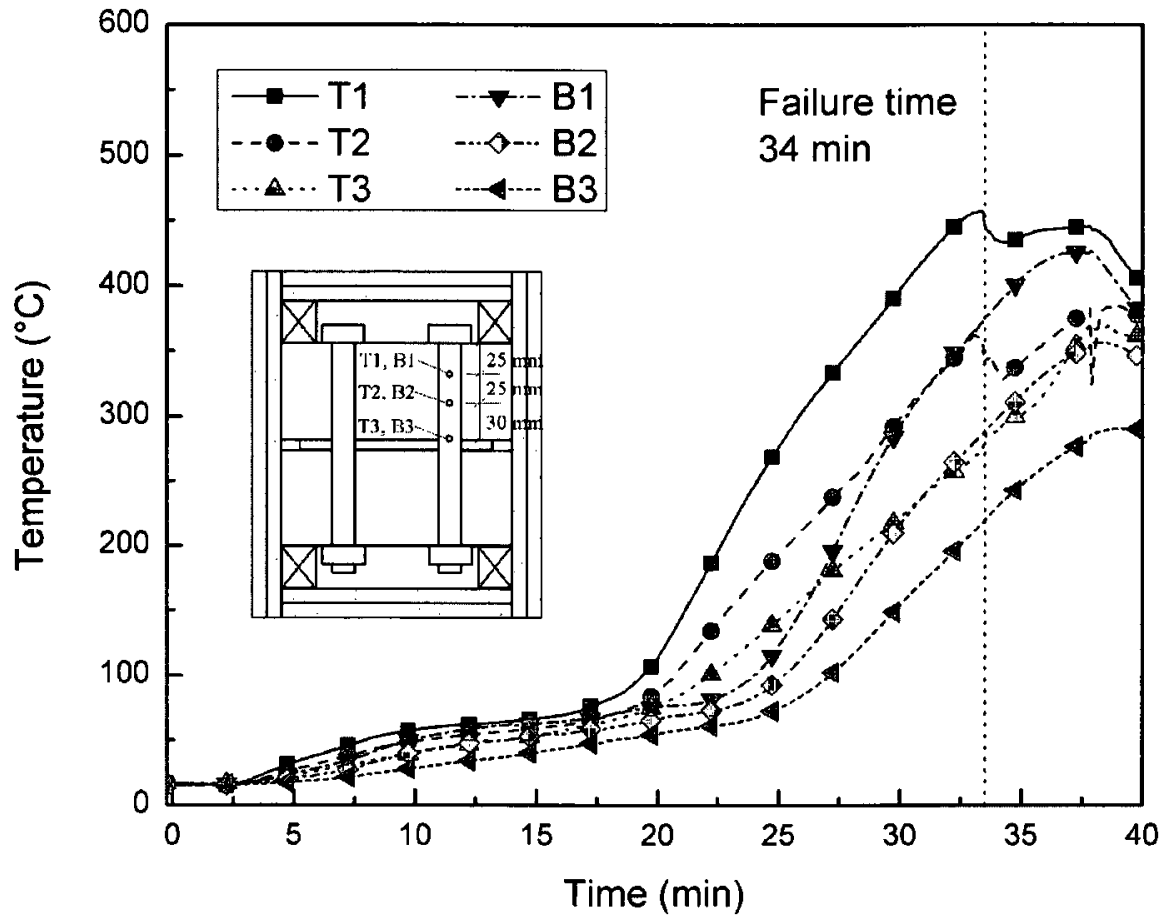

Figure 3.21 Bolt temperature histories for Test \#5.4

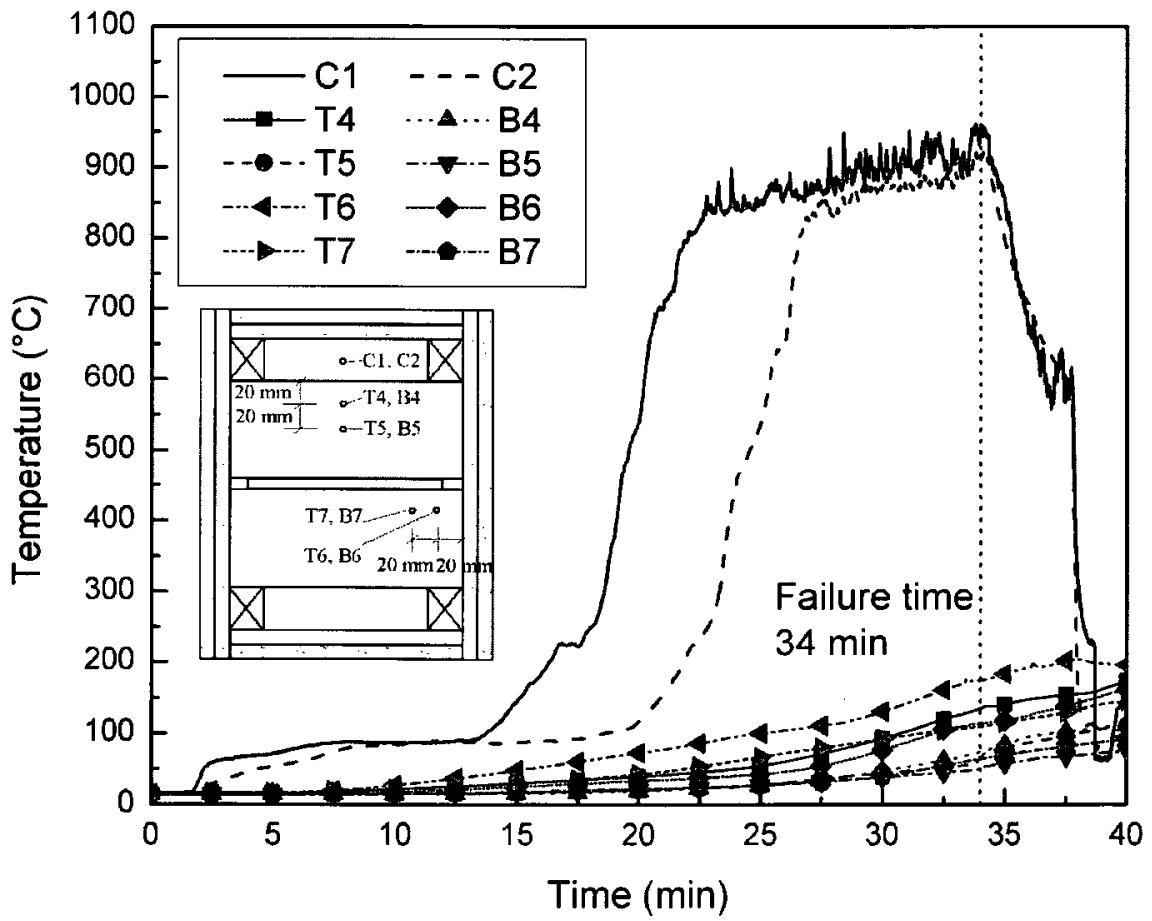

Figure 3.22 Wood and cavity temperature histories for Test \#5.4 


\subsubsection{Failure Time and Failure Mode}

\section{Failure Time}

As defined, the failure time of a specimen in a fire test is the time period from the start of the fire to the moment of structural failure of the specimen. Failure times are summarized in Table 3.3 for the 14 unprotected specimens and 2 protected specimens.

It can be seen in Table 3.3 that all the unprotected specimens had fire resistances less than $45 \mathrm{~min}$. Test results in Group\#1 showed that the failure times for the replicates were very close (i.e., Test \#1.1 and \#1.2, \#1.3 and \#1.4). In each group, decreasing the load ratio increases the fire resistance. Specimens with thicker wood side members were found to have better fire resistances. Protected specimens showed better fire resistances. Further discussions on the effects of wood side member thickness, load ratio, fastener diameter and protection are presented in subsection 3.2.4.

In comparison with solid glulam timber, a $130 \times 190 \mathrm{~mm} 20 \mathrm{f}-\mathrm{EX}$ SP member loaded at 23 $\mathrm{kN}$ (equivalent to $10 \%$ load ratio for specimen WSW\#4.1) or $68 \mathrm{kN}$ (equivalent to $30 \%$ load ratio for specimen WSW\#4.2) has a fire resistance of $84 \mathrm{~min}$ or $73 \mathrm{~min}$, calculated using the TR 10 (AWC 2003) methods. However, specimen WSW\#4.1 and WSW\#4.2 had a fire resistance of only $14 \mathrm{~min}$ and $26 \mathrm{~min}$. It can be seen that the fire resistance has been dramatically reduced for bolted WSW timber connections. 


\section{Failure Mode}

Failure modes and comments are also summarized in Table 3.3 for all the specimens. Generally, all the observed failure modes are shown in Figure 3.23. The most common failure mode was the elongation of the holes in the wood members, seen in Figure 3.23a. The hole elongation might result in a complete cutting-through to the end of wood member, seen in Figure 3.23b; or it could be combined with splitting in the side members as the final failure especially for thinner wood members, seen in Figure 3.23c. Another observed failure mode was edge material tear-out, shown in Figure 3.23d. It occurred because the edge distance of wood members was insufficient to resist shear after charring. 
Table 3.3 Test results: failure time and failure modes

\begin{tabular}{|c|c|c|c|c|c|}
\hline $\begin{array}{c}\text { Test } \\
\#\end{array}$ & $\begin{array}{l}\text { Specimen } \\
\text { Information }\end{array}$ & $\begin{array}{l}\text { Load } \\
\text { Ratio }\end{array}$ & $\begin{array}{l}\text { Failure } \\
\text { Time } \\
\text { (min) }\end{array}$ & Failure Modes & Other Comments \\
\hline 1.1 & \multirow{4}{*}{$\begin{array}{c}\text { SPF-L: } \\
2 @ 38 \times 140 \\
\text { Bolt: } \\
2 \times 12.7\end{array}$} & $10 \%$ & 14.5 & $\begin{array}{l}\text { Hole elongation; } \\
\text { wood member } \\
\text { splitting }\end{array}$ & $\begin{array}{c}\text { No bending of bolts; } \\
\text { minor charring around holes; } \\
\text { minor charring on un-exposed sides. }\end{array}$ \\
\hline 1.2 & & $10 \%$ & 15 & $\begin{array}{l}\text { Hole elongation; } \\
\text { wood member } \\
\text { splitting }\end{array}$ & $\begin{array}{l}\text { One bolt shows slight bending; } \\
\text { no obvious charring around holes; } \\
\text { no obvious charring on un-exposed sides. }\end{array}$ \\
\hline 1.3 & & $29 \%$ & 8 & $\begin{array}{l}\text { Hole elongation; } \\
\text { wood member } \\
\text { splitting }\end{array}$ & $\begin{array}{l}\text { No bending of bolts; } \\
\text { no obvious charring around holes; } \\
\text { minor charring on un-exposed sides. }\end{array}$ \\
\hline 1.4 & & $30 \%$ & 8.5 & $\begin{array}{l}\text { Hole elongation; } \\
\text { wood member } \\
\text { splitting }\end{array}$ & $\begin{array}{l}\text { No bending of bolts; } \\
\text { no obvious charring around holes; } \\
\text { no obvious charring on un-exposed sides. }\end{array}$ \\
\hline 2.1 & \multirow{3}{*}{$\begin{array}{l}\text { SP-G: } \\
130 \times 190 \\
\text { Bolt: } \\
2 \times 12.7\end{array}$} & $11 \%$ & 28 & $\begin{array}{l}\text { Severe hole } \\
\text { elongation }\end{array}$ & $\begin{array}{l}\text { No bending of bolts; } \\
\text { minor charring around holes. }\end{array}$ \\
\hline 2.2 & & $18 \%$ & 22.5 & $\begin{array}{l}\text { Hole elongation; } \\
\text { cutting through }\end{array}$ & $\begin{array}{l}\text { No bending of bolts; } \\
\text { minor charring around holes. }\end{array}$ \\
\hline 2.3 & & $29 \%$ & 17.5 & $\begin{array}{l}\text { Hole elongation; } \\
\text { cutting through }\end{array}$ & $\begin{array}{l}\text { One bolt shows severe bending; } \\
\text { minor charring around holes. }\end{array}$ \\
\hline 3.1 & \multirow{2}{*}{$\begin{array}{l}\text { SP-G: } \\
130 \times 190 \\
\text { Bolt: } \\
1 \times 19.1\end{array}$} & $11 \%$ & 27 & $\begin{array}{l}\text { Hole elongation; } \\
\text { cutting through }\end{array}$ & $\begin{array}{l}\text { No bending of bolts; } \\
\text { charring around holes. }\end{array}$ \\
\hline 3.2 & & $32 \%$ & 15 & $\begin{array}{l}\text { Hole elongation; } \\
\text { wood member } \\
\text { splitting }\end{array}$ & $\begin{array}{l}\text { No bending of bolts; } \\
\text { no obvious charring around holes. }\end{array}$ \\
\hline 4.1 & \multirow{3}{*}{$\begin{array}{l}\text { SP-G: } \\
130 \times 190 \\
\text { Bolt: } \\
4 \times 19.1\end{array}$} & $10 \%$ & 26 & $\begin{array}{c}\text { Hole elongation; } \\
\text { side material } \\
\text { tear-out }\end{array}$ & $\begin{array}{l}\text { No bending of bolts; } \\
\text { charring around holes. }\end{array}$ \\
\hline 4.2 & & $30 \%$ & 14 & $\begin{array}{l}\text { Hole elongation; } \\
\text { cutting through }\end{array}$ & $\begin{array}{l}\text { No bending of bolts; } \\
\text { no obvious charring around holes. }\end{array}$ \\
\hline $4.3^{\dagger}$ & & $30 \%$ & 51 & $\begin{array}{l}\text { Hole elongation; } \\
\text { Cutting through }\end{array}$ & $\begin{array}{l}\text { No obvious bending of bolts; } \\
\text { No obvious charring around holes. }\end{array}$ \\
\hline 5.1 & \multirow{4}{*}{$\begin{array}{c}\text { SP-G: } \\
2 @ 80 \times 190 \\
\text { Bolt: } \\
4 \times 19.1\end{array}$} & $10 \%$ & 36.5 & $\begin{array}{l}\text { Hole elongation; } \\
\text { side material } \\
\text { tear-out }\end{array}$ & $\begin{array}{c}\text { No bending of bolts; } \\
\text { major charring around holes; } \\
\text { minor charring on un-exposed sides. }\end{array}$ \\
\hline 5.2 & & $10 \%$ & 43 & $\begin{array}{l}\text { Hole elongation; } \\
\text { cutting through }\end{array}$ & $\begin{array}{c}\text { No bending of bolts; } \\
\text { major charring around holes; } \\
\text { minor charring on un-exposed sides. }\end{array}$ \\
\hline 5.3 & & $29 \%$ & 19 & $\begin{array}{l}\text { Hole elongation; } \\
\text { cutting through }\end{array}$ & $\begin{array}{l}\text { No bending of bolts; } \\
\text { minor charring around holes; } \\
\text { minor charring on un-exposed sides. }\end{array}$ \\
\hline $5.4^{\ddagger}$ & & $29 \%$ & 34 & $\begin{array}{l}\text { Hole elongation; } \\
\text { cutting through }\end{array}$ & $\begin{array}{c}\text { No bending of bolts; } \\
\text { charring around holes; } \\
\text { minor charring on un-exposed sides }\end{array}$ \\
\hline
\end{tabular}

t: This specimen was protected by a single-layer of $15.9 \mathrm{~mm}$ Type $X$ gypsum board.

$\ddagger$ : This specimen was protected by a double-layer of $12.7 \mathrm{~mm}$ Douglas Fir plywood. 


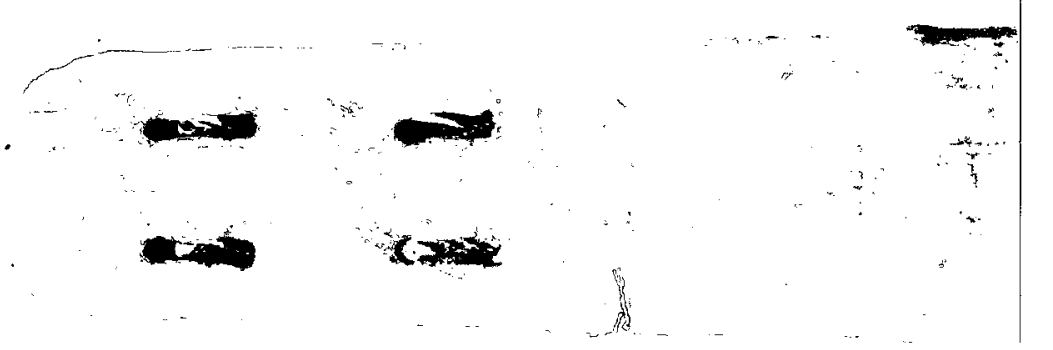

(2)

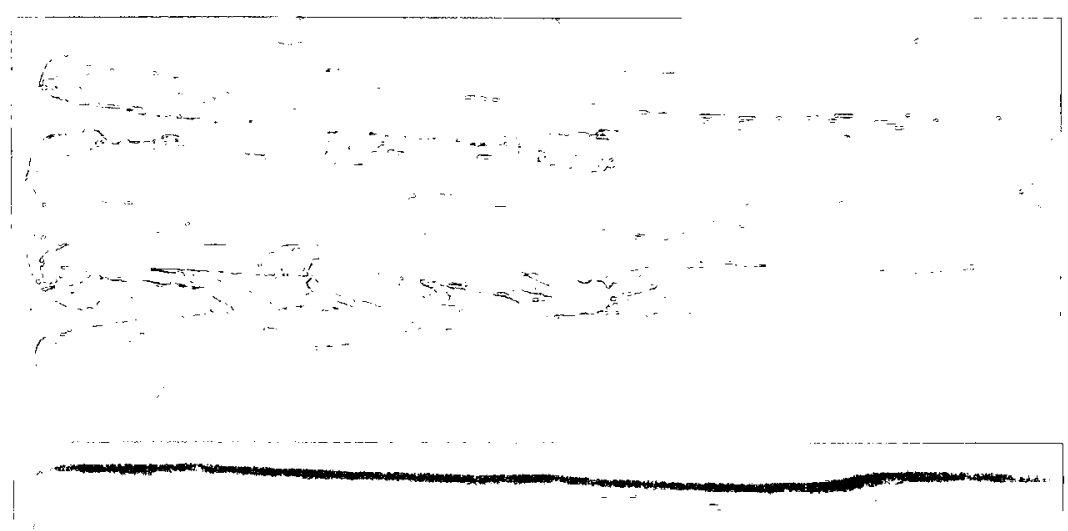

(b)
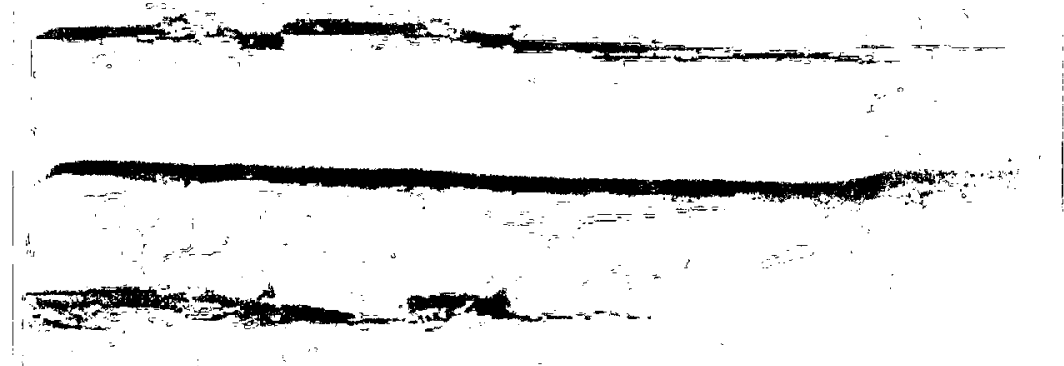

(e)

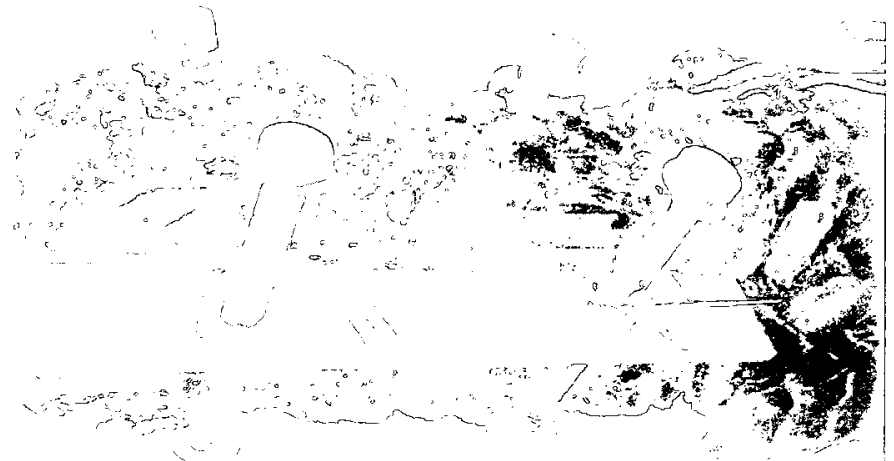

(d)

Figure 3.23 Typicen iminn 


\subsubsection{Charring rate}

Charring rate is a very important factor in fire safety design for timber structures because it is the un-charred wood that carries the applied load in fire. The charring rate is calculated by dividing the charred distance by the exposed time.

After the fire tests, char layers were removed and residual dimensions were measured at two locations. Figure 3.24 shows a typical specimen after char removal and the locations of two cross-sections for measuring. The cross-section A-A is located in the middle of the connection with the central steel plate and the cross-section B-B is located in the exposed solid wood part. Figure 3.25 gives the cross-section view of A-A and B-B.

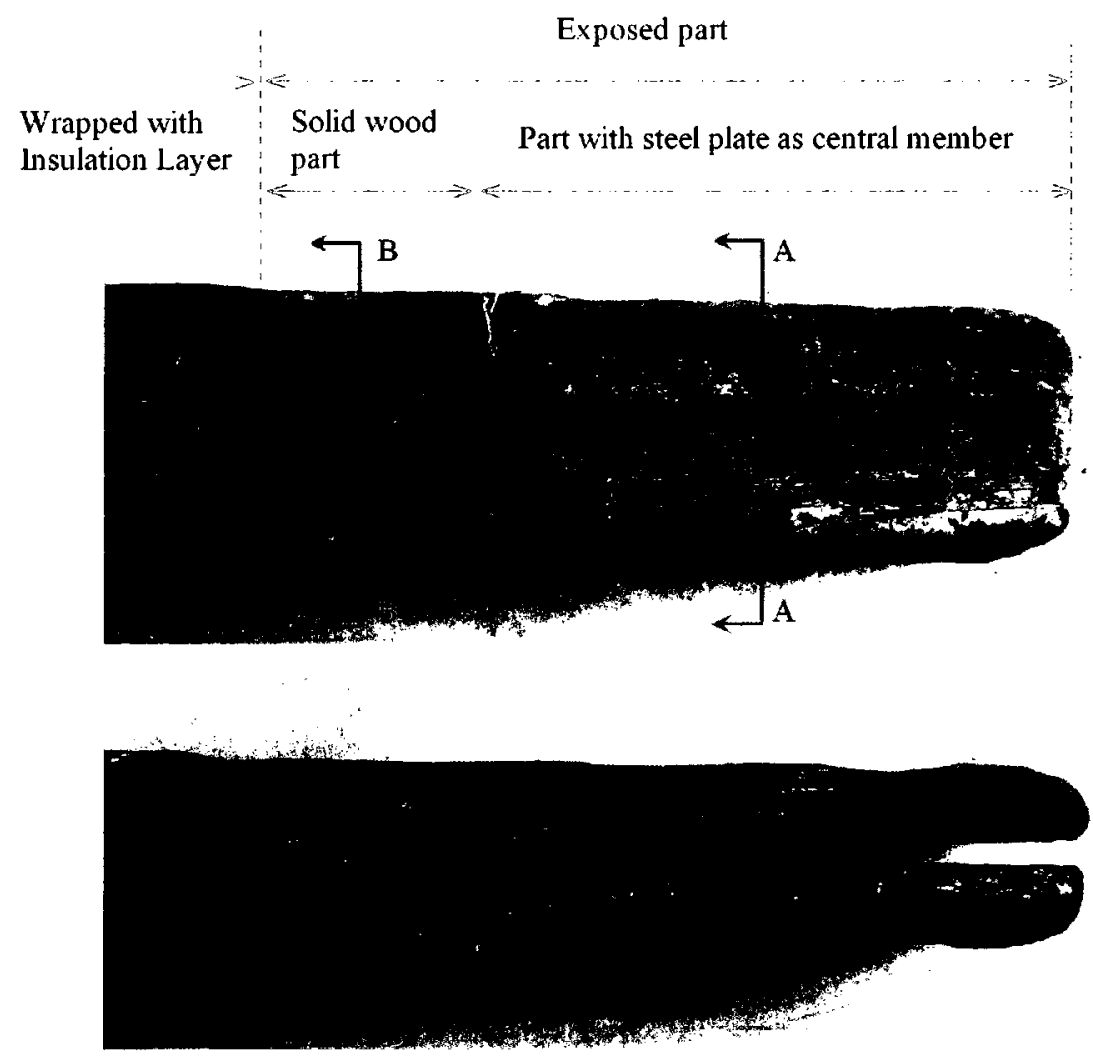

Figure 3.24 A typical specimen after the char was removed 


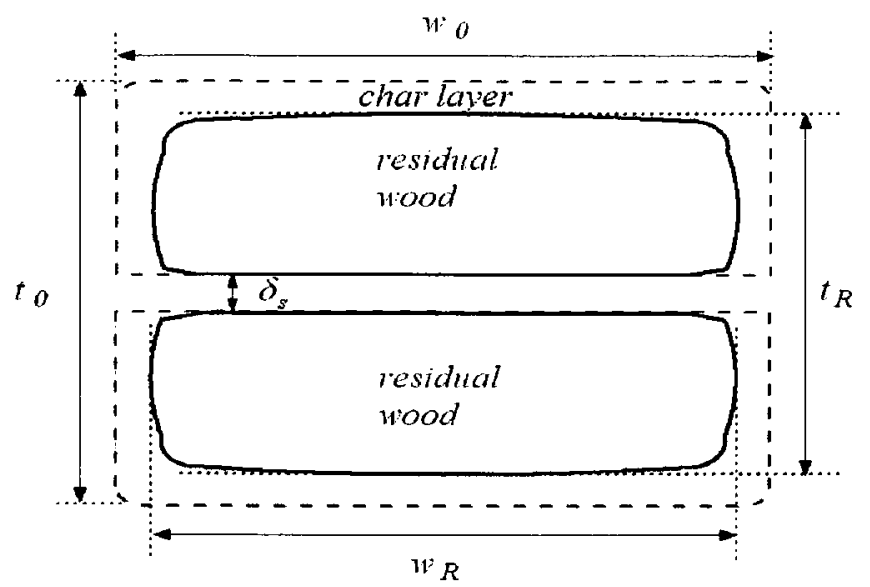

A) cross-setion A-A

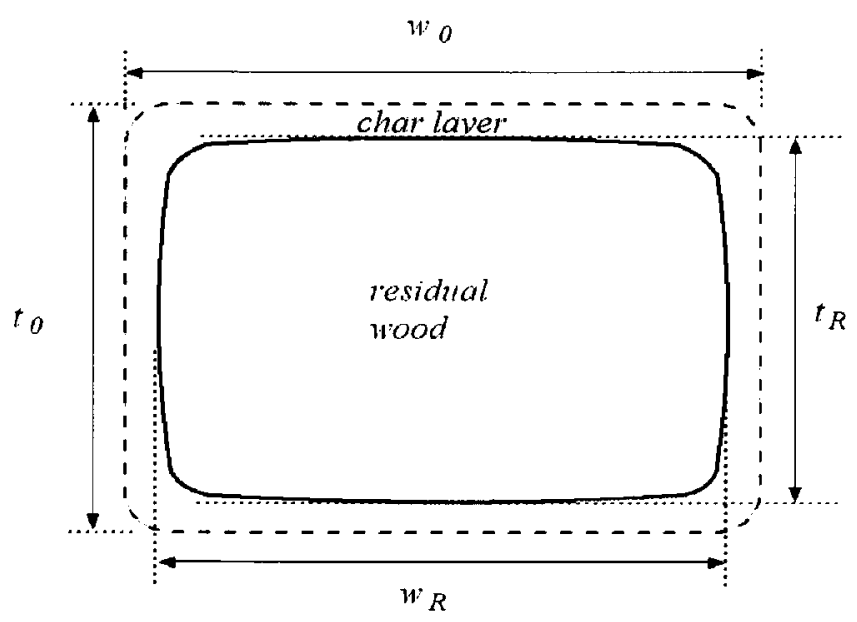

B) cross-setion B-B

Figure 3.25 Charring at both cross-section A-A and B-B

The charring rates at each cross-section in both thickness and width directions can be calculated as:

$$
\begin{aligned}
& \beta_{t}=\left(t_{0}-t_{R}\right) / 2 t_{f} \\
& \beta_{w}=\left(w_{0}-w_{R}\right) / 2 t_{f}
\end{aligned}
$$

where $t_{0}$ and $w_{0}$ are initial dimensions in the thickness and width direction, $t_{R}$ and $w_{R}$ are residual dimensions in the thickness and width direction, and $t_{f}$ is the exposure time. 
The charring rates were then calculated and summarized in Table 3.4. It has to be pointed out that due to the difficulty of stopping wood charring immediately after failure, the charring distances used to calculate the charring rates in Table 3.4 have already been corrected by subtracting the post-heating charring distances. A simple model was assumed to estimate the charring rate as a function of external heat flux (White 1996):

$$
\beta=0.0118 \dot{q}^{\prime \prime}+0.368
$$

where $\dot{q}^{\prime \prime}\left(\mathrm{kW} / \mathrm{m}^{2}\right)=$ external heat flux. However, it is difficult to know the heat flux to a specimen received from the furnace boundary. As a simplified assumption, the charring rate for the post heating period was assumed to be $0.4 \mathrm{~mm} / \mathrm{min}$ to correct the charring rates, by substituting zero external heat flux into Equation (3.2) and rounding up. Normally the post-heating duration was about 3-5 min.

As seen in Table 3.4, the charring rates in the cross-section A-A were averaged as 0.78 $\mathrm{mm} / \mathrm{min}$ and the charring rates in the cross-section $\mathrm{B}-\mathrm{B}$ were averaged as $0.71 \mathrm{~mm} / \mathrm{min}$. The charring rates in the cross-section A-A were higher than those in the cross-section BB. This is due to the fact that the steel plates (and bolts) conducted heat and enhanced the charring rate in the cross-section $\mathrm{A}-\mathrm{A}$. In addition, the charring rates in the width direction $\left(\beta_{w}\right)$ were found to be higher than those in the thickness direction $\left(\beta_{t}\right)$. Two reasons might contribute to this result: the surfaces with a smaller dimension (i.e. 130 $\mathrm{mm}$ ) were more influenced by the two-dimensional heat transfer; the surfaces with a smaller dimension $(130 \mathrm{~mm})$ were facing the burners. These reasons led to a larger $\beta_{w}$ than $\beta_{t}$. 
Table 3.4 Charring rates in fire tests

\begin{tabular}{|c|c|c|c|c|c|c|c|}
\hline \multirow{2}{*}{ Test \# } & \multirow{2}{*}{$\begin{array}{l}\text { Specimen } \\
\text { Information }\end{array}$} & \multirow{2}{*}{$\begin{array}{l}\text { Load } \\
\text { Ratio }\end{array}$} & \multirow{2}{*}{$\begin{array}{l}\text { Failure Time } \\
\quad(\min )\end{array}$} & \multicolumn{2}{|c|}{$\begin{array}{c}\text { Cross-section } \\
\text { A-A }\end{array}$} & \multicolumn{2}{|c|}{$\begin{array}{c}\text { Cross-section } \\
\text { B-B }\end{array}$} \\
\hline & & & & $\begin{array}{c}\beta_{l} \\
(\mathrm{~mm} / \mathrm{min})\end{array}$ & $\begin{array}{c}\beta_{w} \\
(\mathrm{~mm} / \mathrm{min})\end{array}$ & $\begin{array}{c}\beta_{t} \\
(\mathrm{~mm} / \mathrm{min})\end{array}$ & $\begin{array}{c}\beta_{w} \\
(\mathrm{~mm} / \mathrm{min})\end{array}$ \\
\hline 1.1 & \multirow{4}{*}{$\begin{array}{l}\text { SPF-L: } 2 @ 38 \times 140 \\
\quad \text { Bolt: } 2 \times 12.7\end{array}$} & $10 \%$ & 14.5 & 0.76 & 1.07 & 0.72 & 1.03 \\
\hline 1.2 & & $10 \%$ & 15 & 0.7 & 0.93 & 0.63 & 0.83 \\
\hline 1.3 & & $29 \%$ & 8 & 0.63 & 0.84 & 0.63 & 0.88 \\
\hline 1.4 & & $30 \%$ & 8.5 & 0.70 & 0.94 & 0.59 & 0.94 \\
\hline 2.1 & \multirow{3}{*}{$\begin{array}{l}\text { SP-G: } 130 \times 190 \\
\text { Bolt: } 2 \times 12.7\end{array}$} & $11 \%$ & 28 & 0.67 & 0.90 & 0.63 & 0.68 \\
\hline 2.2 & & $18 \%$ & 22.5 & 0.79 & 0.81 & 0.64 & 0.70 \\
\hline 2.3 & & $29 \%$ & 17.5 & 0.77 & 0.85 & 0.68 & 0.68 \\
\hline 3.1 & \multirow{2}{*}{$\begin{array}{c}\text { SP-G: } 130 \times 190 \text {; } \\
\text { Bolt: } 1 \times 19.1\end{array}$} & $11 \%$ & 27 & 0.74 & 0.98 & 0.71 & 0.94 \\
\hline 3.2 & & $32 \%$ & 15 & 0.67 & 0.77 & 0.61 & 0.62 \\
\hline 4.1 & \multirow{3}{*}{$\begin{array}{l}\text { SP-G: } 130 \times 190 \text {; } \\
\text { Bolt: } 4 \times 19.1\end{array}$} & $10 \%$ & 26 & 0.73 & 0.73 & 0.67 & 0.71 \\
\hline 4.2 & & $30 \%$ & 14 & 0.67 & 0.80 & 0.67 & 0.75 \\
\hline $4.3^{\dagger}$ & & $30 \%$ & 51 & - & - & - & - \\
\hline 5.1 & \multirow{4}{*}{$\begin{array}{l}\text { SP-G: } 2 @ 80 \times 190 \\
\quad \text { Bolt: } 4 \times 19.1\end{array}$} & $10 \%$ & 36.5 & 0.69 & 0.82 & 0.67 & 0.78 \\
\hline 5.2 & & $10 \%$ & 43 & 0.65 & 0.90 & 0.63 & 0.80 \\
\hline 5.3 & & $29 \%$ & 19 & 0.68 & 0.71 & 0.59 & 0.68 \\
\hline $5.4^{\ddagger}$ & & $29 \%$ & 34 & - & - & - & - \\
\hline & Average & & & 0.70 & 0.86 & 0.64 & 0.78 \\
\hline
\end{tabular}

: This specimen was protected by a single-layer of $15.9 \mathrm{~mm}$ Type $\mathrm{X}$ gypsum board.

¥: This specimen was protected by a double-layer of $12.7 \mathrm{~mm}$ Douglas Fir plywood.

Note: Charring rates of $\# 4.3$ and $\# 5.4$ are not measured because they were protected. 


\subsubsection{Discussion}

This subsection discusses the effect of different factors, i.e. load ratio, wood member thickness, bolt diameter, edge distance and protection, on the fire performance of bolted WSW connections.

\subsubsection{Effect of Load Ratio}

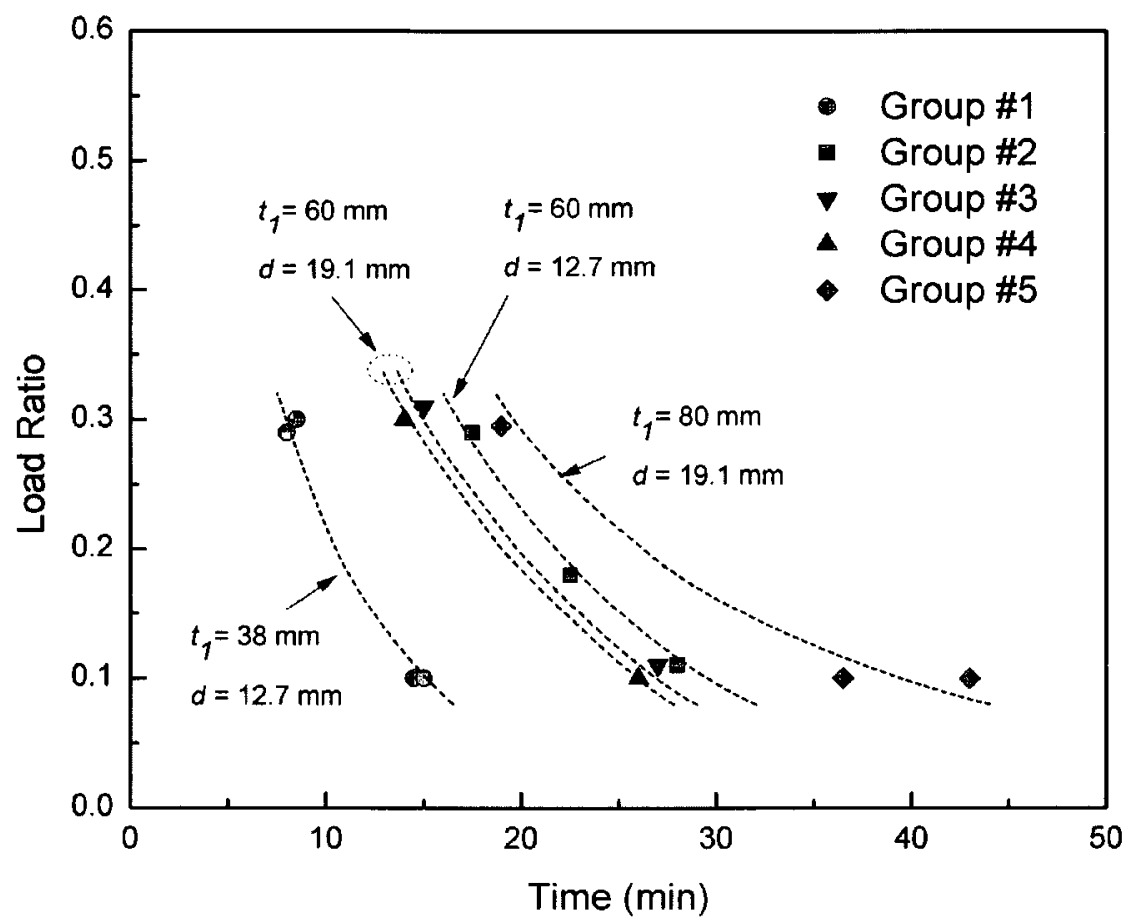

Figure 3.26 Test results of WSW Group \#1-5

Figure 3.26 shows the relationship between load ratios and failure times for all 5 groups. Symbols are test results and dash lines are possible regression lines for each group. It can be clearly seen that specimens loaded at $10 \%$ had a better fire performance than specimens loaded at $30 \%$. Reducing the load ratio from $30 \%$ to $10 \%$ led to about a $7 \mathrm{~min}$ increase of the fire resistance for Group \#1. For Group \#2-4 with $60 \mathrm{~mm}$ thick side members, the increased fire resistance was about 11-12 $\mathrm{min}$ if the load ratio changed from 
$30 \%$ to $10 \%$. In Group \#5, the increase was found to be about $20 \mathrm{~min}$ if the load ratio is reduced from $30 \%$ to $10 \%$.

\subsubsection{Effect of Wood Side Member Thickness}

Figure 3.26 also shows the effect of wood side member thickness on the fire performance of bolted WSW connections. Specimens with thicker wood members had better fire resistance. For example, at the load ratio of $10 \%$, the specimens in Group $\# 2(60 \mathrm{~mm}$ thick) resisted about $15 \mathrm{~min}$ more than the specimens in Group \#1 (38 $\mathrm{mm}$ thick). Similarly, at the same load ratio of $30 \%$, the specimens in Group \#5 (80 mm thick) had about $10 \mathrm{~min}$ more fire resistance than the specimen in Group \#3 or \#4 (60 mm thick). Plus, the specimens in Group \#5 have high load capacities. If the same load level is applied, a specimen in Group \#5 is actually loaded in lower load ratios and will achieve much higher fire resistance than a specimen in Group \#3 or \#4.

\subsubsection{Effect of Bolt Diameter}

In previous research, the effect of fastener diameter has not been considered. However, the bolt diameter played a role on the fire resistance of timber connections, as seen from Group \#2 and \#4. These two groups had the same wood thickness $(60 \mathrm{~mm})$ and bolt numbers (4), but different bolt diameters (12.7 mm vs. $19.1 \mathrm{~mm})$. As shown in Figure 3.26 , the difference in the fire resistance at the same load ratio between Group \#2 and \#4 was found to be about 1-3 min. This was not significant. However, they were loaded at different load levels. The reference loads (ultimate load capacities) were greatly different for Group \#2 and Group \#4 (115 kN vs. $227 \mathrm{kN})$. Therefore, increasing the bolt diameter could reduce the load ratio considerably and accordingly this could improve the fire 
performance of a connection. The influence of the number of bolts was insignificant as seen from Group \#3 and \#4 (difference within $1 \mathrm{~min}$ ).

\subsubsection{Effect of Edge Distance}

Test \#5.1 and Test \#5.2 were designed to study the effect of the initial edge distance of wood. The initial edge distance was $47.5 \mathrm{~mm}$ (2.5d) for specimen \#5.1, and $66.5 \mathrm{~mm}$ (3.5d) for specimen \#5.2. The test results showed that with the extra edge distance, the fire resistance increased from $36.5 \mathrm{~min}$ to $43 \mathrm{~min}$ for Test \#5.2. It was observed that the specimen in Test \#5.1 failed due to insufficient edge material in the fire test.

At ambient temperature, $1.5 d$ edge distance is sufficient to prevent the failure of edge wood material. However, under fire exposure, the edge distance is reduced due to charring and the connection will fail because there is not sufficient edge material to carry the load. Thus, to satisfy a specified fire-resistance rating, the minimum of the initial edge distance must be increased.

If we assume an edge distance of $1.5 d$ is also critical in a fire exposure, and the wood connection is required to resist a $45 \mathrm{~min}$ standard fire, the initial edge distance might be increased to $1.5 \times 19 \mathrm{~mm}+45 \mathrm{~min} \times 0.8 \mathrm{~mm} / \mathrm{min}=65 \mathrm{~mm}$ for bolt diameter $d=19 \mathrm{~mm}$ and charring rate $\beta=0.8 \mathrm{~mm} / \mathrm{min}$.

\subsubsection{Effect of Protection}

Test \#4.3 was protected with a single-layer of $15.9 \mathrm{~mm}$ Type X gypsum board. The test result showed that the protection improved the fire resistance by about $37 \mathrm{~min}$, compared with Test \#4.2. The $140 / 180^{\circ} \mathrm{C}$ finish rating was found to be about $23 \mathrm{~min}$ and the time to 
reach a temperature of $300^{\circ} \mathrm{C}$ behind the protective membranes was $30 \mathrm{~min}$. During the test, the gypsum boards showed cracks but did not fall off until the final failure of the connection.

Test \#5.4 showed that a double-layer of $12.7 \mathrm{~mm}$ DF plywood membranes improved the fire resistance by about $15 \mathrm{~min}$, compared with Test $\# 5.3$. The $140 / 180^{\circ} \mathrm{C}$ finish rating was found to be about $16 \mathrm{~min}$ and the time to reach a temperature of $300^{\circ} \mathrm{C}$ behind the protection was $21 \mathrm{~min}$.

\section{White's Results}

As a comparison, results produced from a series of fire-resistance tests of wood members with directly applied protection are presented here. In White's paper (White 2009), wood members were loaded in tension and exposed to fire with a protection of either $15.9 \mathrm{~mm}$ Type X gypsum boards or $12.7 \mathrm{~mm}$ plywood boards. It was reported that the protection of a single-layer of $15.9 \mathrm{~mm}$ Type $\mathrm{X}$ gypsum board improved the fire resistance ranging from $25 \mathrm{~min}$ to $40 \mathrm{~min}$, with an average of $33 \mathrm{~min}$. The $140 / 180^{\circ} \mathrm{C}$ finish ratings were between 21 and $23 \mathrm{~min}$, with an average of $22 \mathrm{~min}$. The times to reach $300^{\circ} \mathrm{C}$ between the gypsum board and the wood member ranged from 28 to $30 \mathrm{~min}$, with an average of 29 min. For a double-layer of $12.7 \mathrm{~mm}$ plywood protection, the fire-resistance improvement was $15 \mathrm{~min}$, the $140 / 180^{\circ} \mathrm{C}$ finish rating was $15 \mathrm{~min}$, and the time to reach $300^{\circ} \mathrm{C}$ between the plywood and the wood member was $20 \mathrm{~min}$.

Based on the results, it can be concluded that, for both timber connections and timber beams, the fire resistance improvement, the $140 / 180^{\circ} \mathrm{C}$ finish rating and the time to reach $300^{\circ} \mathrm{C}$ behind the protection are found to be close if the same protective membranes are 
used. This information is a very positive sign because the same assigned values for protective membranes in the Component Additive Model (CAM) might be used for both timber connections and structural timber members. The Component Addictive Model estimates the fire resistances of protected wood elements by adding assigned values of different types of membranes to the fire resistances of unprotected wood elements. 


\subsection{Fire-Resistance Tests of SWS Connections}

\subsubsection{Test Specimens}

Similar to the WSW connections, all the tested SWS connections satisfied the Canadian standard CAN/CSA-O86-09 (2009). The SWS connections were fabricated using two steel side members sandwiching a timber center member. A typical bolted SWS connection is shown in Figure 3.27.

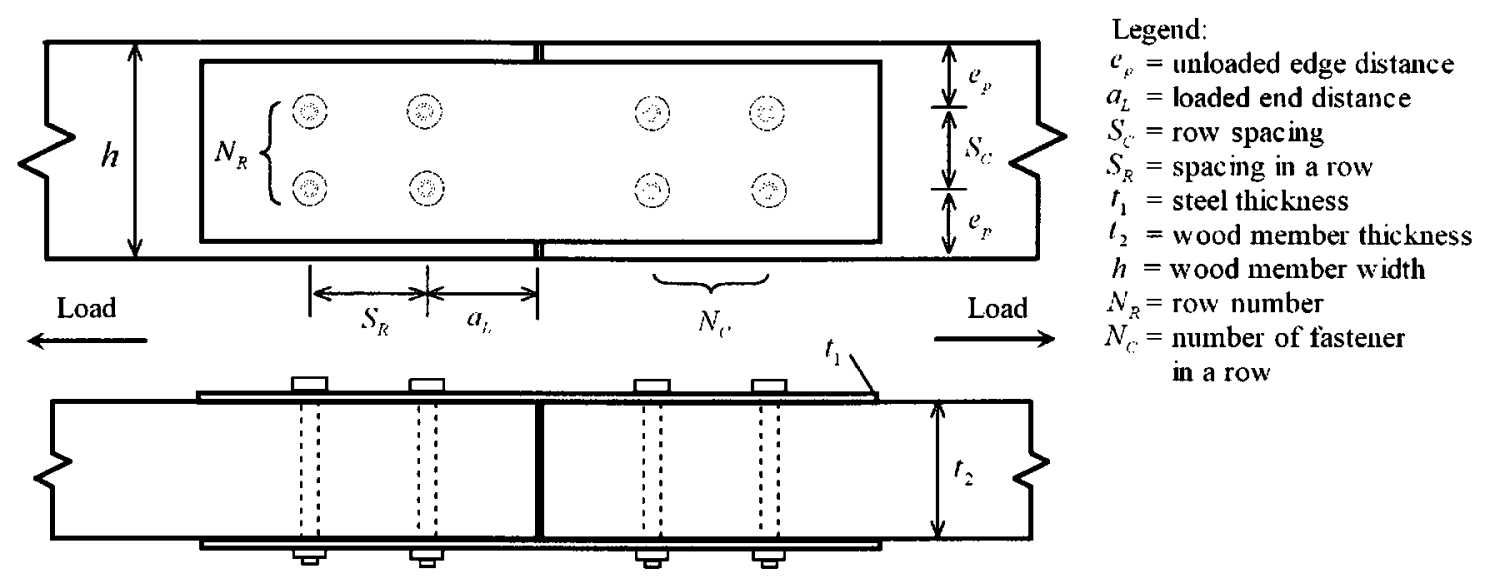

Figure 3.27 Bolted steel-wood-steel connection

Wood members were Douglas fir glulam timber of 24f-EX grade, $80 \mathrm{~mm}$ or $130 \mathrm{~mm}$ thick and $190 \mathrm{~mm}$ wide. All wood members had been conditioned at about $20^{\circ} \mathrm{C}$ and $60 \%$ relative humidity $(\mathrm{RH})$, and the moisture content and density were measured prior to the tests. The moisture content was found to be about $11 \%$ and the density varied between 534 and $577 \mathrm{~kg} / \mathrm{m}^{3}$, with a mean value of $555 \mathrm{~kg} / \mathrm{m}^{3}$. Bolts used in fabricating the connections had diameter of $12.7 \mathrm{~mm}(1 / 2 ")$ or $19.1 \mathrm{~mm}(3 / 4 ")$. The steel plates were 9.5 $\mathrm{mm}$ thick as side members. There were two groups of specimens and configurations are summarized in Table 3.5. 
Table 3.5 Steel-wood-steel specimen configurations

\begin{tabular}{|c|c|c|c|c|c|c|c|c|c|c|c|c|}
\hline \multirow{2}{*}{ 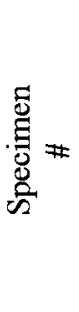 } & \multirow{2}{*}{ 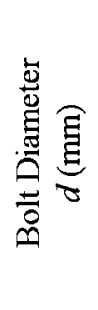 } & \multirow{2}{*}{ 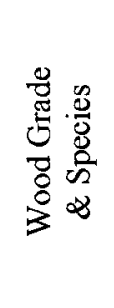 } & \multirow{2}{*}{ 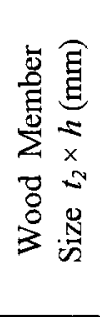 } & \multirow{2}{*}{ 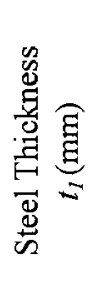 } & \multirow{2}{*}{ 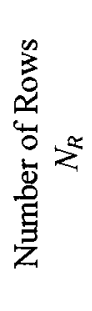 } & \multirow{2}{*}{ 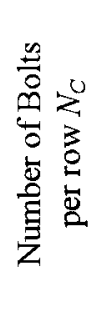 } & \multirow{2}{*}{ 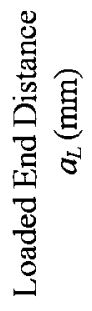 } & \multirow{2}{*}{ 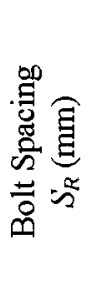 } & \multirow{2}{*}{ 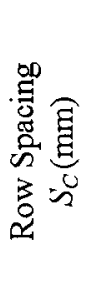 } & \multicolumn{2}{|c|}{$\begin{array}{c}\text { Load } \\
\text { Capacity } \\
(\mathrm{kN})\end{array}$} & \multirow{2}{*}{ 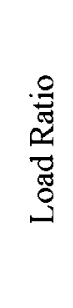 } \\
\hline & & & & & & & & & & $\begin{array}{l}8 \\
8 \\
0\end{array}$ & 总 & \\
\hline $\begin{array}{l}1.1 \\
1.2 \\
1.3^{\dagger} \\
\end{array}$ & 12.7 & $\begin{array}{c}\text { 24f-EX } \\
\text { D.fir }\end{array}$ & $\begin{array}{l}80 \times \\
190\end{array}$ & 9.5 & 2 & 2 & $10 \mathrm{~d}$ & $10 \mathrm{~d}$ & $5 d$ & 68 & 169 & $\begin{array}{l}10 \% \\
30 \% \\
30 \% \\
\end{array}$ \\
\hline $\begin{array}{l}2.1 \\
2.2 \\
2.3^{\ddagger}\end{array}$ & 19.1 & $\begin{array}{c}\text { 24f-EX } \\
\text { D.fir }\end{array}$ & $\begin{array}{c}130 \times \\
190\end{array}$ & 9.5 & 2 & 2 & $10 \mathrm{~d}$ & $10 \mathrm{~d}$ & $5 d$ & 148 & 404 & $\begin{array}{l}10 \% \\
20 \% \\
20 \% \\
\end{array}$ \\
\hline
\end{tabular}

$\dagger$ : This specimen was protected by a single-layer of $15.9 \mathrm{~mm}$ Type $\mathrm{X}$ gypsum board.

‡: This steel plate and bolts were protected by $2 \mathrm{~mm}$ thick intumescent coating.

\section{Load Ratio}

Similar to the WSW connections, the SWS connection specimens should be tested with a tension load that is as close to the factored resistance of the specimen as possible in accordance with the CAN/CSA-O86-09 (2009), and the reduced loads are also allowed to be used in fire-resistance tests and the load conditions should be identified and reported (CAN/ULC-S101 2007).

As discussed, the ratio between the Canadian code design load and the ultimate load capacity for bolted SWS connections was found to be about 0.3 (see subsection 2.3.1.3). Therefore, a load ratio of $30 \%$ was planned as the maximum load ratio for the specimens. However, for Group \#2, only a load ratio of $20 \%$ was planned. This was due to the limitation of the hydraulic cylinder capacity. In addition, a reduced load ratio, $10 \%$, was also chosen to investigate the effect of load ratio on the fire performance of SWS connection. The planned load ratios for each test specimen are shown Table 3.5. In total, there were 6 tests, 4 unprotected and 2 protected. 


\section{Protection}

As shown in Table 3.5, two protected specimens were tested in this study. For Test \#1.3, a single-layer of $15.9 \mathrm{~mm}\left(5 / 8^{\prime \prime}\right)$ thick Type $X$ gypsum board was applied, and for Test \#2.3, intumescent paint $(2 \mathrm{~mm})$ was applied for the steel plates and bolts.

Figure 3.28 illustrates the example of installing protective membranes for Test \#1.3. The wood strips $(38 \times 30 \mathrm{~mm})$ were cut from $2 \times 3$ SPF \#2 lumber. The screws used to fasten furring strips were type $\mathrm{S}$ wall board screws, $57 \mathrm{~mm}(2-1 / 4 ")$ long and placed $20 \mathrm{~mm}$ away from wood edges. A single-layer of membrane was installed to the strips in the width direction using $41 \mathrm{~mm}\left(1-5 / 8^{\prime \prime}\right)$ long type $\mathrm{S}$ wall board screws; while in the thickness direction, a single membrane layer was installed directly to the specimen using $41 \mathrm{~mm}\left(1-5 / 8^{\prime \prime}\right)$ type $\mathrm{S}$ wall board screws, overlapping the protective membrane in the width direction.

Figure 3.29 shows the specimen $\# 2.3$, protected by the intumescent paint. A coating thickness of $2 \mathrm{~mm}$ was applied to the exposed parts of the steel plates and bolt heads/nuts. A report provided by the intumescent paint manufacture (PyroLogistix ${ }^{\mathrm{TM}}$ ) shows that a $2.4 \mathrm{~mm}$ thick coating met a fire resistance rating of about $90 \mathrm{~min}$ for a structural steel column, which is well above the $45 \mathrm{~min}$ or 1 hour requirements for timber connections. Therefore, a thickness of $2 \mathrm{~mm}$ was applied to the steel plates and bolts. Moreover, in a research of the fire performance of nailed timber connections with steel side plates, a 2 mm thick intumescent paint was also applied as protection (Frangi 2009). 


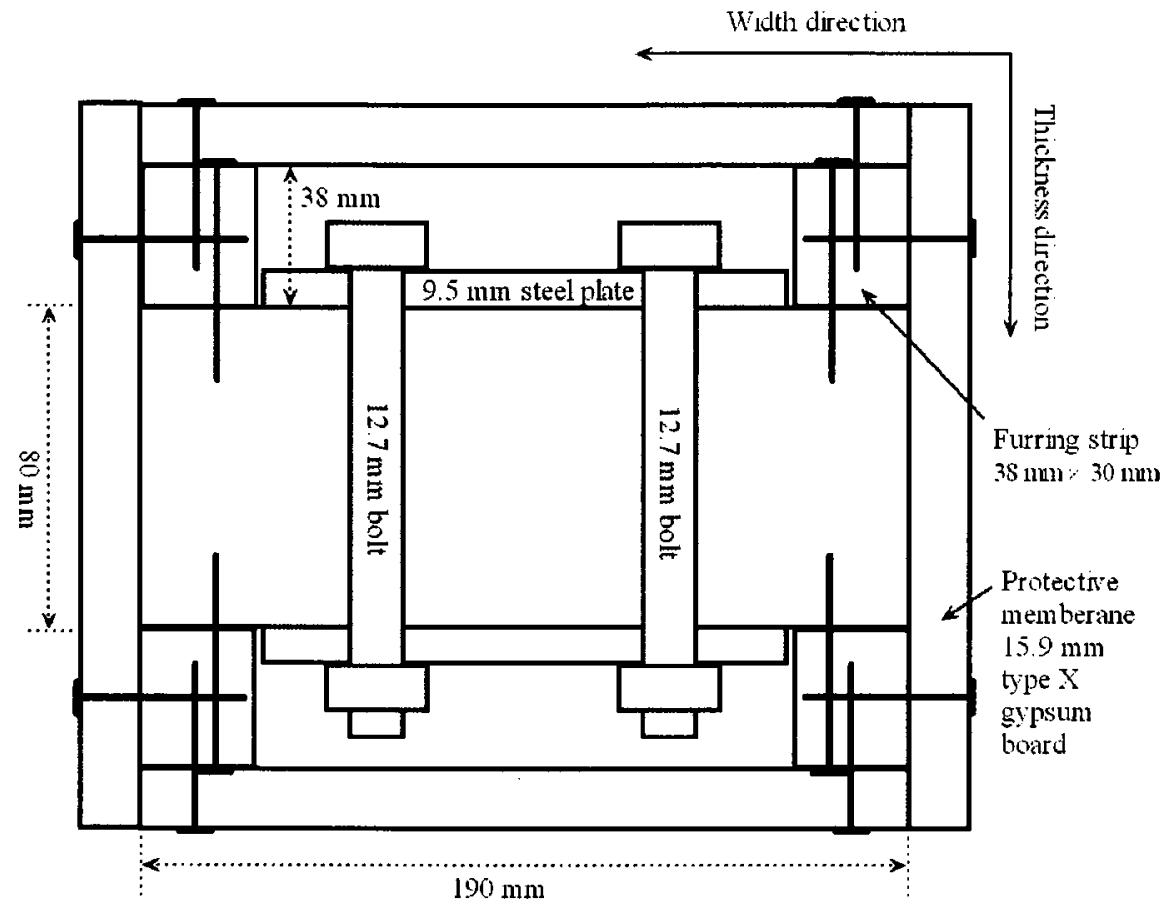

Figure 3.28 Schematic of SWS connection with protective membranes: \#1.3

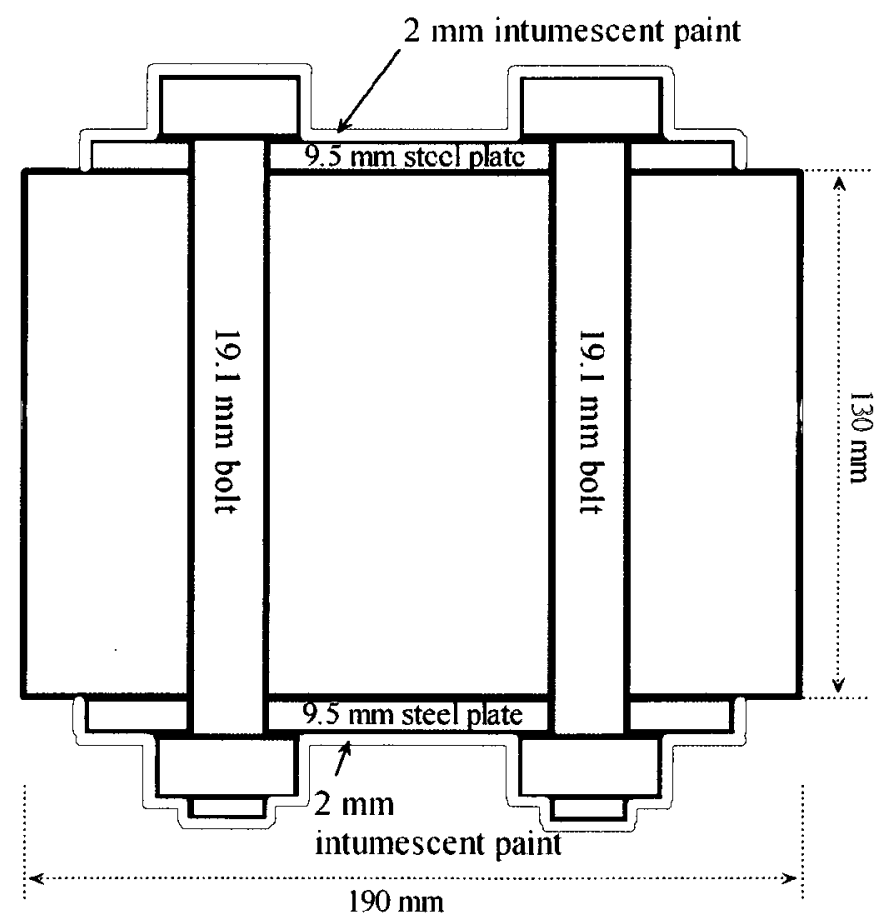

Figure 3.29 Schematic of SWS connection with intumescent paint: \#2.3 


\subsubsection{Test Procedure}

Similar to testing WSW connections, the procedure to conduct a fire-resistance test for bolted SWS connections is given as below:

1. Install the specimen in the furnace;

2. Connect the load system, thermocouples and LVDTs to the data acquisition system;

3. Apply the pre-tensile load at the designated load ratio for more than $20 \mathrm{~min}$;

4. Ignite the fire and sustain the load level until failure;

5. Shut down the propane burners immediately after the failure;

6. Stop charring in wood members by spraying water to the specimen.

Failure was assumed to occur when the specimen could not withstand the applied load, or the load dropped with no recovery in the specimen. After a fire test, the char was removed and the residual dimensions were recorded for the calculation of the charring rate. Again, due to the difficulty of immediately removing the specimen from the furnace after the failure, a correction must be made when the charring rate was calculated. 


\subsubsection{Test Results}

In this subsection, furnace temperature, load, displacement, specimen temperature, failure time, failure mode, and charring rate are presented for bolted SWS connections.

Figure 3.30 shows a typical specimen in the furnace, before and after a test. The connection zone and an additional part of solid wood were exposed to fire, and the rest part of solid wood was insulated with mineral blankets, as seen in Figure 3.30 (left). Figure 3.31 shows a typical specimen after the char was removed. The failure was mainly due to the wood members, but the bolts also had considerable bending deformations.

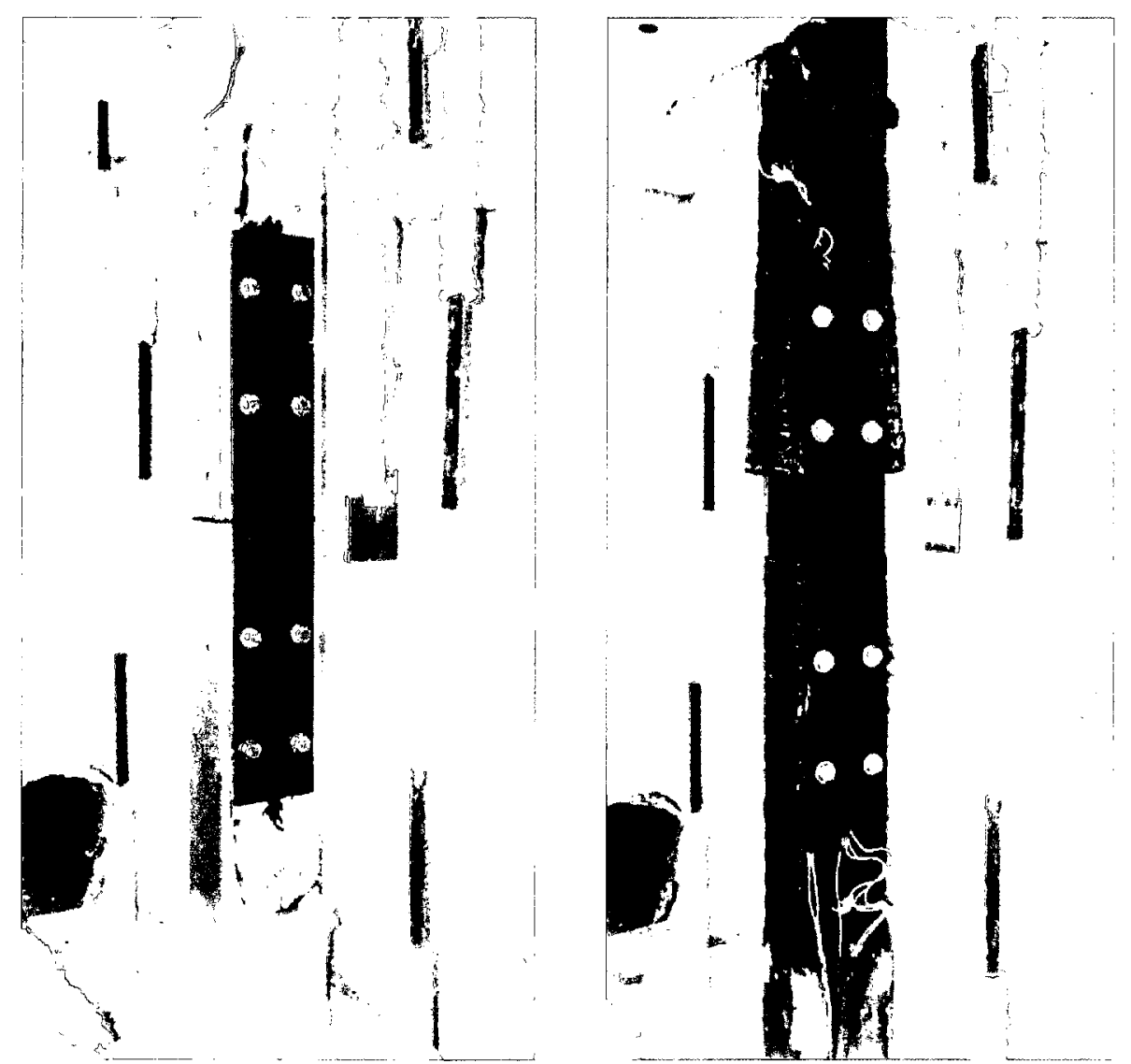

Figure 3.30 A typical specimen before and after the fire test, Test $\# 2.2$ 


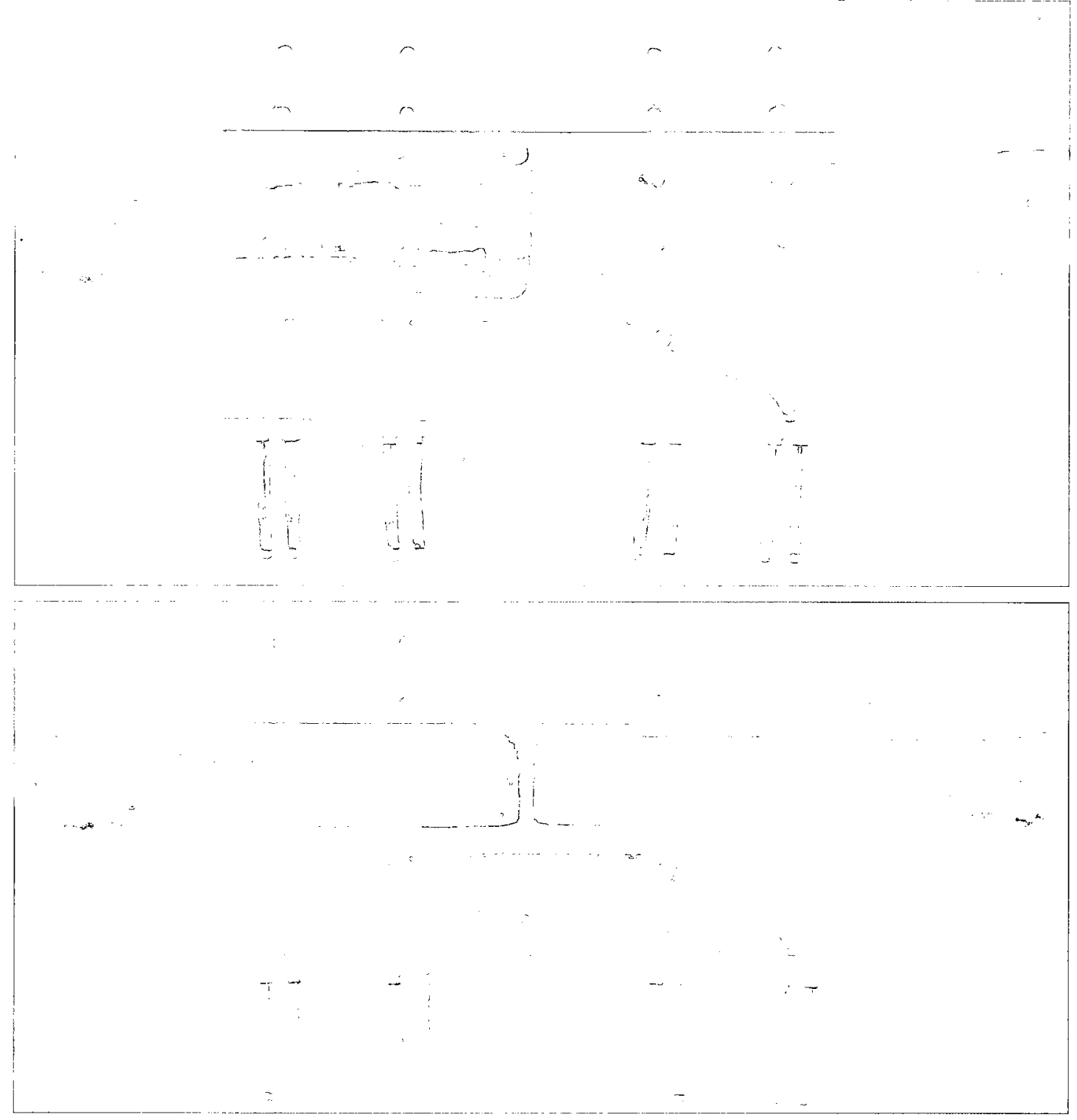

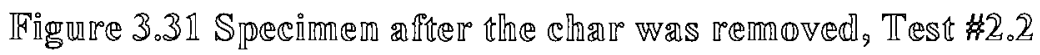




\subsubsection{Furnace Temperature}

As an example, furnace temperature curves averaged from 6 shielded thermocouples (TC) and 2 plate thermometers (PT) are plotted in Figure 3.32 for Test \#2.1. The average TC temperature curve followed the standard curve quite well. The average PT curve showed slightly higher values than the TC curve throughout the test, similar to the WSW connection tests. The curves decreased after $23.5 \mathrm{~min}$ when the specimen failed and the burners were turned off.

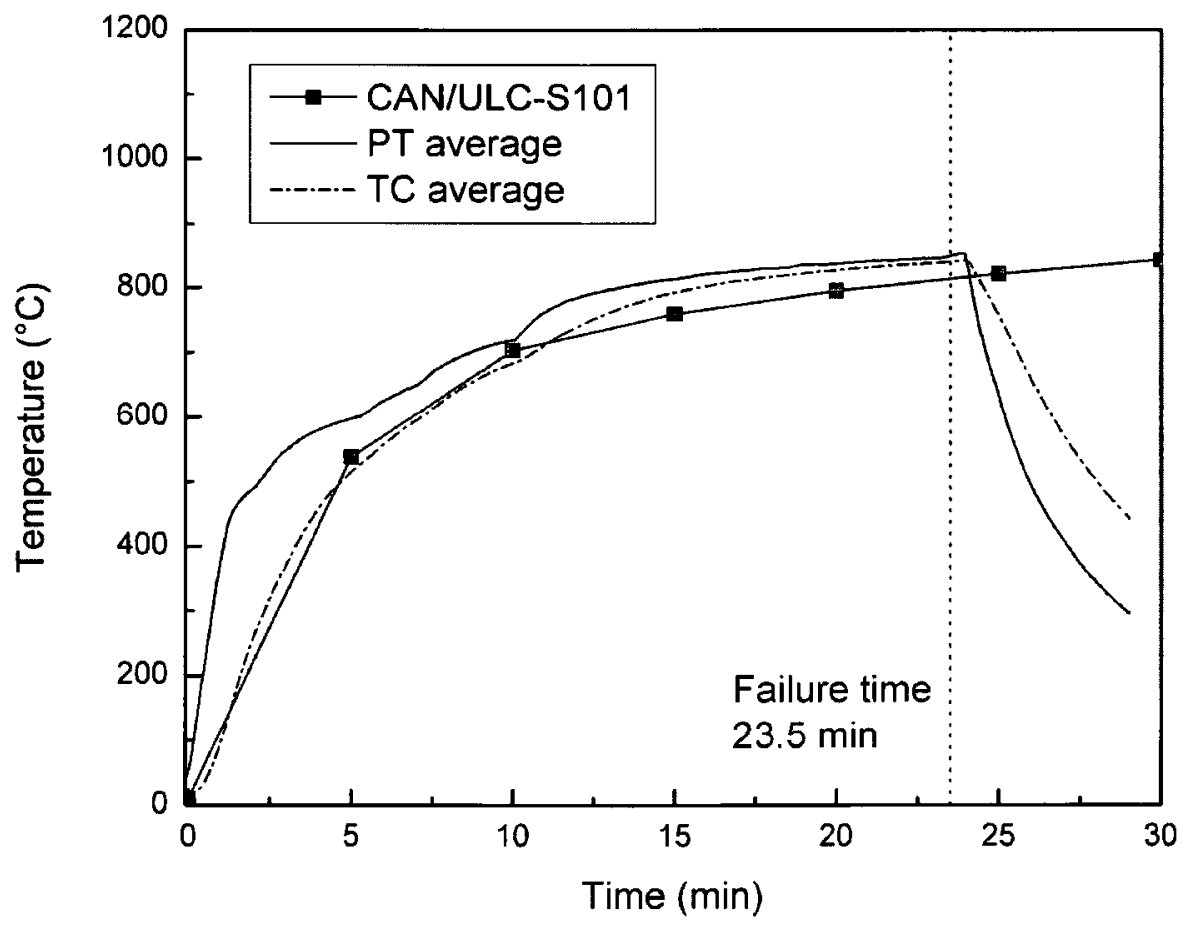

Figure 3.32 A typical plot of furnace temperature, Test \#2.1 


\subsubsection{Load and Displacement}

The load and displacement curves are plotted in Figure 3.33 for Test \#2.2 as an example. The averaged applied load during the test was $75 \mathrm{kN}$. At 15.5 min when the specimen failed, the load curve dropped rapidly without recovery while the displacement curve increased rapidly. The hydraulic pump was stopped after the specimen failed and the displacement curve experienced a plateau after failure, similar to the WSW connection tests.

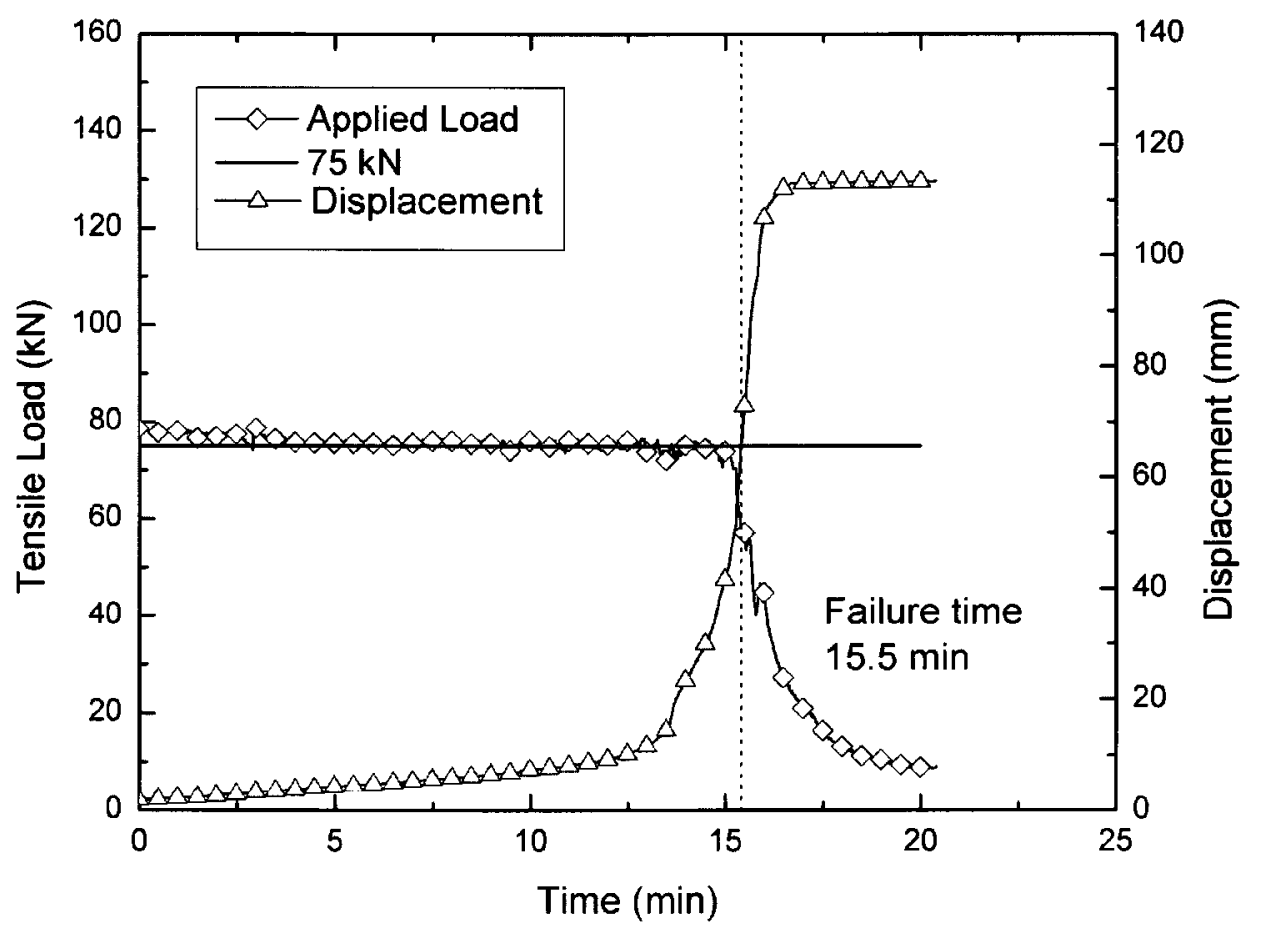

Figure 3.33 A typical plot of applied load and specimen displacement, Test \#2.2 


\subsubsection{Specimen Temperature}

Figure 3.34 shows the thermocouple locations for the specimens in Group \#1. Thermocouples $\mathrm{T} 0-\mathrm{T} 7$ were placed in the top part of the specimen and thermocouples B0B7 were located in the bottom part, symmetrically. Thermocouples T1-3 and B1-3 were placed on bolts and thermocouples T4-7 and B4-7 were placed in wood. T0 and B0 were placed at the interface between the wood and the steel plate. The thermocouple locations for each group are given in Appendix D.

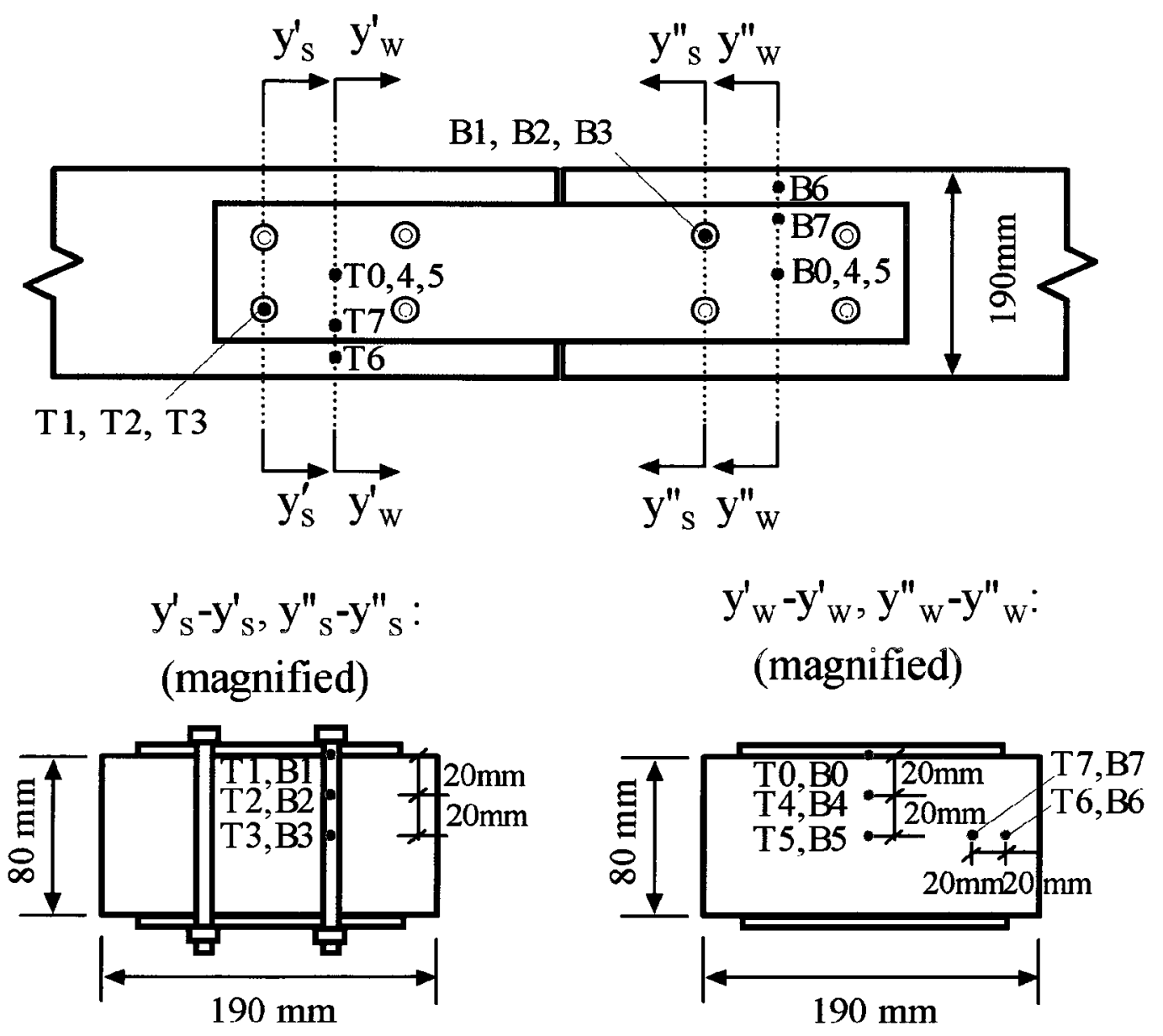

Figure 3.34 Thermocouple locations for Group \#1 
Figure 3.35 shows the measured temperature histories in bolts for Test \#1.1. Similar to WSW connections, the temperature measured in the top bolt was found to be slightly higher than the temperature measured in the bottom bolt, but the difference was not significant. The temperature difference between $\mathrm{T} 2 / \mathrm{B} 2$ and $\mathrm{T} 3 / \mathrm{B} 3$ was small and this means that the temperature gradient along the bolt shank was not as large as that of WSW connections. This is probably because the exposed area was very large compared to the bolt shank area. Thus, the heat loss to wood along the bolt shank was not of the same magnitude to the heat conducted from the exposed steel plates.

For B2 and B3 in Figure 3.35, the temperature curves dropped at about $11 \mathrm{~min}$. This is probably because the thermocouples lost perfect contact with the bolt due to the deformation that occurred in the bolt.

Figure 3.36 shows the measured temperature histories in wood members for Test \#1.1. Thermocouples $\mathrm{T} 0 / \mathrm{B} 0$, located between the steel plates and wood members, showed a faster increase of the temperature than those thermocouples within the wood members. Thermocouples T4/B4 and T5/B5 measured lower temperatures than the thermocouples T6/B6 and T7/B7. This is mainly because T4/B4 and T5/B5 were located under the steel plates, and also because the thickness-wise surfaces $(80 \mathrm{~mm})$ were facing the burners. The wood temperature measured in the top part was found to be slightly higher than the wood temperature measured in the bottom part, but the difference was not significant. 


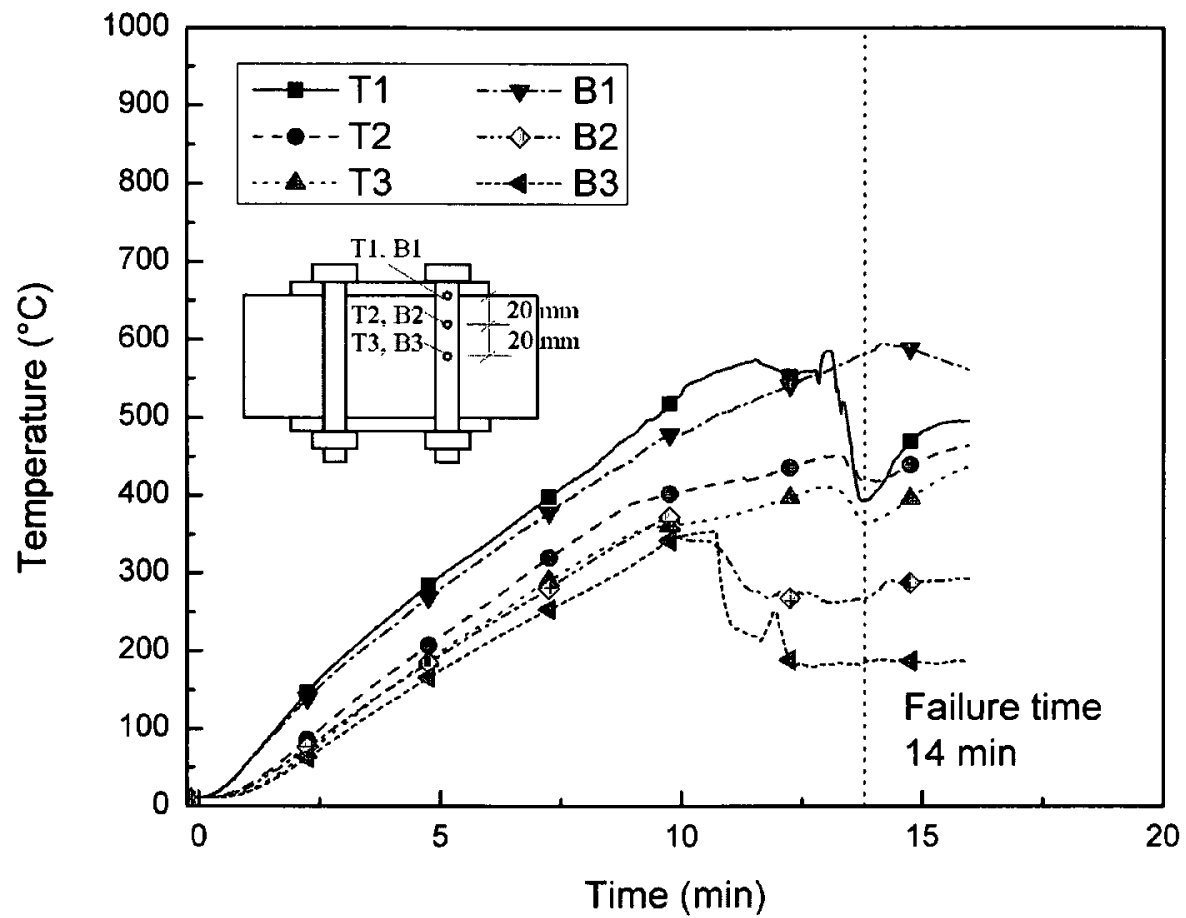

Figure 3.35 Bolt temperature histories for Test \#1.1

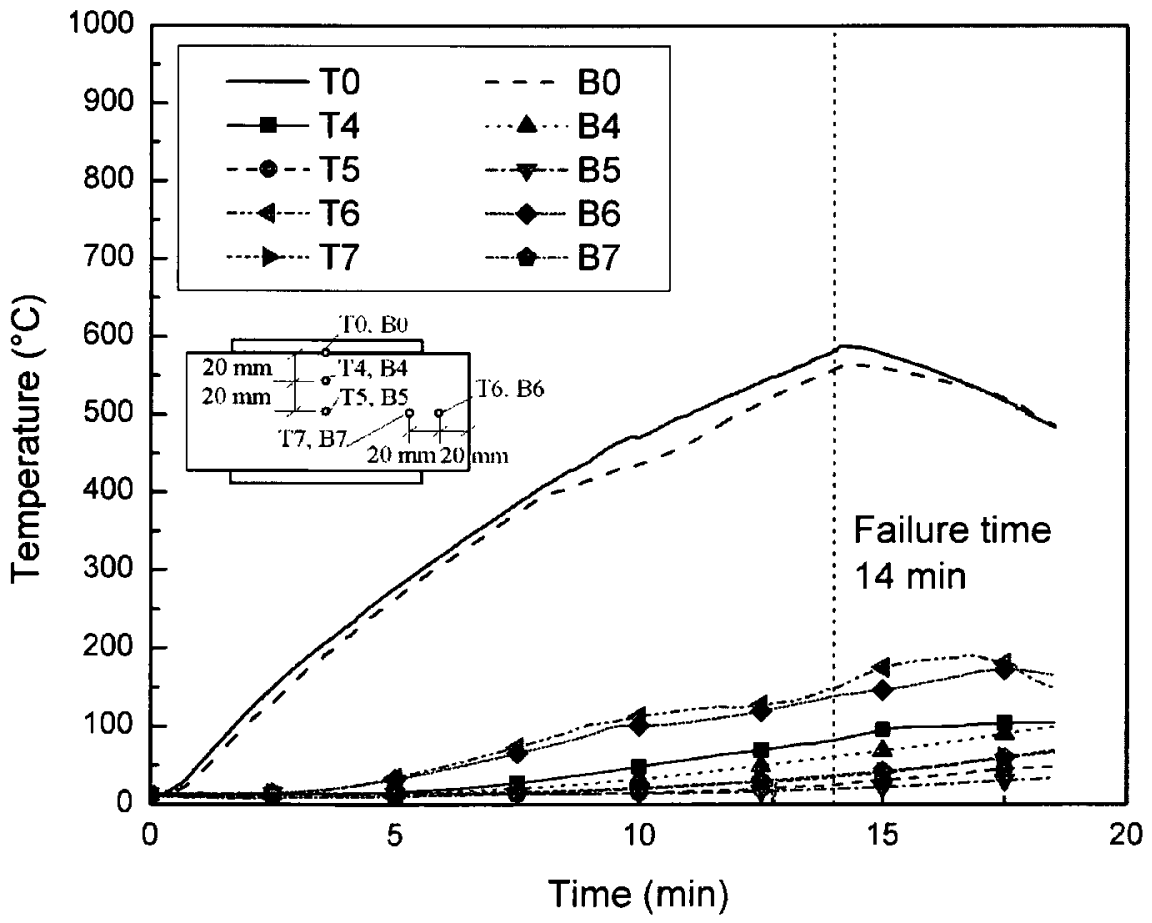

Figure 3.36 Wood temperature histories for Test \#1.1 
Figure 3.37 shows the measured temperature histories in bolts for Test \#1.3, protected by a single-layer of $15.9 \mathrm{~mm}$ Type X gypsum board. Within the first $25 \mathrm{~min}$, the bolt temperatures increased very slowly and remained lower than about $120^{\circ} \mathrm{C}$ due to the protection of the gypsum board. After about 25-30 min, the temperature curves increased quite quickly until the specimen failed. Similar to the protected WSW connection, the temperatures in the top bolt were higher than the temperatures in the bottom bolt through the test. This is also because of the buoyancy effect in the cavity.

Figure 3.38 shows the measured temperature histories in the wood members and cavity for Test \#1.3. Thermocouple $\mathrm{C} 1$ and $\mathrm{C} 2$ were located in the cavity. Thermocouple $\mathrm{T} 0$ and B0 were located between the steel plate and the wood member. At about $20 \mathrm{~min}$, the cavity temperature started to increase quickly. The $140 / 180^{\circ} \mathrm{C}$ finish rating was found to be $20 \mathrm{~min}$ and the time for a temperature to reach $300^{\circ} \mathrm{C}$ behind the protective membranes was $27 \mathrm{~min}$, for the protection of $15.9 \mathrm{~mm}$ Type $\mathrm{X}$ gypsum board.

Figure 3.39 and Figure 3.40 show the measured temperature histories in bolts and wood members for Test \#2.3, protected by a layer of intumescent paint. 


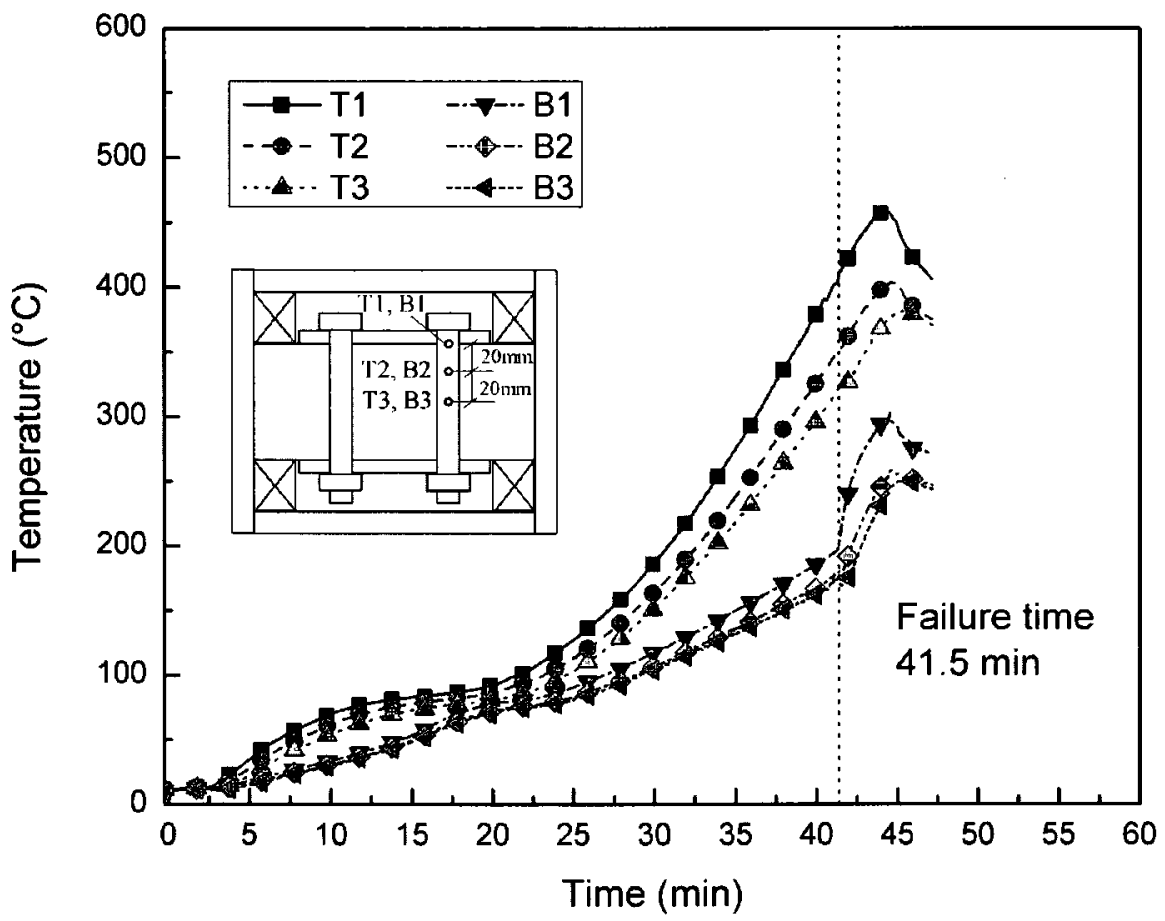

Figure 3.37 Bolt temperature histories for Test \#1.3

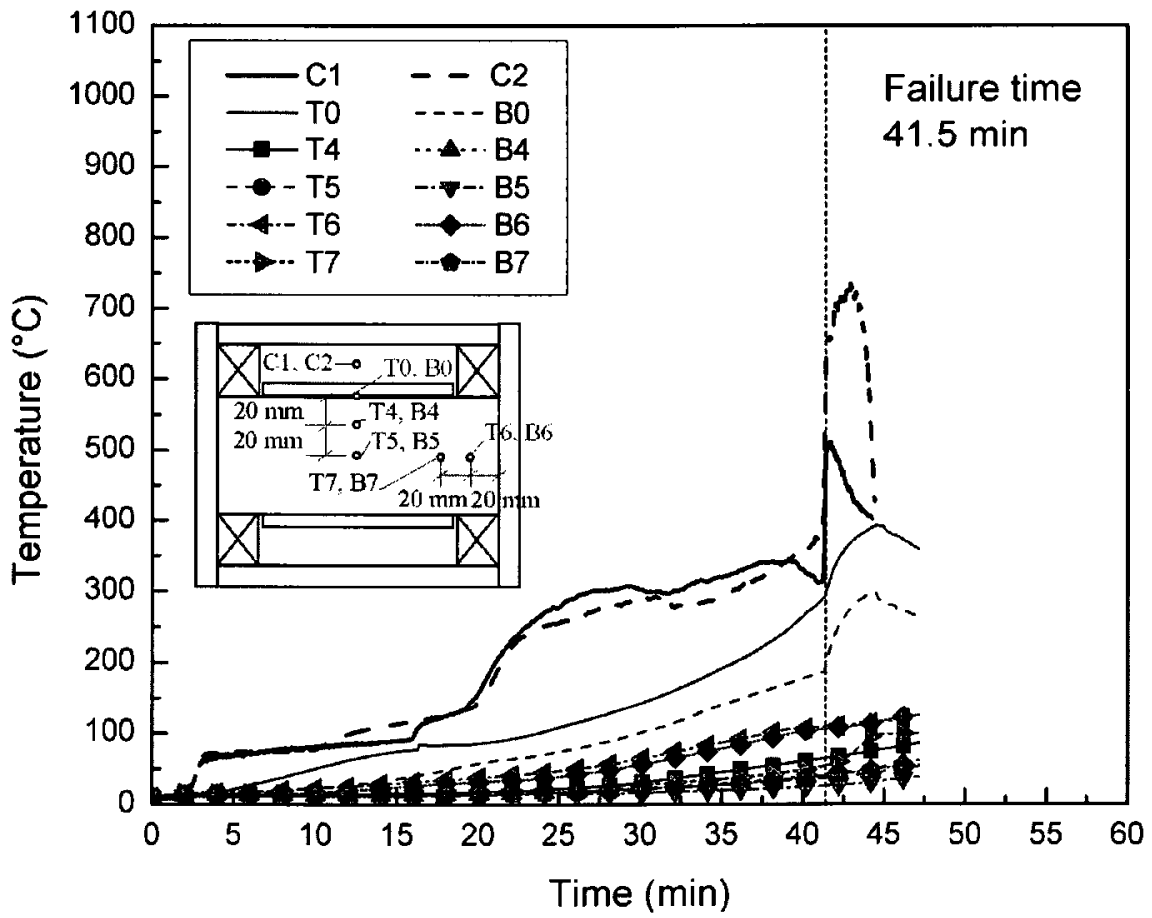

Figure 3.38 Wood and cavity temperature histories for Test \#1.3 


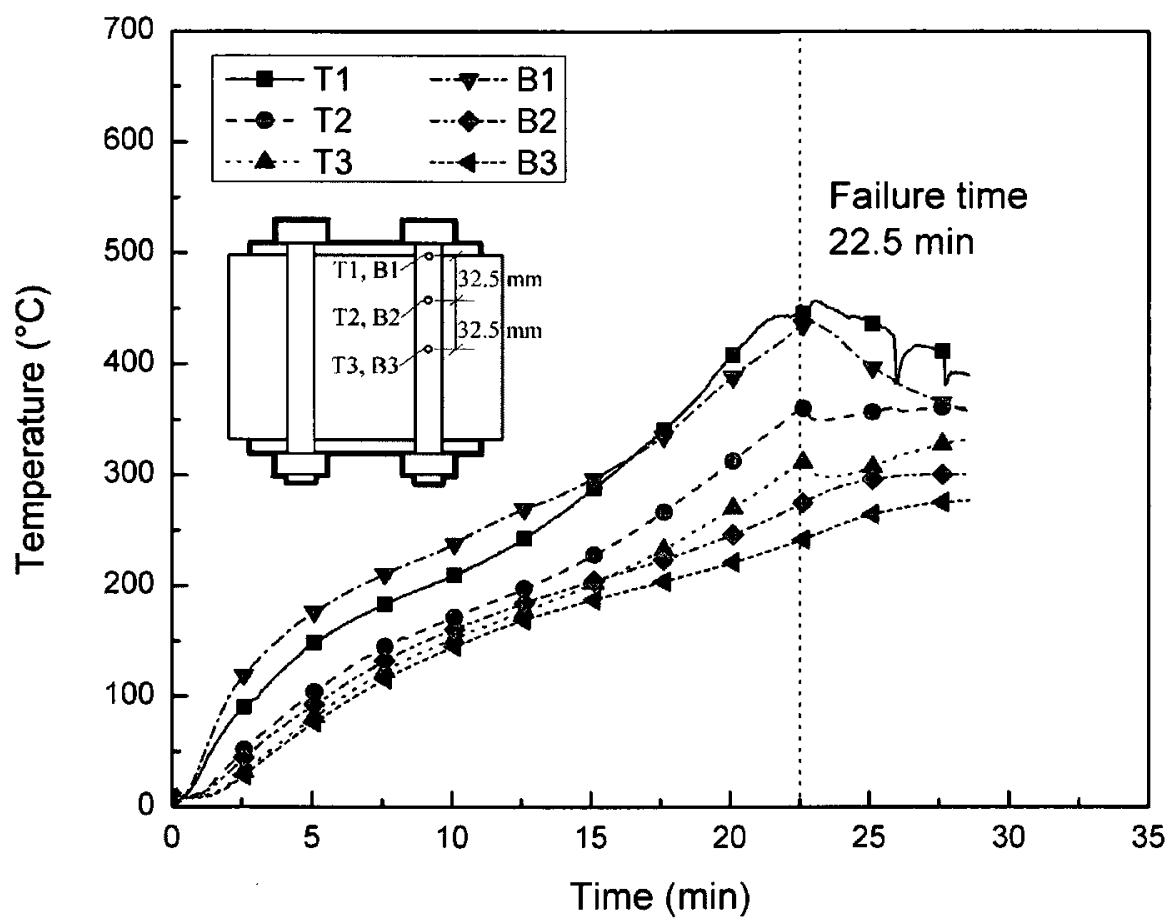

Figure 3.39 Bolt temperature histories for Test $\# 2.3$

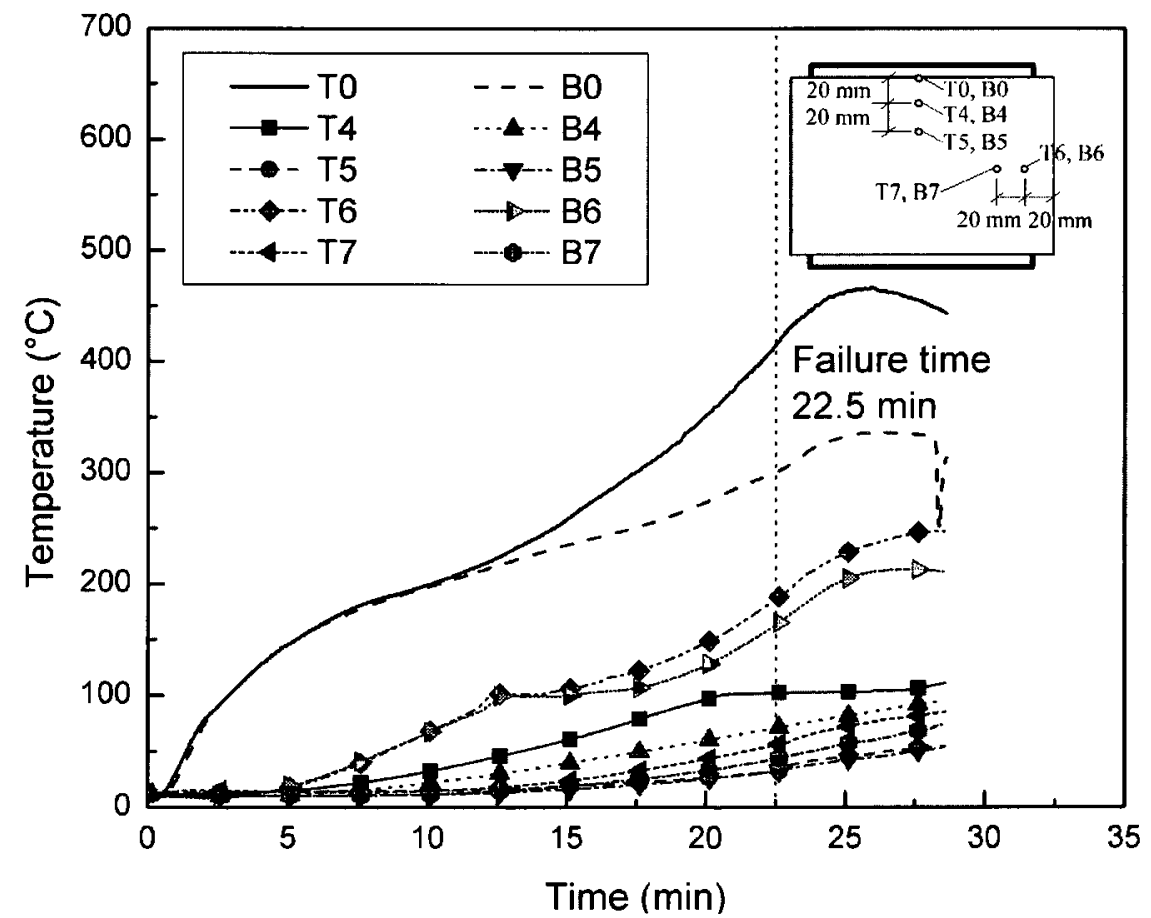

Figure 3.40 Wood temperature histories for Test \#2.3 


\subsubsection{Failure Time and Failure Mode}

Failure times for bolted SWS connections are summarized in Table 3.6. For unprotected specimens, the fire resistances were all less than $25 \mathrm{~min}$. Further discussions on the effects of the load ratio, wood thickness and protection are presented in subsection 3.3.4.

Table 3.6 Test results: failure time and failure modes of SWS connections

\begin{tabular}{|c|c|c|c|c|c|}
\hline Test \# & $\begin{array}{l}\text { Specimen } \\
\text { Information }\end{array}$ & $\begin{array}{l}\text { Load } \\
\text { Ratio }\end{array}$ & $\begin{array}{c}\text { Failure } \\
\text { Time } \\
\text { (min) } \\
\end{array}$ & Failure Modes & Other Comments \\
\hline 1.1 & \multirow{3}{*}{$\begin{array}{c}\text { D. fir-G: } \\
80 \times 190 \\
\text { Bolt: } \\
4 \times 12.7\end{array}$} & $10 \%$ & 14 & $\begin{array}{l}\text { Hole elongation and } \\
\text { Cutting through }\end{array}$ & Slight bending of some bolts \\
\hline 1.2 & & $30 \%$ & 8.5 & $\begin{array}{c}\text { Hole elongation and } \\
\text { wood member splitting }\end{array}$ & Slight bending of some bolts \\
\hline $1.3^{\dagger}$ & & $30 \%$ & 41.5 & $\begin{array}{l}\text { Rapture due to solid } \\
\text { wood member }\end{array}$ & Slight bending of all bolts \\
\hline 2.1 & \multirow{3}{*}{$\begin{array}{c}\text { D. fir-G: } \\
130 \times 190 \\
\text { Bolt: } \\
4 \times 19.1\end{array}$} & $10 \%$ & 23.5 & $\begin{array}{l}\text { Hole elongation and } \\
\text { Cutting through }\end{array}$ & Bending of all bolts \\
\hline 2.2 & & $19 \%$ & 15.5 & $\begin{array}{c}\text { Hole elongation and } \\
\text { wood member splitting }\end{array}$ & Bending of all bolts \\
\hline $2.3^{\ddagger}$ & & $19 \%$ & 22.5 & $\begin{array}{c}\text { Hole elongation and } \\
\text { wood member splitting }\end{array}$ & Bending of all bolts \\
\hline
\end{tabular}

${ }^{\dagger}$ : This specimen was protected by a single-layer of $15.9 \mathrm{~mm}$ Type X gypsum board.

‡: This steel plate and bolts were protected by $2 \mathrm{~mm}$ thick intumescent coating.

Failure modes and comments are also summarized in Table 3.6. Similar to bolted WSW connections, hole elongation, cutting through the wood members and splitting of the wood members were also observed in the tests of bolted SWS connections, as seen in Figure $3.41 \mathrm{a}-\mathrm{c}$. As contrast to bolted WSW connections, bolts were more likely to undergo bending deformation in the fire tests of SWS connections. As discussed before, due to the large exposed area of the steel plates for SWS connections, bolts were heated up more quickly with more uniform temperature distribution along the shank than bolts in WSW connections. The bolts in SWS connections tended to yield at high temperature. Figure $3.41 \mathrm{~d}$ shows some of the bended bolts. 

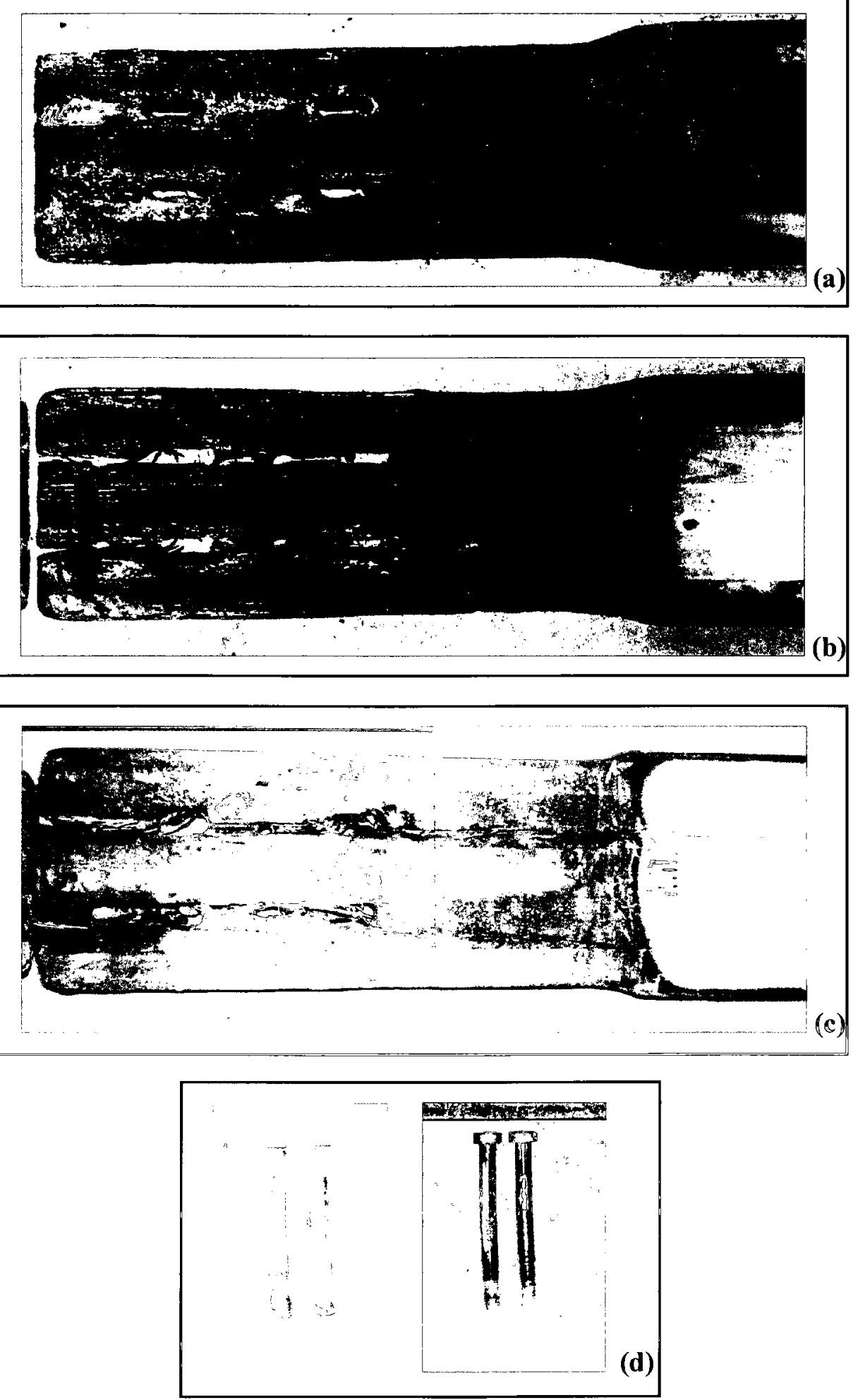

Figure 3.41 Typical failures of SWS connections 


\subsubsection{Charring Rate}

Similar to WSW connections, residual dimensions were measured at two locations for SWS connections. Figure 3.42 shows a typical specimen after the char was removed and the locations of two cross-sections for measuring. The cross-section A-A is located in the middle of the connection with the steel plates as side members and the cross-section B-B is located in the exposed solid wood part. Figure 3.43 gives the cross-section view of A-A and B-B.

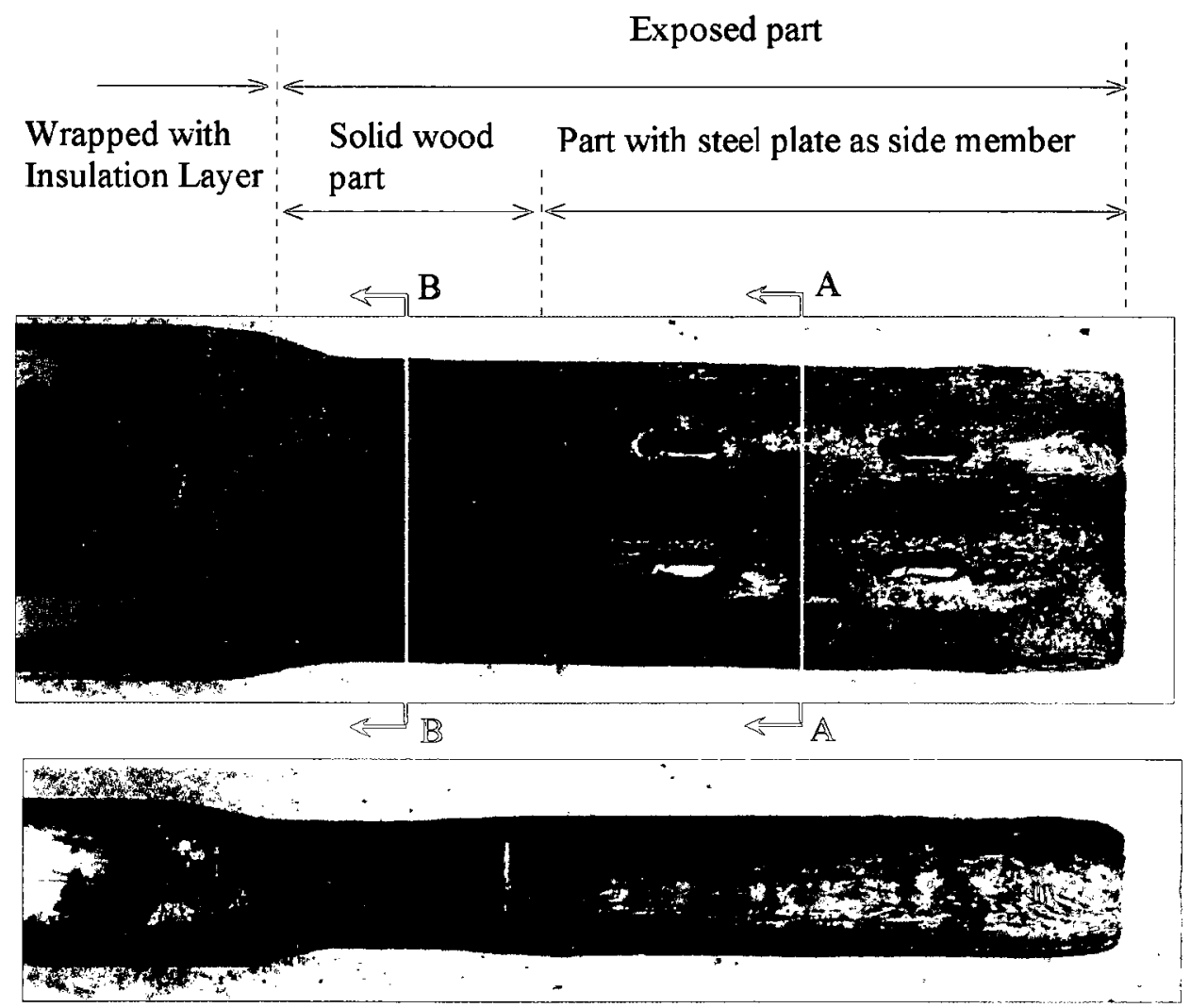

Figure 3.42 A typical SWS specimen after the char was removed 


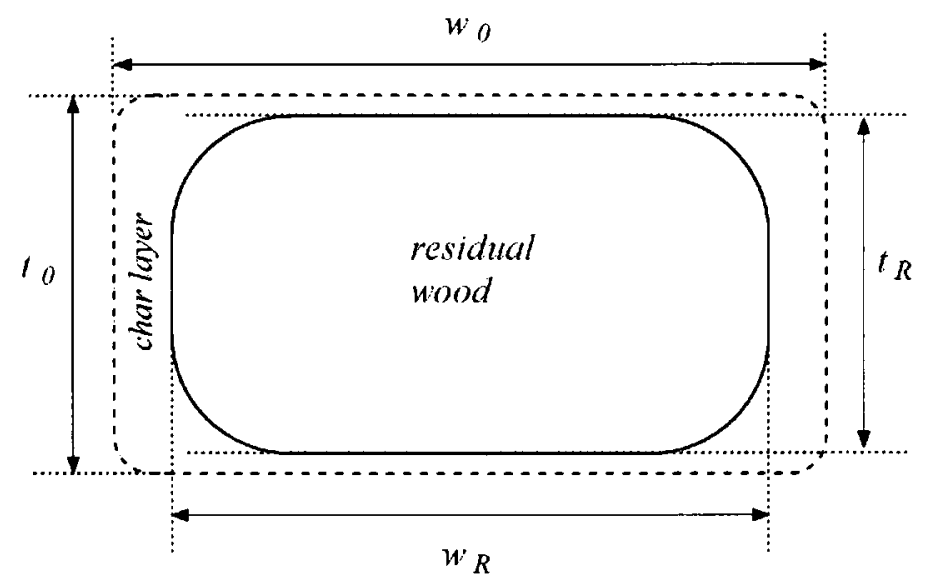

A) cross-setion A-A

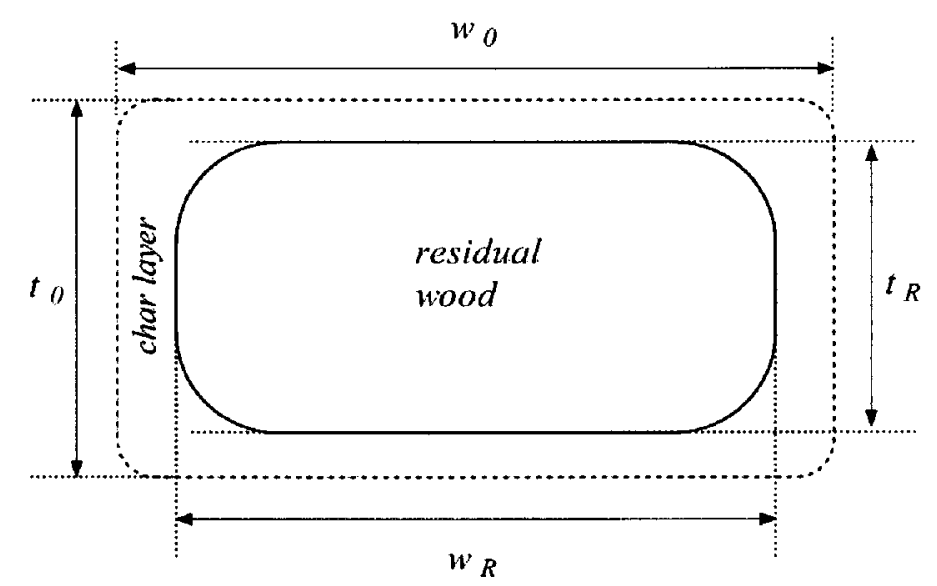

B) cross-setion B-B

Figure 3.43 Charring at both cross-section A-A and B-B

The charring rates at each cross-section in both thickness and width directions can be calculated as:

$$
\begin{aligned}
& \beta_{t}=\left(t_{0}-t_{R}\right) / 2 t_{f} \\
& \beta_{w}=\left(w_{0}-w_{R}\right) / 2 t_{f}
\end{aligned}
$$

where $t_{0}$ and $w_{0}$ are initial dimensions in the thickness and width direction, $t_{R}$ and $w_{R}$ are residual dimensions in the thickness and width direction, and $t_{f}$ is the exposure time. 
The charring rates were then calculated and summarized in Table 3.7. Again, the charring distances used to calculate the charring rates in Table 3.7 have already been corrected by subtracting the post-heating charring distances. The charring rate for post heating period was assumed to be $0.4 \mathrm{~mm} / \mathrm{min}$.

Table 3.7 Charring rates in SWS fire tests

\begin{tabular}{|c|c|c|c|c|c|c|c|}
\hline \multirow{2}{*}{ Test \# } & \multirow{2}{*}{$\begin{array}{l}\text { Specimen } \\
\text { Information }\end{array}$} & \multirow{2}{*}{$\begin{array}{l}\text { Load } \\
\text { Ratio }\end{array}$} & \multirow{2}{*}{$\begin{array}{l}\text { Failure } \\
\text { Time } \\
\text { (min) }\end{array}$} & \multicolumn{2}{|c|}{$\begin{array}{c}\text { Cross-section } \\
\text { A-A } \\
\end{array}$} & \multicolumn{2}{|c|}{$\begin{array}{c}\text { Cross-section } \\
\text { B-B } \\
\end{array}$} \\
\hline & & & & $\begin{array}{c}\beta_{t} \\
(\mathrm{~mm} / \mathrm{min})\end{array}$ & $\begin{array}{c}\beta_{w} \\
(\mathrm{~mm} / \mathrm{min})\end{array}$ & $\begin{array}{c}\beta_{t} \\
(\mathrm{~mm} / \mathrm{min})\end{array}$ & $\begin{array}{c}\beta_{w^{\prime}} \\
(\mathrm{mm} / \mathrm{min})\end{array}$ \\
\hline 1.1 & \multirow{3}{*}{$\begin{array}{l}\text { D.fir-G: } 80 \times 190 \\
\text { Bolt: } 4 \times 12.7\end{array}$} & $10 \%$ & 14 & 0.46 & 0.82 & 0.68 & 0.79 \\
\hline 1.2 & & $30 \%$ & 8.5 & 0.2 & 0.82 & 0.62 & 0.82 \\
\hline 1.3 & & $30 \%$ & 41.5 & - & - & - & - \\
\hline 2.1 & \multirow{3}{*}{$\begin{array}{l}\text { D.fir-G: } 130 \times 190 \\
\text { Bolt: } 4 \times 19.1\end{array}$} & $10 \%$ & 23.5 & 0.56 & 0.70 & 0.72 & 0.68 \\
\hline 2.2 & & $19 \%$ & 15.5 & 0.42 & 0.61 & 0.61 & 0.61 \\
\hline 2.3 & & $19 \%$ & 22.5 & - & - & - & - \\
\hline & Average & & & 0.41 & 0.74 & 0.66 & 0.73 \\
\hline
\end{tabular}

Note: Charring rates of $\# 1.3$ and $\# 2.3$ are not measured because they were protected.

The results in Table 3.7 show that $\beta_{t}$ in the cross-section A-A is much lower than $\beta_{t}$ in the cross-section B-B, $0.41 \mathrm{~mm} / \mathrm{min}$ vs $0.66 \mathrm{~mm} / \mathrm{min}$ on average. This is because the wood in cross-section A-A was shielded by the steel plates as the side members from direct fire exposure. $\beta_{w}$ values were found to be almost the same for both A-A and B-B crosssections, averagely $0.74 \mathrm{~mm} / \mathrm{min}$ vs $0.73 \mathrm{~mm} / \mathrm{min}$. Again, $\beta_{w}$ was found to be higher than $\beta_{t}$ in cross-section $\mathrm{B}-\mathrm{B}, 0.73 \mathrm{~mm} / \mathrm{min}$ vs $0.66 \mathrm{~mm} / \mathrm{min}$ on average, since the surfaces with a smaller dimension (i.e. $80 \mathrm{~mm}$ or $130 \mathrm{~mm}$ ) were facing the burners and the surfaces with a smaller dimension $(130 \mathrm{~mm})$ were more influenced by the two-dimensional heat transfer as well. 


\subsubsection{Discussion}

This subsection discusses the effect of load ratio, wood member thickness, and protection, on the fire performance of bolted SWS connections.

\subsubsection{Effect of Load Ratio and Wood Thickness}

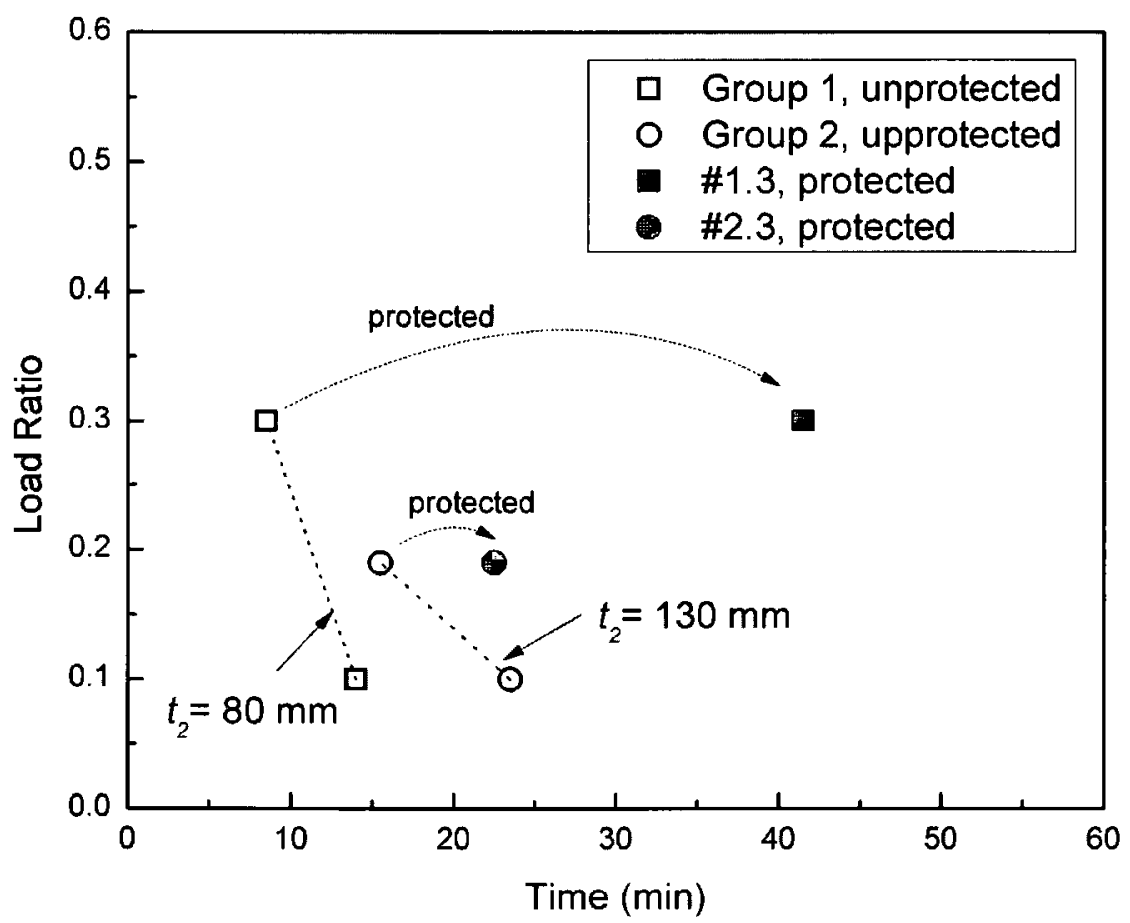

Figure 3.44 Test results of SWS Group \#1 and \#2

Figure 3.44 shows the relationship between load ratios and failure times for Group 1 and 2 , with wood member thickness $t_{2}=80$ or $130 \mathrm{~mm}$, respectively. Although only two groups were tested, the effect of the load ratio on the fire resistance can also be observed. For each group, specimens loaded at $10 \%$ had better fire performance. However, the effect of the load ratio was not very important, for thinner specimens. For example, reducing the load ratio from $30 \%$ to $10 \%$ led to only $5.5 \mathrm{~min}$ increase of the fire resistance for Group \#1. The load ratio played a more important role for specimens with 
thicker wood members. For Group \#2, the increased fire resistance was $8 \mathrm{~min}$ if the load ratio is reduced from $19 \%$ to $10 \%$.

On the other hand, at lower load ratios, i.e. $10 \%$, specimens with thicker wood members had a much better fire resistance. However, this improvement seemed to decrease at higher load ratios. Although no specimen was tested at $30 \%$ in Group 2, it can be seen from the trend that the difference between Group 1 and Group 2 at $30 \%$ load ratio should be very small.

\subsubsection{Effect of Protection}

Test \#1.3 was protected with a single-layer of $15.9 \mathrm{~mm}$ Type $X$ gypsum board. The fire resistance was increased to $41.5 \mathrm{~min}$ from $8.5 \mathrm{~min}$ in Test \#1.2. Figure 3.45 shows the specimen before and after test. It can be seen that failure occurred due to the rapture of the unprotected solid wood instead of the connection itself, the improvement can be determined as more than $33 \mathrm{~min}$ (or $+33 \mathrm{~min}$ ) for this matter. The $140 / 180^{\circ} \mathrm{C}$ finish rating and the time for a temperature of $300^{\circ} \mathrm{C}$ behind the protective membranes were determined as $20 \mathrm{~min}$ and $27 \mathrm{~min}$, respectively. During the test, the gypsum boards showed cracks but did not fall off until the final failure of the connection.

As discussed in Subsection 3.2.4.5 for solid wood beams protected with one layer of 15.9 mm Type $X$ gypsum board, the improved fire resistance, the $140 / 180^{\circ} \mathrm{C}$ finish rating and the time to reach a temperature of $300^{\circ} \mathrm{C}$ behind the protective membranes, were determined to be about $33 \mathrm{~min}, 22 \mathrm{~min}$ and $29 \mathrm{~min}$, respectively (White 2009); and for WSW connections protected with one layer of $15.9 \mathrm{~mm}$ Type X gypsum board, they were determined to be $37 \mathrm{~min}, 23 \mathrm{~min}$ and $30 \mathrm{~min}$, respectively. It can be seen that the values 
obtained here in Test \#1.3 (+33 $\mathrm{min}, 20 \mathrm{~min}$ and $27 \mathrm{~min}$, respectively) are close to those values discussed before.

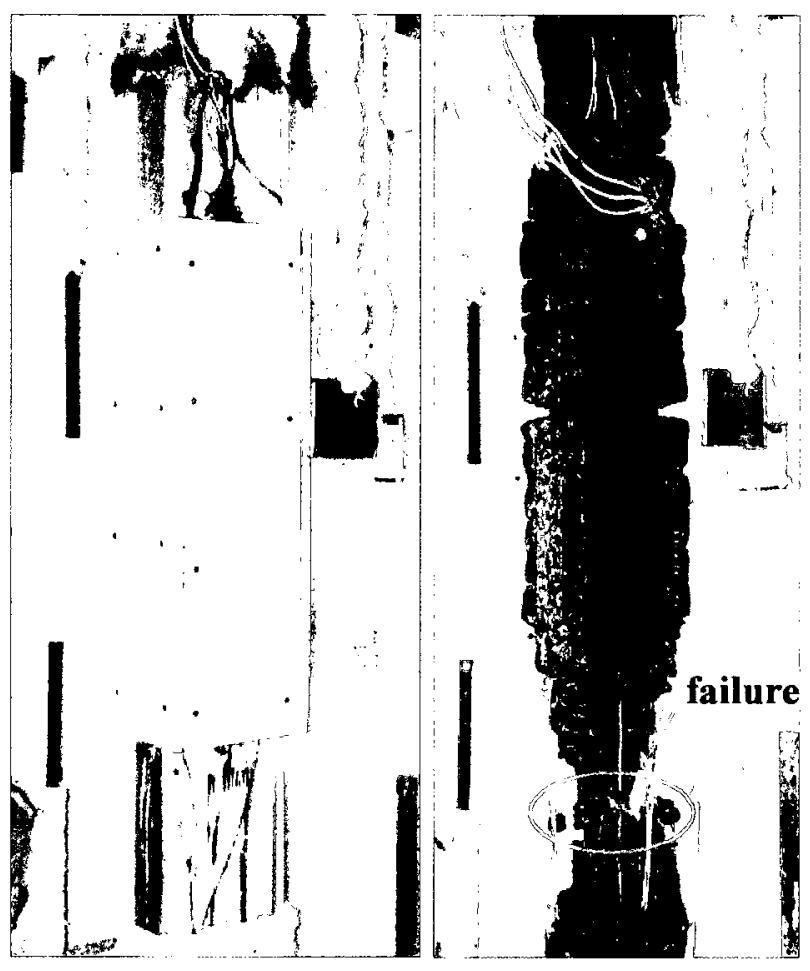

Figure 3.45 SWS Test \#1.3

The test result of specimen $\# 2.3$ showed that a layer of $2 \mathrm{~mm}$ thick intumescent paint only increased the fire resistance by about 7 min. This improvement was not very good, but not surprising because the paint was partially damaged due to adhesion problem at the steel plate edges during the fire test.

As seen in the Figure 3.46, the intumescent paint was damaged, leaving the steel plate exposed to the fire at the edges. However, the paint remained un-damaged on the top of the steel plates. This is probably due to the movement between the steel plate and the 
wood member. The thickness of the swollen paint was measured to be about $2 "-3 "$ (50 $\mathrm{mm}-75 \mathrm{~mm}$ ) after the fire test.

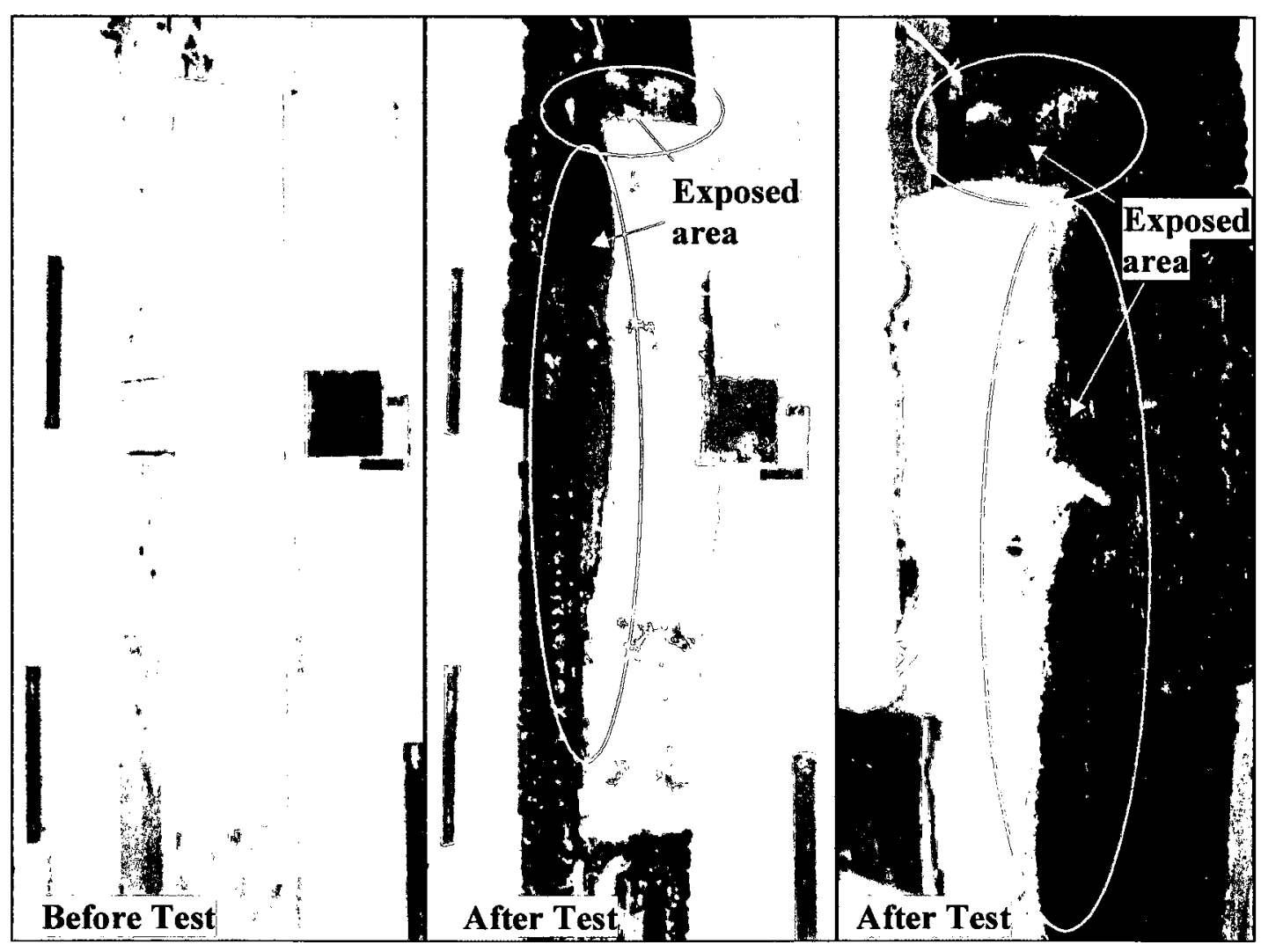

Figure 3.46 Intumescent paint for SWS Test \#2.3 


\subsection{Summary}

The newly designed and constructed medium-size furnace was found to be able to successfully satisfy the time-temperature requirements in accordance with CAN/ULCS101. Under necessary structural modification, the furnace can be used to test the fire resistance of other construction elements.

In total, sixteen bolted WSW specimens were tested under the exposure to the CAN/ULC-S101 standard fire. Particular attention was given to investigating the effects of wood side member thickness, load ratio, fastener diameter, edge distance and protection. The test results showed that the fire resistances of all the tested specimens with no protection were less than $45 \mathrm{~min}$, a target rating for Canadian code compliance. A reduction of the load ratio increased the fire resistance significantly. Increasing the thickness of the wood side member led to a considerable increase in the fire resistance. The bolt diameter did not play an important role on the fire performance, but increasing the bolt diameter would reduce the load ratio considerably, and as a result, it would improve the fire resistance.

Six fire-resistance tests were carried out for bolted SWS specimens. For the specimens without protection, the test results showed that their fire resistances were less than 25 min. The load ratio and wood member thickness were also found to have impact on the fire resistance of bolted SWS connections. However, at higher load ratios (i.e. $30 \%$ ), the wood member thickness did not play a significant role on the fire resistance, and when the wood member was relatively thin (i.e. $80 \mathrm{~mm}$ ), the load ratio seemed to have a less important role on the fire resistance. 
For bolted WSW or SWS connections with protections of a one-layer of $15.9 \mathrm{~mm}$ Type X gypsum board or a double-layer of $12.7 \mathrm{~mm}$ plywood, the improved fire resistance, the $140 / 180^{\circ} \mathrm{C}$ finish rating and the time to reach a temperature of $300^{\circ} \mathrm{C}$ behind the protective membranes, were found to be close to the values reported by White for solid wood beams protected with the same membranes. Therefore, the same assigned values for protective membranes might be used for both timber connections and structural timber members, if the Component Additive Model (CAM) is applied to estimate the fire resistance of protected timber members. 


\section{Chapter 4: Heat Transfer Analysis}

In this chapter, a three dimensional heat transfer analysis approach is presented for predicting temperature distributions of timber connections in standard fire-resistance tests. The heat transfer analysis was performed using ABAQUS/Standard (Hibbitt 2008), a commercial finite element program, and the simulation approach was verified against fire test data presented in Chapter 3. A sensitivity analysis was also carried out to study the effects of mesh generation and uncertainties of input data on the heat transfer modelling.

By knowing temperatures produced by the heat transfer model, the strength of a timber connection at elevated temperatures can be calculated in a structural model, which is presented in the next chapter.

\subsection{Heat Transfer Model}

There are three heat transfer processes involved in modelling a timber connection in fire exposure: convective and radiative heat transfer from the fire to the specimen boundary, heat conduction within the specimen, and heat exchange between contacting members. This section describes the governing equations involved in these processes and methods used in modelling the processes in ABAQUS/Standard.

\subsubsection{Boundary Conditions}

A specimen exposed in a fire-resistance furnace receives heat flux from the fire and surrounding furnace walls through convection and radiation. The convection heat transfer 
is governed by the gas temperature and the radiative heat transfer is governed by an effective radiation temperature, which represents the effect of radiation from both gas and furnace walls. However, these two temperatures are not equal (Craft 2009). In order to use a simple temperature measurement to calculate the heat flux received by the specimen, a measurement device, called plate thermometer, was developed by Wickstrom (1994). The advantage of using it in fire-resistance tests is that the total heat flux can be calculated by replacing the gas temperature and the effective radiation temperature with the temperature measured by the plate thermometer. In this chapter, the plate thermometer measurements were used as the furnace temperature boundary conditions in the heat transfer model.

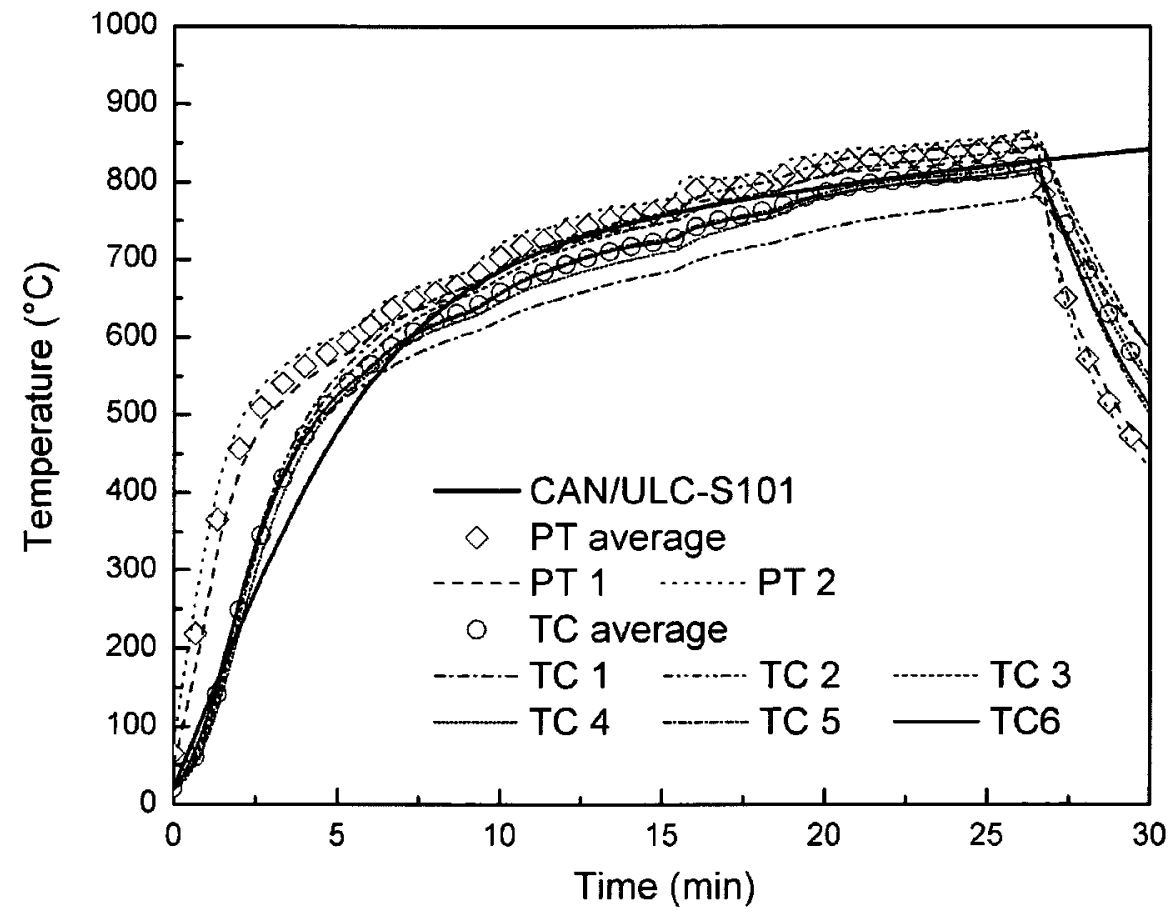

Figure 4.1 Plate thermometer and thermocouple measurements, Test \#4.1

Figure 4.1 shows a typical plot of plate thermometer and thermocouple measurements from WSW Test \#4.1 as an example. Standard shielded thermocouples were used to 
control the furnace temperature to follow the standard curve. A temperature curve (PT average), averaged from the plate thermometer measurements, was used as the boundary condition in modelling.

In ABAQUS/Standard, a user subroutine, called as DSFLUX, was coded in FORTRAN to incorporate the boundary conditions. The heat flux received by the specimen through the boundary is described in Equation (4.1):

$$
\dot{q}^{n}=h_{c}\left(T_{f}-T_{s}\right)+\Phi \varepsilon_{e f f} \sigma\left(T_{f}{ }^{4}-T_{s}{ }^{4}\right)
$$

where $h_{c}\left(\mathrm{~W} / \mathrm{m}^{2} \mathrm{~K}\right)$ is the convection coefficient, $\Phi$ is the configuration factor, $\sigma$ is the Stefan-Boltzman constant $5.67 \times 10^{-8}\left(\mathrm{~W} / \mathrm{m}^{2} \mathrm{~K}^{4}\right), \varepsilon_{e f f}$ is the effective emissivity, $T_{f}(\mathrm{~K})$ is the temperature measured by the plate thermometer and $T_{s}(\mathrm{~K})$ is the surface temperature of the member. The configuration factor $\Phi$ can be taken as 1.0 in the standard fire test. The convection coefficient $h_{c}$ for the standard fire can be assumed as $25\left(\mathrm{~W} / \mathrm{m}^{2} \mathrm{~K}\right)(\mathrm{EN} 1991-1-22003)$. The effective emissivity $\varepsilon_{\text {eff }}$ is given as:

$$
\varepsilon_{e f f}=\frac{\varepsilon_{f} \varepsilon_{s}}{\varepsilon_{f}+\varepsilon_{s}-\varepsilon_{f} \varepsilon_{s}}
$$

where $\varepsilon_{f}$ is the furnace emissivity, and $\varepsilon_{s}$ is the surface emissivity. The furnace emissivity is taken as 0.9 and the surface emissivity is taken as 0.9 for wood members (Mehaffey 1994) and 0.7 for steel members (EN1993-1-2 2005). 


\subsubsection{Heat Conduction within Specimen}

The governing partial differential equation for transient heat transfer within a solid material is given by:

$$
\frac{\partial}{\partial x}\left(\lambda_{x} \frac{\partial T}{\partial x}\right)+\frac{\partial}{\partial y}\left(\lambda_{y} \frac{\partial T}{\partial y}\right)+\frac{\partial}{\partial z}\left(\lambda_{z} \frac{\partial T}{\partial z}\right)+\dot{Q}=\rho c \frac{\partial T}{\partial t}
$$

where $T(\mathrm{~K})$ is temperature, $\lambda_{x, y, z}(\mathrm{~W} / \mathrm{mK})$ are thermal conductivities in $x, y, z$ directions, $\dot{Q}\left(\mathrm{~W} / \mathrm{m}^{3}\right)$ is internally generated heat, $\rho\left(\mathrm{kg} / \mathrm{m}^{3}\right)$ is density, $c(\mathrm{~J} / \mathrm{kgK})$ is specific heat, and $t(\mathrm{~s})$ is time.

Steel is taken as an isotropic material $\left(\lambda_{x}=\lambda_{y}=\lambda_{z}\right)$ with no heat generated at elevated temperatures $(\dot{Q}=0$ ). Wood is considered to be a transversely isotropic material ( $\lambda_{y}=\lambda_{z}, y$ and $z$ are perpendicular to the grain). Mass transfer and heat released within wood are not taken into account $(\dot{Q}=0)$.

\subsubsection{Heat Transfer between Members}

If two materials are in contact perfectly, the temperature drop across the interface between materials can be neglected. However, due to surface roughness, gaps filled with air exist between contact spots on the interface. Therefore, heat transfer is due to conduction across the actual contact area and to conduction and/or radiation across the gaps (Incropera 2006). This phenomenon is known as a result of the thermal contact resistance, which is defined as the ratio between the temperature drop and the average heat flow across the interface.

In a bolted timber-steel connection, there are two contact areas that affect the heat transfer process: wood-steel plate contact and bolt-wood contact. Normally, wood members and 
steel plates are fabricated with pre-drilled holes with a clearance for easy installation. As discussed before, a hole clearance is required in the range of 1.0 to $2.0 \mathrm{~mm}$ for timber connections according to the Canadian standard (CAN/CSA-O86-09 2009).

It is very important to model the heat transfer between member interfaces correctly by defining proper contact properties in ABAQUS/Standard. To model this, the gaps between bolts and wood, and between steel plates and wood members, are assumed to be narrow enough so that heat transfer between these surfaces is restricted to be conduction and radiation through air:

$$
\dot{q}_{G}^{\prime \prime}=\lambda_{a i r} \frac{\Delta T}{L}+\sigma\left(T_{H}{ }^{4}-T_{C}^{4}\right) /\left(\frac{1}{\varepsilon_{H}}+\frac{1}{\varepsilon_{C}}-1\right)
$$

where $\Delta T=T_{H}-T_{C}, \quad \lambda_{\text {air }}(\mathrm{W} / \mathrm{mK})$ is the thermal conductivity of air, $L(\mathrm{~m})$ is the air layer thickness, $\varepsilon_{H}$ is the hot interface emissivity and $\varepsilon_{C}$ is the cold interface emissivity. Assuming a small temperature gradient and replacing $T_{H}{ }^{4}-T_{C}{ }^{4}$ by its approximation $4 \bar{T}^{3} \Delta T$ (Jaouen 1987), Equation (4.4) gives:

$$
\dot{q}_{G}^{n}=\lambda_{\text {air }} \frac{\Delta T}{L}+4 \sigma \bar{T}^{3} \Delta T /\left(\frac{1}{\varepsilon_{H}}+\frac{1}{\varepsilon_{C}}-1\right)
$$

Therefore, an equivalent thermal conductivity $\lambda_{G}$ can be adopted to express the total heat flux through the gap as given in Equation (4.6). This can be defined in ABAQUS/Standard using the GAP CONDUCTANCE option to model the heat transfer across the gap between closely adjacent surfaces. 


$$
\lambda_{G}=\lambda_{\text {air }}+4 \sigma \bar{T}^{3} L /\left(\frac{1}{\varepsilon_{H}}+\frac{1}{\varepsilon_{C}}-1\right)
$$

The thermal conductivity of air is given by Janssens (1994) as:

$$
\lambda_{\text {air }}=0.024+7.05 \times 10^{-5} T_{\text {air }}-1.59 \times 10^{-8} T_{\text {air }}{ }^{2}
$$

where $T_{\text {air }}$ is the air temperature in ${ }^{\circ} \mathrm{C}$.

\subsection{Thermal Properties}

To model heat transfer in a timber connection accurately, proper input data for steel and wood at elevated temperatures are needed. The temperature-dependent thermal properties of steel and wood were summarized in the literature review in Chapter 2. Variations of properties exist in the literature, especially for wood. This section describes the thermal properties used in the heat transfer model. The validation of the thermal properties is presented in the following section.

\subsubsection{Thermal Properties of Wood}

Thermal conductivity, specific heat and density at elevated temperatures used in the heat transfer model were adopted from reports by Janssens (1994) and Konig (2000). As shown in Figure 2.6, Figure 2.7 and Figure 2.8, the adopted values are indicated by the solid lines in these figures.

It has to been noted that the thermal conductivity shown in Figure 2.6 is the transverse conductivity. The longitudinal thermal conductivity is in the range of 1.5 to 2.8 of the transverse conductivity (White 2008). In this study, the longitudinal conductivity was assumed to be twice the transverse conductivity, as an average value between 1.5 and 2.8 . 


\subsubsection{Thermal Properties of Steel}

For steel, the thermal properties at high temperatures have been well documented in the literature. The density of steel is $7850 \mathrm{~kg} / \mathrm{m}^{3}$ remaining constant with temperature. The specific heat and thermal conductivity versus temperature were taken from Eurocode 3 (EN1993-1-2 2005) as shown in Figure 2.14.

\subsection{Model Validation}

Before any application of the model to timber connections, evaluating the finite element model is essential and necessary. Numerical simulations should be validated against experimental results. The evaluation process for the heat transfer model included two stages: the first was to validate the wood properties at elevated temperatures used in the model; the second was the comparison against the experimental test results for WSW and SWS connections generated in Chapter 3.

\subsubsection{Validation of Wood Thermal Properties}

The wood thermal properties were validated against one dimensional heat transfer tests in wood, reported by Konig (1999). The wood specimens used in the tests were built with 5 pieces of wood with dimensions $45 \times 95 \mathrm{~mm}$. The wood specimens were spruce with an average dry density of $425 \mathrm{~kg} / \mathrm{m}^{3}$ and about $12 \%$ moisture content. Wood members were exposed to the ISO 834 standard fire on one side and furnace temperatures were controlled and measured using the plate thermometer. Temperature histories were also recorded at specific locations inside the specimens. Figure 4.2 shows the middle piece of the member and the location of thermocouples. The wood was subjected to fire on the bottom side. 

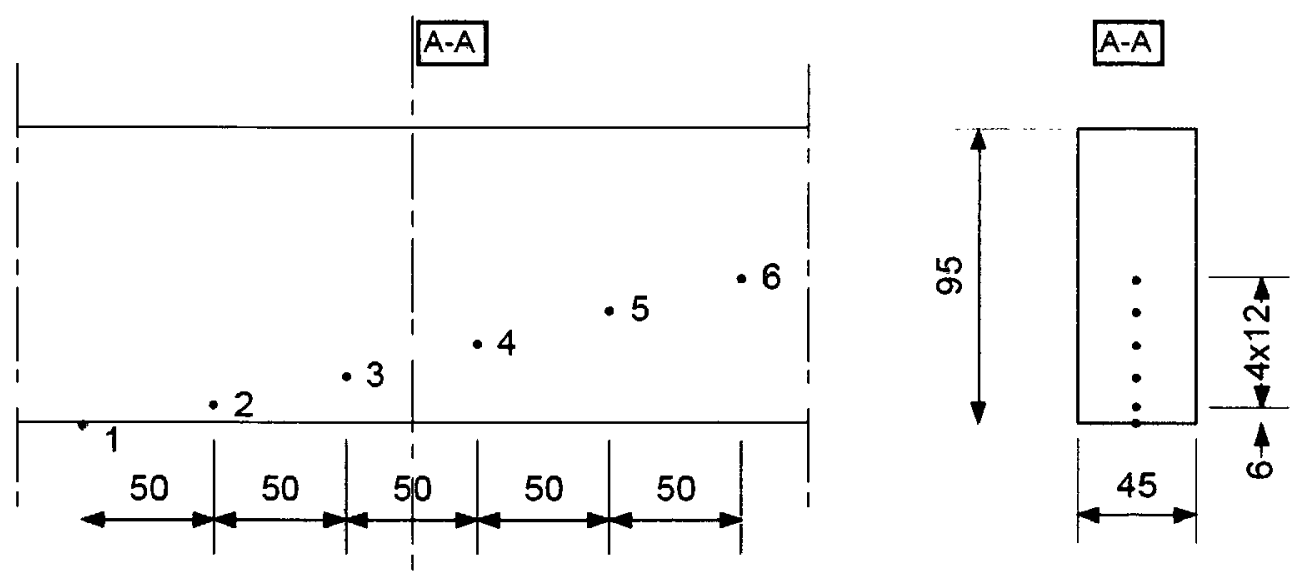

\section{Figure 4.2 Thermocouple locations in Konig's tests}

A simple one dimensional heat transfer analysis was conducted using the finite element program ABAQUS/Standard V6.6 (Hibbitt 2008). The temperature-dependent properties were defined in ABAQUS and the boundary conditions in Equation (4.1) were applied to the exposed surfaces through the user subroutine.

Figure 4.3 shows the predicted temperature curves in the wood compared with Konig's test results. In general, the FEM calculations are in good agreement with results from the fire tests. The calculated temperatures were found to be a little under-estimated when the temperature was less than about $120^{\circ} \mathrm{C}$. This is due to the moisture transfer in the wood specimens. When wood is exposed to fire, a portion of moisture, driven by the heat, tends to move towards the unheated direction, and this also causes the temperature downstream to increase. However, the moisture movement was not considered in the heat transfer analysis. Over $120^{\circ} \mathrm{C}$, when all moisture is evaporated, the calculated temperature curves catch up to the measured temperature curves and give very a good prediction. 


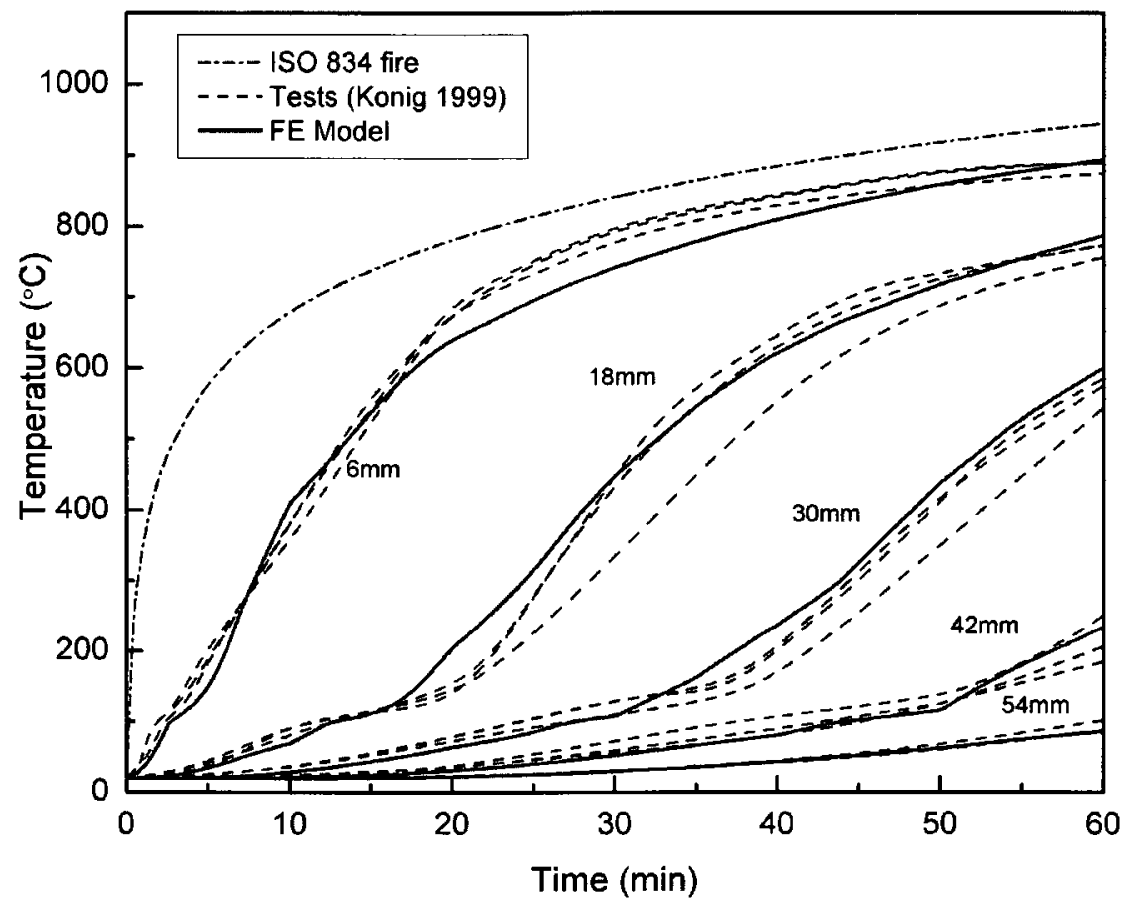

Figure 4.3 Temperature histories in one dimensional heat transfer of wood

\subsubsection{Gap Effect}

As mentioned before, gaps exist initially between members in timber connections. In real fire-resistance tests, this gap can open up when loads are applied and the distance will also increase due to shrinkage of the wood char. The thermal contact resistance will then increase and the heat transfer between members will change. Therefore, prior to modelling a full connection, it was necessary to evaluate the influence of the gap between bolts and wood holes, and the gap between steel plates and wood members. 


\section{Bolt-wood contact}

For the gap between bolts and wood holes, the initial clearance was about $1.6 \mathrm{~mm}\left(1 / 16^{\prime \prime}\right)$ because normally a $1 / 16$ " oversized drill bit was used to drill the holes. During a test, this gap could increases due to the extensive stresses generated around the hole and the crush of wood at high temperatures.
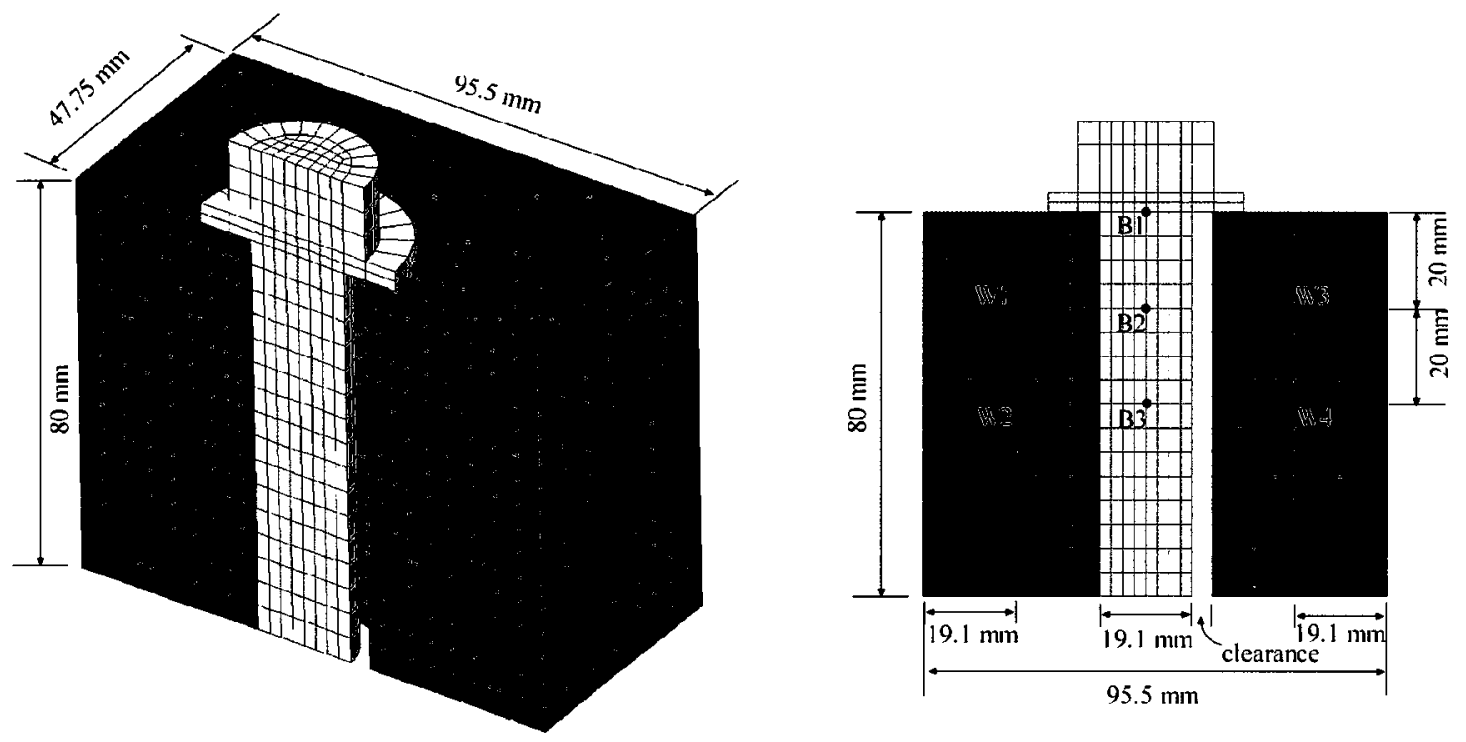

Figure 4.4 A simple bolt-wood assembly

A simple bolt-wood assembly, seen in Figure 4.4, was constructed using a $19.1 \mathrm{~mm}(d)$ bolt with $80 \mathrm{~mm}$ long shank and a piece of wood with dimensions of $95.5 \times 95.5 \mathrm{~mm}(5 d$ $\times 5 d)$ and $80 \mathrm{~mm}$ thick. The hex bolt head was simplified as round with equivalent exposure surface, and the washer was modelled as a part of the bolt. The bolt was initially set to be close to one side of the hole, which is similar to the situation when the assembly is loaded laterally. Simulations were performed in ABAQUS/Standard for different gap clearances in the range of 0 to $4 \mathrm{~mm}$. Figure 4.4 (left) shows a mesh generated in ABAQUS/Standard. Three dimensional 8-node elements (DC3D8) were defined for the 
heat transfer analysis. The assembly was exposed to CAN/ULC-S101 fire from the top surfaces and other surfaces were assumed to be adiabatic. Figure 4.4 (right) shows the locations where the temperatures were investigated. B1-B3 were on the bolt and W1-W4 were in the wood.

Figure 4.5 (left) shows the temperature difference between two sides of the bolt for W1W4 when the gap clearance was $4 \mathrm{~mm}$. The difference seemed to be small. Figure 4.5 (right) shows the temperature histories at $\mathrm{B} 1-\mathrm{B} 3$ and $\mathrm{W} 3-\mathrm{W} 4$, for the gap clearance $=0,2$ $\mathrm{mm}$ and $4 \mathrm{~mm}$, respectively. It is shown that the gap filled with air did not have much influence on the heat transfer.
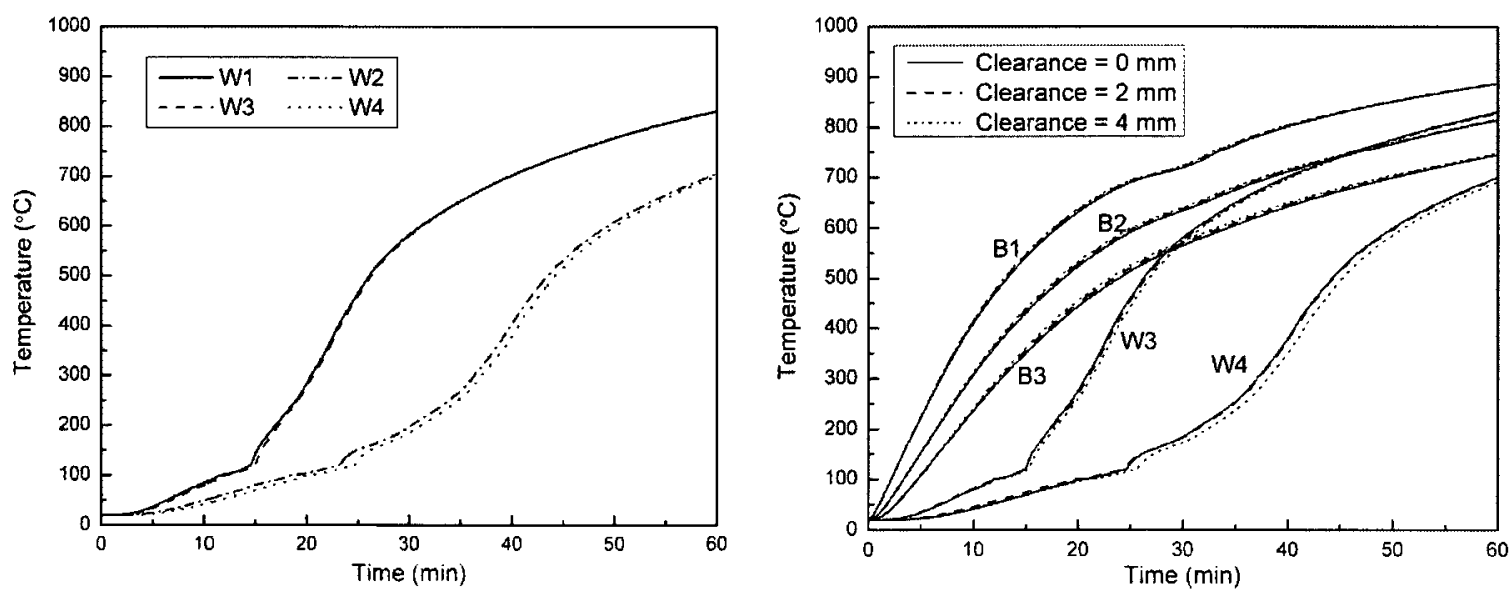

Figure 4.5 Temperature histories for bolt-wood assembly

Actually, in a fire test the gap could increase over $4 \mathrm{~mm}$, but large gaps only occur when the specimen is close to failure. Therefore, the influence of the gap distance was not a significant factor in the heat transfer during most of the test duration. Therefore, the clearances were to be set to be fixed at $1.6 \mathrm{~mm}$ later on for modelling bolt-wood contacts. 


\section{Wood-steel plate contact}

The initial gaps between steel plates and wood can be recognized to be very small, because fasteners were tightened prior to the tests. During a fire test, there was no considerable crushing of wood at the wood-steel plate interface. Therefore, the distance between the wood and steel plate was also considered to be not large in a fire test.

A simple one dimensional heat transfer model was constructed in ABAQUS/Standard. Simulations were performed to evaluate the effect of gap on the heat transfer between wood members and steel plates for different gap distances in the range of 0 to $2 \mathrm{~mm}$. The results indicated that the effect was very small and can be neglected. It is possibly fair to assume that wood members and steel plates are in perfect contact during a fire test.

Therefore, the distance between wood and steel plates were set to zero and no contact resistance was considered later on for modelling wood-steel plate contacts. 


\subsubsection{Validation against Experimental Data}

With the material properties validated and the contact models discussed, a heat transfer analysis was carried out to model timber connections. Modelled temperatures were compared with thermocouple measurements at different locations within the specimens. A comparison with two tests is presented in this subsection for WSW-Test \#2.1 and SWS-Test \#2.1.

\subsubsection{WSW Connection}

The specimen in WSW-Test $\# 2.1$ has $60 \mathrm{~mm}$ thick wood side members and $12.7 \mathrm{~mm}$ diameter bolts. Due to symmetry, only one quarter of the connection was modelled. The mesh generated in ABAQUS/Standard is shown in Figure 4.6a. The element type was a three dimensional 8-node heat transfer element DC3D8. The locations for temperature comparison are shown in Figure 4.6b.

As measured prior to the test, the tested wood member of the specimen had a density of $450 \mathrm{~kg} / \mathrm{m}^{3}$ and a moisture content of $12 \%$. The input temperature boundary conditions were based on the plate thermometer measurements.

One thing that has to be pointed out and discussed here is the heat transfer in the narrow slot beside the steel plate, as seen in the Figure 4.6c.

For surfaces A2-A4, the received heat flux from the open surface A1 (fire) is given in the following equation, if convection is not taken into account in the narrow slot:

$$
\dot{q}^{\prime \prime}=\Phi \varepsilon_{e f f} \sigma\left(T_{f}^{4}-T_{s}^{4}\right)
$$


(a)
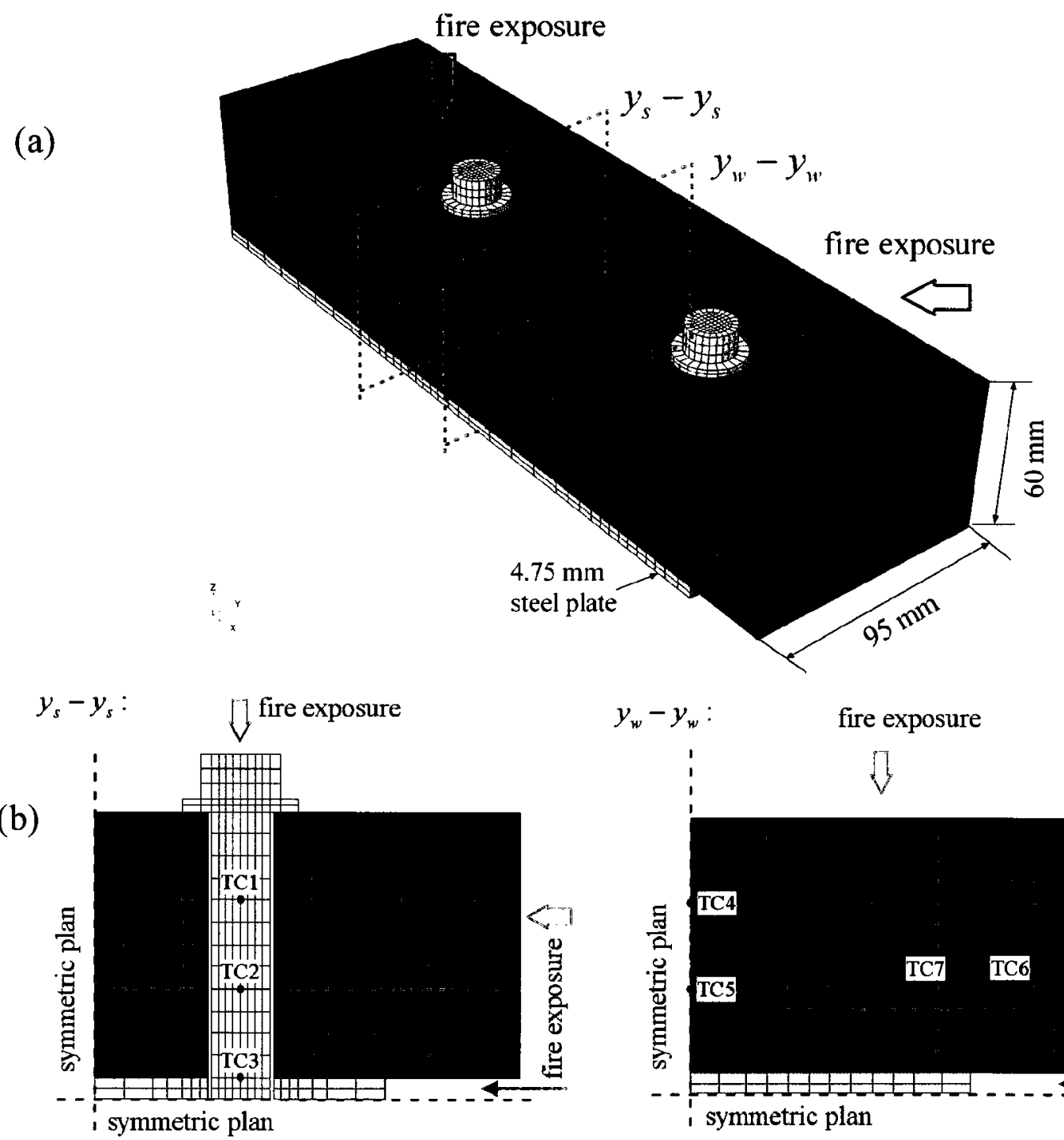

(b)

(c)
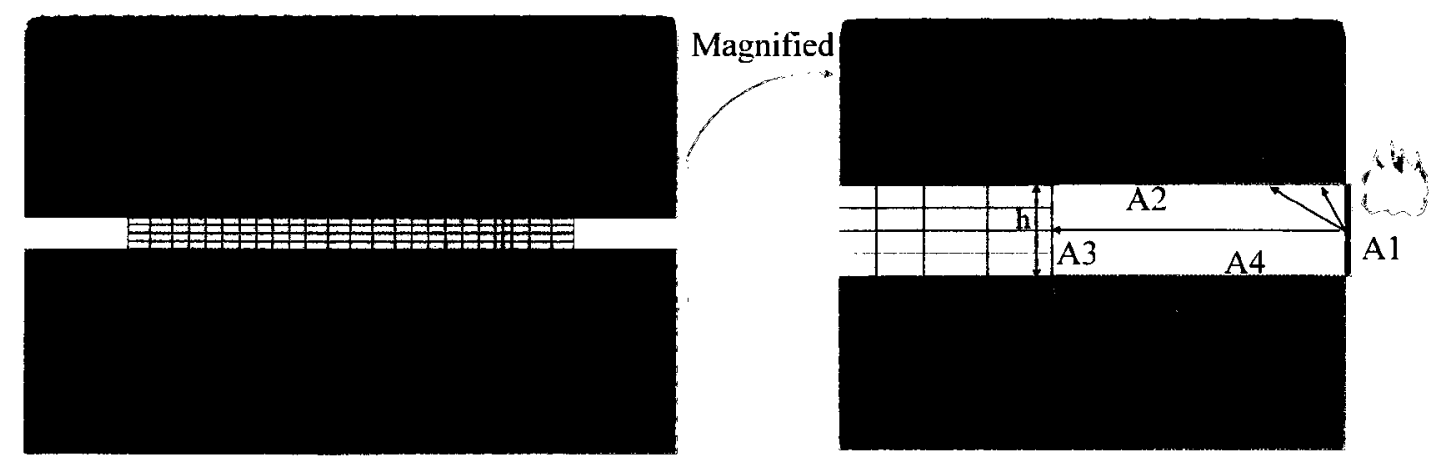

Figure 4.6 Mesh generated in ABAQUS/Standard for WSW-Test\#2, thermocouple locations, and configuration factors 
The configuration factor $\Phi$ has to be determined for each element on surface A2-A4 from surface A1. For an element on surface A3, the configuration factor can be calculated as (Howell 1982):

$$
\Phi_{\mathrm{A}_{1}-\mathrm{A}_{2}}=\left[1+(\mathrm{d} / \mathrm{h})^{2}\right]-(\mathrm{d} / \mathrm{h})
$$

where $\mathrm{d}$ and $\mathrm{h}$ are the depth and the height of the slot, respectively. For element $\mathrm{S} 1$ on surface A2, the configuration factor can be calculated as (Howell 1982):

$$
\Phi_{\mathrm{A}_{1}-\mathrm{S}_{1}}=\left[1+\left(\mathrm{d}_{\mathrm{S}_{1}} / \mathrm{h}\right)-\left(1+\left(\mathrm{d}_{\mathrm{S}_{1}} / \mathrm{h}\right)\right)^{2}\right] / 2
$$

where $d_{S_{1}}$ is the depth of element $\mathrm{S} 1$ on surface A2. Similarly, the configuration factor $\Phi_{\mathrm{A}_{1}-\left(\mathrm{S}_{1}+\mathrm{S}_{2}\right)}$ can be calculated, and the configuration factor for element S2 on surface A2 is then determined as:

$$
\Phi_{\mathrm{A}_{1}-\mathrm{S}_{2}}=\Phi_{\left.\mathrm{A}_{1}-\mathrm{S}_{1}+\mathrm{S}_{2}\right)}-\Phi_{\mathrm{A}_{1}-\mathrm{S}_{1}}
$$

Therefore, the configuration factor for each element on $\mathrm{A} 2$ can be determined using Equation (4.10) and Equation (4.11). However, the radiative heat transfer between A2 and $\mathrm{A} 3$ is not taken into account, because the radiation from $\mathrm{A} 1$ to $\mathrm{A} 2$ and $\mathrm{A} 3$ is the primary process involved in this narrow slot area.

By defining proper material properties and boundary conditions, the model was run in ABAQUS/Standard and predictions were compared to the thermocouple measurements at different locations, as shown in Figure 4.7 and Figure 4.8. 


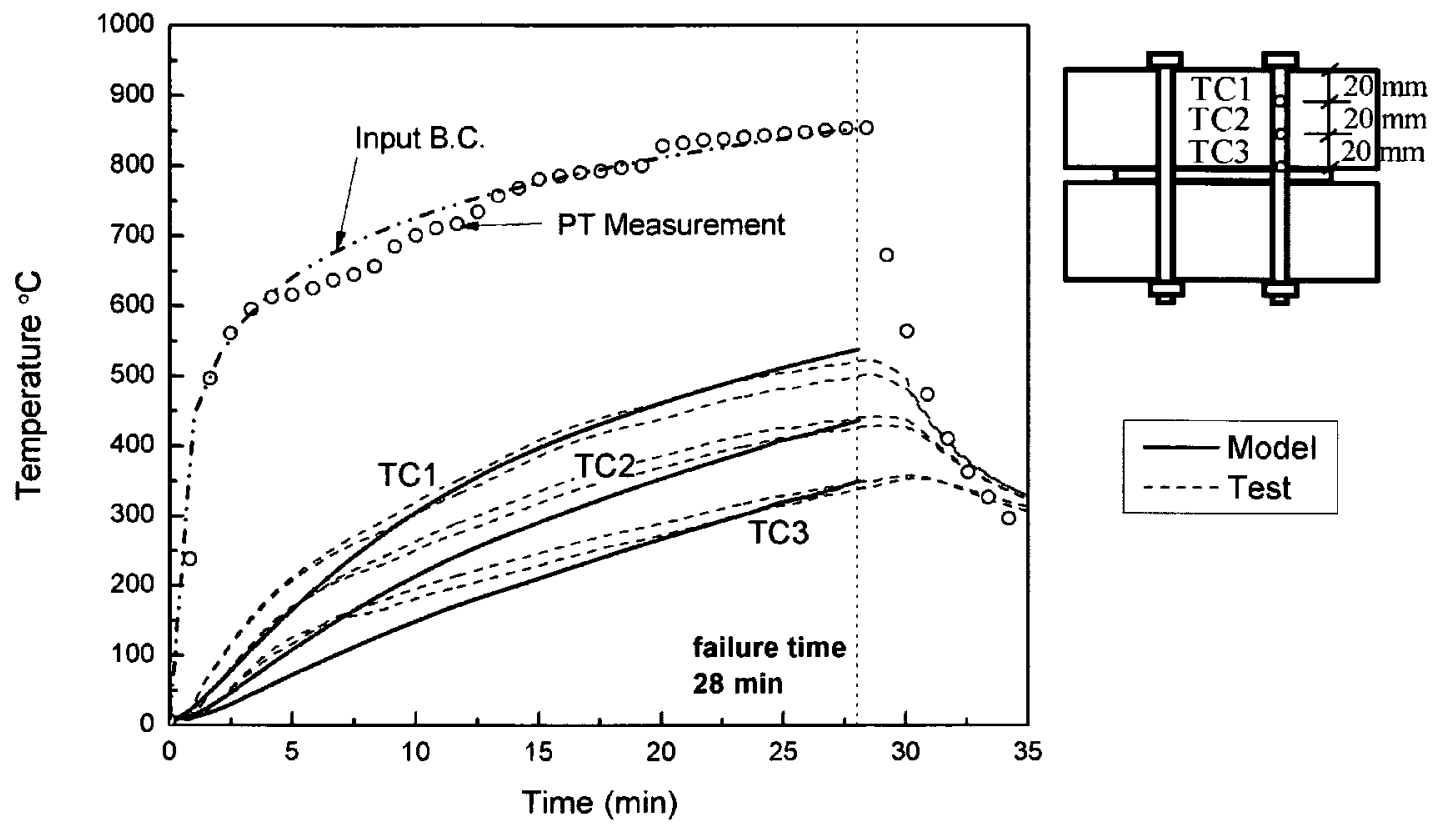

Figure 4.7 Bolt temperatures for WSW specimen \#2.1: model vs. test

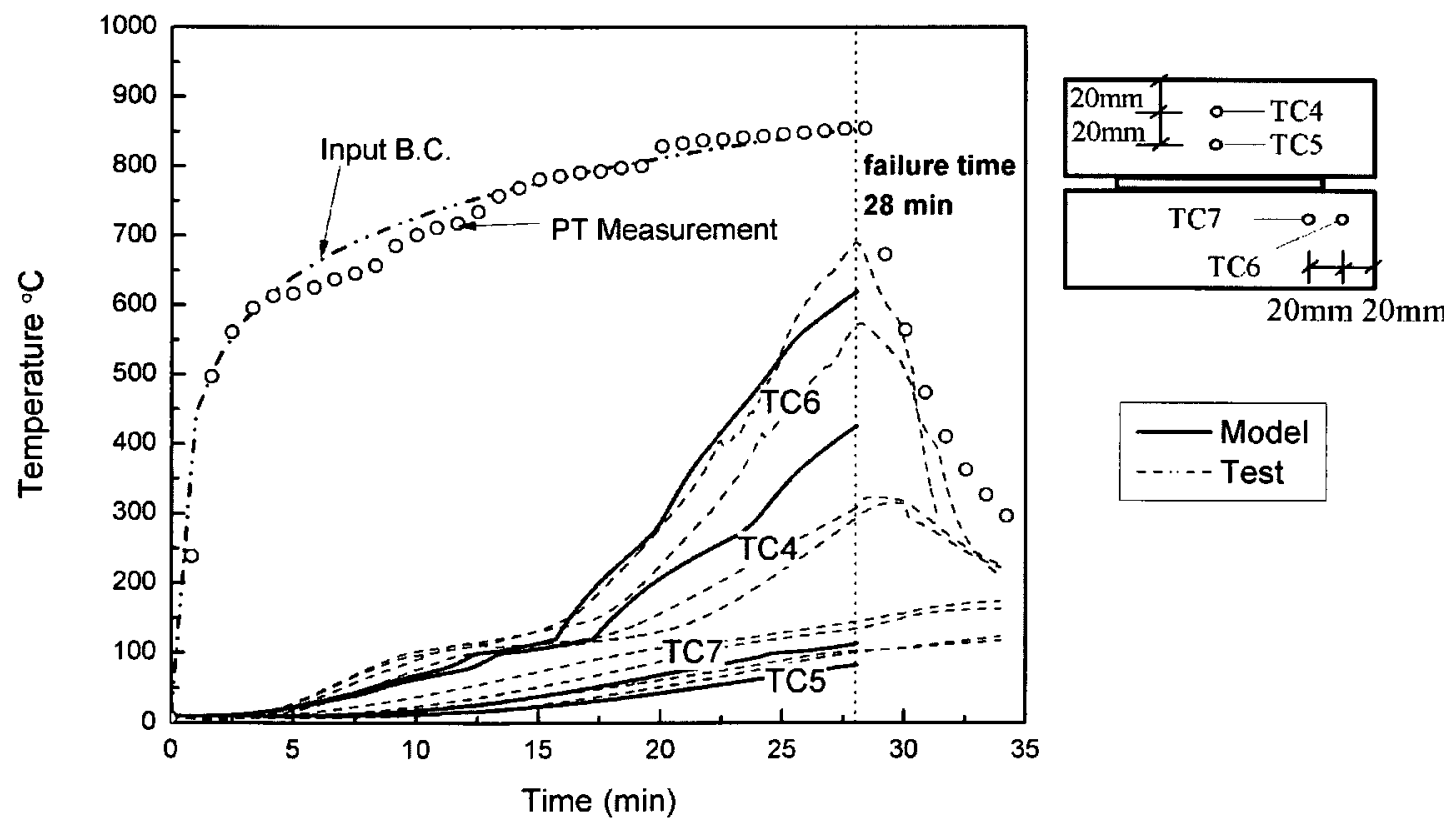

Figure 4.8 Wood temperatures for WSW specimen $\# 2.1$ : model vs. test 
Bolt temperatures are shown in Figure 4.7. Dashed lines are test results measured from the two bolts. In general, the modelled values were in good agreement with the test results. However, the temperatures predicted by the model seemed to be a little lower than the measured temperatures at the beginning (about $50^{\circ} \mathrm{C}-80^{\circ} \mathrm{C}$ lower), but they tended to converge gradually. A possible reason could be that the flow regime is turbulent for the first five to ten minutes in a fire-resistance test, as stated by Thomas (1997). After this time, the flow regime becomes laminar, since the difference between the gas temperature and that of the specimen surface is smaller (Thomas 1997). The convective coefficient might be quite large at the beginning of a fire test. Another possible explanation would be that the convective coefficient of $25 \mathrm{~W} / \mathrm{m}^{2} \mathrm{~K}$ is recommended more likely to large and flat exposed surfaces, like walls and floors (Mehaffey 1994; EN1991-1-2 2003). For bolted timber connections, the uneven surface due to bolt heads/nuts could cause local turbulences and result in a large convective coefficient near the bolts. However, it is recognized that heat transfer in typical fires seems to be not very sensitive to the convective coefficient, while radiation dominates the heat transfer process at high temperatures due to the fourth order of temperature in the heat flux equation $\left(T_{f}^{4}-T_{s}^{4}\right)$ (Thomas 1997). This also accounts for the gradual convergence of the calculated temperatures to the measurements.

Since a difference in temperature (about $50^{\circ} \mathrm{C}-80^{\circ} \mathrm{C}$ ) at the beginning does not affect the strength of the connection much, the constant convective coefficient of $25 \mathrm{~W} / \mathrm{m}^{2} \mathrm{~K}$, a widely accepted value in thermal analysis for standard fire tests, was kept in the heat transfer model in this research. 
Wood temperatures are shown in Figure 4.8. Dash lines are from test measurements. It can be seen that calculated temperatures in wood were under-estimated when the temperature was less than about $120^{\circ} \mathrm{C}$. This is because moisture movement in the wood specimen driven by heat was not taken in to account. When all moisture was evaporated over $120^{\circ} \mathrm{C}$, the curves tended to catch up to the measurements. For TC4, the calculated temperature increased a little faster than the test measurement. This is probably due to the uncertainties of wood thermal properties, but the time difference for reaching $300^{\circ} \mathrm{C}$ was only about 3-4 min. Over all, the calculations were in good agreement with the test results.

Figure 4.9 and Figure 4.10 show the temperature contours at cross-section $y_{s}-y_{s}$ and $y_{w}-y_{w}$ at 28 minutes, the failure time of the tested specimen. Although only $1 / 4$ of a specimen was modelled due to symmetry, the full cross-sections can be shown in ABAQUS/Standard using mirrors. It can be clearly seen that temperatures in the $y_{s}-y_{s}$ plane were higher than those in the $y_{w}-y_{w}$ plane, due to the heat conduction into wood through the bolts.

Figure 4.11 and Figure 4.12 show the residual cross-section views of wood at $y_{s}-y_{s}$ and $y_{w}-y_{w}$ from ABAQUS/Standard, compared with the cuts of the residual test specimen. The gray part in the contour presents the charred wood at which the temperature is over $300^{\circ} \mathrm{C}$. The bolts and steel plates are not shown. It can be seen that the heat transfer model gave a fairly good prediction of the residual wood dimensions when compared to the test results. 


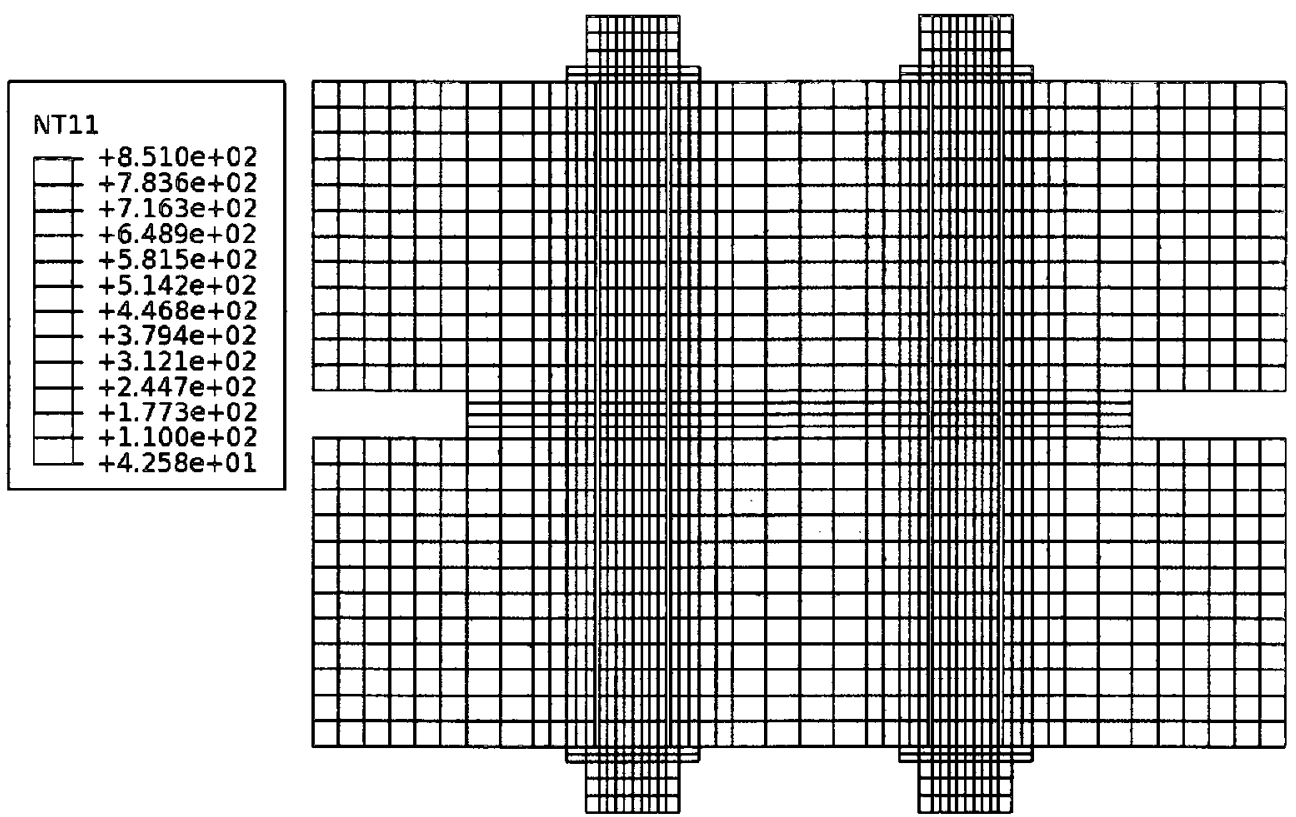

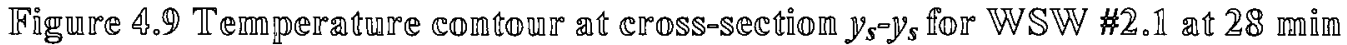

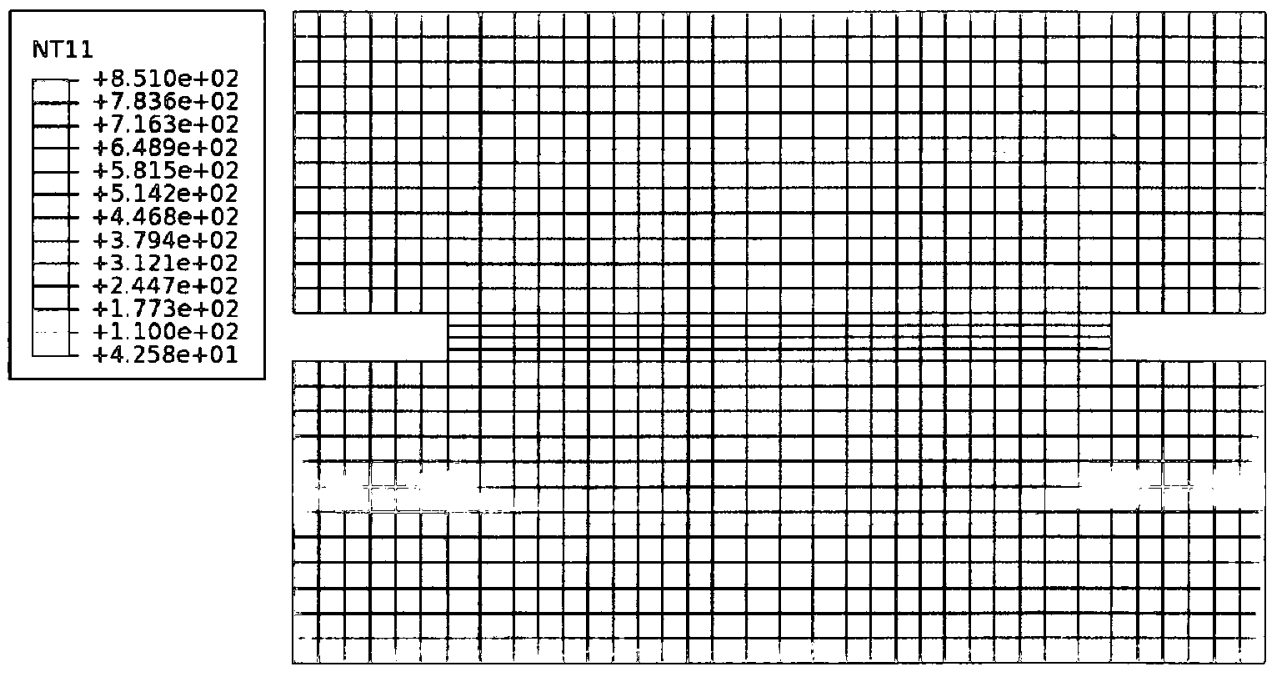

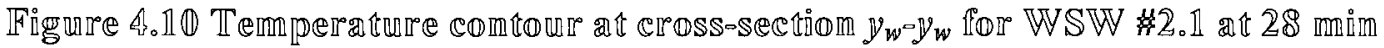



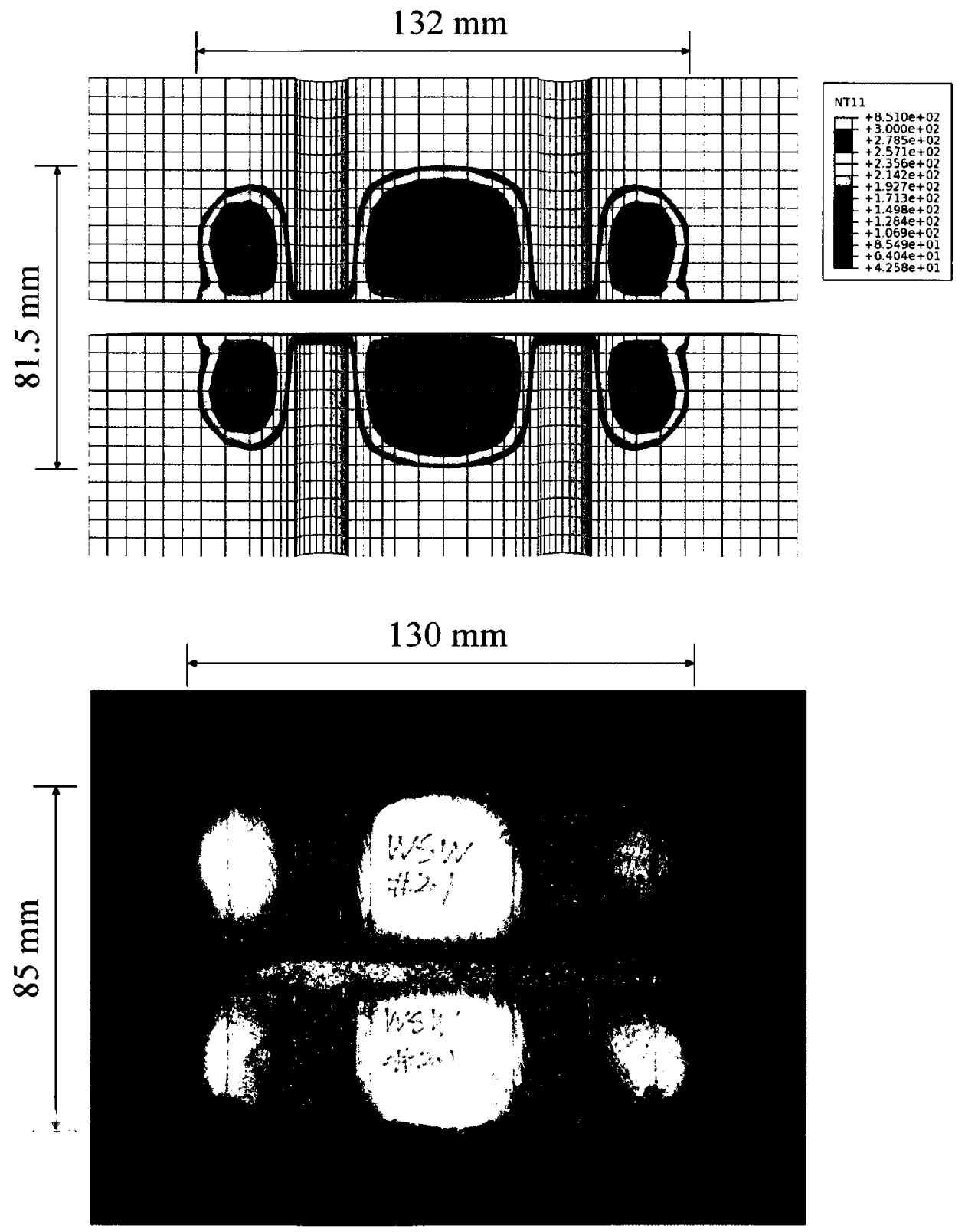

Figure 4.11 Residual cross-section view at $y_{s}-y_{s}$, from ABAQUS/Standard and test 

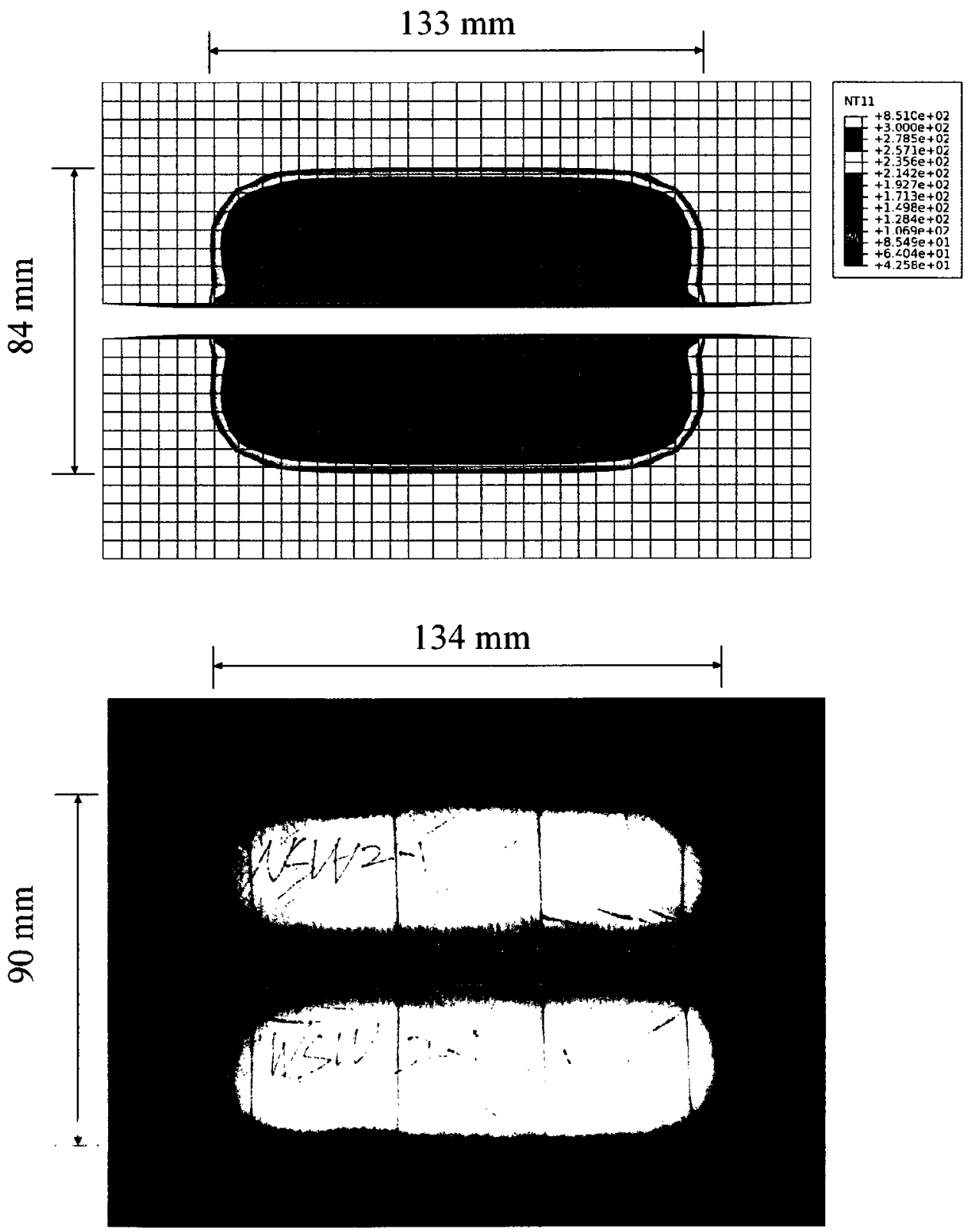

Figure 4.12 Residual cross-section view at $y_{w}-y_{w}$, from ABAQUS/Standard and test 


\subsubsection{SWS Connection}

SWS Test \#2.1 was also chosen to validate the heat transfer model. The specimen in SWS Test \#2.1 had a $130 \mathrm{~mm}$ thick central wood member and $19.1 \mathrm{~mm}$ diameter bolts. The mesh generated in ABAQUS/Standard is shown in Figure 4.13a. The element type was a three dimensional 8-node heat transfer element DC3D8. Due to symmetry, only one quarter of the connection was modelled. Figure $4.13 \mathrm{~b}$ shows the locations for temperature comparisons.

The wood member of the tested specimen was measured to have a density of $550 \mathrm{~kg} / \mathrm{m}^{3}$ and a moisture content of $11 \%$ prior to the test. The input temperature boundary conditions were based on the plate thermometer measurements.

By defining material properties and boundary conditions, the model was run in ABAQUS/Standard and predictions were compared to the thermocouple measurements at different locations, shown in Figure 4.14 and Figure 4.15.

As shown in Figure 4.14, the bolt temperature measured in the test increased faster than the bolt temperatures predicted by the model at the beginning, but they also tended to converge gradually. This is similar to the WSW connection modeling. The constant convective coefficient $25 \mathrm{~W} / \mathrm{m}^{2} \mathrm{~K}$ seems to be too small a value at the beginning but this does not matter later in the test when radiation dominates the heat transfer. In fact, the small difference of temperatures at the beginning does not affect the connection strength much. For wood temperatures, as shown in Figure 4.15, predicted temperatures increased slowly below $120^{\circ} \mathrm{C}$, but they also tend to catch up over $120^{\circ} \mathrm{C}$. Overall, the model 
predicted the specimen temperatures quite close to the measured results in the bolted SWS test.

(a)

(b)
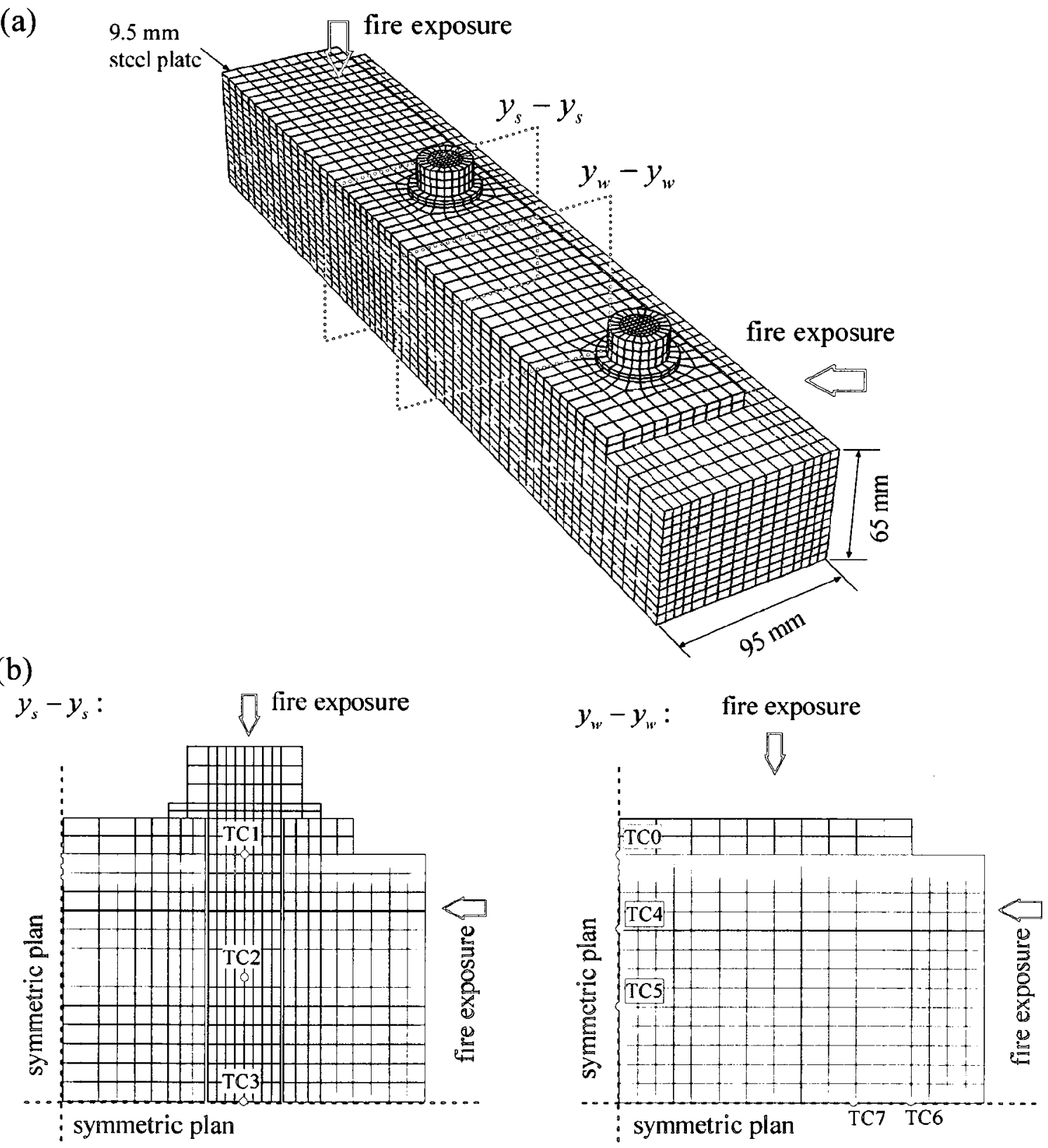

Figure 4.13 Mesh genergted in ABAQUS/Standard for SWS-Grouptzand thermocouple locations 


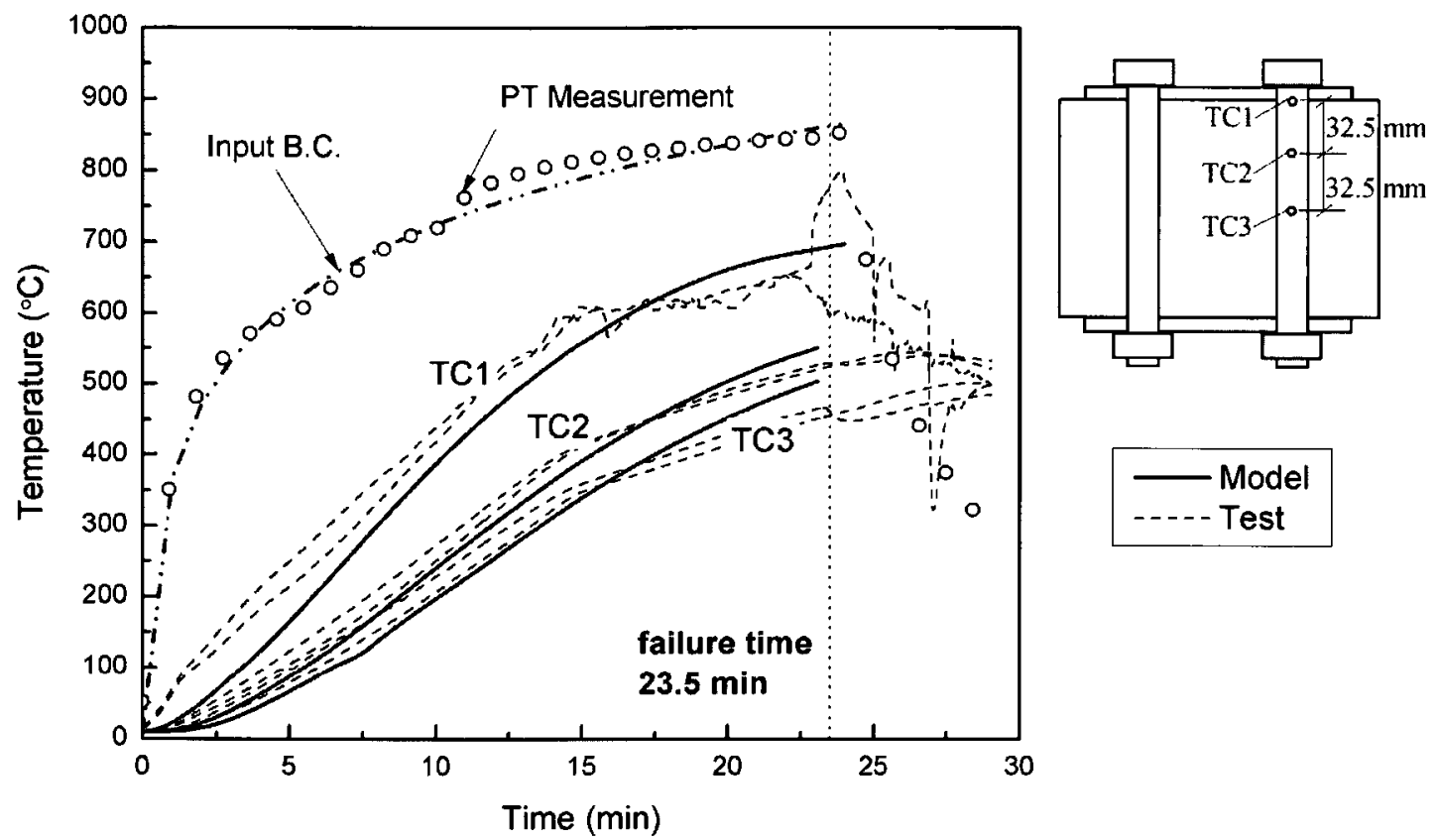

Figure 4.14 Bolt Temperatures for SWS specimen \#2.1: model vs. test

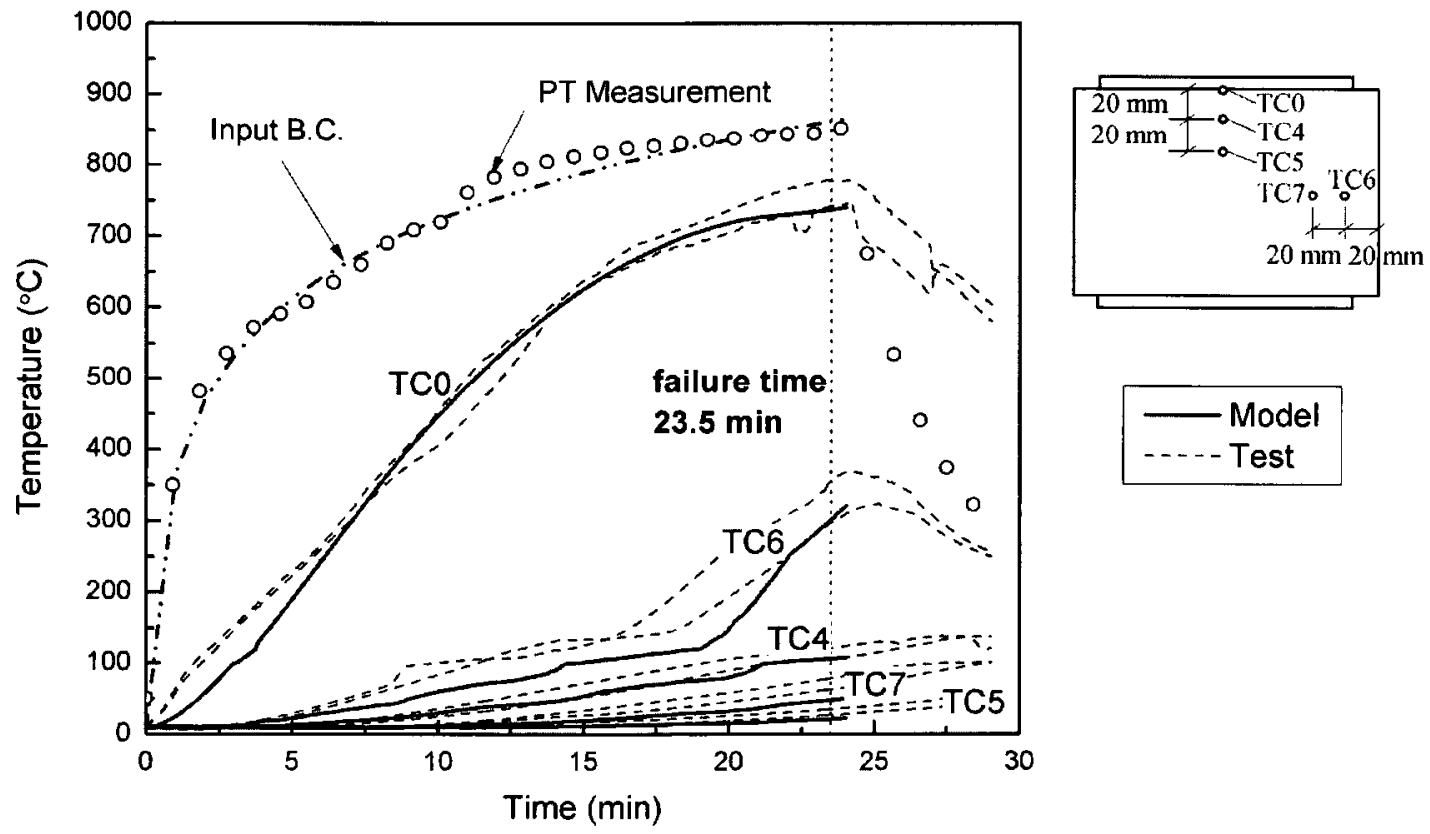

Figure 4.15 Wood Temperatures for SWS specimen \#2.1: model vs. test 
Figure 4.16 and Figure 4.17 show the temperature contours at cross-section $y_{s}-y_{s}$ and $y_{w^{-}}$ $y_{w}$ from ABAQUS/Standard at 23.5 minutes, the failure time of the tested specimen. Also, it can be seen that heat has been conducted into the wood through steel bolts and caused fast temperature rise in the wood.

Figure 4.18 and Figure 4.19 show the modelled residual cross-sections views of wood at $y_{s}-y_{s}$ and $y_{w}-y_{w}$ from ABAQUS/Standard, compared with the cuts of the residual test specimen. The gray part in the model contour presents the charred wood at which the temperature is over $300^{\circ} \mathrm{C}$. Again, it can be seen that the heat transfer model gave a good prediction on the residual wood dimensions. 

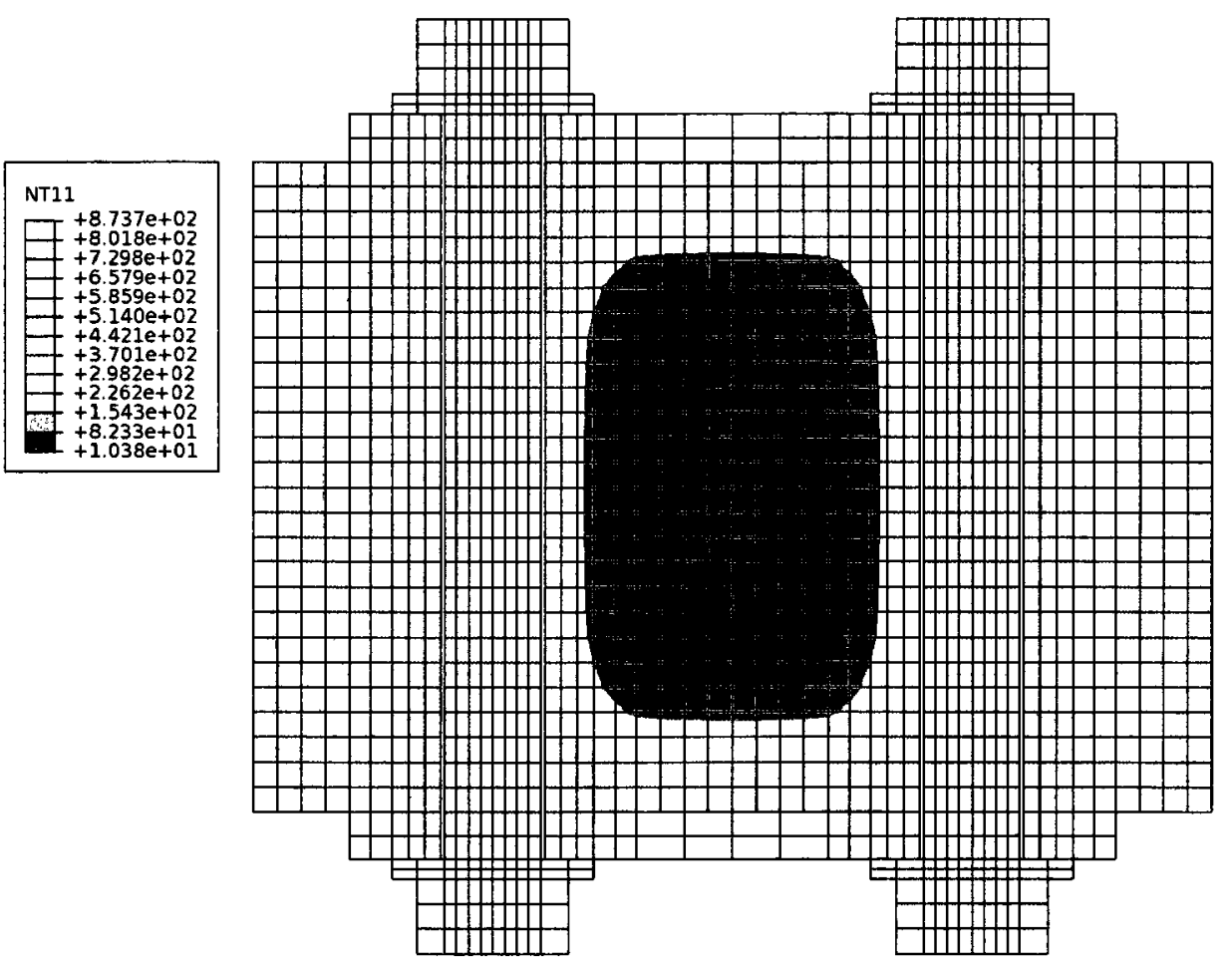

Figure 4.16 Temperature contour at cross-section $y_{s}-y_{s}$ for SWS \#2.1 at $23.5 \mathrm{~min}$
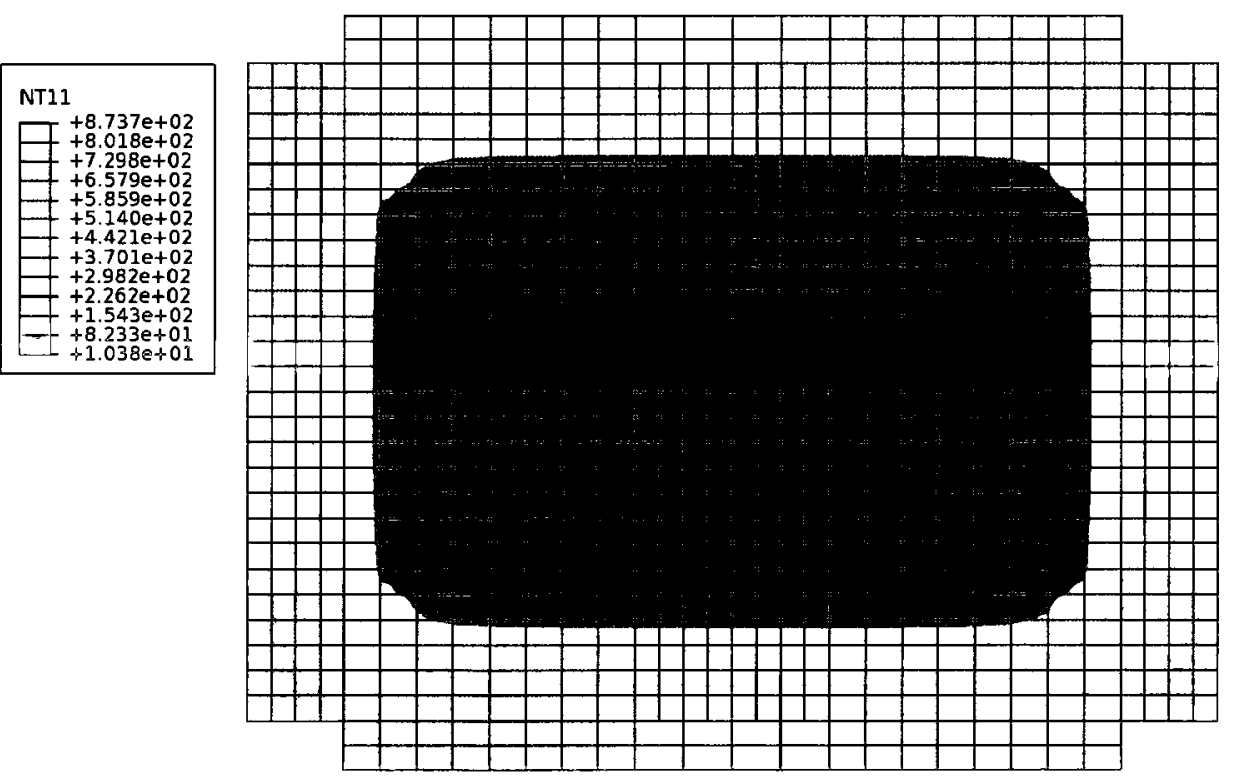

Figure 4.17 Temperature contour at cross-section $y_{w}-y_{w}$ for SWS $\# 2.1$ at $23.5 \mathrm{~min}$ 

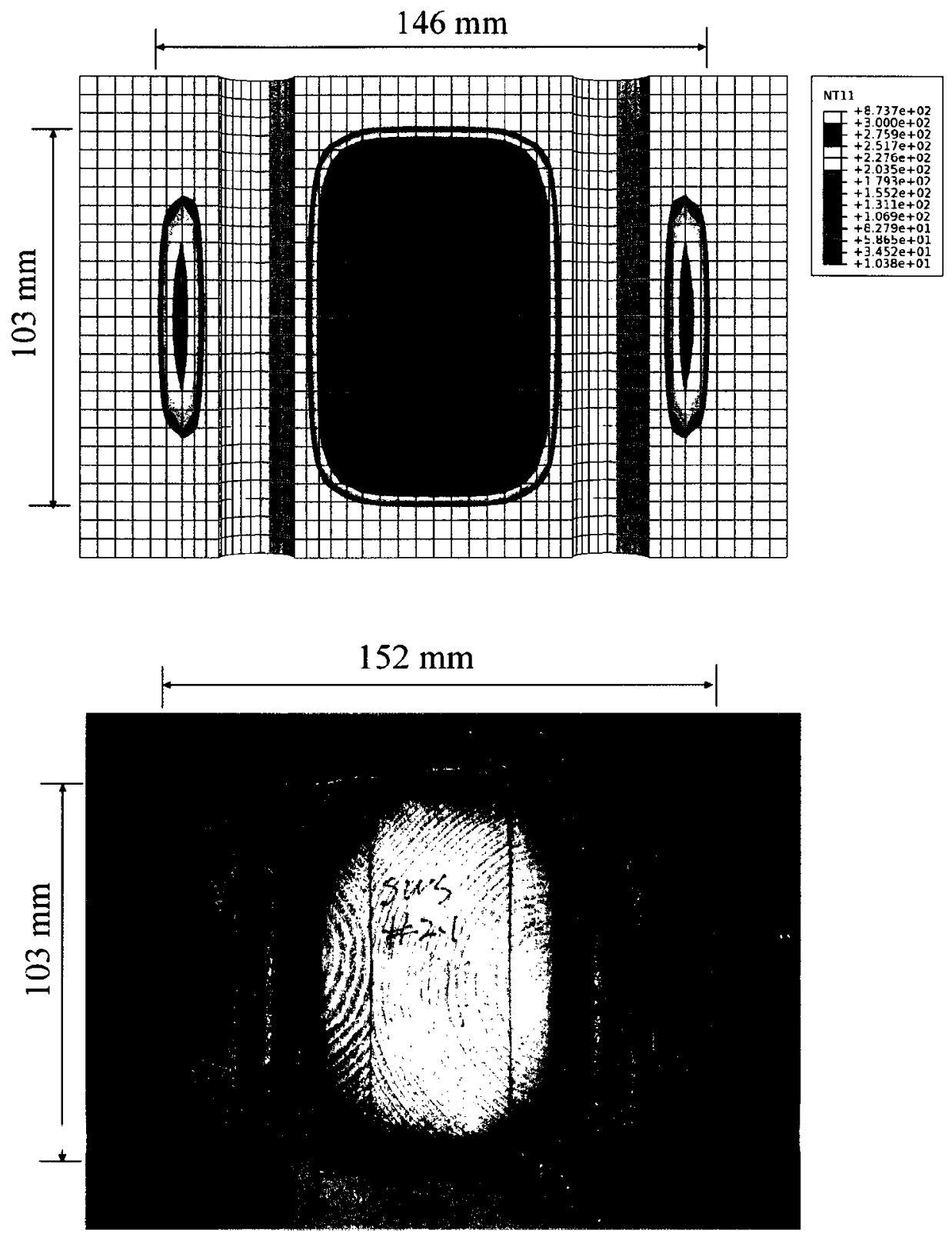

Figure 4.18 Residual cross-section view at $y_{s}-y_{s}$, from ABAQUS/Standard and test 

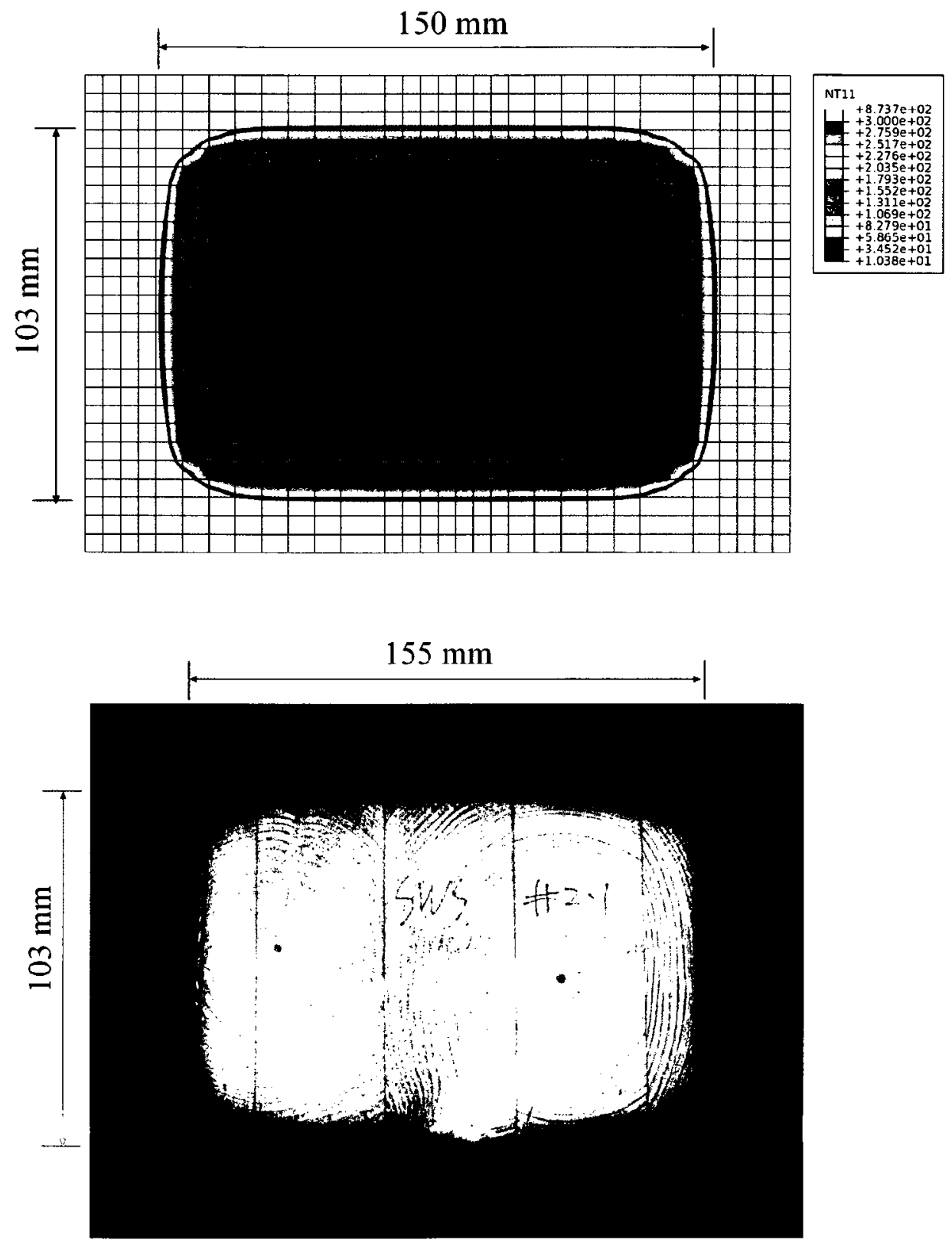

Figure 4.19 Residual cross-section view at $y_{w}-y_{w}$, from ABAQUS/Standard and test 


\subsection{Sensitivity Analysis}

In this section, firstly a mesh study was carried out to investigate the sensitivity of model predictions to the fineness of grids. Then, a sensitivity analysis was carried out to study the effects of uncertainties of input data on the heat transfer modelling. The variability of heat conductivity, specific heat and density of wood were included. In addition, the effect of boundary temperatures on the heat transfer modelling was also studied.

\subsubsection{Mesh}

As discussed before, when a timber connection is exposed in fire, heat is conducted into wood members through bolts and it increases the temperatures of the wood member close to the interface. A high temperature gradient appears near the bolt-hole interface, and therefore a fine mesh is required to predict the temperature distribution in this region. A mesh study was carried out in this subsection to determine the mesh generation on the heat transfer in a simple bolt-wood assembly.

A mesh, called Mesh A, was generated as shown in Figure 4.20 (left). The mesh is similar to the simple assembly that was used to study the gap effects in Figure 4.4 , but the clearance was set to be $1.6 \mathrm{~mm}$. The minimum mesh size of the wood in the transverse plane to the fastener was about $2.5 \mathrm{~mm}$ for Mesh A, and the mesh size in the thickness direction was $5 \mathrm{~mm}$.

The examined temperature locations are shown in Figure 4.20 (right). B1 and B2 were located in the bolt, W1 and W2 were located in the wood $9.5 \mathrm{~mm}$ (about $0.5 d$ ) away from the interface, and W3 and W4 were in the wood about $1 d$ away from the interface. 

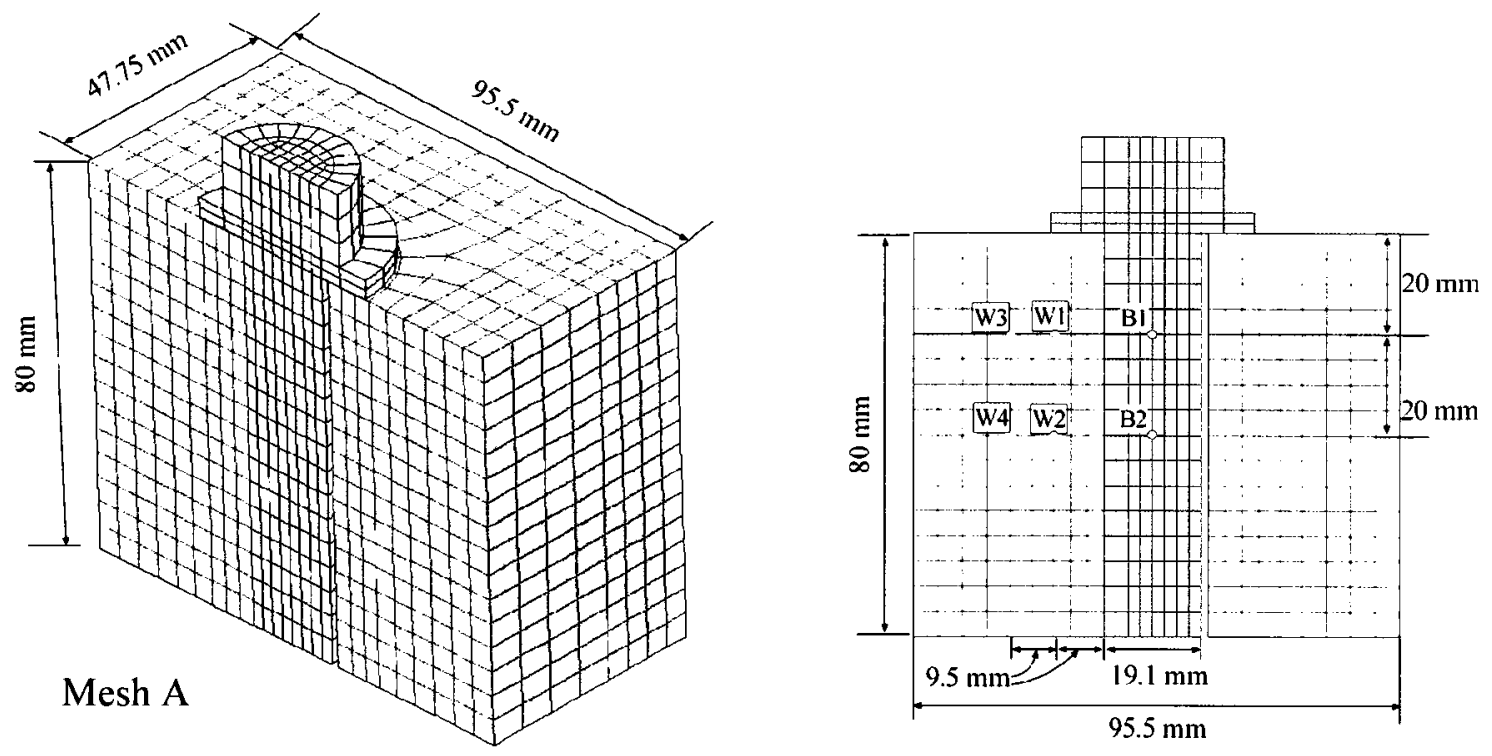

Figure 4.20 Mesh A and temperature locations
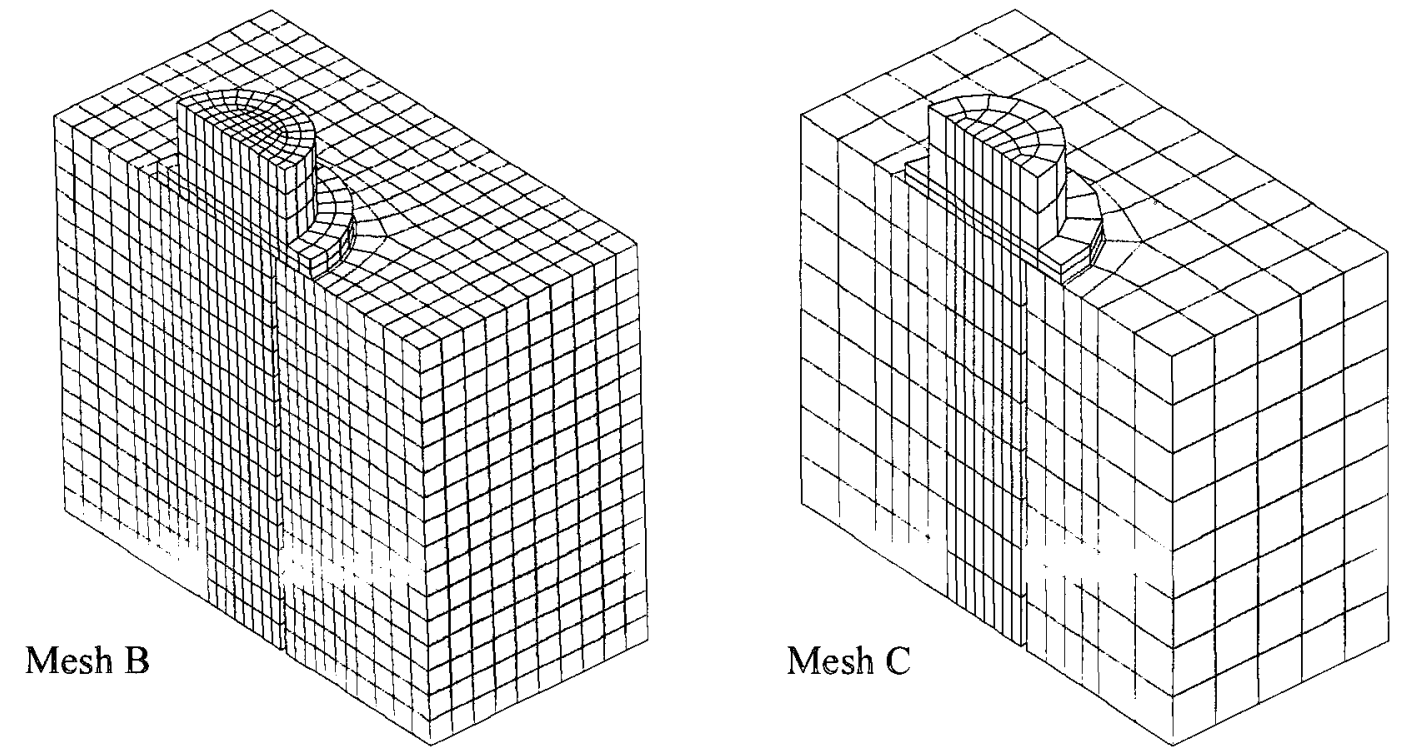

Figure 4.21 Mesh and Mesh $\mathbb{C}$ for mesh síndy

A finer Mesh $\mathbb{B}$ and a coarser Mesh $\mathbb{C}$, were also generated, as shown in Figure 4.21. Mesh $B$ has finer grids around the wood hole. The minimum mesh size of the wood in the transverse plan to the fastener was about $1.9 \mathrm{~mm}$ and the mesh size in the thickness 
direction was $5 \mathrm{~mm}$ for Mesh B, which is the same as Mesh A. Mesh C had coarser grids, with a minimum mesh size of about $4 \mathrm{~mm}$ in the transverse plane to the fastener and 10 $\mathrm{mm}$ in the thickness direction. The examined temperature locations for Mesh B and C were the same as those for Mesh A.

Temperature histories at different locations for the three meshes are shown in Figure 4.22. It can be observed that the differences of bolt temperatures for these cases were very small (left); while there were some differences in wood temperatures for the three meshes, but the maximum differences, ranging from about $20^{\circ} \mathrm{C}$ to $30^{\circ} \mathrm{C}$, are not significant.

As Mesh A had an affordable calculation time and relatively fine grids, it was chosen as the base case for investigating the sensitivity to thermal conductivity, specific heat and density of wood. In each sensitivity run of the model, one parameter was varied from the base case, and the difference is discussed.
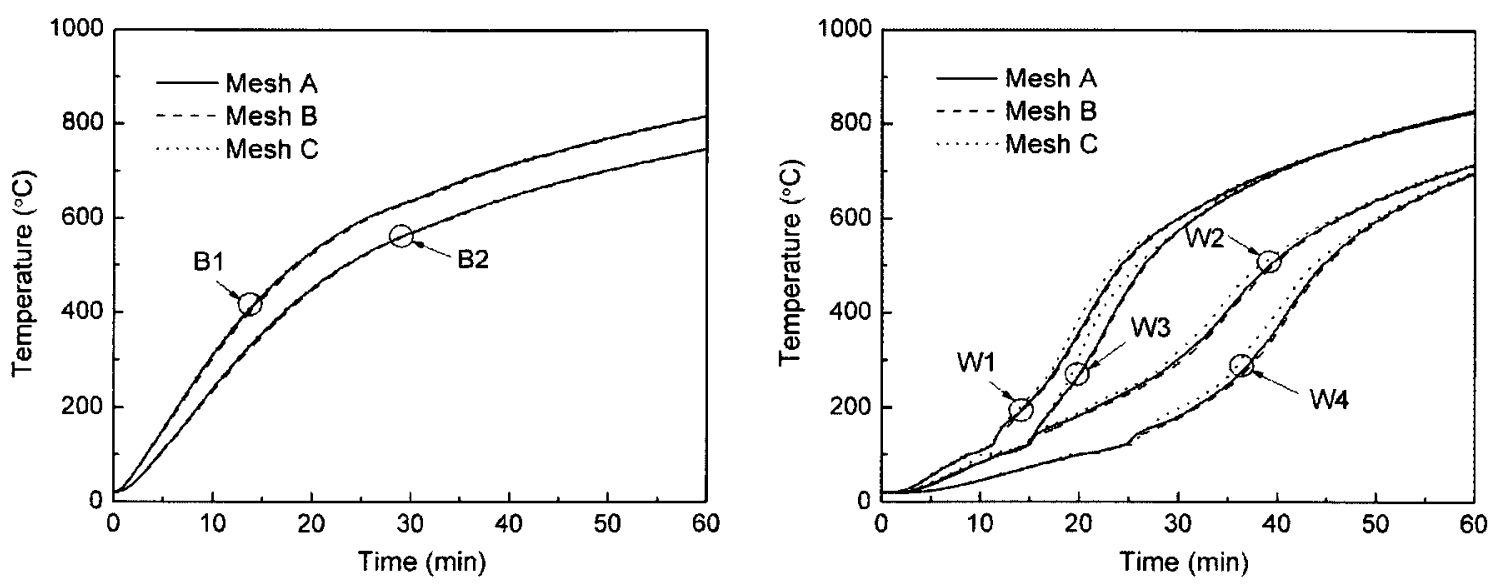

Figure 4.22 Temperature histories for mesh study 


\subsubsection{Wood Thermal Conductivity}

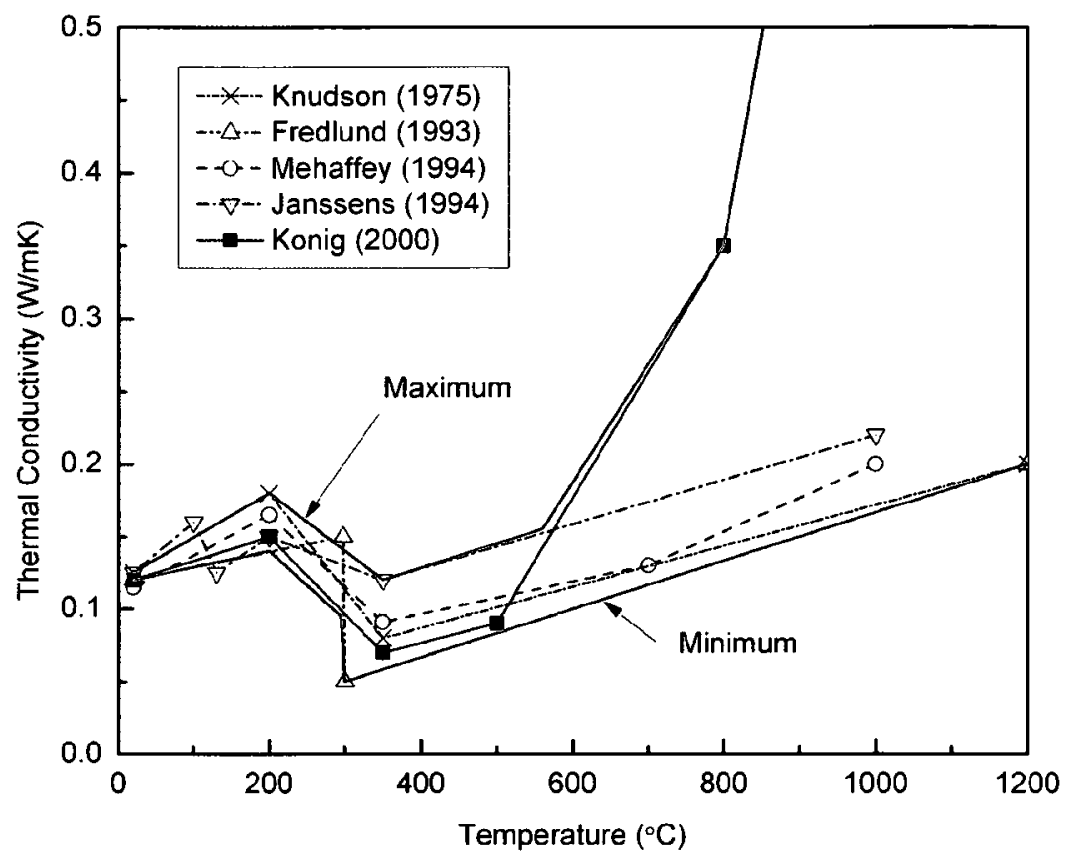

Figure 4.23 Thermal conductivity of wood at elevated temperatures

The maximum and minimum values of the wood thermal conductivity as a function of temperature are plotted in Figure 4.23, as well as other values from the literature. The value used in the base case was taken from Konig's report. The simple assembly, as shown in Figure 4.20, was used for the analysis.

Figure 4.24 shows the temperature history results of the maximum, minimum and base case. The differences of bolt temperatures for these cases were very small, but the temperature differences in wood were significant for the three cases. Especially, the wood temperatures for the minimum case were significantly lower than those of the base and maximum cases. It seems that it is necessary to increase the thermal conductivity of wood at high temperatures to take into account the effect of char cracks and shrinkage, as Konig did. 

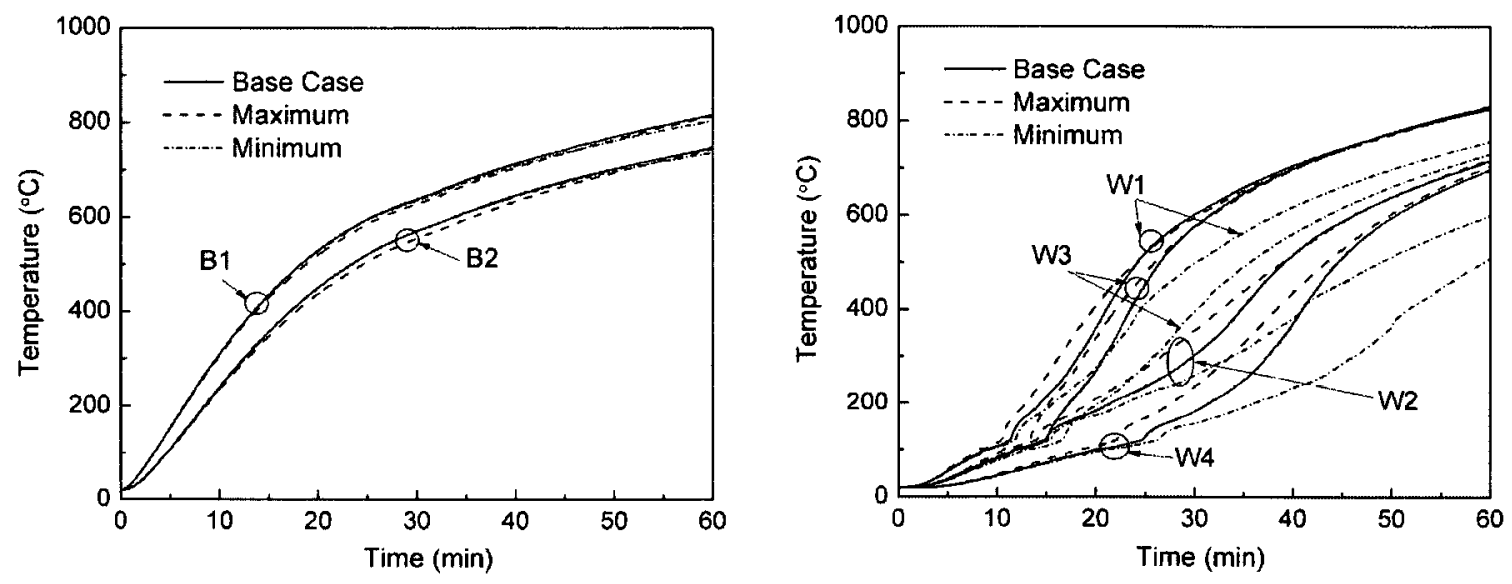

Figure 4.24 Temperature histories for wood thermal conductivity sensitivity analysis

\subsubsection{Wood Specific Heat}

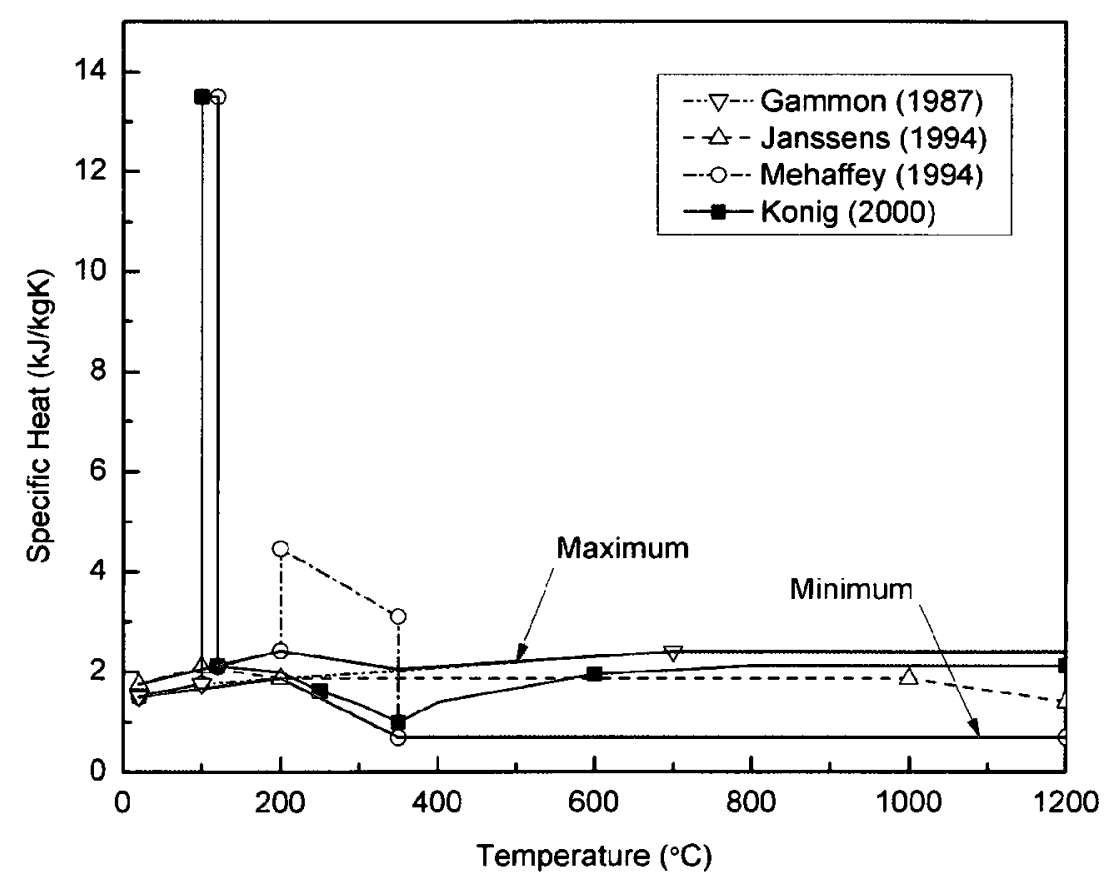

Figure 4.25 Specific heat of wood at elevated temperatures

Figure 4.25 shows the maximum and minimum values of the wood specific heat as a function of temperature, as well as different curves from the literature. A peak value presenting the extra energy to evaporate moisture between $100^{\circ} \mathrm{C}$ and $120^{\circ} \mathrm{C}$ was not 
considered in the maximum and minimum specific heat values. The value used in the base case was taken from Konig's report. Again the simple assembly, as shown in Figure 4.20 , was used for the analysis.

Figure 4.26 shows the results of the maximum, minimum and base case. The temperature histories in wood and bolt were plotted. Again, the differences of bolt temperatures for these cases were very small, but big differences of wood temperatures existed for the three cases. Especially, the wood temperatures for the minimum case increased much faster than those of the base and maximum cases. This indicates that if a high thermal conductivity of wood is used at high temperatures, a relatively high specific heat should be used as well at high temperatures.
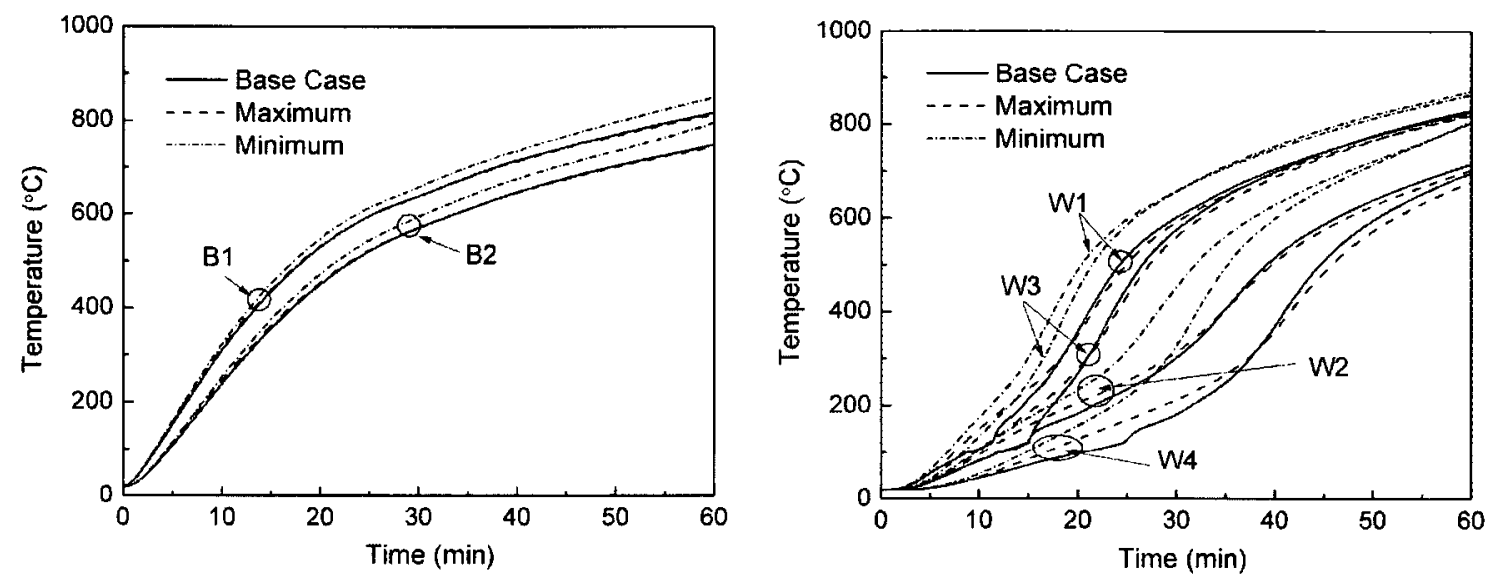

Figure 4.26 Temperature histories for wood specific heat sensitivity analysis 


\subsubsection{Wood Density}

As reported in Chapter 3, the recorded densities of SPF lumber and SP glulam specimens varied between $416 \mathrm{~kg} / \mathrm{m}^{3}$ and $503 \mathrm{~kg} / \mathrm{m}^{3}$, with a mean density of $455 \mathrm{~kg} / \mathrm{m}^{3}$ and an average moisture content of $11 \%$. In this subsection, the maximum and minimum densities used in the analysis were $415 \mathrm{~kg} / \mathrm{m}^{3}$ and $505 \mathrm{~kg} / \mathrm{m}^{3}$, respectively. The value used in the base case was $455 \mathrm{~kg} / \mathrm{m}^{3}$. The moisture content was set to be $11 \%$ for all cases. The same simple assembly, as shown in Figure 4.20, was used for the analysis.

Figure 4.27 shows the results of the maximum, minimum and base case. The temperature histories in wood and bolt were plotted. It can be seen that wood density has a considerable impact on the wood temperature distribution.
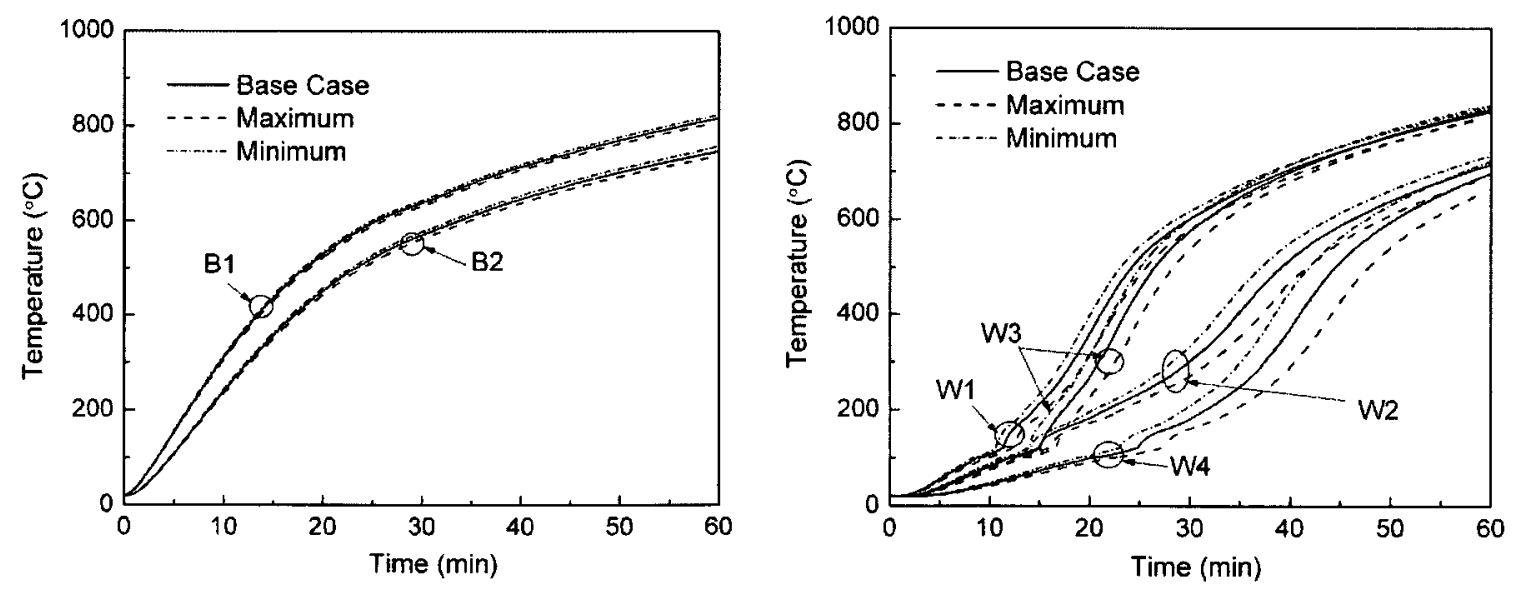

Figure 4.27 Temperature histories for density sensitivity analysis 


\subsubsection{Furnace Temperature}

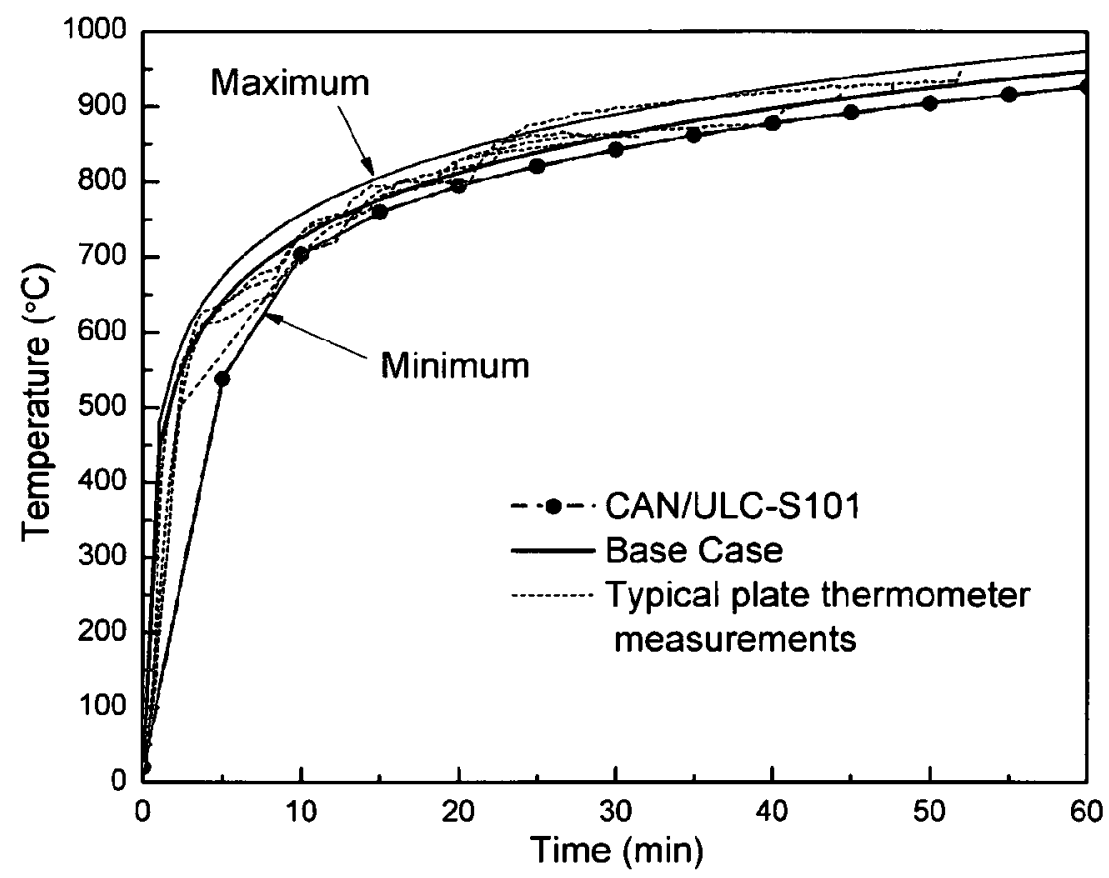

Figure 4.28 Furnace temperature vs. time

It was noticed that for every fire test, the boundary conditions could not be exactly identical. According to CAN/ULC-S101 (2007), the allowable tolerance of temperatures measured by thermocouples is $\pm 10 \%$ for a fire test within one hour duration. This is a large range and might cause considerable difference for some tests. Therefore, a sensitivity analysis was carried out to evaluate the variation of furnace temperatures on the heat transfer of a timber connection.

Figure 4.28 shows a couple of typical furnace temperature curves measured by plate thermometers. It can be seen that variations existed in the fire tests. A curve, which represents average temperature history of most of the tests, was selected as the base case. 
Maximum and minimum curves are also shown in Figure 4.28 as red lines. The minimum curve was chosen to be the same curve as the CAN/ULC-S101 curve.

Figure 4.29 shows the results of the maximum, minimum and base case. The temperature histories in wood and bolt were plotted. It can be seen that the variation of furnace temperatures has a considerable effect on the bolt and wood temperature distributions.
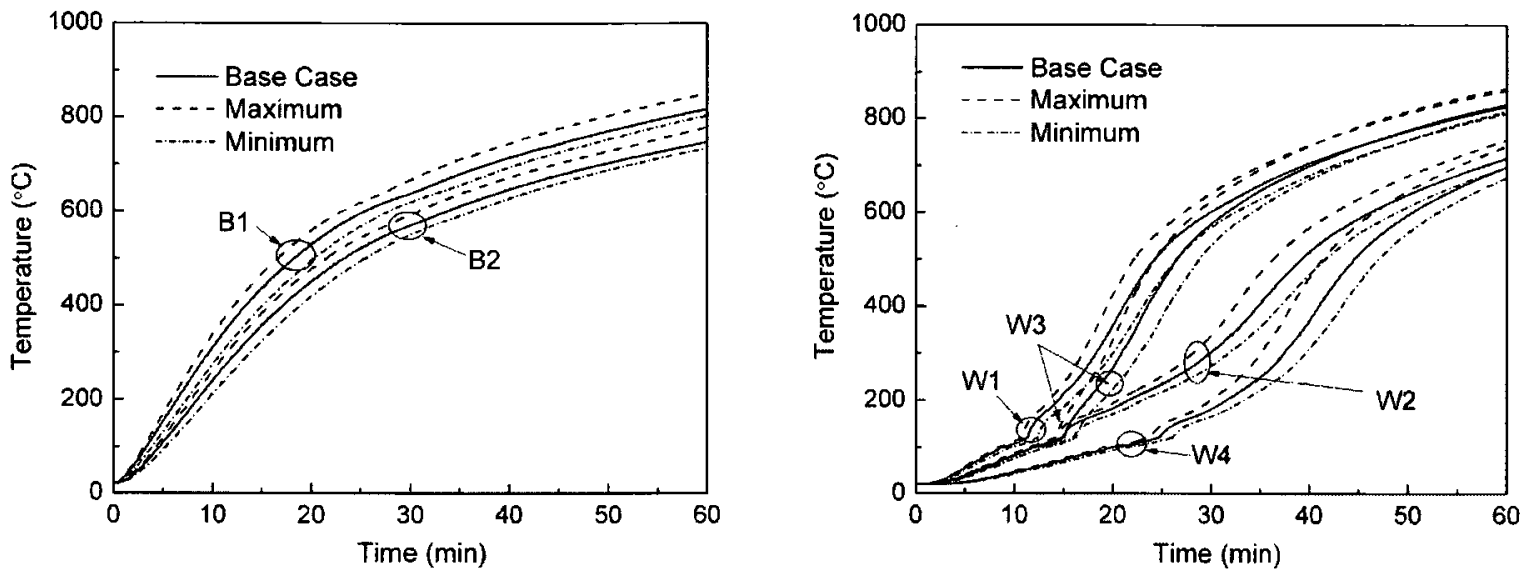

Figure 4.29 Temperature histories for furnace temperature sensitivity analysis

\subsection{Summary}

Firstly, wood thermal properties used in this study were validated against experimental data in a one dimensional heat transfer analysis. Secondly, the contact thermal resistance at the bolt-wood interface and the wood-steel plate interface was evaluated and it was found that the gap effect at these interfaces is very small.

The three dimensional heat transfer model has been compared to the fire-resistance test results of both bolted WSW and bolted SWS connections. Overall, the predicted temperatures were found to be close to the measurements. At the beginning of a fire test, 
the model seemed to underestimate the bolt temperatures for about $50-80^{\circ} \mathrm{C}$, and the model also underestimated the wood temperatures when the temperature was less than $120^{\circ} \mathrm{C}$. However, the predicted temperatures tended to catch up to the measured results later on for both wood and bolt temperatures. Since small differences at lower temperatures do not have significant influence on the timber connection strength, the heat transfer model is considered to be able to predict the temperature profiles in a timber connection with a good agreement.

Furthermore, a mesh study was carried out to optimize the simulation and a relatively fine mesh was used for all the sensitivity analysis. The sensitivity analysis showed that the variations of wood conductivity, specific heat and density have a large impact on the heat transfer model results. It was found that if the wood thermal conductivity value was increased at high temperatures (Konig's assumption), accordingly, a small value should be used for specific heat at high temperatures, and vice versa. The density is one of the material properties that can be well measured and defined. Therefore, depending on the purpose of analysis, either the $5^{\text {th }}$ percentile value or average value can be chosen in the model. The furnace temperature is another factor that has considerable effect on the specimen temperature distributions. The overall influences of the density and the furnace temperature on the fire resistance of timber connections will be discussed in the following chapter. 


\section{Chapter 5: Structural Analysis}

This chapter describes the structural analysis of timber connections at elevated temperatures. The structural analysis was based on the strength of timber connections due to possible failure modes at elevated temperatures. The temperature distribution with in the connection was calculated using the heat transfer model as described in Chapter 4 . Johansen's yield theory was used to determine the strength of timber connections under fire exposure. The embedding strength reduction relationships at elevated temperatures proposed by various researchers were discussed and the structural analysis results were compared with the experimental results. In addition, applications were also carried out, based on the heat transfer model and the structural model, to analyze the fire resistances of timber connections with larger dimensions, which were not researched experimentally in this study.

\subsection{Structural Analysis for WSW Connections}

As discussed in Chapter 3, the most common failure mode observed in the fire-resistance tests of bolted WSW connections was the extensive elongation of holes. In most tests, bolts did not show any bending deformation, and steel plates did not show considerable deformation as well. Therefore, the capacity of bolted WSW connections can be calculated based on the theory predicting the crushing failure of wood (refer to ductile failure mode 1 as shown in Figure 2.18), by taking into account the embedding strength reduction at elevated temperatures. 
Thermal expansion was not considered in the structural model. For wood members, thermal expansion is very small and can be neglected (Frangi 2003). For steel members, although thermal expansion does occur at high temperatures, no extra restraint was applied because clearances were left between the bolts, steel plates and wood members. Therefore, no high stress would be generated due to thermal expansion of the bolts and steel plates.

\subsubsection{Methodology}

The embedding strength at room temperature was calculated by (EN1995-1-1 2004):

$$
f_{w}=0.082(1-0.01 d) \rho
$$

where $\rho$ is the wood density in $\mathrm{kg} / \mathrm{m}^{3}$, and $d$ is the fastener diameter in $\mathrm{mm}$. The unit of $f_{w}$ is in MPa.

Figure 5.1 shows the external and internal forces on a fastener for ductile failure mode 1 . Due to the temperature gradient, the embedding strength along the bolt is not uniform. The capacity of one fastener in a WSW connection was calculated by integrating embedding strength along the bolt length:

$$
R_{f i}=2 \cdot \sum_{i=1}^{\mathrm{n}}\left(\left(f_{w}\left(x_{i}\right) \cdot d\right) \cdot x_{i}\right)
$$

where ' $i$ ' is an element along the bolt from 1 to $\mathrm{n}$ for one side member $\left(t_{1}\right), x_{i}$ is the length of this element, $f_{w}\left(x_{i}\right)$ is the temperature-dependent embedding strength at the element $i$, and $d$ is the fastener diameter. 


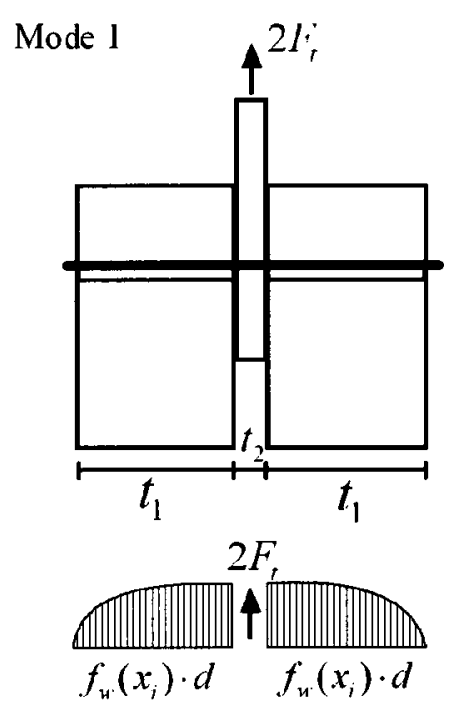

Figure 5.1 Failure mode 1 of a WSW connection

As observed in the fire tests, a few specimens, especially specimens in Group \#1 with thinner wood side members tended to fail due to splitting. However, the specimens also showed a considerable hole elongation prior to the final splitting failure. Therefore, only failure mode 1 was considered in the calculation of the strength of WSW connections.

The relationships between the reduction factor of wood embedding strength and the temperature were summarised in subsection 2.3.3.2 and re-plotted in Figure 5.2. Basically, there are two approaches with different assumptions used by researchers to estimate the embedding strength in wood members under fire exposure. In Moss's research (Moss 2008), the temperatures at the bolt-hole interface were used to determine the embedding strength $f_{w}$ at the elevated temperatures. An issue with this approach is that a connection can not carry any load when the interface temperature exceeds over $300^{\circ} \mathrm{C}$, due to the formation of char. Therefore, in order to predict the failure time accurately, Moss assumed that wood had approximately $20 \%$ of the ambient embedding strength 
above $270^{\circ} \mathrm{C}$. With this assumption, Moss found that the strength of timber connections at elevated temperatures can be predicted accurately.

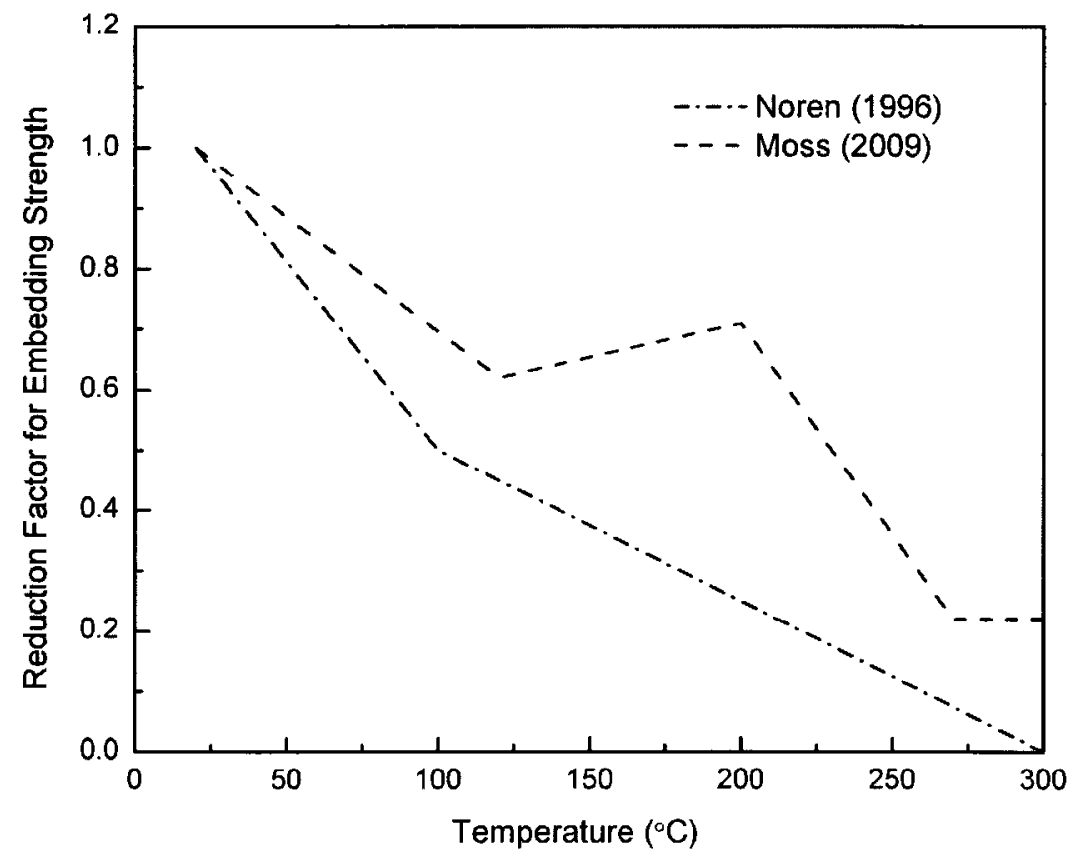

Figure 5.2 Reduction of wood embedding strength at elevated temperatures

In Noren's research (Noren 1996), however, the temperatures in the wood members about $2 \mathrm{~mm}$ away from the nail/hole interface were used to determine the embedding strength $f_{w}$ at the particular temperatures. The diameter of the nails was $4 \mathrm{~mm}$. The temperaturedependent embedding strength values used by Noren are smaller than the embedding strength values used by Moss. No residual embedding strength above $270^{\circ} \mathrm{C}$ was assumed, since temperatures decrease as the location moves away from the interface. Noren also commented that the moisture effect in the residual specimen was considered in the relationship. Erchinger used a mean temperature of elements that are in the range of $3.5 d$ away from the fastener to determine embedding strength (Erchinger 2010). 
In this research, both approaches were used and compared. As shown in Figure 5.3, in Moss' approach, temperatures of the elements at the bolt/hole interface (i.e. $i_{1}$ or $j_{1}$ ) were used to determine the embedding strength; in Noren's approach, the elements at $0.5 d$ away from the interface (i.e. $i_{2}$ or $j_{2}$ ) were used to calculate the strength.

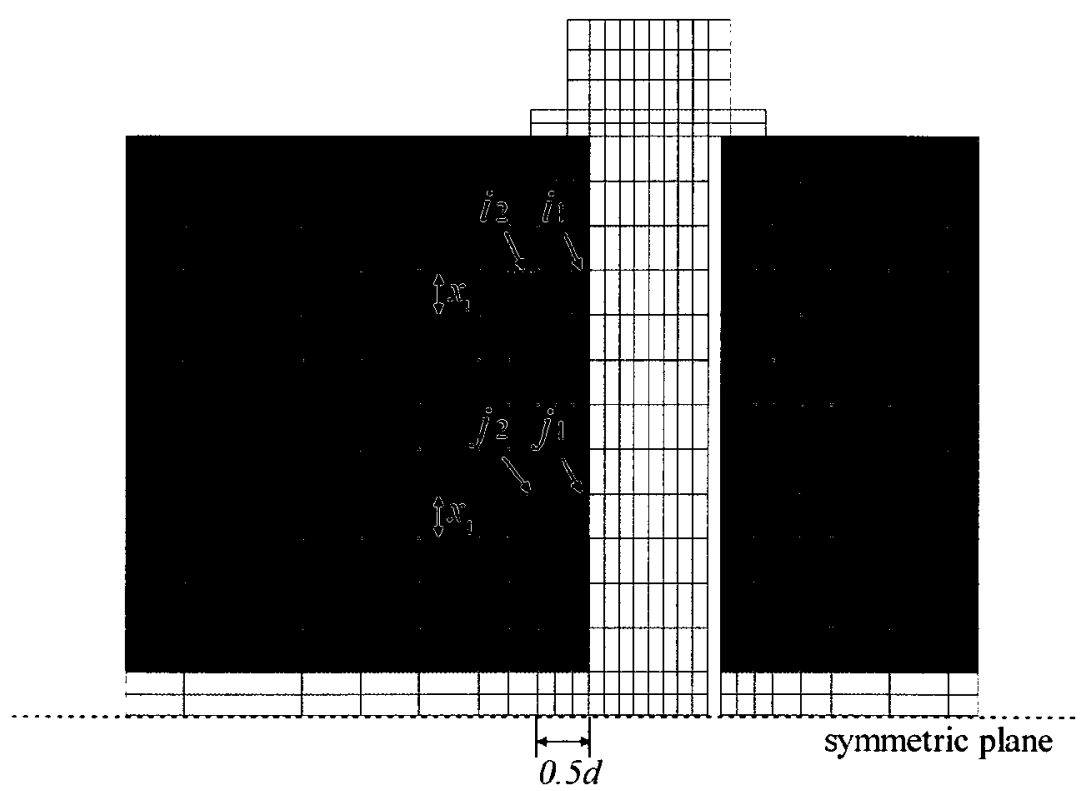

Figure 5.3 Elements used to determine the embedding strength for both Moss's and Noren's approach

\subsubsection{Result}

As discussed before, the capacity of a fastener at elevated temperatures could be calculated by integrating the embedding strength along the bolt length, using either Noren's or Moss's approach. The capacity of a connection was then taken as the sum of the strength of each fastener. The calculated capacity was converted to the load ratio, and plotted in Figure 5.5 to Figure 5.7 for WSW Groups \#1-5. WSW Groups \#3 and \#4 are shown in one plot because the effect of number of bolts is insignificant. 


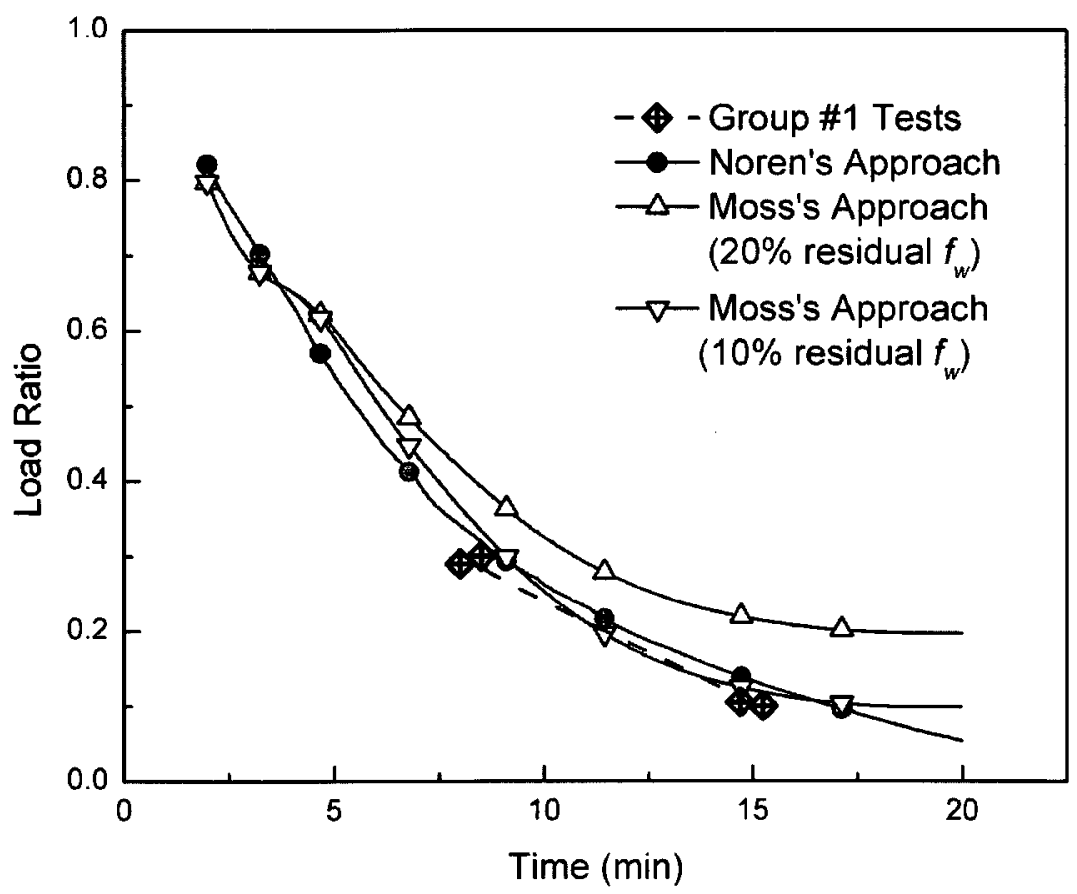

Figure 5.4 Calculated results compared with test results for WSW Group \#1

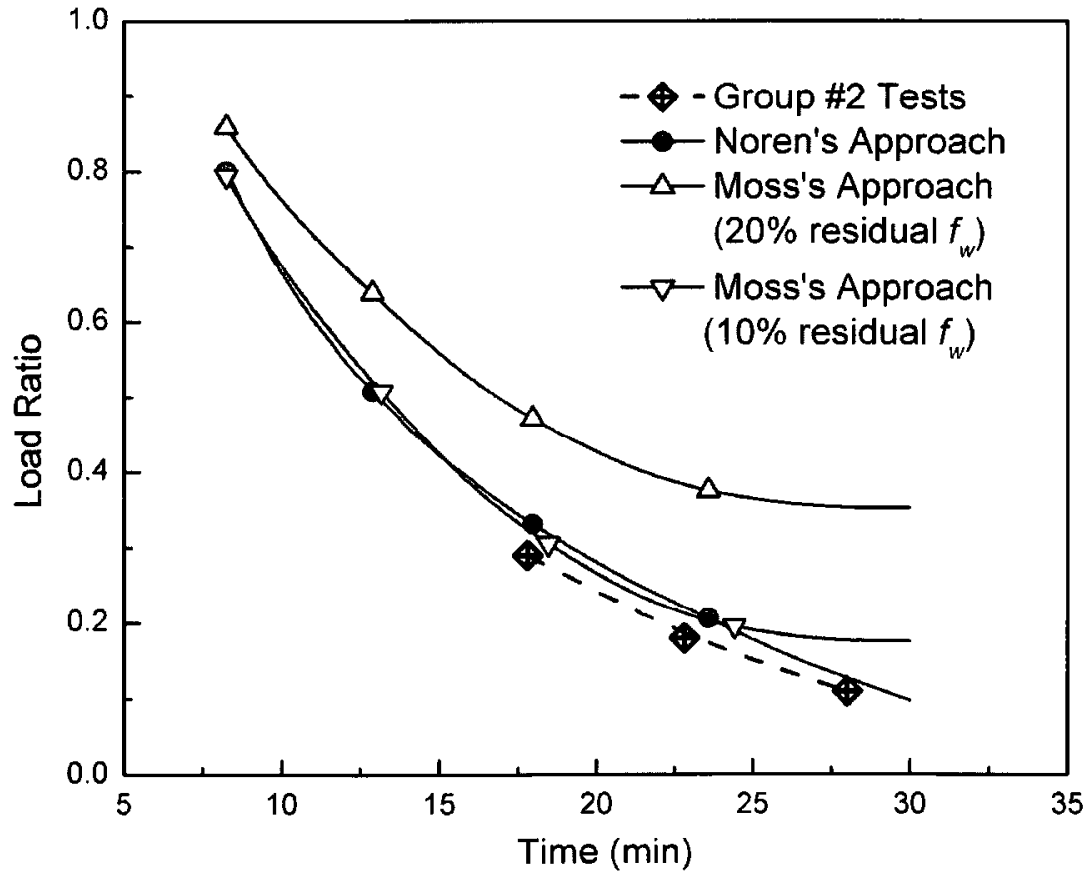

Figure 5.5 Calculated results compared with test results for WSW Group \#2 


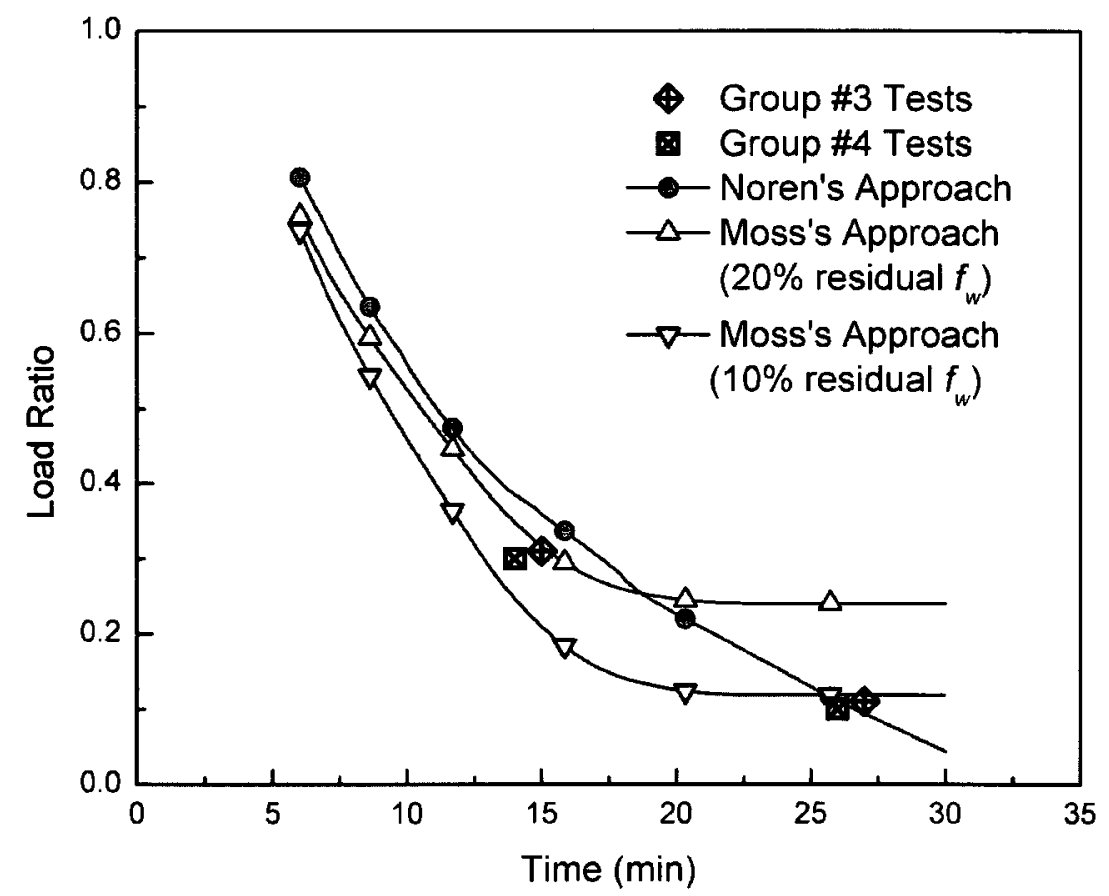

Figure 5.6 Calculated results compared with test results for WSW Group \#3 and \#4

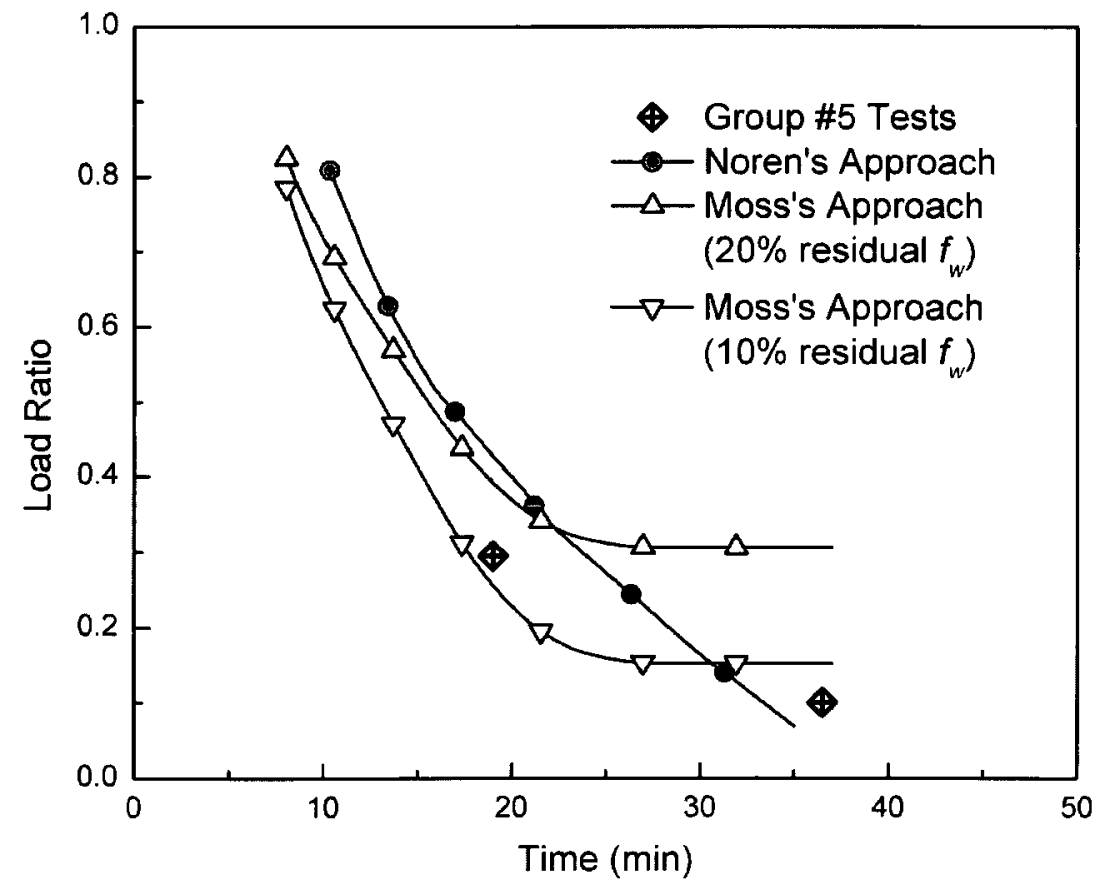

Figure 5.7 Calculated results compared with test results for WSW Group \#5 
It can be seen that Noren's approach seemed to give a more accurate prediction. As for Moss' approach, a residual embedding strength $\left(f_{w}\right)$ at either $20 \%$ or $10 \%$ of the ambient embedding strength was used for the calculation and compared with test results. A residual $f_{w}$ at a ratio of $20 \%$ was initially used in Moss' study for LSL timber connections. However, the comparison with test results generated in this study showed that a residual $f_{w}$ at a ratio of $10 \%$ for glulam timber connections gave a better prediction than a residual $f_{w}$ at a ratio of $20 \%$.

However, Moss' approach tended to yield a flat curve for a longer exposure time at lower load ratios. This is because for a long exposure time, the constant residual embedding strength along the interface was reached due to the assumption, and thus the calculated strength tended to be flat. Therefore, this assumption led to overestimation of the failure time at lower load ratios, as seen in the figures.

\subsection{Structural Model for SWS Connections}

For bolted SWS connections, the most common failure mode observed in the fireresistance tests was the extensive elongation of holes combined with slight or significant bending deformation of bolts. Splitting failure was observed for a few specimens. However, the specimens also showed a considerable hole elongation prior to the final splitting failure. Therefore, the capacity of bolted WSW connections could be calculated based on the theories of ductile failure model 1 and 4, referring to Figure 2.18. Again, thermal expansion was not considered in the structural model. 


\subsubsection{Methodology}

Figure 5.8 shows the external and internal forces on a fastener for ductile failure mode 1 . The capacity of one fastener for failure mode 1 was calculated as:

$$
R_{f i}=\sum_{i=1}^{\mathrm{n}}\left(\left(f_{w}\left(x_{i}\right) \cdot d\right) \cdot x_{i}\right)
$$

where ' $i$ ' is an element along the bolt from 1 to $\mathrm{n}$ in the wood member $\left(t_{2}\right), x_{i}$ is the length of this element, $f_{w}\left(x_{i}\right)$ is the temperature-dependent embedding strength at the element $\mathrm{i}$, and $d$ is the fastener diameter.

Mode 1
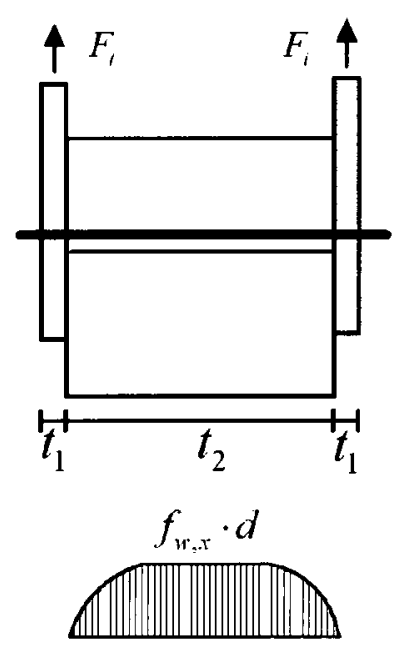

Figure 5.8 Failure mode 1 of a SWS connection

For failure mode 4 , the strength is governed by a combination of embedding strength and bolt yield strength. As seen in Figure 5.9(a), theoretically, four plastic hinges are developed in the bolt for mode 4 . However, in real tests, no clear four plastic hinges were observed. Instead, more plastic hinges were formed along the bolt length until the entire length of the bolt was deformed, as shown in Figure 5.9(b) and (c). Therefore, the behaviour of SWS timber connections is more likely to transform from failure mode 4 to 
1 as shown in Figure 5.9(b). The mode 1 equation (5.3) is recognized as a lower bound solution for SWS timber connections if bearing failure governs (Quenneville 2000). For this reason, Equation (5.3) was the only equation used to calculate the strength of bolted SWS connections at elevated temperatures.

(a) Mode 4

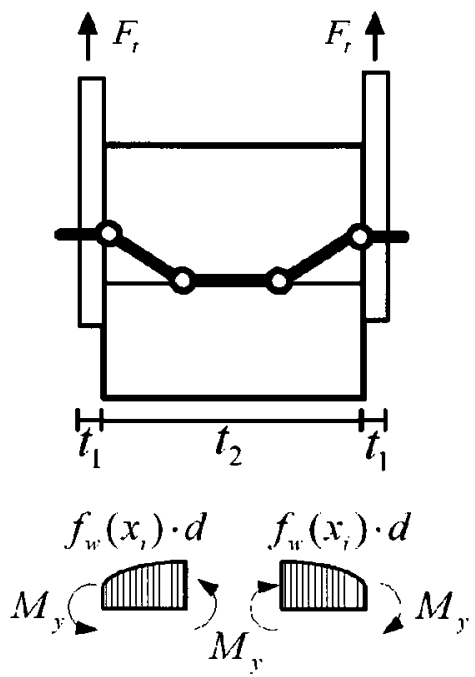

(b) Mode 4 to 1
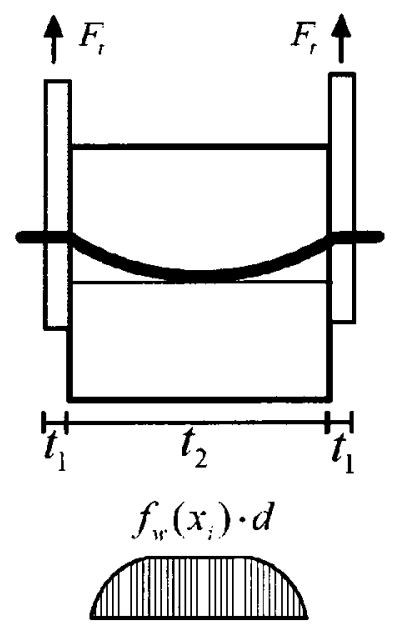

(c)

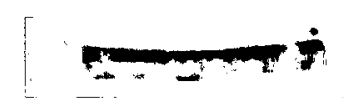

Figure 5.9 Failure mode 4 of a SWS connection

\subsubsection{Result}

Similar to WSW timber connections, the two approaches from Noren and Moss were used and compared for SWS timber connections. For Moss' approach, temperatures of the elements at the bolt-hole interface were used to determine the embedding strength, and a residual embedding strength $\left(f_{w}\right)$ at either $20 \%$ or $10 \%$ of the ambient embedding strength was considered; for Noren's approach, the elements at $0.5 \mathrm{~d}$ away from the interface were used to calculate the strength.

The results are shown in Figure 5.10 and Figure 5.11. Again, Noren's approach seemed to give a more accurate prediction. For Moss' approach, a residual embedding strength $\left(f_{w}\right)$ 
at either $20 \%$ or $10 \%$ of the ambient embedding strength seemed not in good agreement with the test results.

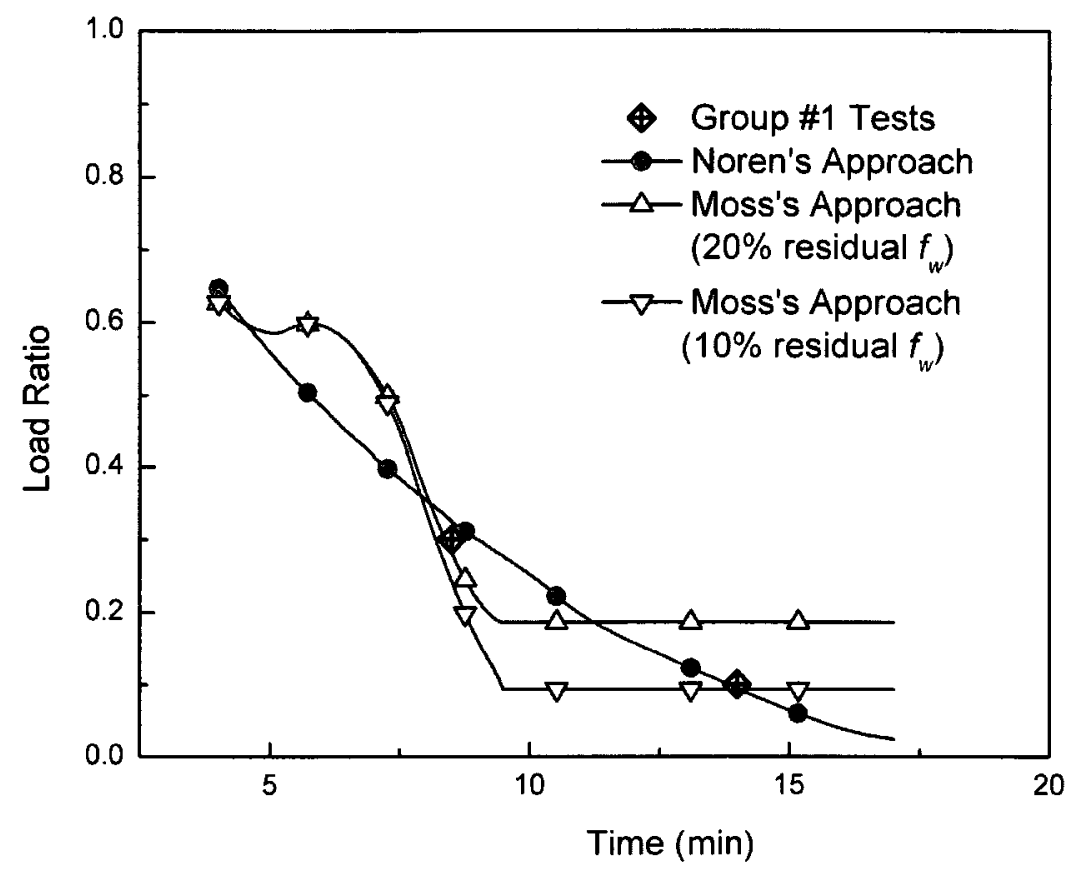

Figure 5.10 Calculated results compared with test results for SWS Group \#1

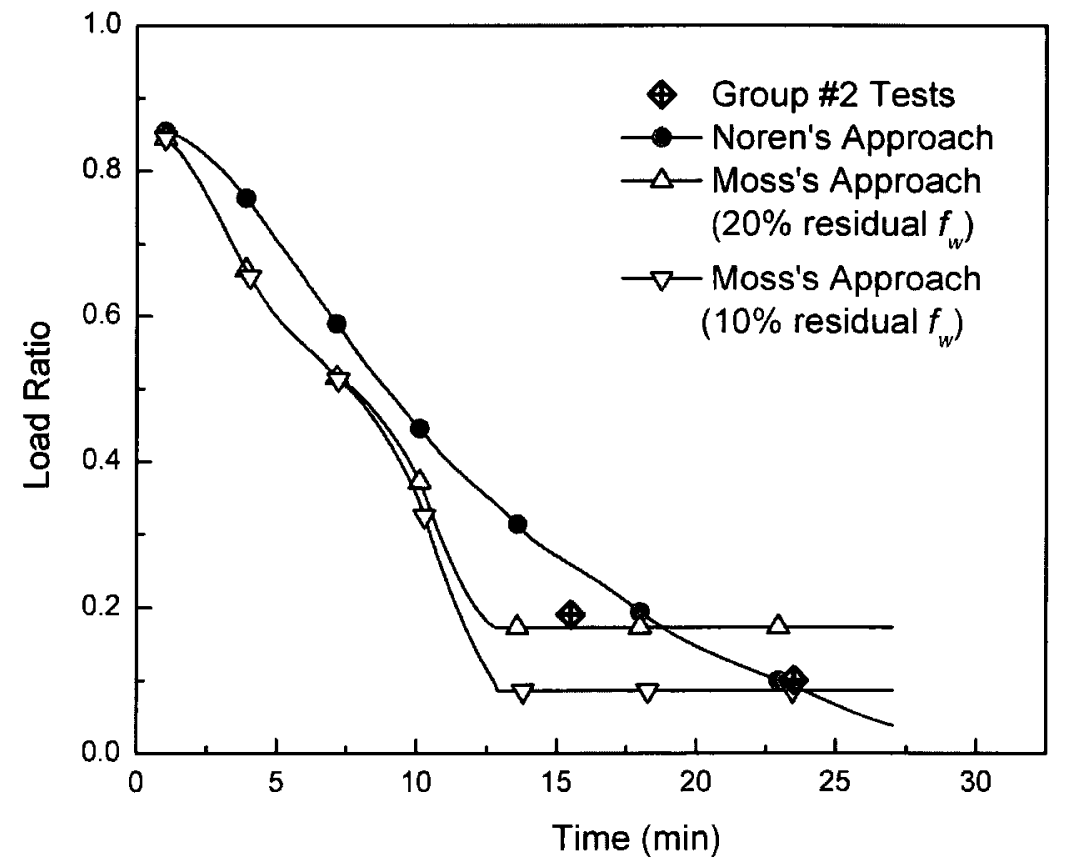

Figure 5.11 Calculated results compared with test results for SWS Group \#2 


\subsection{Applications}

As the structural analytical method was validated against the test results, it is feasible to apply the heat transfer model and structural model to predict fire resistances of other timber connections, which were not tested in this research.

Two specimens are presented in this section as an application of the models described in Chapter 3 and 4 . Since bolt number does not play an important role on the fire performance of timber connections, specimens with one bolt were studied in this section.

\subsubsection{Case One}

One of the specimens was a bolted WSW connection. The side wood members were 100 $\mathrm{mm}$ thick and $190 \mathrm{~mm}$ wide. The steel plate was $9.5 \mathrm{~mm}$, and the bolt had a diameter of $19.1 \mathrm{~mm}$. The loaded end distance was assumed to be $190 \mathrm{~mm}(10 d)$.

\section{Wood Species}

Two different wood species were assumed to be used in this case, to study the species difference on the fire resistance of timber connections. One specimen was assumed to be spruce-pine (SP) timber, with a density of $455 \mathrm{~kg} / \mathrm{m}^{3}$ and a moisture content of $11 \%$. According to the Canadian Standard CAN/CSA-O86-09, the resistance capacity of this specimen is $28.4 \mathrm{kN}$. If the ultimate load capacity of this connection is assumed to be $32 \%$ of the ultimate load capacity $(32 \%$ is the average ratio for bolted WSW connections, see Appendix B), the ultimate load capacity of this connection is about $88 \mathrm{kN}$.

The other specimen was assumed to be Douglas Fir (DF) timber, with a density of 550 $\mathrm{kg} / \mathrm{m}^{3}$ and a moisture content of $11 \%$. According to CAN/CSA-O86-09, the resistance 
capacity of this specimen is $30.6 \mathrm{kN}$. If this CAN/CSA-O86-09 resistance capacity is assumed to be $32 \%$ of the ultimate load capacity, the ultimate load capacity of this connection is about $95 \mathrm{kN}$.

The input temperature boundary conditions were those typically measured by plate thermometers, as shown in Figure 4.28.

\section{Furnace Temperature}

As we discussed in the sensitivity analysis in Chapter 4, for each fire test, the boundary condition could not be identical and this boundary difference has an impact on the heat transfer in a timber connection. Therefore, it is necessary to evaluate the effect of furnace temperatures on the fire resistance of a WSW connection.

Similarly to subsection 4.4 .5 , the most typical measurements were selected as the base case, and maximum and minimum curves shown in Figure 4.28 were also used. The wood members were assumed to be either SP timber, with a density of $455 \mathrm{~kg} / \mathrm{m}^{3}$ and a moisture content of $11 \%$, or DF timber, with a density of $550 \mathrm{~kg} / \mathrm{m}^{3}$ and a moisture content of $11 \%$.

\section{Result}

The first step to study the fire resistance of the specimens in this case was to predict the temperature distributions by running the heat transfer model in ABAQUS/Standard. By knowing the temperature distributions for each time, the second step was to use the structural analysis method to predict the capacity of the specimen at each particular time. 
The results for case one are shown in Table 5.1 for different wood species and boundary conditions.

Table 5.1 Fire resistances for Case One

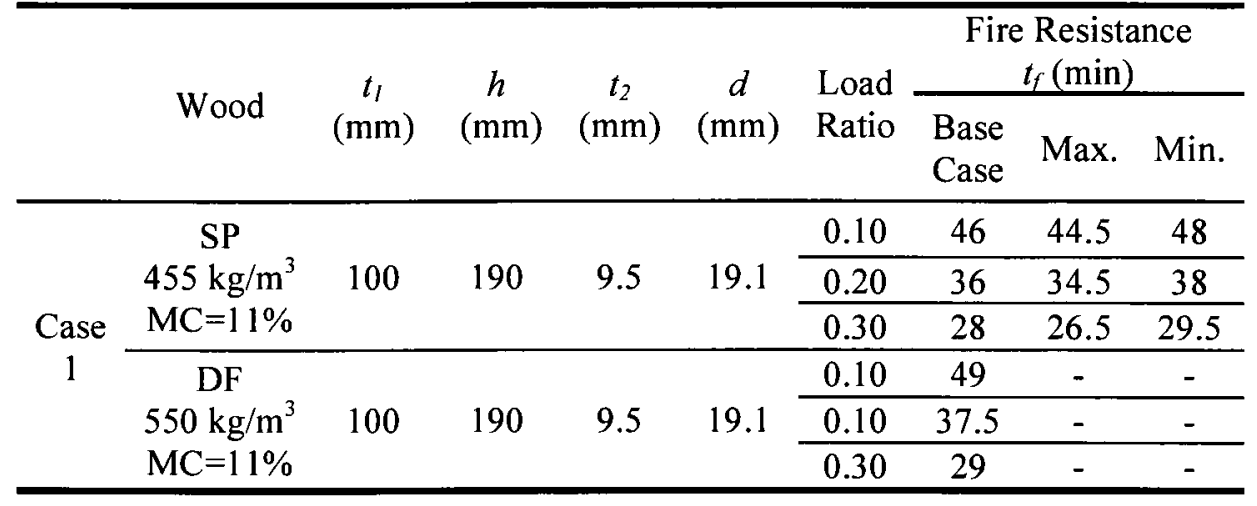

It is interesting to see that the two specimens had very close fire resistances regardless of the wood species. The differences in time were about 1-3 minutes. As we discussed in the sensitivity analysis in Chapter 4, different densities had a considerable effect on the heat transfer. In addition, the embedding strength of a timber connection is also a function of density. However, overall, the wood density seemed not to be a significant factor on the fire resistance of a timber connection.

It is also interesting to note that the boundary conditions did not have a significant influence on the fire resistance of a WSW connection. The difference between the maximum or minimum boundary and the base case was found to be about 2 minutes. 


\subsubsection{Case Two}

Case two was a bolted SWS connection. The wood member was $175 \mathrm{~mm}$ thick and 190 $\mathrm{mm}$ wide as the central member. The steel plates were $9.5 \mathrm{~mm}$, and the bolt had a diameter of $19.1 \mathrm{~mm}$. The loaded end distance was assumed to be $190 \mathrm{~mm}(10 d)$.

\section{Wood Species}

Again, two specimens of different wood species were modelled. One specimen was made of SP timber, with a density of $455 \mathrm{~kg} / \mathrm{m}^{3}$ and moisture content of $11 \%$. According to the Canadian standard CAN/CSA-O86-09, the resistance capacity of this specimen is $35 \mathrm{kN}$. If this resistance capacity is $31 \%$ of the ultimate load capacity ( $31 \%$ is the average ratio for bolted SWS connections, see Appendix B), the ultimate load capacity is assumed to be about $113 \mathrm{kN}$.

The other specimen was assumed to be DF timber, with a density of $550 \mathrm{~kg} / \mathrm{m}^{3}$ and a moisture content of $11 \%$. According to CAN/CSA-O86-09, the resistance capacity of this specimen is $38 \mathrm{kN}$. If this resistance capacity is $31 \%$ of the ultimate load capacity, the ultimate load capacity is assumed to be about $123 \mathrm{kN}$.

The input temperature boundary was the most typical measurements by plate thermometers, as shown in Figure 4.28.

\section{Furnace Temperature}

Similar to Case One, the base case, maximum and minimum boundary conditions were studied. The most typical measurements were selected as the base case and maximum and 
minimum curves shown in Figure 4.28 were also used. For wood members, they were assumed to be DF timber, with a density of $550 \mathrm{~kg} / \mathrm{m}^{3}$ and a moisture content of $11 \%$.

\section{Result}

The first step was to predict the temperature distributions by running the heat transfer model in ABAQUS/Standard. By knowing the temperature distribution at each time, the second step was to use the structural analysis method to predict the capacity of the specimen at each particular time.

The results for Case Two are shown in Table 5.2 for different wood species and boundary conditions.

Table 5.2 Fire resistances for Case Two

\begin{tabular}{|c|c|c|c|c|c|c|c|c|c|}
\hline & \multirow{2}{*}{ Wood } & \multirow{2}{*}{$\begin{array}{c}t_{l} \\
(\mathrm{~mm})\end{array}$} & \multirow{2}{*}{$\begin{array}{c}t_{2} \\
(\mathrm{~mm})\end{array}$} & \multirow{2}{*}{$\begin{array}{c}h \\
(\mathrm{~mm})\end{array}$} & \multirow{2}{*}{$\begin{array}{c}d \\
(\mathrm{~mm})\end{array}$} & \multirow{2}{*}{$\begin{array}{l}\text { Load } \\
\text { Ratio }\end{array}$} & \multicolumn{3}{|c|}{$\begin{array}{c}\text { Fire Resistance } \\
t_{f}(\min ) \\
\end{array}$} \\
\hline & & & & & & & $\begin{array}{l}\text { Base } \\
\text { Case }\end{array}$ & Max. & Min. \\
\hline \multirow{6}{*}{$\begin{array}{c}\text { Case } \\
2\end{array}$} & SP & \multirow{3}{*}{9.5} & \multirow{3}{*}{175} & \multirow{3}{*}{190} & \multirow{3}{*}{19.1} & 0.10 & 27 & - & - \\
\hline & $455 \mathrm{~kg} / \mathrm{m}^{3}$ & & & & & 0.20 & 20 & - & - \\
\hline & $\mathrm{MC}=11 \%$ & & & & & 0.30 & 16 & - & - \\
\hline & DF & \multirow{3}{*}{9.5} & \multirow{3}{*}{175} & \multirow{3}{*}{190} & \multirow{3}{*}{19.1} & 0.10 & 29.5 & 28.5 & 31 \\
\hline & $550 \mathrm{~kg} / \mathrm{m}^{3}$ & & & & & 0.20 & 22 & 21.5 & 24 \\
\hline & $\mathrm{MC}=11 \%$ & & & & & 0.30 & 17.5 & 17 & 19 \\
\hline
\end{tabular}

It is also seen that the differences for the two specimens were very small, about 1-3 minutes, and the differences between the maximum or minimum boundary and the base case was found to be about $1-3$ minutes. 


\subsection{Summary}

Both Noren and Moss's approaches were used to calculate the fire resistances of bolted WSW connections and SWS connections. The comparisons with experimental results showed that Noren's approach seemed to be able to predict the fire resistance of a timber connection in good agreement with experiment, at a load ratio between $10 \%$ and $30 \%$. The temperature used to determine the reduced embedding strength was found to be about $0.5 d$ away from the bolt-hole interface.

For Moss' approach, two residual embedding strength ratios were used and compared. It was found that a residual embedding strength ratio at $10 \%$ seemed to give a better prediction for bolted WSW connections. However, Moss's approach did not accurately predict the fire resistance at lower load ratios, because there was a flat curve at lower load ratios due to the assumption of the residual embedding strength.

As an application, the structural model combined with the heat transfer model presented in Chapter 4 was used to study the fire resistance of two cases with thick wood members, which were not studied in the experimental program. The effects of wood density variation and different furnace temperature boundary conditions were also studied in these two cases. As discussed in Chapter 4, wood density and boundary condition had considerable influence on the heat transfer. However, their impact on the fire resistance was found to be small. The differences were within about 2-3 minutes. 


\section{Chapter 6: Calculation Method}

The heat transfer and structural approaches, presented in Chapter 3 and 4 , have been validated to be able to predict the fire resistance of timber connections. However, these approaches, which are based on the $3 \mathrm{D}$ heat transfer analysis and the integration of embedding strength in each element, are also complex for design purposes. Therefore, there is a great necessity that simplified calculation methods, involving the variability of connection types, load ratios, and connection and fastener dimensions, be developed to assess the fire resistance of timber connections.

This chapter describes simplified empirical methods proposed by the author to estimate fire resistances of WSW, WWW and SWS timber connections using either bolts or dowels as fasteners. The calculation methods were developed using test data from this study and from the literature. Various factors, i.e. timber thickness, fastener diameter, load ratio and protection, were considered in the methods.

\subsection{Test Data}

Firstly, the existing data from the literature and this study, which were used to develop the simplified calculation methods, are summarized in this section for different types of timber connections. 


\subsubsection{WWW Connections}

\section{Bolted WWW}

Table 6.1 summarizes the fire-resistance test results of bolted WWW connections. The side wood member thicknesses varied from $45 \mathrm{~mm}$ to $60 \mathrm{~mm}$, the fasteners had a diameter of $12 \mathrm{~mm}$ or $20 \mathrm{~mm}$, and the load ratios were in a range between 0.13 and 0.59 . Charring rates were reported to be $0.70 \mathrm{~mm} / \mathrm{min}$ from Chuo (2007), $0.67 \mathrm{~mm} / \mathrm{min}$ from Lau (2006), and $0.58 \mathrm{~mm} / \mathrm{min}$ averaged from Dhima (1999).

Table 6.1 Fire-resistance results of bolted WWW connections

\begin{tabular}{cccccccccc}
\hline Ref. & $\begin{array}{c}\text { Wood } \\
\text { and } \\
\text { Fasteners }\end{array}$ & $\begin{array}{c}\text { Side } \\
\text { Wood } \\
\text { Thickness } \\
t_{1}(\mathrm{~mm})\end{array}$ & $\begin{array}{c}\text { Central } \\
\text { Wood } \\
\text { Thickness } \\
t_{2}(\mathrm{~mm})\end{array}$ & $\begin{array}{c}\text { Wood } \\
\text { Width } \\
h(\mathrm{~mm})\end{array}$ & $\begin{array}{c}\text { Fastener } \\
\text { Diameter } \\
d(\mathrm{~mm})\end{array}$ & $\begin{array}{c}\text { Number } \\
\text { of } \\
\text { Bolts }\end{array}$ & $\begin{array}{c}\text { Load } \\
\text { Ratio }\end{array}$ & $\begin{array}{c}\text { Fire } \\
\text { Resistance } \\
t_{f}(\mathrm{~min})\end{array}$ \\
\hline $\begin{array}{c}\text { Chuo } \\
(2007)\end{array}$ & $\begin{array}{c}\text { LVL; } \\
\text { Bolts }\end{array}$ & 45 & 63 & 150 & 12 & 1 & 0.14 & $17.5^{*}$ \\
\hline $\begin{array}{c}\text { Lau } \\
(2006)\end{array}$ & $\begin{array}{c}\text { LVL; } \\
\text { Bolts }\end{array}$ & 45 & 63 & 150 & 12 & 6 & 0.15 & $20.5^{*}$ \\
\hline & & 60 & 100 & 240 & 20 & 4 & 0.28 & 22 \\
\hline $\begin{array}{c}\text { Dhima } \\
(1999)\end{array}$ & $\begin{array}{c}\text { GL28h; } \\
\text { Bolts }\end{array}$ & 60 & 100 & 240 & 20 & 8 & 0.36 & 14 \\
\hline & & 50 & 80 & 170 & 12 & 8 & 0.59 & 24 \\
\hline
\end{tabular}

*: equivalent time due to the difference between the furnace temperature and ISO 834 .

\section{Doweled WWW}

Table 6.2 summarizes the fire-resistance test results of doweled WWW connections. The side wood member thicknesses varied from $50 \mathrm{~mm}$ to $80 \mathrm{~mm}$, the fastener diameters included $12 \mathrm{~mm}, 16 \mathrm{~mm}$ and $20 \mathrm{~mm}$, and the load ratios were in a range between 0.13 and 0.59 . Charring rates were reported to be $0.65 \mathrm{~mm} / \mathrm{min}$ averaged from Dhima's tests and $0.70 \mathrm{~mm} / \mathrm{m}$ in average from Laplache's tests. 
Table 6.2 Fire-resistance results of doweled WWW connections

\begin{tabular}{|c|c|c|c|c|c|c|c|c|}
\hline Ref. & $\begin{array}{c}\text { Wood } \\
\text { and } \\
\text { Fasteners }\end{array}$ & $\begin{array}{c}\text { Side } \\
\text { Wood } \\
\text { Thickness } \\
t_{l}(\mathrm{~mm}) \\
\end{array}$ & $\begin{array}{c}\text { Central } \\
\text { Wood } \\
\text { Thickness } \\
t_{2}(\mathrm{~mm}) \\
\end{array}$ & $\begin{array}{l}\text { Wood } \\
\text { Width } \\
h(\mathrm{~mm})\end{array}$ & $\begin{array}{c}\text { Fastener } \\
\text { Diameter } \\
d(\mathrm{~mm})\end{array}$ & $\begin{array}{c}\text { Number } \\
\text { of } \\
\text { Fasteners }\end{array}$ & $\begin{array}{l}\text { Load } \\
\text { Ratio }\end{array}$ & $\begin{array}{c}\text { Fire } \\
\text { Resistance } \\
t_{f}(\min )\end{array}$ \\
\hline \multirow{6}{*}{$\begin{array}{l}\text { Dhima } \\
\text { (1999) }\end{array}$} & \multirow{6}{*}{$\begin{array}{l}\text { GL28h; } \\
\text { Dowels }\end{array}$} & \multirow{2}{*}{60} & \multirow{2}{*}{100} & \multirow{2}{*}{240} & \multirow{2}{*}{20} & \multirow{2}{*}{6} & 0.33 & 35 \\
\hline & & & & & & & 0.65 & 7 \\
\hline & & \multirow{2}{*}{60} & \multirow{2}{*}{100} & \multirow{2}{*}{400} & \multirow{2}{*}{20} & \multirow[b]{2}{*}{12} & 0.21 & 38 \\
\hline & & & & & & & 0.42 & 23 \\
\hline & & \multirow{2}{*}{50} & \multirow{2}{*}{80} & \multirow{2}{*}{170} & \multirow{2}{*}{12} & \multirow{2}{*}{6} & 0.28 & 32 \\
\hline & & & & & & & 0.56 & 13 \\
\hline \multirow{7}{*}{$\begin{array}{l}\text { Laplanche } \\
\text { (2006) }\end{array}$} & \multirow{7}{*}{$\begin{array}{l}\text { GL28h; } \\
\text { Dowels }\end{array}$} & \multirow{5}{*}{64} & \multirow{5}{*}{112} & \multirow{5}{*}{254} & \multirow{5}{*}{16} & \multirow{5}{*}{8} & 0.10 & 59 \\
\hline & & & & & & & 0.20 & 45 \\
\hline & & & & & & & 0.20 & 46 \\
\hline & & & & & & & 0.30 & 38 \\
\hline & & & & & & & 0.30 & 41 \\
\hline & & \multirow{2}{*}{84} & \multirow{2}{*}{160} & \multirow{2}{*}{254} & \multirow{2}{*}{16} & \multirow[b]{2}{*}{8} & 0.10 & 79 \\
\hline & & & & & & & 0.30 & 54 \\
\hline
\end{tabular}

\subsubsection{WSW Connections}

\section{Bolted WSW}

Table 6.3 summarizes the fire-resistance test results of bolted WSW connections. The side wood member thicknesses varied from $45 \mathrm{~mm}$ to $80 \mathrm{~mm}$, the fastener diameters included 12.7 (or 12) $\mathrm{mm}, 19.1$ (or 20) $\mathrm{mm}$, and the load ratios were in a range between 0.1 and 0.58 . In addition, the modelled results for bolted WSW connections (SP glulam and $t_{1}=100 \mathrm{~mm}$ ), were also included in the table. Charring rates were reported to be $0.82 \mathrm{~mm} / \mathrm{min}$ from Chuo (2007), $0.60 \mathrm{~mm} / \mathrm{min}$ from Lau $(2006), 0.53 \mathrm{~mm} / \mathrm{min}$ averaged from Dhima (1999) and $0.8 \mathrm{~mm} / \mathrm{min}$ from present study.

\section{Doweled WSW}

Table 6.4 summarizes the fire-resistance test results of doweled WSW connections. The side wood member thicknesses varied from $75 \mathrm{~mm}$ to $100 \mathrm{~mm}$, the fastener diameters included $12 \mathrm{~mm}, 16 \mathrm{~mm}$ and $20 \mathrm{~mm}$, and the load ratios were between 0.1 and 0.3 . 
Charring rates were reported to be $0.81 \mathrm{~mm} / \mathrm{min}$ averaged from Ayme's tests, except the $100 \mathrm{~mm}$ thick specimens with a charring rate of $0.68 \mathrm{~mm} / \mathrm{min}$.

Table 6.3 Fire-resistance results of bolted WSW connections

\begin{tabular}{|c|c|c|c|c|c|c|c|c|}
\hline Ref. & $\begin{array}{l}\text { Wood } \\
\text { and } \\
\text { Fasteners }\end{array}$ & $\begin{array}{c}\text { Side } \\
\text { Wood } \\
\text { Thickness } \\
t_{l}(\mathrm{~mm})\end{array}$ & $\begin{array}{c}\text { Steal } \\
\text { Plate } \\
\text { Thickness } \\
t_{2}(\mathrm{~mm})\end{array}$ & $\begin{array}{l}\text { Wood } \\
\text { Width } \\
h(\mathrm{~mm})\end{array}$ & $\begin{array}{c}\text { Fastener } \\
\text { Diameter } \\
d(\mathrm{~mm})\end{array}$ & $\begin{array}{c}\text { Number } \\
\text { of } \\
\text { Bolts }\end{array}$ & $\begin{array}{l}\text { Load } \\
\text { Ratio }\end{array}$ & $\begin{array}{c}\text { Fire } \\
\text { Resistance } \\
t_{f}(\min )\end{array}$ \\
\hline \multirow{2}{*}{$\begin{array}{c}\text { Chuo } \\
(2007)\end{array}$} & LVL; & \multirow{2}{*}{45} & \multirow{2}{*}{6} & \multirow{2}{*}{150} & \multirow{2}{*}{12} & 1 & 0.14 & $16.5^{*}$ \\
\hline & Bolts & & & & & 4 & 0.12 & $15.1 *$ \\
\hline $\begin{array}{c}\text { Lau } \\
(2006)\end{array}$ & $\begin{array}{l}\text { LVL; } \\
\text { Bolts }\end{array}$ & 45 & 6 & 150 & 12 & 5 & 0.14 & $16.5^{*}$ \\
\hline \multirow{10}{*}{$\begin{array}{l}\text { Dhima } \\
\text { (1999) }\end{array}$} & \multirow{10}{*}{$\begin{array}{l}\text { GL28; } \\
\text { Bolts }\end{array}$} & \multirow{2}{*}{60} & \multirow{2}{*}{6} & \multirow{2}{*}{240} & \multirow{2}{*}{20} & \multirow{2}{*}{8} & 0.19 & 22 \\
\hline & & & & & & & 0.39 & 15 \\
\hline & & \multirow{2}{*}{60} & \multirow[t]{2}{*}{6} & \multirow{2}{*}{400} & \multirow{2}{*}{20} & \multirow{2}{*}{16} & 0.19 & 23 \\
\hline & & & & & & & 0.38 & 16 \\
\hline & & \multirow[t]{2}{*}{50} & \multirow{2}{*}{6} & \multirow{2}{*}{170} & \multirow{2}{*}{12} & \multirow{2}{*}{4} & 0.29 & 17 \\
\hline & & & & & & & 0.58 & 10 \\
\hline & & \multirow{2}{*}{50} & \multirow{2}{*}{6} & \multirow{2}{*}{170} & \multirow{2}{*}{12} & \multirow{2}{*}{8} & 0.25 & 18 \\
\hline & & & & & & & 0.49 & 11 \\
\hline & & \multirow{2}{*}{50} & \multirow{2}{*}{6} & 240 & 12 & 16 & 0.24 & 18 \\
\hline & & & & 240 & 12 & 16 & 0.48 & 13 \\
\hline & & & & & & & 0.10 & 14.5 \\
\hline & & 38 & 05 & 190 & 127 & 2 & 0.10 & 15 \\
\hline & & Jo & 3.0 & 170 & 16.8 & 2 & 0.29 & 8 \\
\hline & & & & & & & 0.30 & 8.5 \\
\hline & & & & & & & 0.10 & 28 \\
\hline & SPF \#2. & 60 & 9.5 & 190 & 12.7 & 4 & 0.18 & 22.5 \\
\hline Present & or & & & & & & 0.29 & 17.5 \\
\hline study & SP-G; & 60 & 05 & 190 & 101 & 1 & 0.11 & 27 \\
\hline & Bolts & 60 & 9.5 & 190 & 19.1 & 1 & 0.32 & 15 \\
\hline & & 60 & 95 & 190 & 191 & 4 & 0.10 & 26 \\
\hline & & 60 & 9.5 & 190 & 19.1 & 4 & 0.30 & 14 \\
\hline & & & & & & & 0.10 & 36.5 \\
\hline & & 80 & 9.5 & 190 & 19.1 & 4 & 0.10 & 43 \\
\hline & & & & & & & 0.29 & 19 \\
\hline & & & & & & & 0.1 & $46^{\dagger}$ \\
\hline $\begin{array}{l}\text { Present } \\
\text { study }\end{array}$ & SP-G; & 100 & 9.5 & 190 & 19.1 & 1 & 0.2 & $36^{\dagger}$ \\
\hline & & & & & & & 0.3 & $28^{\dagger}$ \\
\hline
\end{tabular}

*: equivalent time due to the difference between the furnace temperature and ISO 834 .

${ }^{\dagger}$ : modelled results using the models presented in previous chapters. 
Table 6.4 Fire-resistance results of doweled WSW connections

\begin{tabular}{|c|c|c|c|c|c|c|c|c|}
\hline Ref. & $\begin{array}{l}\text { Wood } \\
\text { and } \\
\text { Fasteners }\end{array}$ & $\begin{array}{c}\text { Side } \\
\text { Timber } \\
\text { Thickness } \\
t_{l}(\mathrm{~mm})\end{array}$ & $\begin{array}{c}\text { Steal } \\
\text { Plate } \\
\text { Thickness } \\
t_{2}(\mathrm{~mm})\end{array}$ & $\begin{array}{l}\text { Wood } \\
\text { Width } \\
h(\mathrm{~mm})\end{array}$ & $\begin{array}{c}\text { Fastener } \\
\text { Diameter } \\
d(\mathrm{~mm})\end{array}$ & $\begin{array}{c}\text { Number } \\
\text { of } \\
\text { Fasteners }\end{array}$ & $\begin{array}{l}\text { Load } \\
\text { Ratio }\end{array}$ & $\begin{array}{c}\text { Fire } \\
\text { Resistance } \\
t_{f}(\mathrm{~min})\end{array}$ \\
\hline \multirow{11}{*}{$\begin{array}{l}\text { Ayme } \\
(2003)\end{array}$} & \multirow{11}{*}{$\begin{array}{l}\text { GL28h; } \\
\text { Dowels }\end{array}$} & \multirow{5}{*}{76} & \multirow{5}{*}{-2} & \multirow{5}{*}{254} & \multirow{5}{*}{16} & \multirow{5}{*}{8} & 0.10 & 55 \\
\hline & & & & & & & 0.10 & 56 \\
\hline & & & & & & & 0.20 & 41 \\
\hline & & & & & & & 0.30 & 36 \\
\hline & & & & & & & 0.30 & 36 \\
\hline & & \multirow{2}{*}{75} & \multirow{2}{*}{10} & \multirow{2}{*}{294} & \multirow{2}{*}{20} & \multirow{2}{*}{8} & 0.10 & 52 \\
\hline & & & & & & & 0.30 & 37 \\
\hline & & \multirow{2}{*}{77} & \multirow[t]{2}{*}{6} & \multirow{2}{*}{214} & \multirow{2}{*}{12} & \multirow{2}{*}{8} & 0.10 & 54 \\
\hline & & & & & & & 0.30 & 39 \\
\hline & & \multirow[t]{2}{*}{100} & \multirow[t]{2}{*}{10} & \multirow[t]{2}{*}{294} & \multirow[t]{2}{*}{20} & \multirow[t]{2}{*}{8} & 0.10 & 90 \\
\hline & & & & & & & 0.30 & 45 \\
\hline
\end{tabular}

\subsubsection{SWS Connections}

Table 6.5 Fire-resistance results of bolted SWS connections

\begin{tabular}{|c|c|c|c|c|c|c|c|c|c|}
\hline \multirow{2}{*}{ Ref. } & \multirow{2}{*}{$\begin{array}{c}\text { Wood } \\
\text { and } \\
\text { Fasteners }\end{array}$} & \multirow{2}{*}{$\begin{array}{c}\text { Wood } \\
\text { Member } \\
\text { Thickness } \\
t_{l}(\mathrm{~mm})\end{array}$} & \multirow{2}{*}{$\begin{array}{c}\text { Steal } \\
\text { Plate } \\
\text { Thickness } \\
t_{2}(\mathrm{~mm})\end{array}$} & \multirow{2}{*}{$\begin{array}{l}\text { Wood } \\
\text { Width } \\
h(\mathrm{~mm})\end{array}$} & \multirow{2}{*}{$\begin{array}{c}\text { Fastener } \\
\text { Diameter } \\
d(\mathrm{~mm})\end{array}$} & \multirow{2}{*}{$\begin{array}{c}\text { Number } \\
\text { of } \\
\text { Bolts }\end{array}$} & \multirow{2}{*}{$\begin{array}{l}\text { Load } \\
\text { Ratio }\end{array}$} & \multicolumn{2}{|c|}{$\begin{array}{c}\text { Fire Resistance } \\
t_{f}(\mathrm{~min}) \\
\end{array}$} \\
\hline & & & & & & & & Test & Model $^{\dagger}$ \\
\hline \multirow{2}{*}{$\begin{array}{c}\text { Chuo } \\
(2007) \\
\end{array}$} & \multirow{2}{*}{$\begin{array}{l}\text { LVL; } \\
\text { Bolts }\end{array}$} & \multirow{2}{*}{63} & \multirow{2}{*}{6} & \multirow{2}{*}{150} & \multirow{2}{*}{12} & 1 & 0.12 & $7.4^{*}$ & - \\
\hline & & & & & & 4 & 0.15 & $10.6^{*}$ & - \\
\hline $\begin{array}{c}\text { Lau } \\
(2006)\end{array}$ & $\begin{array}{l}\text { LVL; } \\
\text { Bolts }\end{array}$ & 63 & 6 & 150 & 12 & 4 & 0.18 & $8.8^{*}$ & - \\
\hline \multirow{15}{*}{$\begin{array}{l}\text { Present } \\
\text { study }\end{array}$} & \multirow{15}{*}{$\begin{array}{l}\text { DF-G; } \\
\text { Bolts }\end{array}$} & \multirow{5}{*}{80} & \multirow{5}{*}{9.5} & \multirow{5}{*}{190} & \multirow{5}{*}{12.7} & \multirow{5}{*}{4} & 0.10 & 14 & 13.8 \\
\hline & & & & & & & 0.15 & - & 12.2 \\
\hline & & & & & & & 0.20 & - & 10.9 \\
\hline & & & & & & & 0.25 & - & 10.0 \\
\hline & & & & & & & 0.30 & 8.5 & 9.0 \\
\hline & & \multirow{5}{*}{130} & \multirow{5}{*}{9.5} & \multirow{5}{*}{190} & \multirow{5}{*}{19.1} & \multirow{5}{*}{4} & 0.10 & 23.5 & 22.9 \\
\hline & & & & & & & 0.15 & - & 19.8 \\
\hline & & & & & & & 0.19 & 15.5 & 18.0 \\
\hline & & & & & & & 0.25 & - & 15.9 \\
\hline & & & & & & & 0.30 & - & 13.8 \\
\hline & & \multirow{5}{*}{175} & \multirow{5}{*}{9.5} & \multirow{5}{*}{190} & \multirow{5}{*}{19.1} & \multirow{5}{*}{1} & 0.10 & - & 29.6 \\
\hline & & & & & & & 0.15 & - & 25.5 \\
\hline & & & & & & & 0.20 & - & 22.2 \\
\hline & & & & & & & 0.25 & - & 20.0 \\
\hline & & & & & & & 0.30 & - & 17.5 \\
\hline
\end{tabular}

*: equivalent time due to the difference between the furnace temperature and ISO 834 .

${ }^{\dagger}$ : modelled results using the models presented in previous chapters.

Table 6.5 summarizes the fire-resistance results of bolted SWS connections, obtained from both tests and modelling. The wood member thicknesses varied from $63 \mathrm{~mm}$ to 175 
$\mathrm{mm}$, the fastener diameters included 12.7 (or 12) $\mathrm{mm}$ and $19.1 \mathrm{~mm}$, and the load ratios were between 0.1 and 0.3 . Charring rates were reported to be $0.35 \mathrm{~mm} / \mathrm{min}$ from Chuo (2007), $0.57 \mathrm{~mm} / \mathrm{min}$ from Lau (2006), $0.41 \mathrm{~mm} / \mathrm{min}$ averaged from present study.

\subsection{Correlations for WSW and WWW Connections}

WWW connections and WSW connections act similarly under fire exposure since the central member, either the steel plate or wood member, is protected by the side wood members from direct fire exposure. The performance of the side wood members in fire dominates the failure of the connection rather than the central member. In this matter, similar calculation methods were proposed for WSW and WWW connections with either bolts or dowels as fasteners.

For a given timber connection, the fire resistance was assumed to be expressed by the following function:

$$
t_{f}=f\left(R_{f i}, t_{1}, d\right)
$$

where $t_{f}(\mathrm{~min})$ is the fire resistance, $t_{1}(\mathrm{~mm})$ is the wood side member thickness, $R_{f i}(\mathrm{kN})$ is the load applied in a fire test and $d(\mathrm{~mm})$ is the fastener diameter.

Define non-dimensional factors: $t^{*}=t_{f} /\left(t_{1} / \beta\right), \eta=R_{f i} / R_{0}$ and $d^{*}=d / t_{1}$ to represent the failure time, the load ratio and the fastener diameter, respectively. The charring rate of the side wood member is defined as $\beta(\mathrm{mm} / \mathrm{min})$. Since the side member thickness $t_{1}$ has been incorporated into $t^{*}$ and $d^{*}$, Equation (6.1) can be rewritten in a dimensionless form as: 


$$
t^{*}=f\left(\eta, d^{*}\right)
$$

A power law equation was proposed:

$$
t^{*}=1-(\eta)^{M}\left(d^{*}\right)^{N}
$$

where $M$ and $N$ are connection factors. The following assumptions were made when developing the power law equation:

(a) All specimens were exposed to standard fires (either ISO 834 or ULC-S101).

(b) The charring rate of the side wood member of a timber connection could be determined from fire-resistance tests by approximately using a constant value $\beta$.

(c) If no load was applied during the fire $(\eta=0)$, the failure time was supposed to be the completely charred time for the wood side member $\left(t_{f}=t_{1} / \beta\right)$.

(d) If the specimen was loaded close to the ultimate level $(\eta \rightarrow 1)$, the failure time was close to zero $\left(t_{f} \rightarrow 0\right)$.

To satisfy assumption (d), $N$ must be a small value. It is worth mentioning that in Equation (6.3), $M$ and $N$ represent the influence of load ratio $(\eta)$ and non-dimensional bolt diameter $\left(d^{*}\right)$ on the fire performance of timber connections. The larger the $M$ and $N$, the more the influence of the load ratio $(\eta)$ and the non-dimensional bolt diameter $\left(d^{*}\right)$.

Rewriting Equation (6.3) in a linear relationship by taking its logarithm, gave:

$$
\ln \left(1-t^{*}\right)=M \ln (\eta)+N \ln \left(d^{*}\right)
$$


$M$ and $N$ could be determined from the fire-resistance test data using best-fitting by the method of least-squares. Since different types of connections may have different values of $M$ and $N$, four pairs of $M$ and $N$ needed to be determined individually for WWW and WSW connections with both bolts and dowels, respectively.

The test data used to determine $M$ and $N$ have been summarized in Table 6.1 to Table 6.4. The charring rate $\beta$, was approximated as $0.7 \mathrm{~mm} / \mathrm{min}$ for WWW connections and 0.8 $\mathrm{mm} / \mathrm{min}$ for WSW connections based on the results of fire tests. In order to take into account the nonlinear charring rate as a function of time, slightly smaller values were used as $0.65 \mathrm{~mm} / \mathrm{min}$ for WWW connections and as $0.7 \mathrm{~mm} / \mathrm{min}$ for WSW connections, if the fire exposure time was over one hour.

Correlation results are shown in Figures 6.1 to 6.4 for WWW and WSW connections with bolts and dowels, respectively. It was found that $M=0.1881$ and $N=0.0709$ for WWW with bolts and $M=0.1599$ and $N=0.0554$ for WSW connections with bolts, as shown in Figure 6.1 and 6.2. As shown in Figure 6.3 and 6.4, the connection factors were determined to be $M=0.4456$ and $N=-0.0193$ for dowel-type WWW connections and $M$ $=0.3586$ and $N=0.0304$ for dowel-type WSW connections.

In Figure 6.2 , the coefficient of determination is 0.8396 , which is slightly lower than the coefficients for other types of timber connections. This is probably due to the fact that different thermocouples were used in controlling the furnace temperatures for the tests. In Dhima's tests, bare thermocouples were used, while shielded thermocouples were used in the present study. The resulting difference in exposure conditions in the two furnaces 
could cause variations in the test results. However, the relationship is also strong since the value of the coefficient of determination is $R^{2}=0.8396$ where $0 \leq R^{2} \leq 1$.

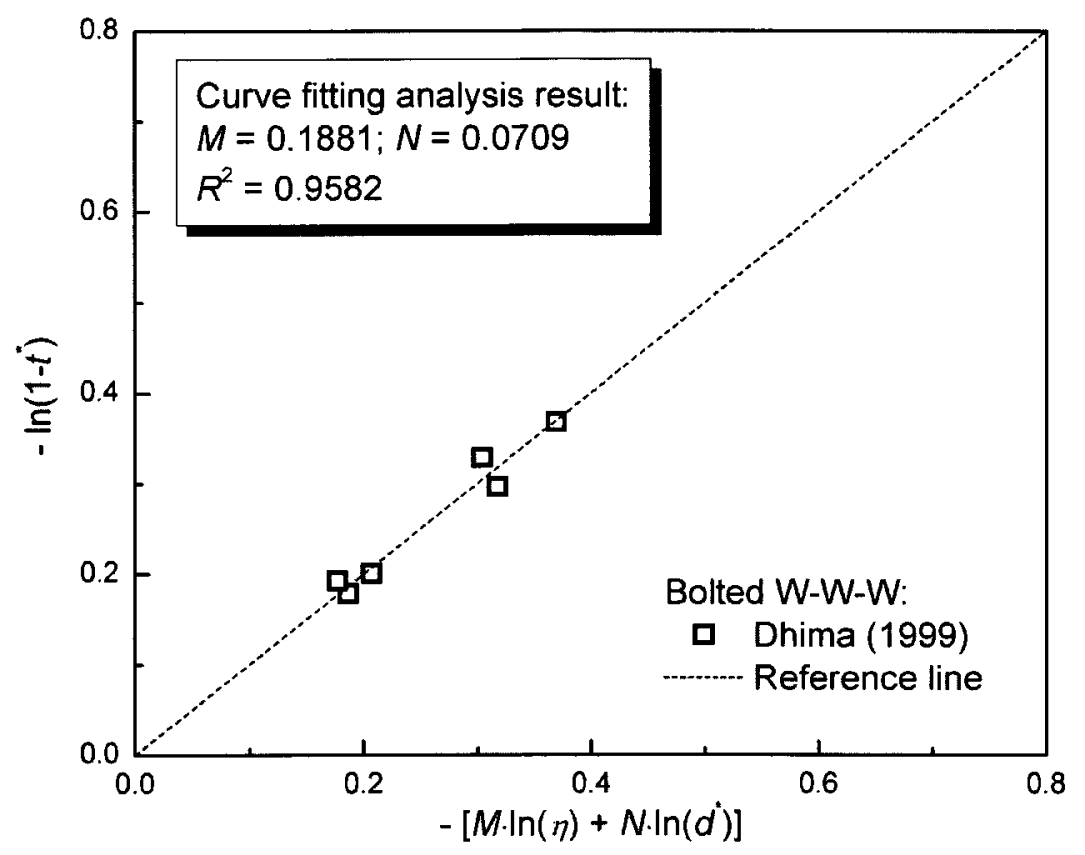

Figure 6.1 Curve fitting analysis result for bolted WWW connections

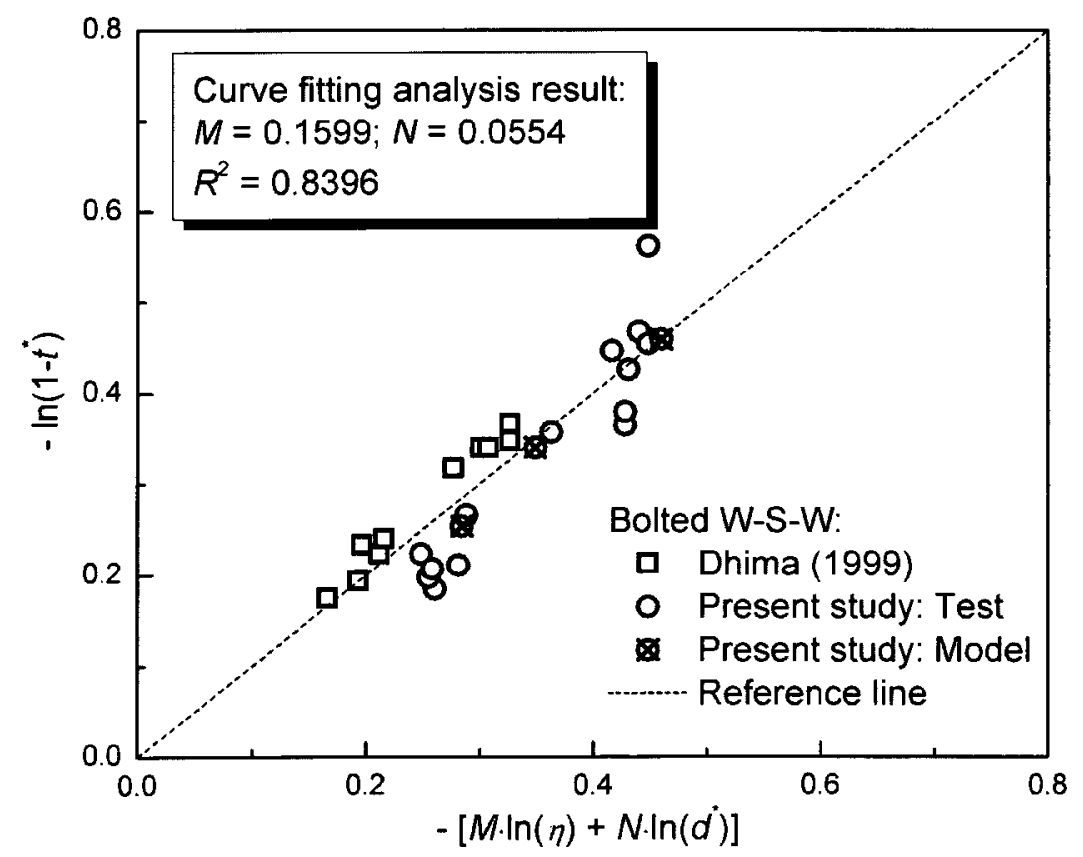

Figure 6.2 Curve fitting analysis result for bolted WSW connections 


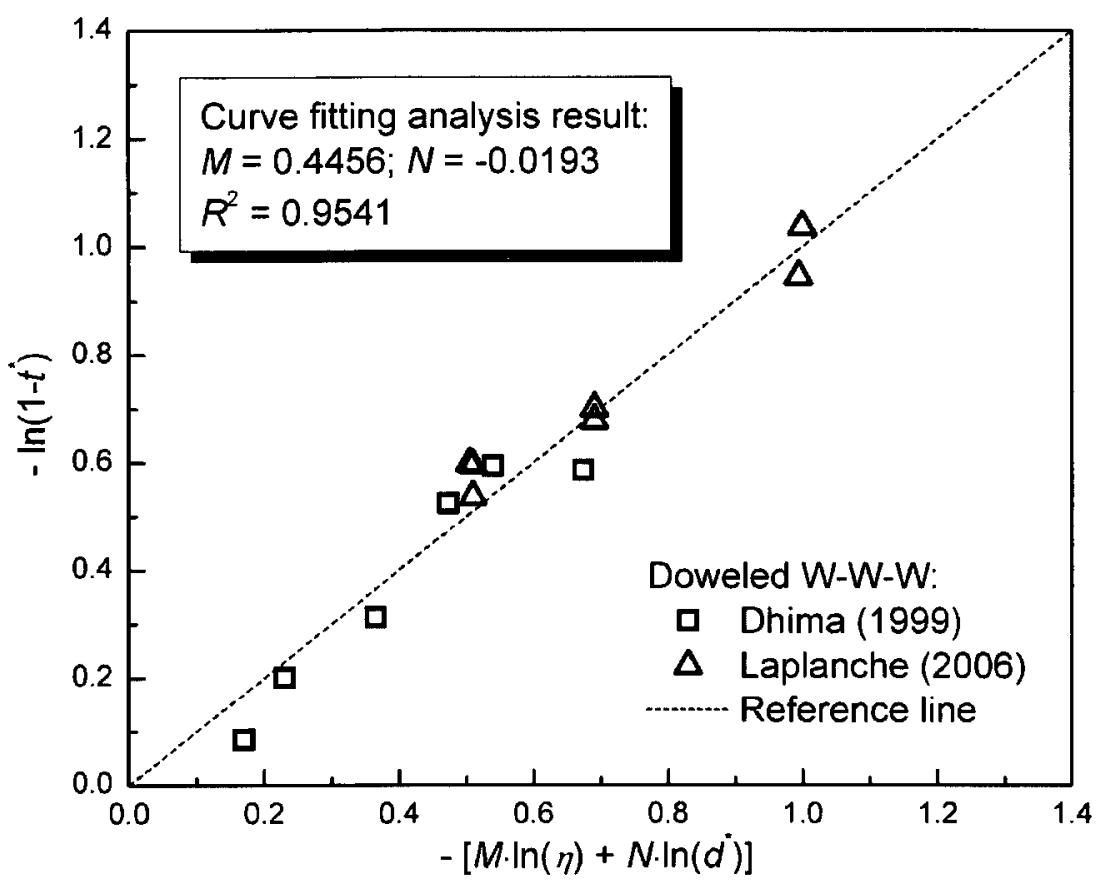

Figure 6.3 Curve fitting analysis result for doweled WWW connections

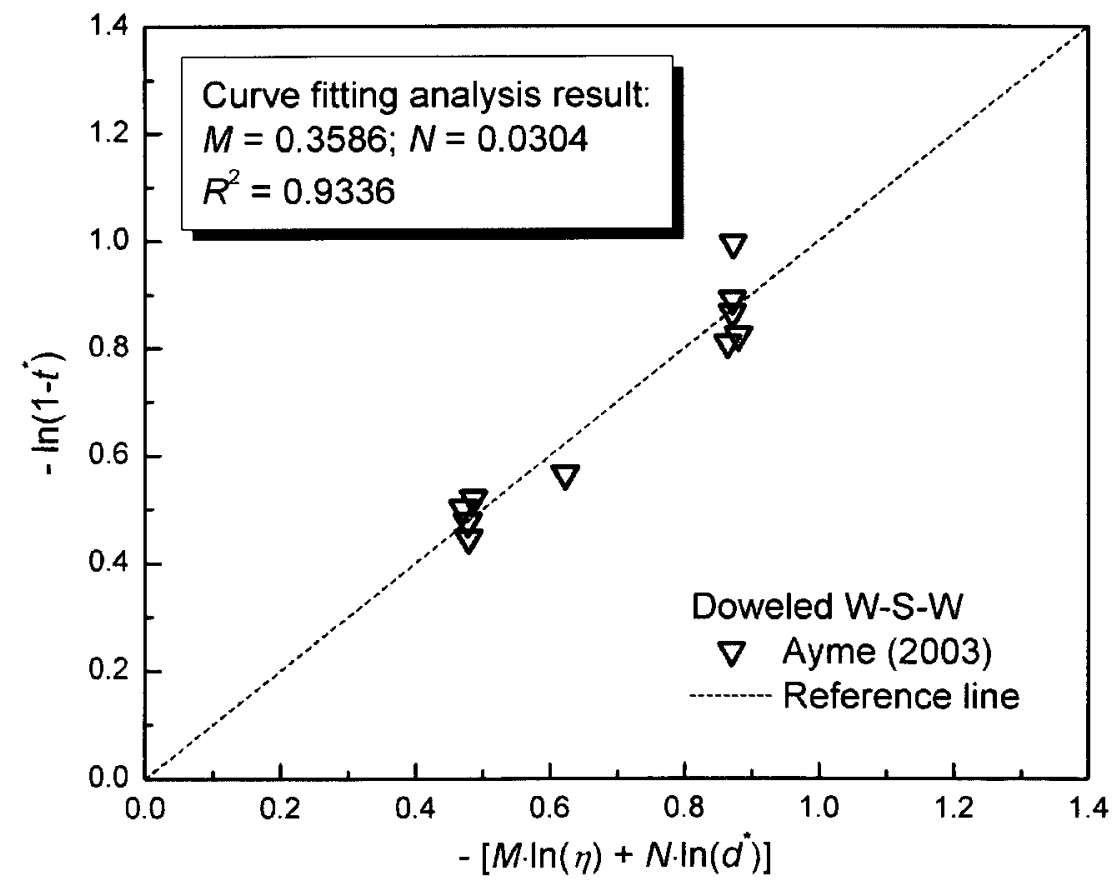

Figure 6.4 Curve fitting analysis result for doweled WSW connections 
Table 6.6 summarizes the four pairs of coefficients determined in Figure 6.1 to 6.4. It is interesting to note that for bolt-type connections, both $M$ and $N$ factors were close for WWW and WSW connections (i.e. $M=0.1881$ vs. 0.1599 ; while $N=0.0709$ vs. 0.0554 ). Similarly, the $M$ s and $N$ s were found to be close for dowel-type connections (i.e. $M=$ 0.4456 vs. 0.3586 ; while $N=-0.0193$ vs. 0.0304 ).

Table 6.6 Correlation results

\begin{tabular}{cccc}
\hline Fastener Type & Connection Type & $M$ & $N$ \\
\hline Bolt & WWW & 0.1881 & 0.0709 \\
Bolt & WSW & 0.1599 & 0.0554 \\
Dowel & WWW & 0.4456 & -0.0193 \\
Dowel & WSW & 0.3586 & 0.0304 \\
\hline
\end{tabular}

Therefore, as a further simplification, average values could be used to estimate $M$ and $N$ as 0.174 and 0.063 for bolt-type connections, and 0.402 and 0.005 for dowel-type connections, respectively.

Table 6.7 Connection factors for timber connections

\begin{tabular}{ccccc}
\hline & \multicolumn{2}{c}{ WWW Connections } & \multicolumn{2}{c}{ WSW Connections } \\
& Bolted & Doweled & Bolted & Doweled \\
\hline$\beta(\mathrm{mm} / \mathrm{min})$ & $0.7^{\dagger}$ & $0.7^{\dagger}$ & $0.8^{\dagger \dagger}$ & $0.8^{\dagger \dagger}$ \\
$M$ & 0.174 & 0.402 & 0.174 & 0.402 \\
$N$ & 0.063 & 0.005 & 0.063 & 0.005 \\
\hline$: 0.65$ should be used if the fire exposure time is more than 1 hour. \\
${ }^{\dagger \dagger}: 0.7$ should be used if the fire exposure time is more than 1 hour. \\
\hline
\end{tabular}

Rearranging Equation (6.4) to the dimensional form yielded the following equation that could estimate the fire resistance of a WWW or WSW connection using either bolts or dowels as fasteners:

$$
t_{f}=\left(t_{1} / \beta\right)\left(1-\eta^{M}\left(d / t_{1}\right)^{N}\right)
$$


Equation (6.5) combined with new $M$ and $N$ values listed in Table 6.7, was used to calculate the fire resistances and the results were compared to the test or modelled results, shown in Figure 6.5.

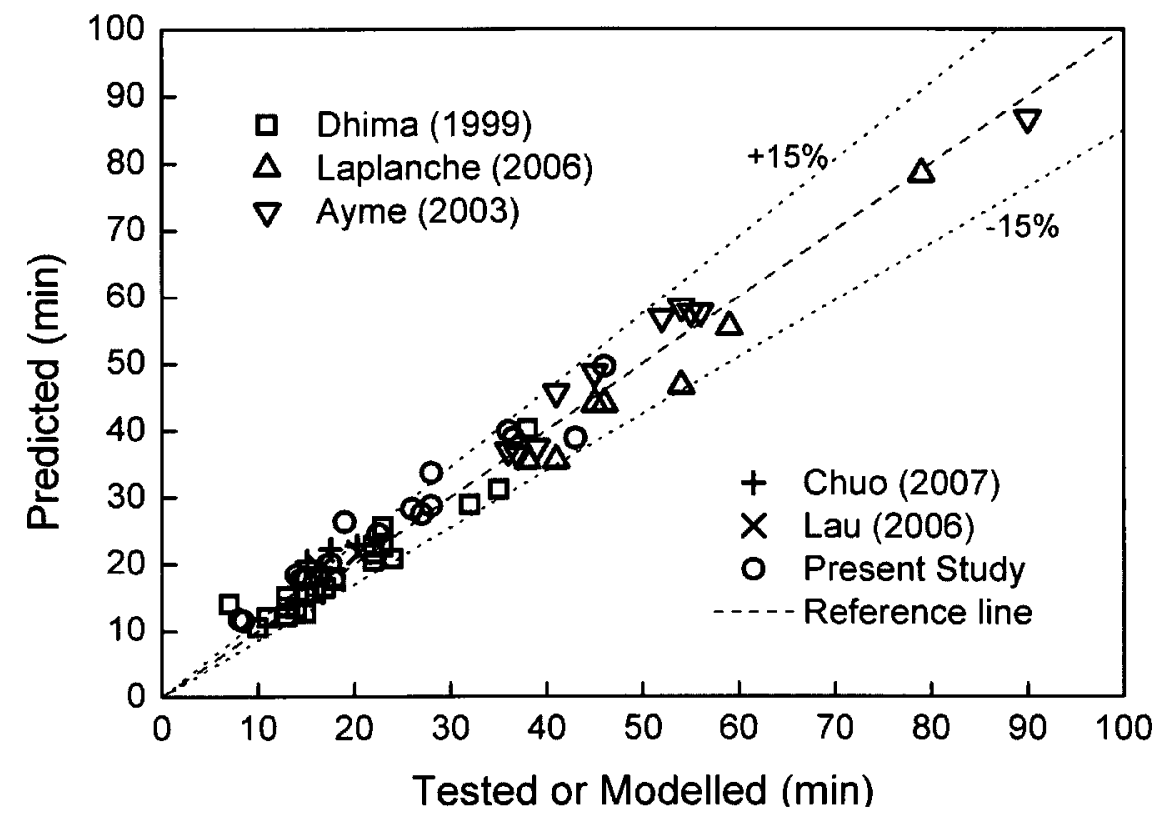

Figure 6.5 Comparison between measured or modelled fire resistances and predicted fire resistances using Equation (6.5)

\section{Limitations}

It can be seen in Figure 6.5 that the correlations work up to about $90 \mathrm{~min}$. Particularly between 30 and $90 \mathrm{~min}$, the predicted times are almost within the $\pm 15 \%$ envelope. However, below $30 \mathrm{~min}$, the predictions tend to be overestimated. For design purposes, further modifications should be made to make predictions on the safe side.

Moreover, the correlations were validated for WWW and WSW connections with side wood member thicknesses from $38 \mathrm{~mm}$ to $100 \mathrm{~mm}$, bolt diameters from $12 \mathrm{~mm}$ to 20 $\mathrm{mm}$, and load ratios from $10 \%$ to $60 \%$. 


\subsection{Correlation for SWS Connections}

As observed in the experimental tests and modelling part, the wood member thickness and load ratio played important roles on the fire resistance of a SWS connection. An empirical calculation method was developed by taking into account the effect of wood member thickness and load ratio.

Figure 6.6 shows the relationship between the failure time $\left(t_{f}\right)$ and the load ratio $(-\ln (\eta))$ from both the test data and model results. It is interesting to see that these data can be fitted into linear curves with different slopes depending on the thickness of wood members $\left(t_{2}\right)$. Further, the slope of these linear curves was found to be proportional to the wood thickness. Therefore, if the failure time was plotted as a function of $\left(-\ln (\eta) \cdot t_{2}\right)$, all the data fitted into a linear curve, as shown in Figure 6.7.

Based on Figure 6.7, a simple calculation formula was then proposed to predict the fire resistance of SWS connections:

$$
t_{f}=-0.0785 \ln (\eta) \cdot t_{2}
$$

Figure 6.8 shows the predictions using Equation (6.6) vs. the tested and modelled fire resistances. It can be seen that the predicted fire resistances using Equation (6.6) were almost within the $\pm 10 \%$ envelope. 


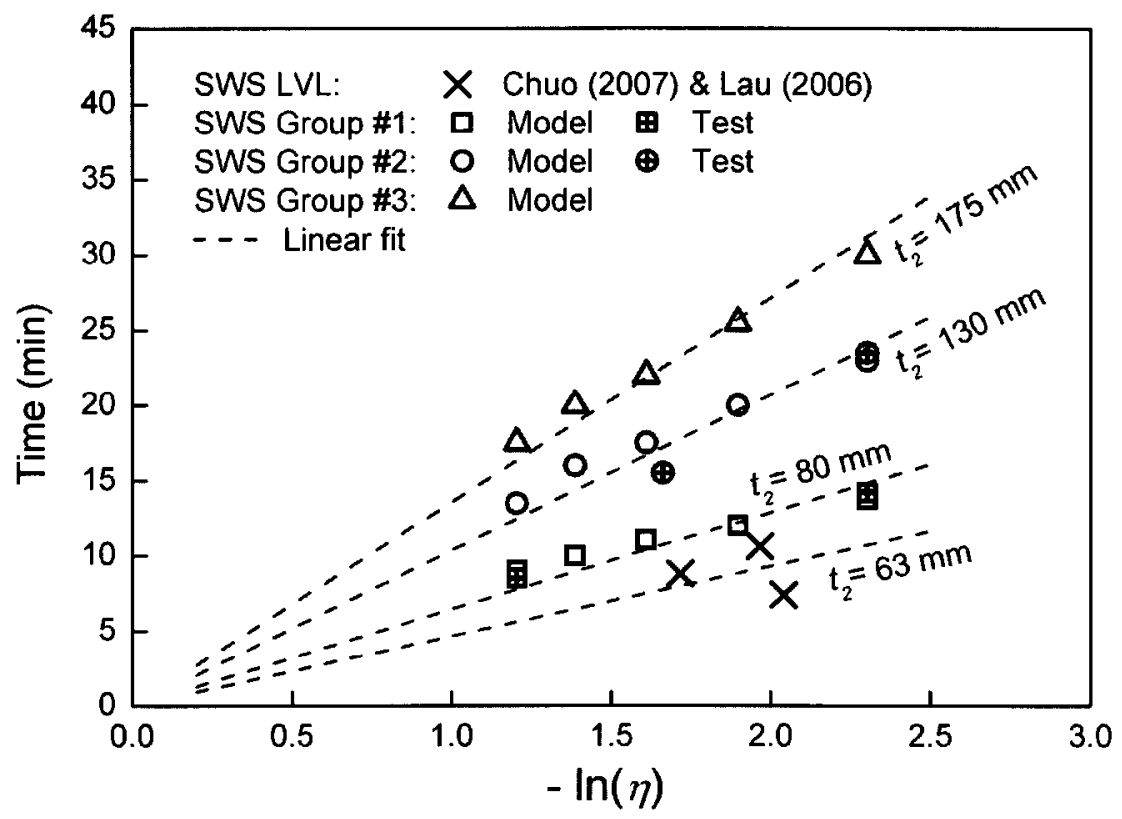

Figure 6.6 Failure time vs. load ratio for SWS connections

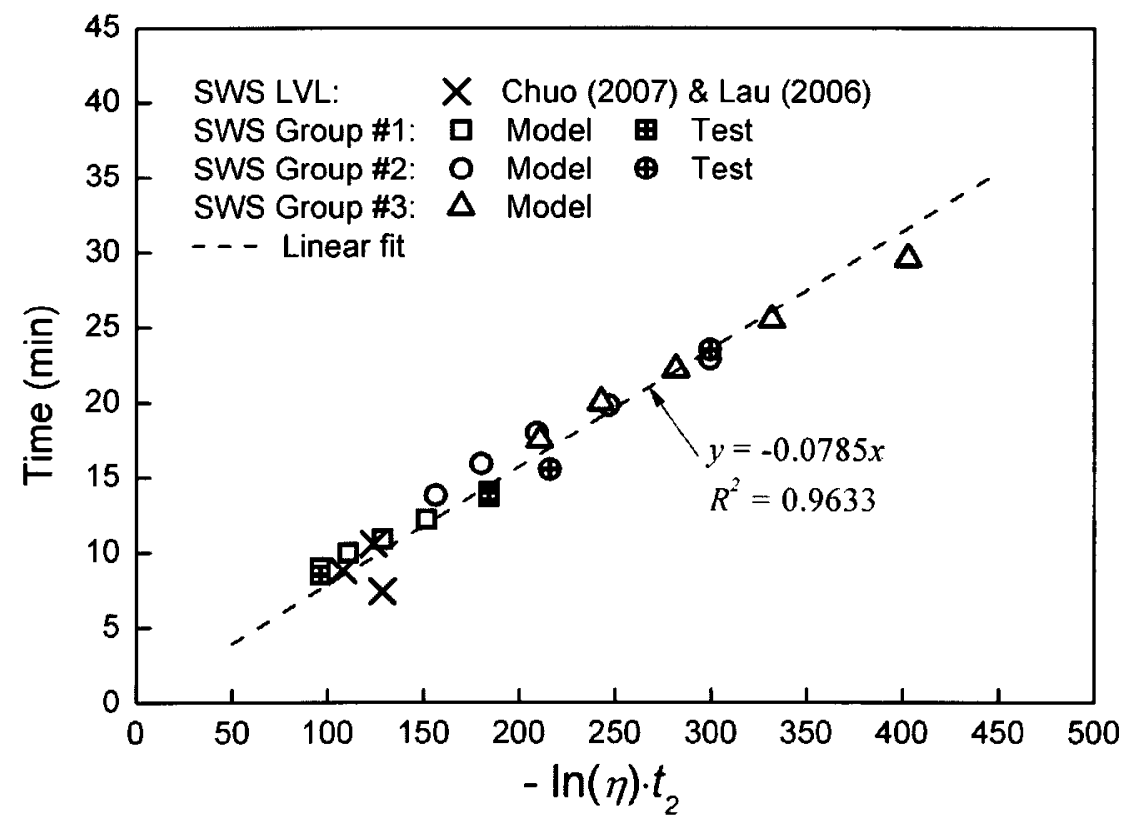

Figure 6.7 Correlation result for SWS connections 


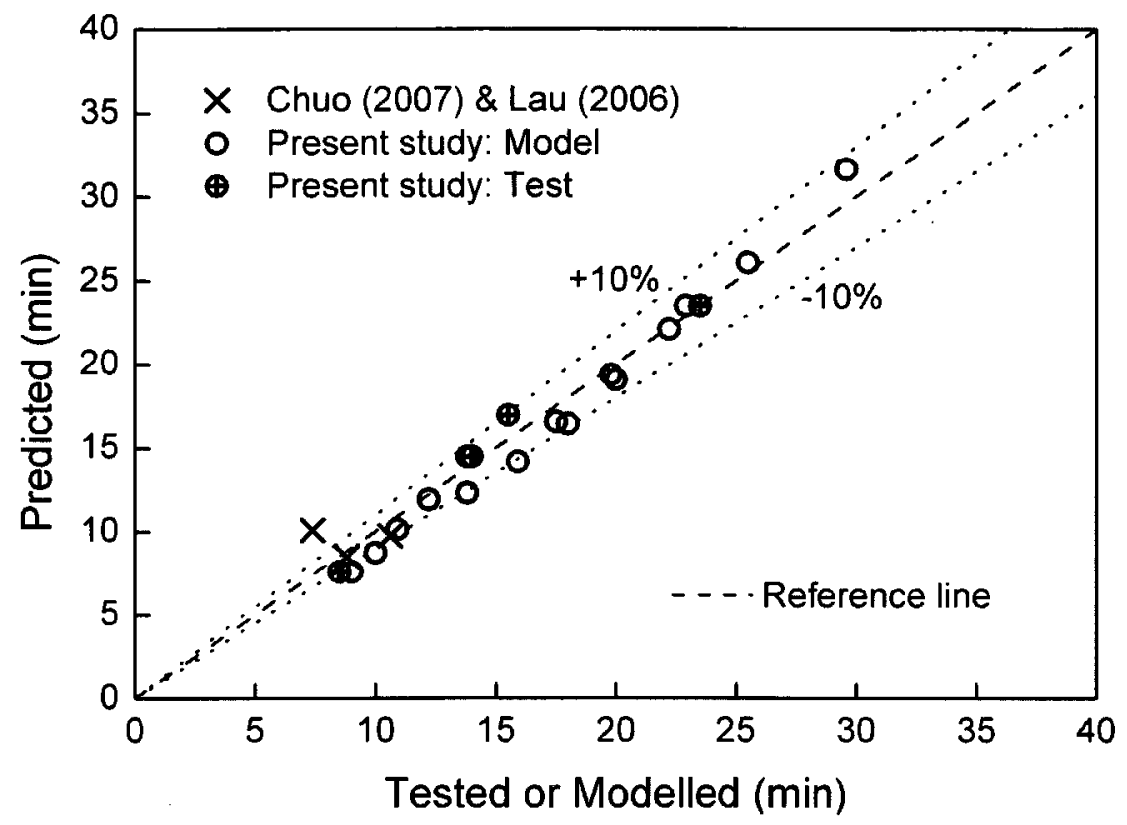

Figure 6.8 Comparison between measured or modelled fire resistances and predicted fire resistances using Equation (6.6)

\section{Limitations}

It can be seen in Figure 6.8 that the correlation was only validated for time less than 30 min. The tested specimens had wood member thicknesses from $63 \mathrm{~mm}$ to $130 \mathrm{~mm}$, and load ratios from $10 \%$ to $30 \%$. Although the modelled results for specimens with thick wood members were also found to fit into the correlation, it is recommended that a few tests be carried out to extend the validation of the correlation. 


\subsection{Protected Timber Connections}

In the previous two sections, simplified calculation methods have been developed to predict the fire resistances of unprotected timber connections. It can be concluded that, in order to meet the fire resistance requirement of the code, either much larger timber members should be used, or lower load ratios should be used for timber connections. Another possible solution is using protection to increase the fire resistance of timber connections.

This section discusses calculation methods which could be used to assess the fireresistance of protected timber connections.

\subsubsection{Contribution of Protective Membrane}

For wood construction, gypsum boards and plywood panels are used as two common types of membrane to offer fire protection for structural wood members. The fireresistance of a protected member is mainly determined by the type and thickness of the protective membrane (White 2008). For a light-framed wall, floor and roof assemblies, a code-adopted method in North American, to determine the fire resistance is called as the Component Additive Method (CAM). In the CAM, the times are assigned for the protective membranes, shown in Table 6.8. 
Table 6.8 Time assigned to protective membranes (White 2008)

\begin{tabular}{lc}
\hline Description of Finish & Time (min) \\
\hline 9.5-mm (3/8-in.) Douglas fir plywood, phenolic bonded & 5 \\
13-mm (1/2-in.) Douglas fir plywood, phenolic bonded & 10 \\
16-mm (5/8-in.) Douglas fir plywood, phenolic bonded & 15 \\
9.5-mm (3/8-in.) gypsum board & 10 \\
13-mm ( $1 / 2-$-in.) gypsum board & 15 \\
16-mm (5/8-in.) gypsum board & 20 \\
13-mm (1/2-in.) type X gypsum board & 25 \\
16-mm ( $5 / 8$-in.) type X gypsum board & 40 \\
Double 9.5-mm (3/g-in.) gypsum board & 25 \\
13-mm + 9.5-mm (1/2-in. + 3/8-in.) gypsum board & 35 \\
Double 13-mm (1/2-in.) gypsum board & 40 \\
\hline
\end{tabular}

As described in the literature review, TR 10 (AWC 2003) provides a simple solution by assuming that the protection of fire-rated gypsum board (5/8" thick) or $38 \mathrm{~mm}$ thick wood can provide the entire one-hour fire-resistance rating to timber connections, without taking into account the inherent fire resistance of the connection itself. However, two protected connections in this research showed that the protection of one-layer of $5 / 8 "$ Type X gypsum board had a fire resistance of less than 1-hour.

A more reasonable, yet simple method, for estimating the fire resistance of protected timber connections would be similar to the CAM, as shown in Equation (6.7):

$$
t_{f, \text { protected }}=t_{a}+t_{f}
$$

where $t_{a}$ is the time assigned to different types of protective membranes, and $t_{f}$ is the fire resistance of unprotected timber connections, which can be calculated using the methods presented in previous sections. 


\section{Gypsum Board}

As tested and discussed in Chapter 3, the improvement for a single layer of $15.9 \mathrm{~mm}$ thick Type $\mathrm{X}$ gypsum board to a timber connection was more than 33 minutes. This value is very close to the average value (33 minutes) for solid wood beams protected with the same protected membrane reported by White (2009). In addition, the $140 / 180^{\circ} \mathrm{C}$ finish rating and the time to reach a temperature of $300^{\circ} \mathrm{C}$ behind the $15.9 \mathrm{~mm}$ Type $\mathrm{X}$ gypsum board were also found to be close the values reported by White (2009) for solid protected timber beams. Therefore, the same assigned time to timber beams, 30 minutes, for a single-layer of $15.9 \mathrm{~mm}$ Type $\mathrm{X}$ gypsum board, can be assigned to timber connections.

\section{Plywood Panel}

Similar to gypsum board, the improvement for a double-layer of $12.7 \mathrm{~mm}$ thick plywood panels to a timber connection (15 minutes) was found to be close to White's result (15 minutes), as well as the $140 / 180^{\circ} \mathrm{C}$ finish rating and the time to reach a temperature of $300^{\circ} \mathrm{C}$. Therefore, it can be concluded that a time, 15 minutes, can be assign for a doublelayer of $12.7 \mathrm{~mm}$ plywood panels to timber connections.

White also reported that the improvement for a single layer of $12.7 \mathrm{~mm}$ thick plywood panel was 8 minutes. Although this protective membrane was not studied in this research for timber connections, it can be assumed that the same time can be assigned for a singlelayer of $12.7 \mathrm{~mm}$ plywood panel to timber connections, based on the similar results for Type X gypsum boards and double-layer of 12.7 plywood panels. 


\subsubsection{Concealed Fasteners}

Although timber connections with concealed fasteners were not tested in this research, it is worth discussing the effect of this type of protection on the fire resistances for WWW or WSW connections, based on the knowledge and information generated in this study.

Figure 6.9 shows a WSW connection with a concealed bolt or dowel as an example. Wood plugs are used to cover the holes. The original thickness of the wood side member is $t_{1}+a$, but the effective bearing thickness is $t_{1}$ as shown in Figure 6.9. A concealed timber connection can be recognized as an equivalent timber connection with the wood side member thickness of $t_{l}$, protected with additional wood with a thickness of $a$.

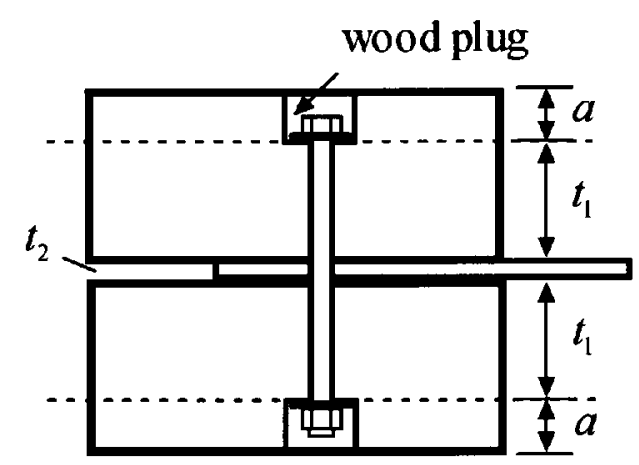

(a) concealed bolt

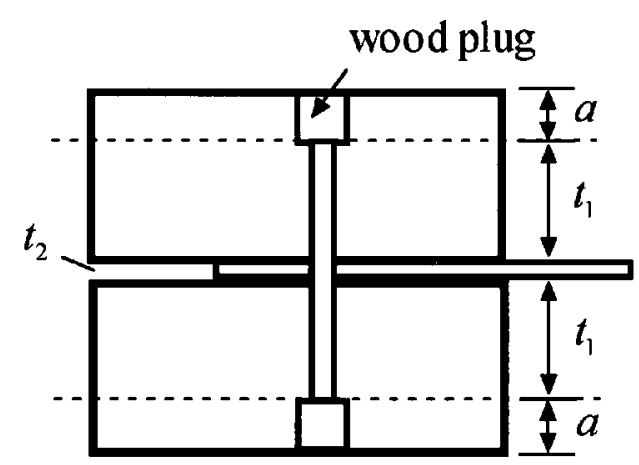

(b) concealed dowel

Figure 6.9 Concealed fasteners in WSW connections

Generally, timber connections with concealed fasteners have the advantages that they have no metal directly exposed to fire, and also have nice appearance. However, a disadvantage is that the effective wood bearing length is reduced from $t_{l}+a$ to $t_{l}$, due to the holes drilled to conceal the bolts. Therefore, if the same load is applied, a connection with concealed fasteners has a higher load ratio compared to a timber connection with unconcealed fasteners, and a higher load ratio means a lower fire resistance of the 
connection. In addition, in order to conceal the fasteners, a large amount of wood material needs to be removed. It may not be possible for timber connections with smaller crosssection area, because a too large portion of wood would be removed to accommodate the fasteners.

It is assumed that the additive method used for timber connections with protective membranes can be used here. The fire resistance of a timber connection with concealed fasteners can be calculated as:

$$
t_{f, \text { concealed }}=t_{a}+t_{f}
$$

where $t_{f}$ is the fire resistance of an equivalent timber connection with a wood side member thickness of $t_{l}$, which can be calculated using the methods presented in previous sections. $t_{a}$ is the fire resistance of the side wood with a thickness of $a$ :

$$
t_{a}=a / \beta
$$

where $\beta$ is the charring rate for the extra side wood with a thickness of $a$. In Eurocode 5, a charring rate 0.9 or $1.0 \mathrm{~mm} / \mathrm{min}$ is recommended for wood-based panels or plywood panels attached to main members. However, for the solid wood $a$ as a part of the mean member, it will not fall off during a test like wood-based panels. Therefore, a lower value of $0.7 \mathrm{~mm} / \mathrm{min}$, as close to the charring rate of solid timber might be suitable to be assigned to $\beta$ for concealed timber connections.

It has to be pointed out that further fire-resistance tests might be necessary to validate this assumption to use the additive method for timber connections with concealed fasteners. 


\subsubsection{Intumescent Paint}

In steel construction, fire-resistance coatings, including intumescent paint, are commonly applied to structural members to increase the fire-resistance duration. When intumescent paint is heated, the material swells up into a significant thickness and chars. It acts as a thermal barrier and insulates the structural members beneath (Buchanan 2001).

As tested in this research, a SWS timber connection, with side steel plates and bolt heads/nuts protected with $2 \mathrm{~mm}$ thick intumescent paint, only increased the fire resistance by 7 minutes. It was observed in the test that the displacement between the steel plate and the wood member during the fire test caused adhesion problem to the intumescent paint. The paint was therefore damaged at the edges of the steel plate, leaving the steel plate exposed to the fire at this area.

Thus, using intumescent paint to protect steel plates may not be a good solution for timber connections with steel side plates, due to the adhesion problem of intumescent paint at the steel plate edges.

For comparison, Lau (2006) found that the improved fire resistance for bolted steelwood-steel connections and the nailed steel-wood-steel connections were about 9.9 minutes and 8.2 minutes, respectively. Frangi (2009) stated that the protection of a $2 \mathrm{~mm}$ thick intumescent paint to steel side plates increased the fire resistance of nailed steeltimber-steel connections by about 18 minutes. 


\subsection{Summary}

Simplified empirical methods were developed to predict the fire resistance of unprotected WWW, WSW and SWS timber connections.

The same equations were proposed for WWW and WSW connections since they have similar action in fire exposure. However, different values of parameters were determined in the equations, in order to take into account different connection types and fastener types (i.e. WWW or WSW, bolt or dowel).

Overall, the comparison with experimental results showed that the developed methods could predict the fire resistance of WWW and WSW timber connections with an accuracy of $\pm 15 \%$.

With the calculation methods developed, it is possible to assess the thickness of wood side member for a WWW or WSW connection to achieve the minimum target rating for Canadian code compliance, 45 minutes: i.e. about $82 \mathrm{~mm}$ for doweled WWW, $93 \mathrm{~mm}$ for doweled WSW, $115 \mathrm{~mm}$ for bolted WWW and $130 \mathrm{~mm}$ for bolted WSW, if the connections are loaded at a load ratio of $30 \%$ and the fasteners have a diameter of $19.1 \mathrm{~mm}$.

The equation proposed for SWS connections was simpler than the equations for WWW and WSW connections. Load ratio and timber thickness were two factors considered in the equation. The comparison with experimental data and model results showed that the developed method could predict the fire resistances of SWS timber connections with an accuracy of $\pm 10 \%$. Using the developed method, it is found that the fire resistance of a 
SWS connection with $215 \mathrm{~mm}$ thick wood member (at $30 \%$ load ratio) is just $20 \mathrm{~min}$. Therefore, to achieve a fire-resistance rating of 45 minutes, a SWS connection must be protected.

For timber connections with protective membranes, the additive method can be used by adding the additive fire resistances of protective membranes to the fire resistances of unprotected timber connections. The fire resistances of a single layer of $15.9 \mathrm{~mm}$ Type X gypsum board and a double layer of $12.7 \mathrm{~mm}$ plywood panel were found to be 30 minutes and 15 minutes, respectively.

For WWW and WSW timber connections with concealed fasteners, the fire resistances can be calculated by adding the extra fire resistances of the side wood with a thickness of $a$, to the fire-resistance ratings of unprotected timber connections with a wood thickness equivalent to $t_{l}$.

For SWS timber connections with steel plates protected with intumescent paint, the improvement was less than 10 minutes due to the adhesion problem. 


\section{Chapter 7: Summary and Conclusions}

\subsection{Summary}

The objective of this research was to develop calculation methods to predict the fire resistances of heavy timber connections. To this end, fire-resistance tests have been conducted to study the effects of wood member thickness, load ratio, fastener diameter, and protection on the fire resistance of bolted WSW and SWS connections. A threedimensional numerical heat transfer model and an analytical structural model were applied to simulate the temperature profiles in the timber connections and the strengths of the timber connections at elevated temperatures.

In order to validate the numerical heat transfer model and the analytical structural model, the data generated from the fire-resistance tests were used for comparison. Comparison between the heat transfer model predictions and measured temperatures during the fireresistance tests were found to be in a good agreement for both WSW and SWS connections. Although the steel temperatures were a little overestimated at the beginning and the wood temperatures were underestimated when the temperature was less than $120^{\circ} \mathrm{C}$, the predicted temperatures tended to catch up to the measured results later on for both wood and bolt temperatures. Comparison between the analytical structural model and the fire-resistance test results showed that, based on the temperature profiles calculated using the heat transfer model, the failure time could be predicted with good agreement by using the appropriate embedding strength reduction approach. 
The sensitivity analysis demonstrated that the variations of wood conductivity, specific heat, density and furnace temperature have a large impact on the heat transfer model results. However, the influence on the fire resistance was found to be small for wood densities and furnace temperatures.

The simplified calculated methods, based on the correlations using the data generated in this study or obtained from the literature, were found to be able to predict the fire resistances of WWW and WSW connections with either bolts or dowels, and SWS timber connections with bolts. Comparison between the calculation methods and the test results showed that the predictions for WWW and WSW connections were usually within a $15 \%$ envelope, and the predictions for SWS connections were usually within a $10 \%$ envelope.

\subsection{Conclusions}

Based on the research reported in this thesis, the following conclusions can be drawn on the fire performance of heavy timber connections:

- The test results show that the fire resistances of all the tested WSW connections using bolts as fasteners with no protection were less than $45 \mathrm{~min}$, a target rating for Canadian code compliance.

- The test results show that the fire resistances of the tested SWS connections using bolts as fasteners with no protection were less than $25 \mathrm{~min}$.

- The test results show that for timber connections with protective membranes, the improved fire resistance, the $140 / 180^{\circ} \mathrm{C}$ finish rating and the time to reach a temperature of $300^{\circ} \mathrm{C}$ behind the protective membranes are close to the values 
reported for solid wood beams protected with the same membranes. A single-layer of $15.9 \mathrm{~mm}$ Type $\mathrm{X}$ gypsum board improves the fire resistance by at least 30 minutes and a double-layer of $12.7 \mathrm{~mm}$ plywood improves the fire resistance by about 15 minutes.

- In order to accurately predict the temperature profiles in timber connections, proper wood thermal properties and furnace boundary conditions should be defined in the heat transfer model. Validation of the heat transfer model shows that adopting Konig's wood thermal properties and using the plate thermometer measurements to define boundary conditions could lead to good agreement of the temperature profiles in timber connections.

- The analytical structural model, combined with temperature profiles calculated using the heat transfer model, can be used to predict the fire resistance of a timber connection. Validation of the analytical structural model shows that using the wood temperature $0.5 d$ away from the bolt/hole interface and Noren's embedding strength reduction relationship at elevated temperatures, gives a good prediction of the fire resistance.

- The proposed simplified calculation methods form a basic design tool for evaluating the fire performance of unprotected WWW, WSW and SWS timber connections, and the additive method provides an approach to assess the fire performance of timber connections with protective membranes. By changing timber connection types, wood member thicknesses, load ratios and protections, timber connections can be designed to satisfy required fire-resistance ratings according to building codes. 


\subsection{Recommendations}

With the calculation methods developed to predict the fire resistances of timber connections, recommendations can be made on how to design suitable timber connections in compliance with code requirements.

For unprotected timber connections, increasing the wood member thickness, diameter of fasteners and number of fasteners would be possible solutions to achieve code requirements. Although the diameter and number of fasteners do not have direct impact on the fire resistance of timber connections, increasing the diameter or number of fasteners does decrease the load ratio, and this effort results in an increase in the fire resistance. To achieve a better fire resistance, dowels are a good solution instead of bolts for the same wood member thickness, diameter and number of fasteners.

If appearance is not a factor, protective membranes can be used to increase the fire resistance of timber connections. The additive method can be used to calculate the fire resistance of protected timber connections. If appearance is a factor, fasteners can be concealed within wood members and wood plugs can be used to cover the fasteners. The additive method can also be used to calculate the fire resistances of concealed timber connections.

Recommendations can also be made for future studies. Since the three-dimensional heat transfer model and the analytical structural model were successfully used to predict the fire resistances of the timber connections, those models can be used to study the behaviour of other types of timber connections in the future, i.e. timber connections 
subjected to bending or tension perpendicular to the grain. In addition, a three dimensional thermo-mechanical coupled model, taking into account local failure criteria, could be considered to make more accurate predictions for the splitting and shear failure modes as a future study.

Moreover, although the timber connections with thicker wood members were modelled using the heat transfer and the structural model, and the modelled results were found to fit the correlations with the experimental data, a few more fire-resistance tests are recommended to be carried out to validate the developed calculation methods for bolted WSW and SWS timber connections with large thickness of wood members. 


\section{References}

ASTM D1761-88 (2000). Standard Test Methods for Mechanical Fasteners in Wood. American Society for Testing and Materials, Washingon, DC, USA.

ASTM E119 (2007). Standard methods of fire tests of building constructions and materials. American Society for Testing and Materials, West Conshohochen, PA, USA.

Austruy, C. (2008). Fire resistance of timber connections. Fire Engineering Research Report 08/2, Dept. of Civil Engineering, University of Canterbury, New Zealand.

AWC (2003). Calculating the fire resistance of exposed wood members. Technical Report 10 (TR10), American Wood Council, American Forest and Paper Association, Washington, DC.

Ayme, N. (2003). Assemblages bois-métal en double cisaillement. Rapport Du Comportement Au Feu D'Assemblages Bois, CTICM Ref. SR21-03/121-NA/PB, CTICM, Paris, France.

Benichou, N. and M. Sultan (2000). Fire Resistance Performance of Lightweight WoodFramed Assemblies. Fire Technology, 36(2): 184-219.

Bowchair, A. and A. Vergne (1995). An application of the Tsai criterion as a plastic flow law for timber bolted joint modeling. Wood Science and Technology, 30: 3-19.

Buchanan, A.H. (2001). Structural Design for Fire Safety. John Wiley \& Sons Ltd, Chichester, West Sussex, England.

Cachim, P.B. and J.M. Franssen (2009). Numerical modelling of timber connections under fire loading using a component model. Fire Safety Journal, 44(6): 840-853.

CAN/CSA-O86-01 (2005). Engineering Design in Wood CAN/CSA-O86-1. Canadian Standards Association, Rexdale, ON, Canada. 
CAN/CSA-O86-09 (2009). Engineering Design in Wood CAN/CSA-O86-1. Canadian Standards Association, Rexdale, ON, Canada.

CAN/ULC-S101 (2007). Standard methods of fire endurance tests of building construction and materials. Underwriter's Laboratories of Canada, Scarborough, Canada.

Carling, O. (1989). Fire resistance of joint details in load bearing timber construction - $a$ literature survey. BRANZ Study Report SR 18, Building Research Association of New Zealand, New Zealand.

Chang, F.K. and Chang, K.Y. (1987). A progressive damage model for laminated composites containing stress concentration. Journal of Composite Materials, 21: 834-855.

Chuo, T.C.B. (2007). Fire performance of connections in LVL structures. Fire Engineering Research Report 07/4, Dept. of Civil Engineering, University of Canterbury, New Zealand.

Cooke, G. (1994). Can harmonization of fire resistance furnaces be achieved by plate thermometer control? . Proceedings of the Fourth International Symposium on Fire Safety Science (IAFSS): 1195-1207.

Craft, S.T. (2009). CUWoodFrame - $A$ heat and mass transfer model for light-frame wood floors exposed to fire. Ph.D. Thesis, Carleton University, Ottawa, Canada.

Dhima, D. (1999). Vérification expérimentale de la résistance au feu des assemblages d'éléments en bois. CTICM Ref. INC-99/399-DD/NB, CTICM, Paris, France.

EN 1991-1-2 (2003). Eurocode 1: Actions on structures - Part 1-2: General actions Actions on structures exposed to fire. CEN, Brussels, Belgium.

EN 1993-1-2 (2005). Eurocode 3 - Design of steel structures, Partl-2: General rules Structural fire design. CEN, Brussels, Belgium.

EN 1995-1-1 (2004). Eurocode 5 - Design of timber structures, Part 1-1: General rules and rules for buildings. CEN, Brussels, Belgium. 
EN 1995-1-2 (2004). Eurodode 5 - Design of timber structures, Part 1-2: Structural fire design.

Erchinger, C. (2006a). Multiple shear steel-to-timber connections in fire. 6th International PhD Symposium in Civil Engineering, Swiss Federal Institute of Technology ETH Zurich, Switzerland.

Erchinger, C. Frangi, A. and Mischler, A. (2006b). Thermal investigations on multiple shear steel-to-timber connections. 9th World Conference on Timber Engineering WCTE, Portland/Oregon, USA.

Erchinger, C., Frangi, A. and Fontana, M. (2010). Fire design of steel-to-timber dowelled connections. Engineering Structures, 32(2): 580-589.

Frangi, A. and Fontana, M. (2003). Thermal expansion of wood and timber-concrete composite members under ISO-fire exposure. Fire Safety Science, 7: 1111-1122.

Frangi, A., Erchinger, C. and Fontana, M. (2009). Experimental fire analysis of steel-totimber connections using dowels and nails. Fire and Materials, 34(1): 1-19.

Fredlund, B. (1993). Modelling of Heat and Mass Transfer in Timber Structures During Fire. Fire Safety Journal, 20(39-69).

Gammon, B.W. (1987). Reliability analysis of wood-frame assemblies exposed to fire. Ph.D. Thesis, University of California, Berkeley, USA.

Gerhards, C.C. (1982). Effect of the moisture content and temperature on the mechanical properties of wood: an analysis of immediate effects. Wood and Fibre, 14(1): 4-36.

Guan, Z.W. and Rodd, P.D. (2000). A three-dimensional finite element model for locally reinforced timber joints made with hollow dowel fasteners. Canadian Journal of Civil Engineering, 27: 785-797.

Hashin, Z. (1980). Failure criteria for unidirectional fiber composites. ASME Journal of Applied Mechanics, 47(2): 329-334. 
Hibbitt, Karlsson \& Sorensen Inc. 2008. (2008). ABAQUS/Standard User's manual. Pawtucket, Rhode Island.

Hill, R. (1950). The mathematical theory of plasticity. Oxford University Press, New York.

Hoffman, O. (1967). The brittle strength of orthotropic materials. Journal of Composite Materials, 1:200-206.

Hong, J. (2007). Three-dimensional nonlinear finite element model for single and multiple dowel-type wood connections. Ph.D. Thesis, Department of wood science, University of British Columbia, Vancouver, BC, Canada.

Howell, J. (1982). A catalog of radiation configuration factors. McGraw-Hill Book Co., New York.

Incropera, F.P., DeWitt, D.P., Bergman, T.L., and Lavin, A.S. (2006). Fundamentals of Heat and Mass Transfer. 6th ed., John Wiley \& Sons, New York.

ISO 834 (1999). Fire resistance tests - Elements of building construction, Part 1: General requirements. International Organization for Standardization, Switzerland.

Janssens, M.L. (1994). Thermo-physical properties for wood pyrolysis models. Pacific Timber Engineering Conference, Gold Coast, Australia: 607-618.

Janssens, M.L. (1997). A method for calculating the fire resistance of exposed timber decks. Proceedings of the Fifth International Symposium on Fire Safety Science ISFSS, Australia: 1189-1200.

Janssens, M.L. and White, R.H. (1994b). Temperature profiles in wood members exposed to fire. Fire and Materials, 18: 263-265.

Jaouen, J.L. and Klarsfeld, S., (1987). Heat transfer through a still air layer. Thermal Insulation: Materials and Systems, ASTM STP 922, F.J. Powell and S.L. Matthews, Eds., American Society for Testing and Materials, Philadelphia: 283-294. 
Jaunky, N., Ambur, D.R., Davila, C.G. and Hilburger, M. (2001). Progressive failure studies of composite panels with and without cutouts. NASA/CR-2001-211223, ICASE Report No.2001-27, ICASE, Hampton, Virginia.

Johansen, K.W. (1949). Theory of timber connectors. International Association of Bridge and Structural Engineering (IABSE), Bern, Switzerland, 9: 249-262.

Jorissen, A. (1998). Double shear timber connections with dowel type fasteners. Ph.D. Thesis, Delft University, Delft, Netherlands.

Kharouf, N. (2001). Post-elastic behavior of bolted connections in wood. Ph.D. Thesis, Department of Civil Engineering and Applied Mechanics, McGill University, Montreal, Canada.

Knudson, R.M. (1973). Performance of structural wood members exposed to fire. Ph.D. Thesis, University of California, Berkeley, USA.

Konig, J. and Walleij, L. (1999). One-dimensional charring of timber exposed to standard and parametric fires in initially unprotected and post-protection fire situations. Rapport I 9908029, Swedish Institute for Wood Technology Research, Stockholm.

Konig, J. and Walleij, L. (2000). Timber frame assemblies exposed to standard and parametric fires, Part 2: a design model for standard fire exposure. Rapport I 0001001, Swedish Institute for Wood Technology Research, Stockholm.

Konig, J. and M. Fontana (2001). The performance of timber connections in fire test results and rules of Eurocode 5. Proceedings of International Rilem Symposium 'Joints in Timber Structures', University of Stuttgart, Rilem Publications s.a.r.l., Cachan, France.

Kruppa, J., Lamadon, T. and Rachet, P. (2000). Fire Resistance Test of Timber Connections. CTICM Ref. INC-00/187-JK/NB, CTICM, Paris, France.

Laplanche, K. (2006). Fire performance of timber connections: experimental and modelling approach. Ph.D. Thesis, Clermont-Ferrand: Blaise Pascal University (in French). 
Larsen, H. (1973). The yield load of bolted and nailed joints. Structural Research Laboratory, Department of Structural Engineering and Materials, Technical Universtiy of Denmark, International Union of Forestry Research Organizations(IUFRO), Division 5, Copenhagen, Denmark.

Lau, P.H. (2006). Fire resistance of connections in laminated veneer lumber. Fire Engineering Research Report 06/3, Dept. of Civil Engineering, University of Canterbury, New Zealand.

Lie, T.T. (1992). Structural Fire Protection. American Society of Civil Engineers, New York.

Lie, T.T. (1977). A method of assessing the fire resistance of laminated timber beams and columns. Canadian J. of Civil Eng., 4: 161-169.

LS-DYNA (2007). Manual for LS-DYNA wood material model 143 (FHWA-HRT-04097). U.S. Department of Transportation, Federal Highway Administration, Research, Development and Technology Turner-Fairbank Highway Research Center, McLean, VA, USA.

Masse, D.I., Salinas, J.J., and Turnbull, J.E. (1988). Lateral strength and stiffness of single and multiple bolts in glued-laminated timber loaded parallel to grain.Unpublished Contract No. C-029, Engineering and Statistical Research Center, Research Branch, Agriculture Canada, Ottawa, Canada.

McCarthy, C.T. (2003). Three-dimensional finite element analysis of the effects of clearance on the mechanical behaviour of composite bolted joints. Ph.D. Thesis, University of Limerick, Ireland.

Mehaffey, J. R. (2003). Fire performance of heavy timber connections. Report No. 3223, Forintek Canada Corp., Ottawa, ON, Canada.

Mehaffey, J. R., Cuerrier, P. and Carisse, G. (1994). A model for predicting heat transfer through gypsum board/wood stud walls exposed to fire. Fire and materials, 18: 297-305. 
Mohammad, M. and Quenneville, J.H.P. (2001). Bolted wood-steel and wood-steel-wood connections: verification of a new design approach. Can J Civil Eng, 28: 254-263.

Moraes, P.D., Rogaume, Y., Bocquet, J.F. and Triboulot, P. (2005). Influence of temperature on the embedding strength. Holz als Roh- und Werkstoff 63(4): 297-302.

Moses, D. (2000). Constitutive and analytical models for structural composite lumber with application to bolted connections. Ph.D. Thesis, University of British Columbia, Vancouver, Canada.

Moss, P.J., Buchanan, A., Fragiacomo, M. and Austruy, C. (2008). On the design of timber bolted connections subjected to fire. 5th International Conference on Structures in Fire, Nanyang Technological University, Singapore.

NBCC (2005). National Building Code of Canada. Canadian Commission on Building and Fire Code, National Research Council of Canada, Ottawa, ON, Canada.

NBHP (1988). Swedish National Board of Housing and Planning, Swedish Building Code. NR1.BFS 1988:18.

NDS (2005). National Design Specification for Wood Construction - ANSI/AF\&PA NDS-2005. American Forest \& Paper Association, American Wood Council, Washington, DC.

Noren, J. (1996). Load-bearing capacity of nailed joints exposed to fire. Fire and Materials, 20: 133-143.

Ostman, B.A. (1985). Wood tensile strength at temperatures and moisture contents simulating fire conditions. Wood Science and Technology, 19: 103-116.

Patton-Mallory, M. (1996). The three-dimensional mechanics and failure of single bolt wood connections. Ph.D. Thesis, Civil Engineering Department, Colorado State University, Fort Collins, CO, USA. 
Preusser, R. (1968). Plastic and elastic behaviour of wood affected by heat in open systems. Holztechnologie, 9(4): 229-231.

Quenneville, J.H.P. (1998). Predicting the failure modes and strength of brittle bolted connections. Proceedings of the 5th World Conference on Timber Engineering (WCTE), Montreux, Switzerland: 137-144.

Quenneville, J.H.P. and Mohammad, M. (2000). On the failure modes and strength of steel-to-timber bolted connections loaded parallel-to-grain. Can J Eng., 27: 761-773.

Rahman, M.U., Chiang, Y.J. and Rowlands, R.E. (1991). Stress and failure analysis of double-bolted joints in Douglas-fir and Sitka spruce. Wood and Fiber Science, 23: 567589.

Rodd, P.D. (1973). The analysis of timber joints made with circular dowel connectors. Ph.D. Thesis, University of Sussex, England.

SAA (1990). Timber structures, Part4: Fire resistance of structural timber members. AS 1720-4-1990, Standards Association of Australia.

Schaffer, E.L. (1970). Elevated Temperature Effect on the Longitudinal Mechanical Properties of Wood. Ph.D. Thesis, Department of Mechanical Engineering, Univ. Wisconsin, Madison, WI, USA.

Sjodin, J., Serrano, E. and Enquist, B. (2008). An experimental and numerical study of the effect of friction in single dowel joints. Holz Roh Werkst, 66: 363-372.

SNZ (1993). Code of practice for timber design. NZS 3603, Standards New Zealand, Welllington, New Zealand.

Sultan, M. (2006). Fire resistance furnace temperature measurements: plate thermometer vs. shields thermocouples. Fire Technology, 42: 253-267.

Takeda, H. and Mehaffey, J.R. (1998). WALL2D: a model for predicting heat transfer through wood-stud walls exposed to fire. Fire and Materials, 22: 133-140. 
Thomas, G.C. (1997). Fire resistance of light timber framed walls and floors. Ph.D. Thesis, School of Engineering, University of Canterbury, New Zealand.

Tsai, S.W. and Wu, E.M. (1971). A general theory of strength for composite anisotropic materials. Journal of Composite Materials, 5: 58-80.

Tserpes, K.I., Papanikos, P. and Kermanidis, T.H. (2001). A three-dimensional progressive damage model for bolted joints in composite laminates subjected to tensile loading. Fatigue and Fracture Engineering Materials and Structures, 24(10): 663-675.

UL (1993). Fire Resistance Directory. Vol. 1, Underwriters Laboratories.

White, R.H. (1988). Charring rates of different wood species. Ph.D. Thesis, University of Wisconsin-Madison, Madison, WI, USA.

White, R.H. (2000). Charring rate of composite timber products. The Proceedings of Wood and Fire Safety, Part1, $4^{\text {th }}$ International Scientific Conference, Zvolen, Slovak Republic: 353-363.

White, R.H. (2008). Analytical methods for determining fire resistance of timber members. Section 4/Chapter 11, SFPE Handbook of Fire Protection Engineering, $4^{\text {th }}$ Edition.

White, R.H. (2009). Fire resistance of wood members with directly applied protection. Fire and materials 2009: 11th International Conference and Exhibition, Fisherman's Wharf, San Francisco, USA.

White, R.H. and Tran, H.C. (1996). Charring rate of wood exposed to a constant heat flux. Wood and fire safety: 3rd International Scientific Conference, The High Tatras, Slovak Republic: $175-183$.

Wickstrom, U. (1994). The plate thermometer - a simple instrument for reaching harmonized fire resistance tests. Fire Technology, 30(2): 195-208. 
WoodHandbook (1999). Wood Handbook - Wood as an engineering material. U.S. Department of Agriculture, Forest Services, Forest Products Laboratory, Madison, WI, USA.

Xu, B., Taazount, M. and Racher P. (2008). Mechanical analysis of timber connection using $3 D$ finite element model. 10th World Conference on Timber Engineering WCTE, Miyazaki, Japan. 


\section{Appendix A: Calculation of Load Capacity of Timber Connections at Ambient Temperature}

The calculation of the load capacity of timber connections at ambient temperature is based on the Canadian standard CAN/CSA-O86-09. The load capacity of a connection is the smallest resistance value calculated based on all potential failure modes as discussed in the following.

\section{Yielding Resistance}

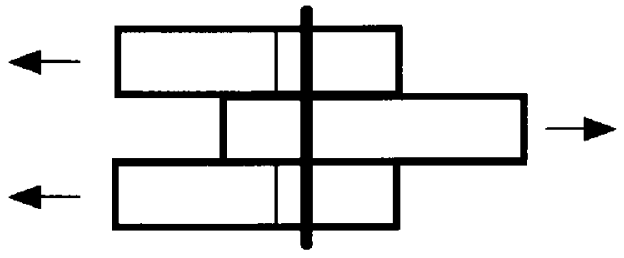

(1)

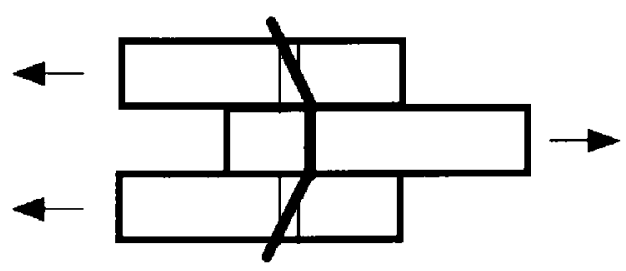

(3)

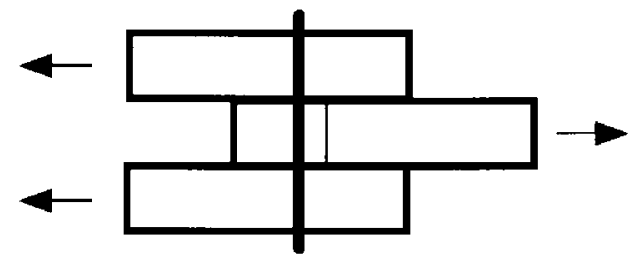

(2)

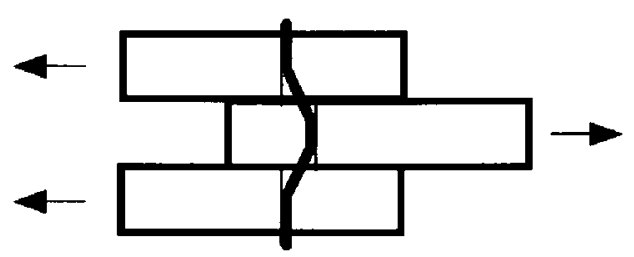

(4)

Figure A.1 Ductile failure modes for double-shear timber connections, reproduced from CAN/CSA-086-09 (2009)

Figure A.1 shows the four possible ductile failure modes. The factored yielding resistance of a connection shall be taken as the minimum value calculated from the following expressions: 
- for failure mode 1: $\quad N_{r}=\phi_{y} n_{s} n_{f} f_{1} d_{F} t_{1}$

- for failure mode 2: $\quad N_{r}=\phi_{y} n_{s} n_{f} \frac{1}{2} f_{2} d_{F} t_{2}$

- for failure mode 3 :

$$
N_{r}=\phi_{y} n_{s} n_{f} f_{1} d_{F}^{2}\left(\sqrt{\frac{1}{6} \frac{f_{2}}{\left(f_{1}+f_{2}\right)} \frac{f_{y}}{f_{1}}}+\frac{1}{5} \frac{t_{1}}{d_{F}}\right)
$$

- for failure mode 4 :

$$
N_{r}=\phi_{y} n_{s} n_{f} f_{1} d_{F}^{2} \sqrt{\frac{2}{3} \frac{f_{2}}{\left(f_{1}+f_{2}\right)} \frac{f_{y}}{f_{1}}}
$$

where:

$\phi_{y} \quad=$ resistance factor for ductile failures

$$
=0.8
$$

$n_{s} \quad=$ number of shear planes in the joint

$n_{f} \quad=$ number of fasteners in the joint

$f_{1} \quad=$ embedding strength of side member, $\mathrm{Mpa}$

$f_{2} \quad$ = embedding strength of main member, Mpa

$f_{y} \quad=$ bolt yield strength, $\mathrm{MPa}$

$=310 \mathrm{MPa}$ for ASTM A307 or SAE J429 Grade 2 bolts

$t_{l} \quad=$ side member thickness, $\mathrm{mm}$

$t_{2}=$ main member thickness, $\mathrm{mm}$

$d_{F} \quad=$ fastener diameter, $\mathrm{mm}$

For wood members, embedding strength:

$f=50 G\left(1-0.01 d_{F}\right)$ for parallel to the grain loading

$$
G=\text { mean relative density }
$$


For steel members, embedding strength:

$$
\begin{aligned}
f & =3 f_{u}\left(\phi_{\text {steel }} / \phi_{y}\right) \\
f_{u} & =\text { ultimate strength of steel, Mpa } \\
\phi_{\text {steel }} & =\text { resistance factor for metal member } \\
& =0.67 \\
\phi_{y} & =\text { resistance factor for ductile failures } \\
& =0.8
\end{aligned}
$$

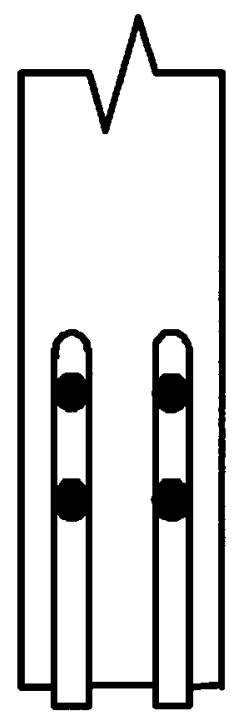

(a) Row shear

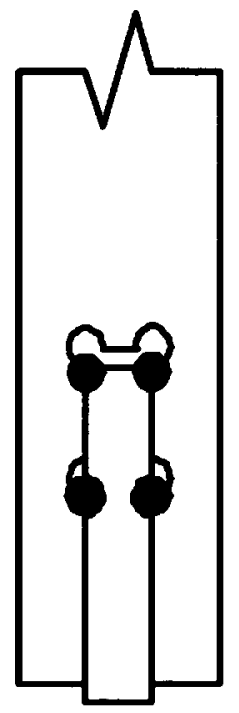

(b) Group tear-out

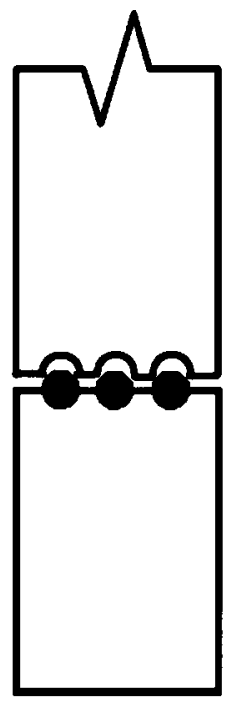

(c) Net Tension

Figure A.2 Brittle failure modes of timber connections, reproduced from CAN/CSA-086-09

\section{Row Shear Resistance}

Figure A.2 (a) shows the row shear failure mode. The total factored shear resistance of a connection shall be calculated as the sum of the factored row shear resistance of the wood members resisting the load, as follows: 


$$
P R_{r T}=\Sigma\left(P R_{r i}\right)
$$

The factored row shear resistance in a wood member $i$ shall be calculated as follows:

$$
P R_{r_{i}}=\phi_{w} P R_{i j \min } n_{R}\left(K_{D} K_{S F} K_{T}\right)
$$

where:

$\phi_{w} \quad=$ resistance factor for brittle failures

$$
=0.7
$$

$P R_{i j \text { min }}=$ minimum row shear resistance of any row in the connection from $P R_{i 1}$ to $P R_{i n_{R}}$

$$
n_{R} \quad=\text { number of fastener rows }
$$

$P R_{i j} \quad=$ shear resistance of fastener row $j$ in member $i, \mathrm{~N}$

$$
=1.2 f_{v} K_{l s} t n_{c} a_{c r i}
$$

$f_{v} \quad=$ specified strength in shear for member $i, \mathrm{MPa}$

$K_{l s} \quad=$ factor for member loaded surfaces

$=0.65$ for side member

$=1$ for internal member

$t \quad=$ member thickness, $\mathrm{mm}$

$n_{c} \quad=$ number of fasteners in row $j$ of member $i$

$a_{c r i}=$ minimum of $a_{L}$ and $S_{R}$ for row $j$ of member $i, \mathrm{~mm}$ 


\section{Group Tear-out Resistance}

Figure A.2 (b) shows the group tear-out failure mode. The total factored group tear-out resistance of a connection shall be calculated as the sum of the factored group tear-out resistance of the wood members resisting the load, as follows:

$$
P G_{r T}=\Sigma\left(P G_{r i}\right)
$$

The factored group tear-out resistance in a wood member $i$ with $n_{R}$ rows shall be calculated as follows:

$$
P G_{r i}=\phi_{w}\left[\frac{\left(P R_{i 1}+P R_{i n_{R}}\right)}{2}+\left[f_{t}\left(K_{D} K_{S F} K_{T}\right) A_{P G i}\right]\right]
$$

where:

$\phi_{w} \quad=$ resistance factor for brittle failures

$$
=0.7
$$

$P R_{i 1}=$ shear resistance along row 1 of member $i$ bounding the fastener group, $\mathrm{N}$

$$
=1.2 f_{v}\left(K_{D} K_{S F} K_{T}\right) K_{l s} t_{c} a_{c r 1}
$$

$P R_{i n_{\mathrm{R}}}=$ shear resistance along row $n_{R}$ of member $i$ bounding the fastener group, $\mathrm{N}$

$$
=1.2 f_{v}\left(K_{D} K_{S F} K_{T}\right) K_{l s} t n_{c} a_{c r} n_{R}
$$

$f_{t} \quad=$ specified strength in tension of member $i, \mathrm{MPa}$

$A_{P G i}=$ critical perpendicular net area between rows 1 and $n_{R}$ member $i, \mathrm{~mm}^{2}$ 


\section{Net Tension Resistance}

Figure A.2 (c) shows the net tension failure mode. The total factored net tension resistance of a connection at a group of fastener shall be calculated as follows:

$$
T N_{r T}=\Sigma\left(T N_{r i}\right)
$$

$T N_{r i}$ of member $i$ at a group of fasteners shall be determined as follows:

$T N_{r i}=$ factored tensile resistance of member $i, \mathrm{Mpa}$

$=\phi f_{t}\left(K_{D} K_{S F} K_{T}\right) A_{n} K_{Z t}$

$\phi \quad=$ resistance factor for net tension failures

$=0.9$

$f_{t} \quad=$ specified strength in tension of member $i, \mathrm{MPa}$

$A_{n} \quad=$ net area of cross-section, $\mathrm{mm}^{2}$ 


\section{Appendix B: Code Capacity vs. Ultimate Capacity}

This appendix summarizes the code capacities and ultimate capacities for bolted WSW and SWS connections. The equations presented in Appendix A were used to calculate the code capacities in compliance with the Canadian standard CAN/CSA-O86-09.

The mean ultimate capacities of bolted WSW connections in Table B.1 were obtained from the literature (Mohammad 2001), except Group WSW \#1 was tested in this study. The $5^{\text {th }}$ percentile values were calculated using a two-parameter Weibull distribution with $75 \%$ confidence and a factor of $80 \%$ was applied for the normal-duration application, reported by Mohammad (Mohammad 2001). It can be seen from Table B.1 that the average ratio between the CAN/CSA-O86-09 capacity and the mean ultimate capacity is 0.32 for bolted WSW connections.

In Table B.2, the $5^{\text {th }}$ percentile capacities were obtained from the literature (Quenneville 2000). The mean ultimate capacities were not directly reported in the literature. However, the mean ultimate capacities for Group SWS \#1 and SWS \#2 were supplied by Dr. Mohammad (a co-author of the literature). It can be seen from Table B.2 that the average ratio between the CAN/CSA-O86-09 capacity and the $5^{\text {th }}$ percentile capacity is 0.65 for bolted SWS connections. The ratio between the $5^{\text {th }}$ percentile capacity (normal-duration) and the mean ultimate capacity can be estimated as $0.8 \times 0.6=0.48$, where 0.8 is a factor for the normal-duration application and 0.6 is a factor converting the mean value to the $5^{\text {th }}$ percentile value. Therefore, the average ratio between the CAN/CSA-O86-09 capacity 
and the mean ultimate capacity can be estimated as $0.48 \times 0.65=0.31$ for bolted SWS connections.

Table B.1 Code capacities and ultimate capacities for WSW connections

\begin{tabular}{|c|c|c|c|c|c|c|c|c|c|c|c|}
\hline Group* & $\begin{array}{l}\text { Wood } \\
\text { Type }\end{array}$ & $\begin{array}{l}\text { Specimen } \\
\text { Size }(\mathrm{mm})\end{array}$ & $\begin{array}{c}d \\
(\mathrm{~mm})\end{array}$ & $N_{R}$ & $N_{C}$ & $\begin{array}{r}\text { Mean } \\
(\mathrm{kN}) \\
\end{array}$ & $\begin{array}{c}5^{\text {th }} \\
(\mathrm{kN})\end{array}$ & $\begin{array}{c}\text { O86-09 } \\
(\mathrm{kN})\end{array}$ & $\begin{array}{c}\text { O86-09/ } \\
\text { Mean }\end{array}$ & $\begin{array}{c}\text { O86-09/ } \\
5^{\text {th }}\end{array}$ & Comment \\
\hline 1 & SP G & $2 @ 80 \times 152$ & 19.1 & 1 & 1 & 57 & 35 & 20 & 0.36 & 0.58 & \\
\hline 2 & SP G & $2 @ 80 \times 153$ & 12.7 & 1 & 1 & 46 & 24 & 14 & 0.30 & 0.57 & \\
\hline 3 & SP G & $2 @ 80 \times 190$ & 19.1 & 1 & 1 & 68 & 37 & 26 & 0.39 & 0.71 & \\
\hline 4 & SP G & $2 @ 80 \times 190$ & 12.7 & 1 & 1 & 56 & 30 & 14 & 0.26 & 0.48 & \\
\hline 5 & SP G & $130 \times 190$ & 19.1 & 1 & 1 & 42 & 26 & 11 & 0.26 & 0.42 & \\
\hline 6 & SP G & $130 \times 190$ & 19.1 & 1 & 1 & 65 & 39 & 22 & 0.34 & 0.56 & WSW \#3 \\
\hline 7 & SP G & $2 @ 80 \times 190$ & 19.1 & 1 & 2 & 103 & 61 & 29 & 0.28 & 0.48 & \\
\hline 8 & SP G & $130 \times 190$ & 19.1 & 1 & 2 & 95 & 61 & 22 & 0.23 & 0.36 & \\
\hline 9 & SP G & $2 @ 80 \times 190$ & 19.1 & 2 & 2 & 181 & 107 & 58 & 0.32 & 0.55 & \\
\hline 10 & SP G & $2 @ 80 \times 190$ & 19.1 & 1 & 1 & 48 & 29 & 15 & 0.30 & 0.50 & \\
\hline 11 & SP G & $2 @ 80 \times 190$ & 19.1 & 2 & 1 & 106 & 69 & 29 & 0.28 & 0.42 & \\
\hline 17 & SP G & $130 \times 190$ & 19.1 & 2 & 2 & 175 & 106 & 44 & 0.25 & 0.41 & \\
\hline 18 & DF G & $130 \times 190$ & 19.1 & 2 & 2 & 181 & 96 & 50 & 0.28 & 0.52 & \\
\hline 19 & DF G & $2 @ 80 \times 190$ & 19.1 & 2 & 2 & 225 & 120 & 67 & 0.30 & 0.56 & \\
\hline 20 & SP G & $2 @ 80 \times 190$ & 19.1 & 2 & 2 & 243 & 141 & 105 & 0.43 & 0.75 & WSW \#5 \\
\hline 21 & SP G & $130 \times 190$ & 19.1 & 2 & 1 & 88 & 49 & 22 & 0.25 & 0.45 & \\
\hline 22 & SP G & $130 \times 190$ & 19.1 & 2 & 2 & 227 & 147 & 88 & 0.39 & 0.60 & WSW \#4 \\
\hline 27 & SP G & $130 \times 190$ & 12.7 & 2 & 2 & 115 & 64 & 51 & 0.44 & 0.80 & WSW \#2 \\
\hline 28 & DF G & $130 \times 190$ & 12.7 & 2 & 2 & 140 & 89 & 55 & 0.39 & 0.62 & \\
\hline 29 & SP G & $2 @ 80 \times 190$ & 12.7 & 2 & 2 & 142 & 80 & 57 & 0.40 & 0.72 & \\
\hline 30 & DF G & $2 @ 80 \times 190$ & 12.7 & 2 & 2 & 143 & 93 & 62 & 0.43 & 0.66 & \\
\hline- & SPF & $2 @ 38 \times 140$ & 12.7 & 1 & 2 & 58 & - & 16 & 0.28 & - & WSW \#1 \\
\hline \multicolumn{2}{|c|}{ Average } & & & & & & & & 0.32 & 0.56 & \\
\hline
\end{tabular}

*: Group numbers refer to the literature (Quenneville 2000). 
Table B.2 Code capacities and ultimate capacities for SWS connections

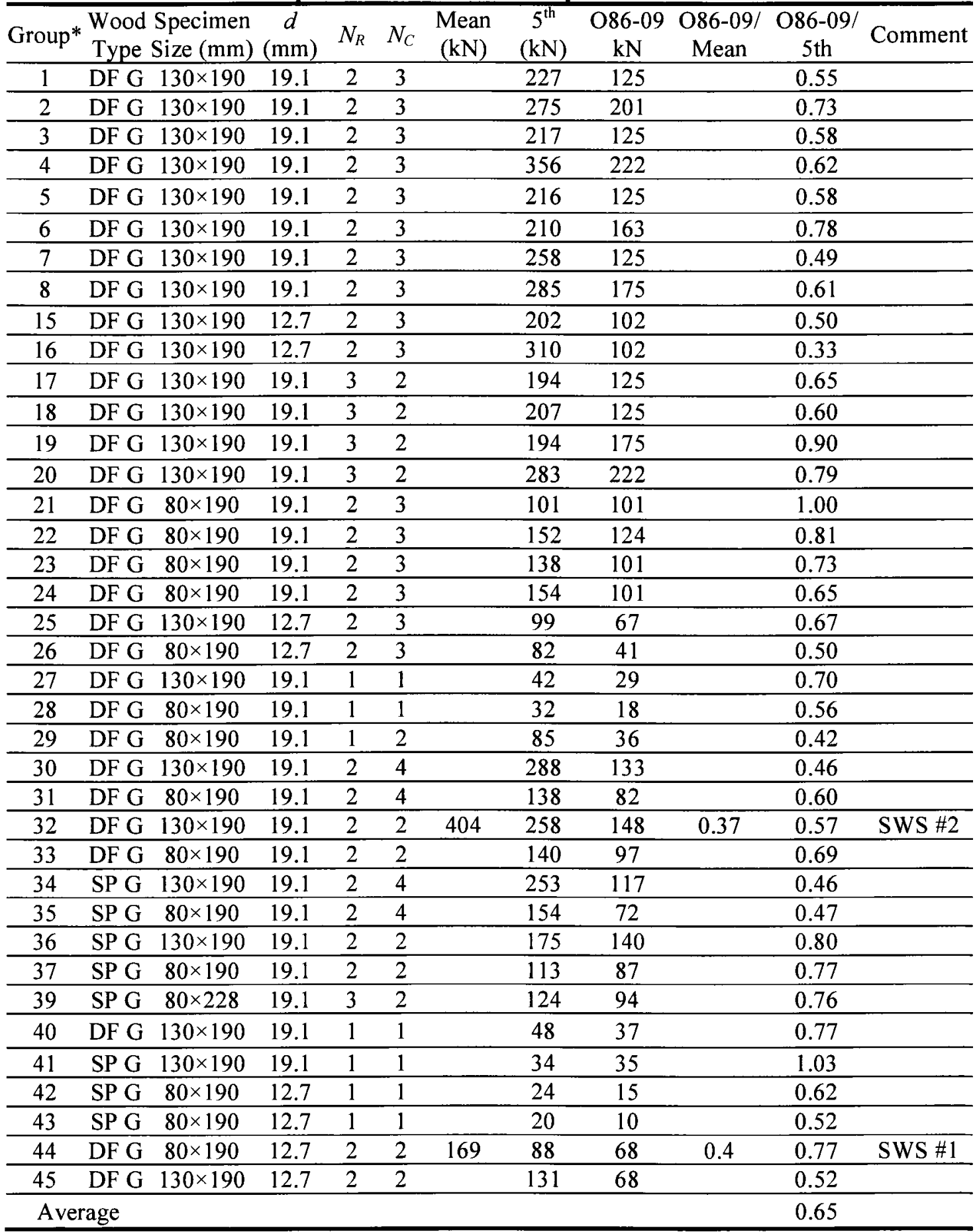

*: Group numbers refer to the literature (Mohammad 2001). 


\section{Appendix C: Tensile Tests of Timber Connections at Ambient}

This appendix describes the tensile tests of timber connections at ambient temperature. As mentioned in Chapter 3, only WSW Group \#1 was tested using the furnace loading system prior to the fire-resistance tests. For other groups in WSW and SWS, the tensile tests were conducted by Mohammad (2001) and Quenneville (2000). All tensile tests were carried out in compliance with the ASTM Standard D1761-88 (2000). Specimens were subjected to a displacement-control tensile force at a rate of $0.9 \mathrm{~mm} / \mathrm{min}$, and the maximum load recorded before failure was determined as the ultimate load-carrying capacity.

For WSW Group \#1, three specimens were tested and the load-displacement curves are shown in Figure C.1. The average value of the maximum loads was determined as the ultimate load for WSW Group \#1, $58 \mathrm{kN}$ in this case.

Figure C.2 shows the load-displacement curves for WSW Group \#3 as an example from Mohammad (2001). Ten physical specimens, including twenty connections (2 connections per specimen), were tested in one group and the mean value the maximum loads was determined as the ultimate load, $65 \mathrm{kN}$ in this case. 


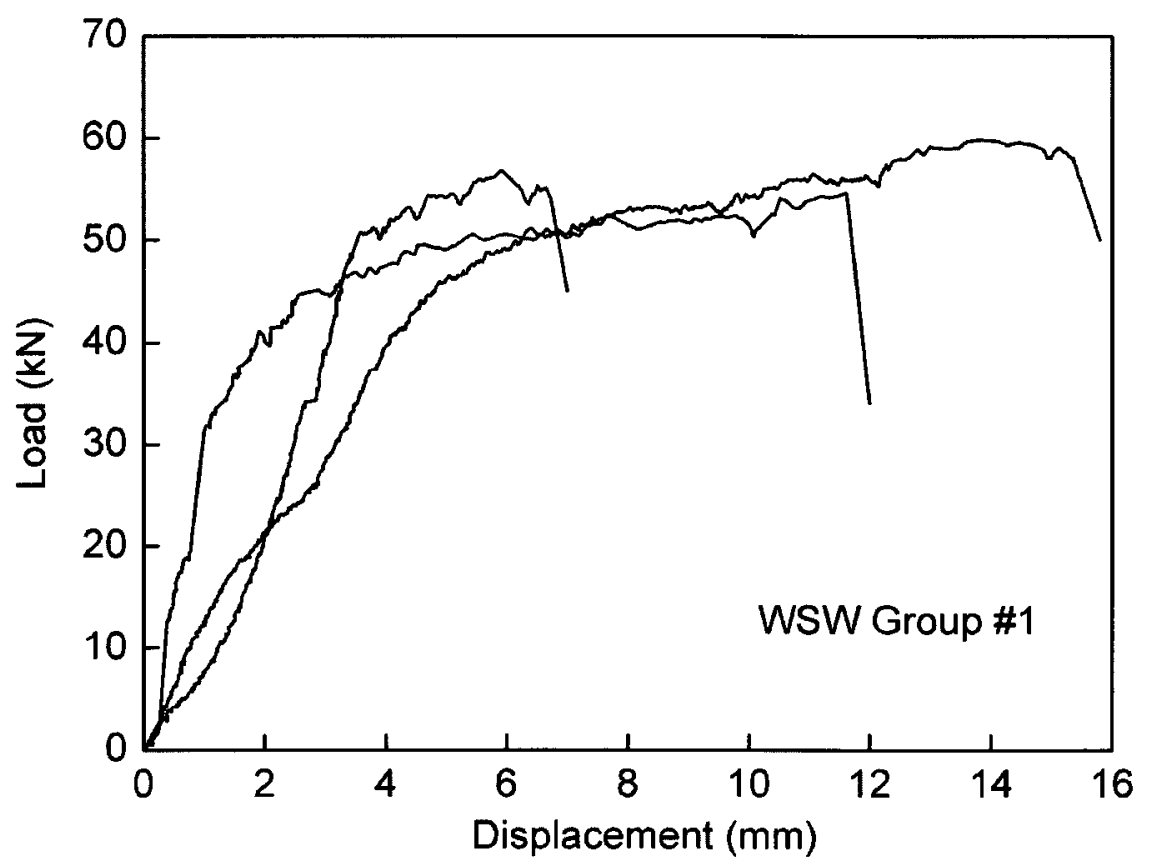

Figure C.1 Load-displacement curves for WSW Group \#1

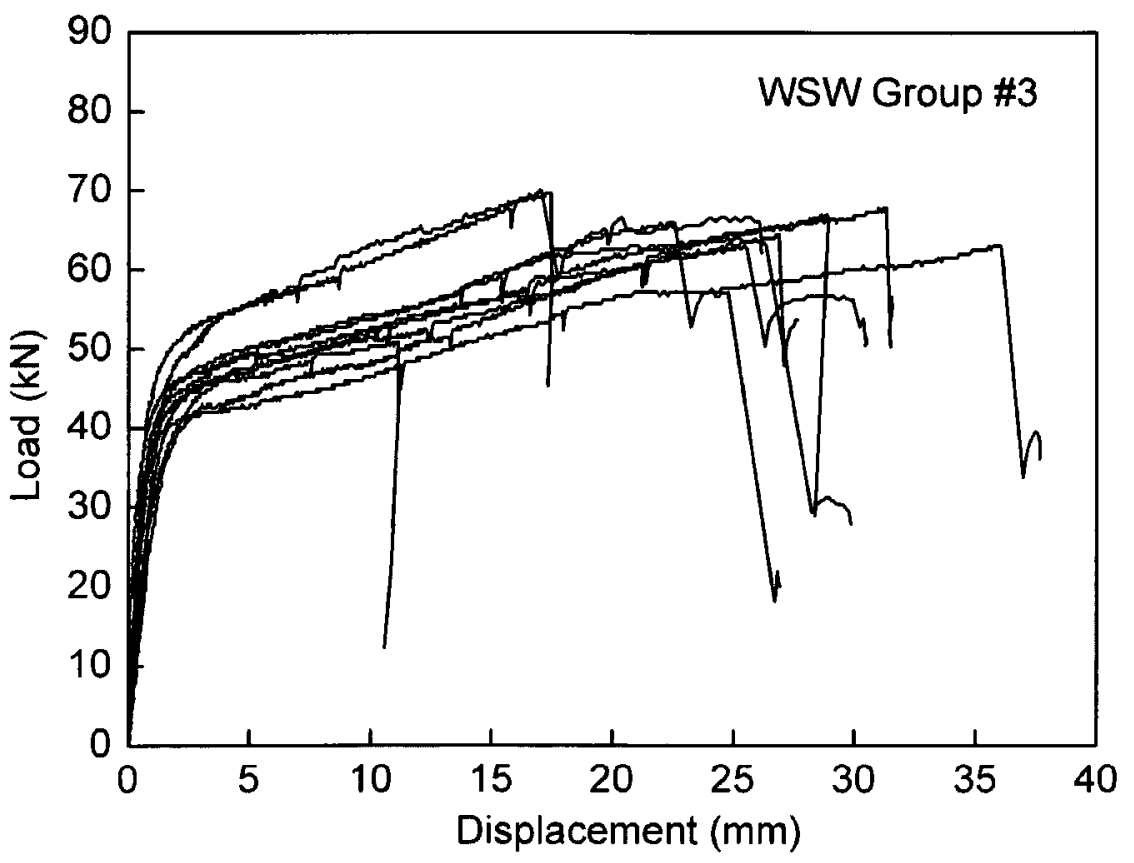

Figure C.2 Load-displacement curves for WSW Group \#3 


\section{Appendix D: Thermocouple Locations in Fire- Resistance Tests}

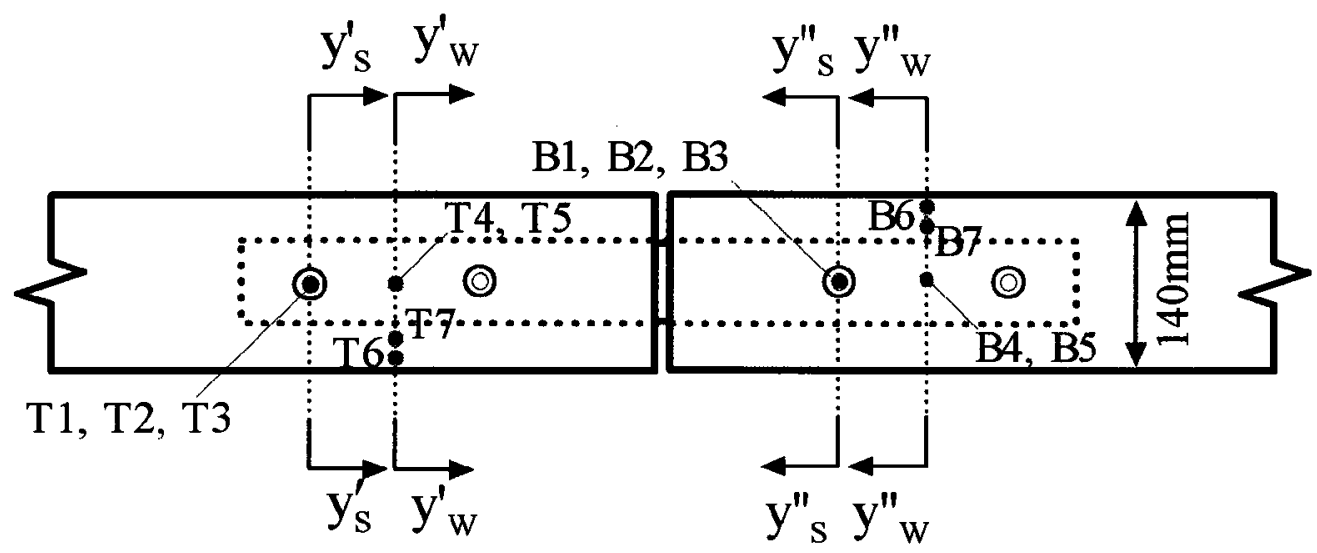

$\mathrm{y}_{\mathrm{s}}^{\prime}-\mathrm{y}_{\mathrm{s}}^{\prime}, \mathrm{y}_{\mathrm{s}}{ }_{\mathrm{s}}-\mathrm{y}_{\mathrm{s}}{ }_{\mathrm{s}}$ : (magnified)

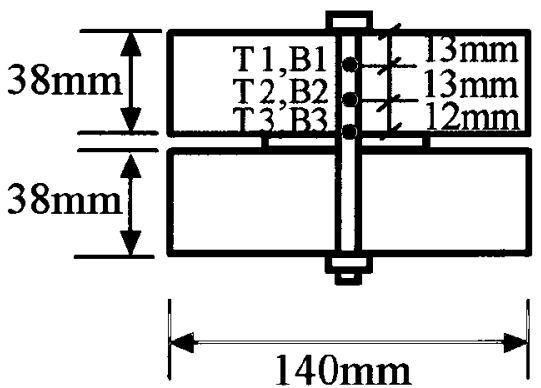

$\mathrm{y}_{\mathrm{w}}^{\prime}-\mathrm{y}_{\mathrm{w}}^{\prime}, \mathrm{y}^{\prime \prime}{ }_{\mathrm{w}}-\mathrm{y}^{\prime \prime}{ }_{\mathrm{w}}$ : (magnified)

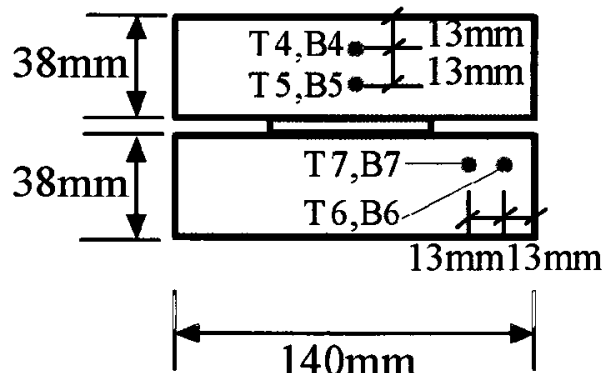

Figure D.1 Thermocouple locations for specimens in WSW Group \#1 


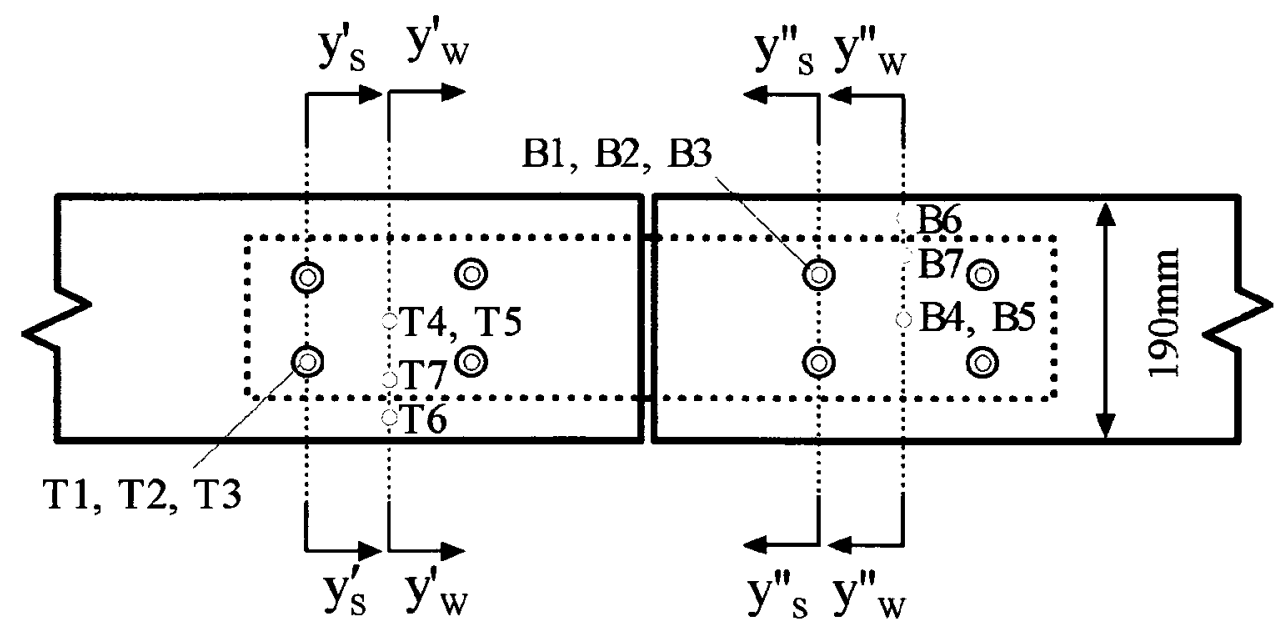

$y_{S}^{\prime}-y_{S}^{\prime}, y^{\prime \prime}{ }_{s}-y_{s}^{\prime \prime}:$

(magnified)
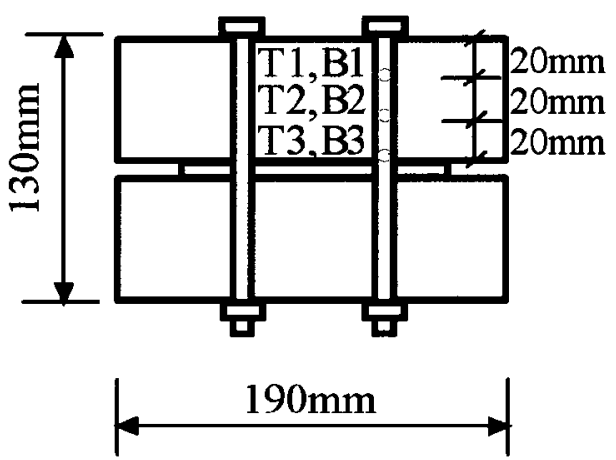

$y^{\prime}{ }_{w}-y^{\prime}{ }_{w}, y^{\prime \prime}{ }_{w}-y^{\prime \prime}{ }_{w}:$ (magnified)

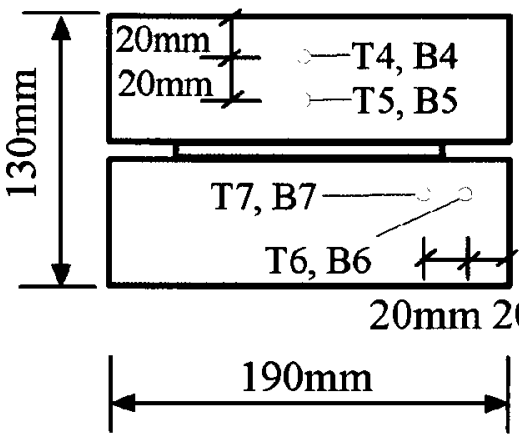

Figure D.2 Thermocouple locations for specimens in WSW Group \#2 


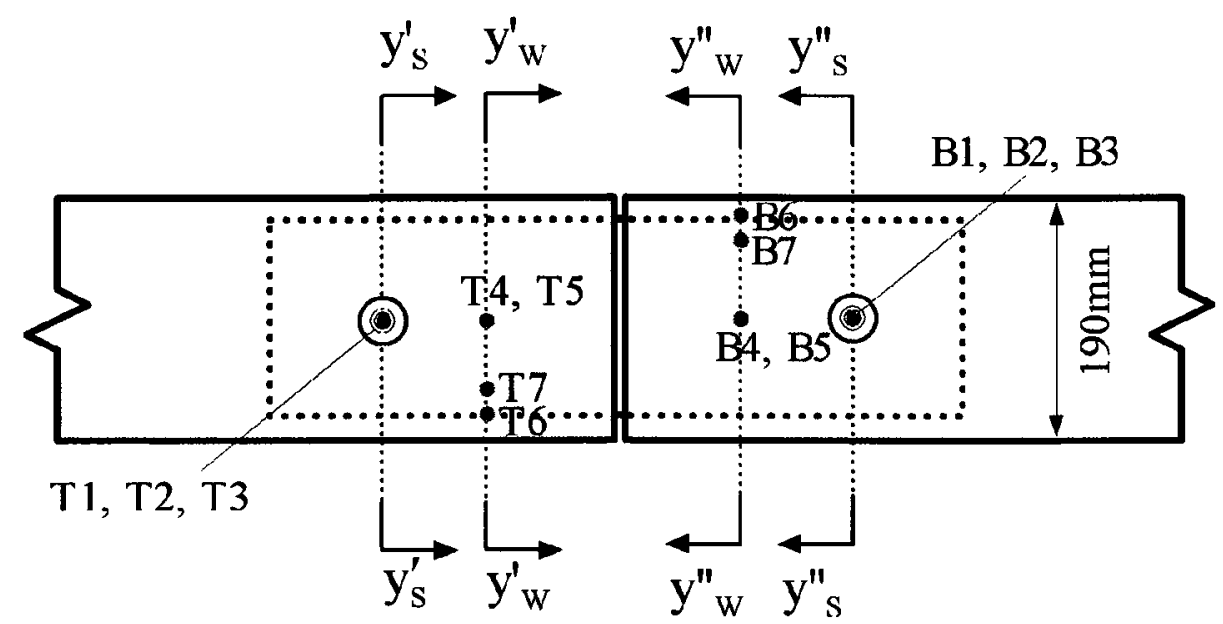

$y_{s}^{\prime}-y_{s}^{\prime}, y^{\prime \prime}-y^{\prime \prime}$ : (magnified)

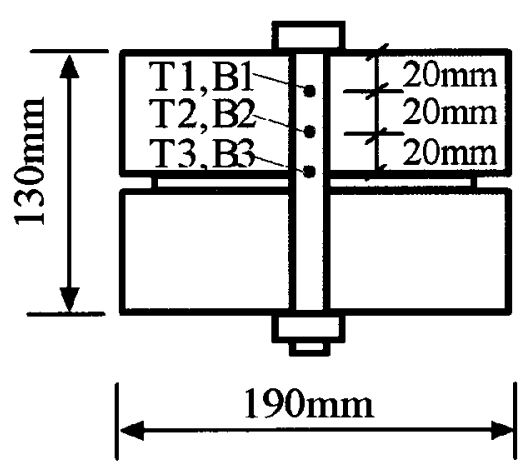

$y^{\prime}{ }_{w}-y^{\prime}{ }_{w}, y^{\prime \prime}{ }_{w}-y^{\prime \prime}{ }_{w}$ : (magnified)

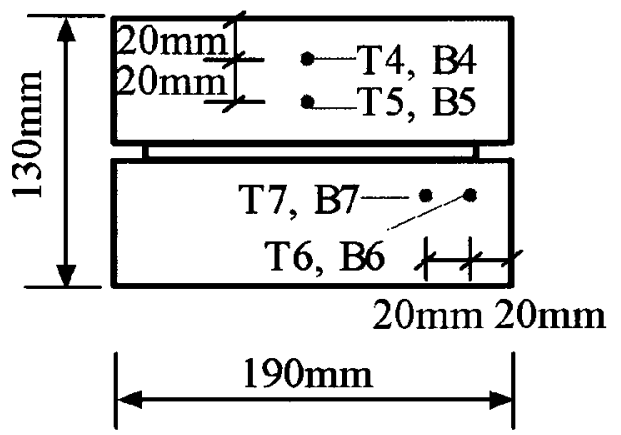

Figure D.3 Thermocouple locations for specimens in WSW Group \#3 

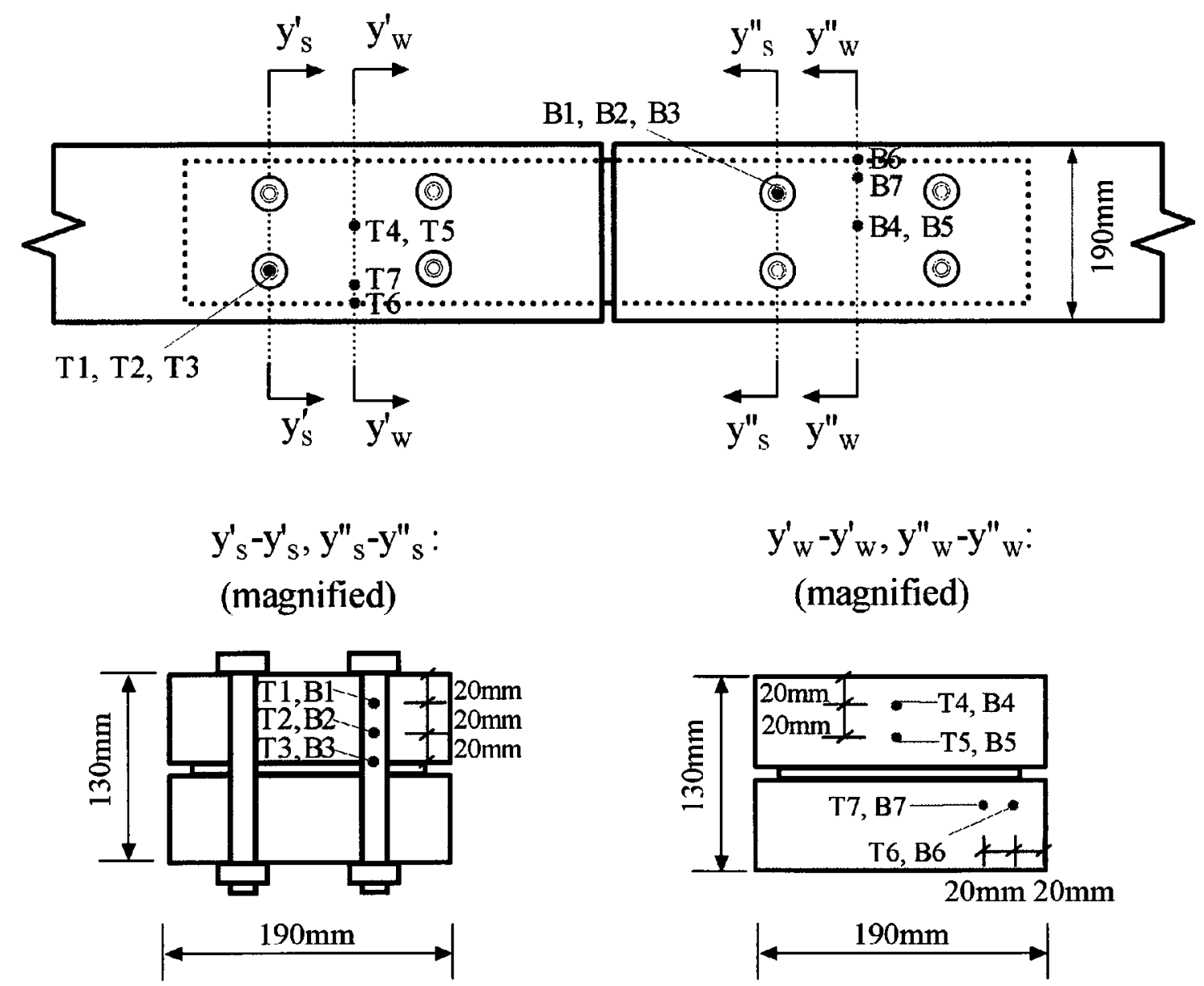

Figure D.4 Thermocouple locations for specimens in WSW Group \#4 


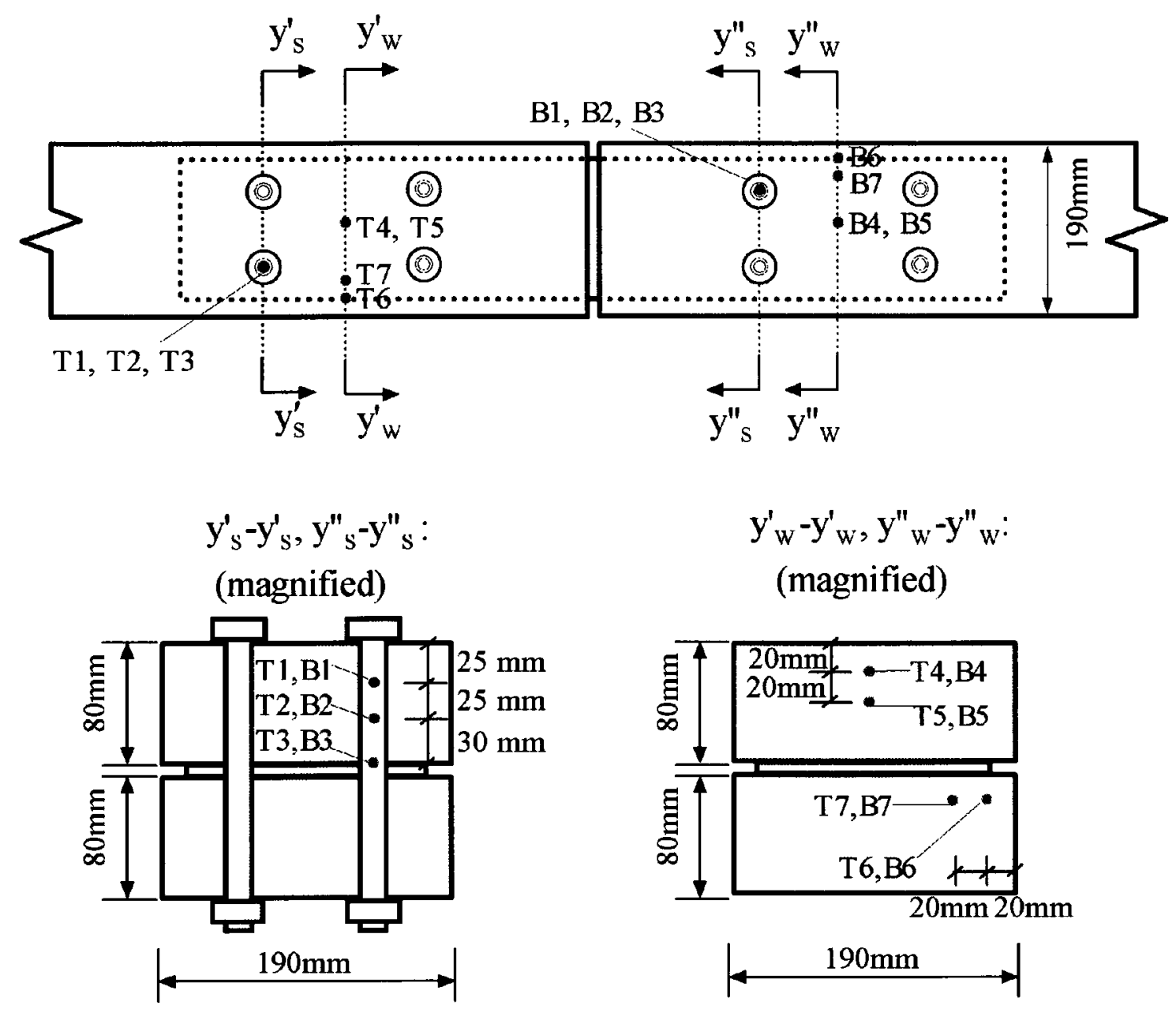

Figure D.5 Thermocouple locations for specimens in WSW Group \#5 

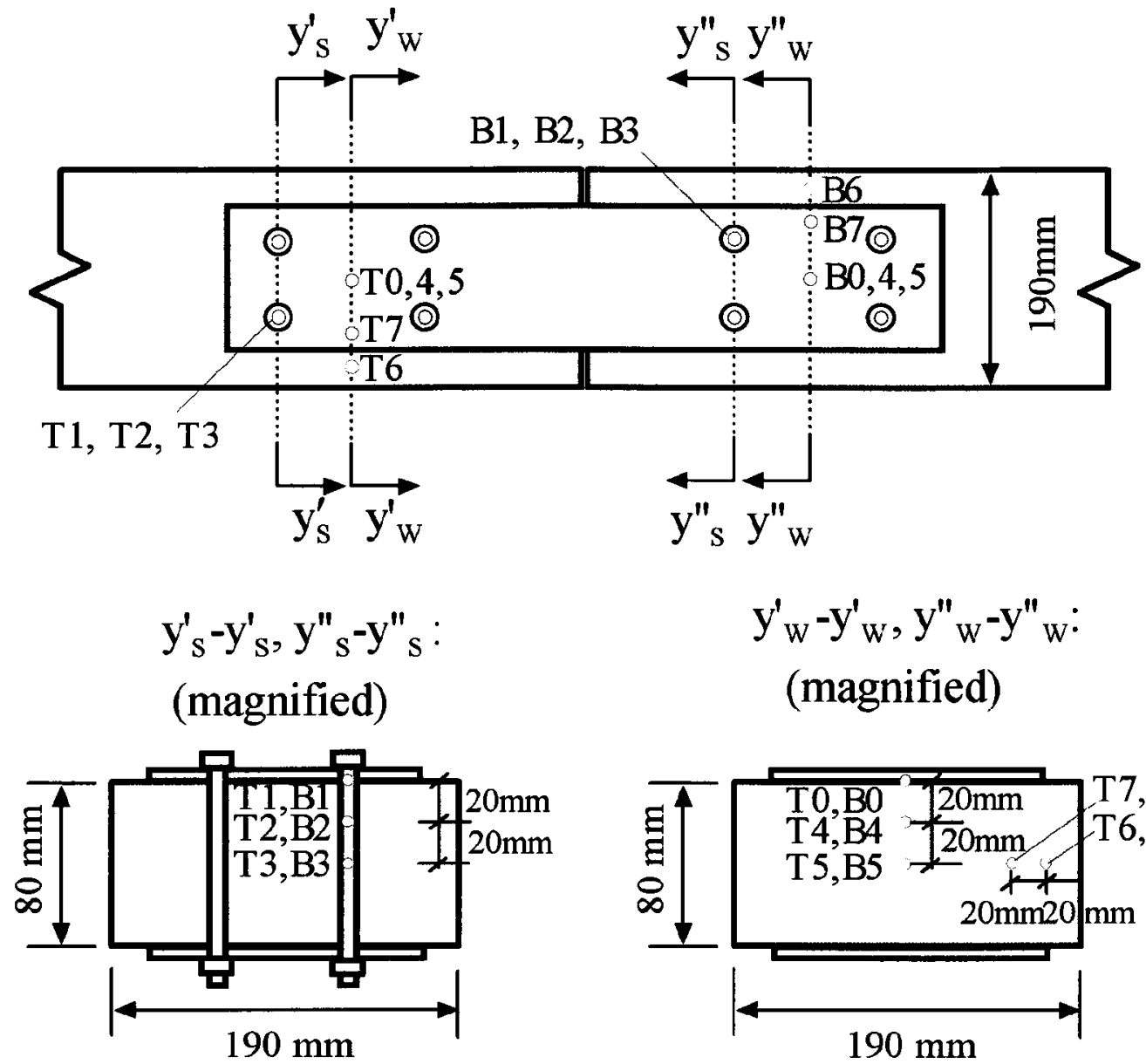

$\mathrm{y}^{\prime}{ }_{\mathrm{w}}-\mathrm{y}_{\mathrm{w}}^{\prime}, \mathrm{y}^{\prime \prime}{ }_{\mathrm{w}}-\mathrm{y}^{\prime \prime}{ }_{\mathrm{w}}$ :

(magnified)

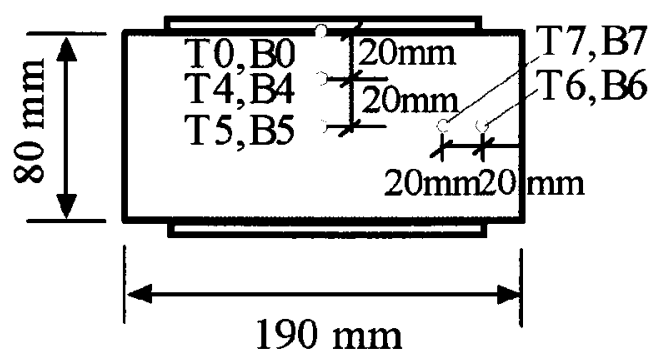

Figure D.6 Thermocouple locations for specimens in SWS Group \#1 


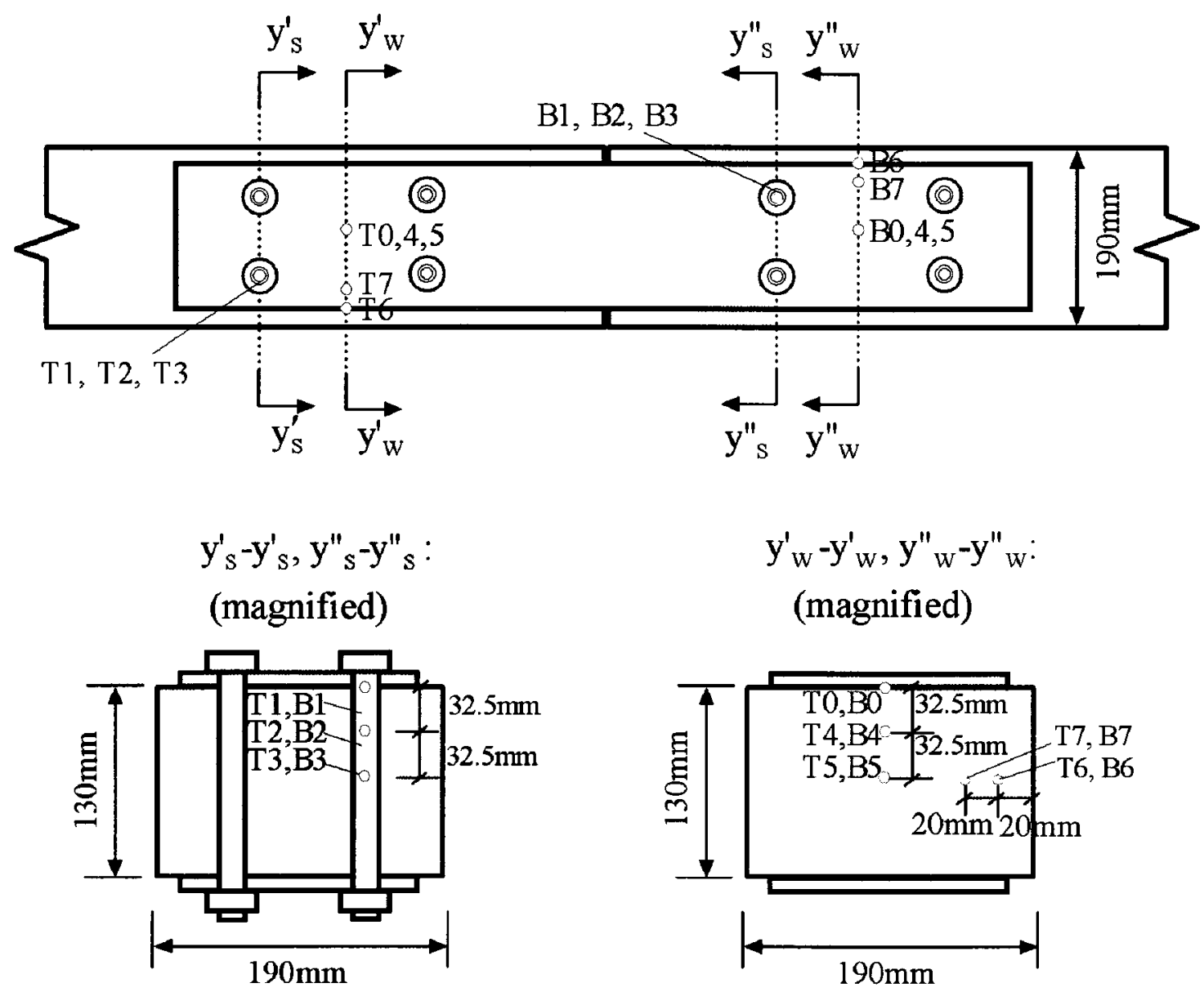

Figure D.7 Thermocouple locations for specimens in SWS Group \#2 